\title{
Drainage versus defense
}

Citation for published version (APA):

Kietadisorn, R. (2018). Drainage versus defense: The management of vascular leakage in cardiovascular diseases. [Doctoral Thesis, Maastricht University]. Ridderprint BV.

https://doi.org/10.26481/dis.20180523rk

Document status and date:

Published: 01/01/2018

DOI:

10.26481/dis.20180523rk

Document Version:

Publisher's PDF, also known as Version of record

\section{Please check the document version of this publication:}

- A submitted manuscript is the version of the article upon submission and before peer-review. There can be important differences between the submitted version and the official published version of record.

People interested in the research are advised to contact the author for the final version of the publication, or visit the DOI to the publisher's website.

- The final author version and the galley proof are versions of the publication after peer review.

- The final published version features the final layout of the paper including the volume, issue and page numbers.

Link to publication

\footnotetext{
General rights rights.

- You may freely distribute the URL identifying the publication in the public portal. please follow below link for the End User Agreement:

www.umlib.nl/taverne-license

Take down policy

If you believe that this document breaches copyright please contact us at:

repository@maastrichtuniversity.nl

providing details and we will investigate your claim.
}

Copyright and moral rights for the publications made accessible in the public portal are retained by the authors and/or other copyright owners and it is a condition of accessing publications that users recognise and abide by the legal requirements associated with these

- Users may download and print one copy of any publication from the public portal for the purpose of private study or research.

- You may not further distribute the material or use it for any profit-making activity or commercial gain

If the publication is distributed under the terms of Article $25 \mathrm{fa}$ of the Dutch Copyright Act, indicated by the "Taverne" license above, 


\section{Drainage versus defense: \\ The management of vascular leakage in cardiovascular diseases}

Rinrada Kietadisorn 
(C) 2018, Rinrada Kietadisorn, Maastricht

All rights reserved. No part of this book may be reproduced, stored in a retrieval system of any nature, or or transmitted in any form or by any means (electeonic, mechanical, photocopying, recording or otherwise) without prior written permission of the author, or when appreciate, by the publishers of the publications.

ISBN

Author:

Layout \& figure design:

Cover art and design:

Printed by:
978-94-6299-930-5

Rinrada Kietadisorn

Rinrada Kietadisorn

Rinrada Kietadisorn

Ridderprint BV, www.ridderprint.nl 


\title{
Drainage versus defense: \\ The management of vascular leakage in cardiovascular diseases
}

\author{
Dissertation \\ to obtain the degree of Doctor at Maastricht University, \\ on the authority of the Rector Magnificus, Prof.dr. Rianne M. Letschert, \\ in accordance with the decision of the Board of Deans, \\ to be defended in public \\ on Wednesday, $23^{\text {rd }}$ of May 2018 at 10.00 hours
}

by

Rinrada Kietadisorn

Born on 14 March 1973 in Nakhon Sawan, Thailand 


\section{Supervisor}

Prof. dr. Erik A.L. Biessen

\section{Co-supervisor}

Dr. Judith C. Sluimer

\section{Assessment committee}

Prof. dr. I.C.W. Arts (chairman)

Dr. N. van de Akker

Prof. dr. H.J.G.M. Crijns

Prof. dr. D.J.G.M. Duncker, Erasmus University Medical Center

Dr. M.R. de Vries, Leiden University Medical Center 


\section{Table of contents}

$\begin{array}{lll}\text { Chapter } 1 \text { General introduction } & 7\end{array}$

$\begin{array}{lll}\text { Chapter } 2 & \text { Targeting endothelial and myocardial dysfunction with } & 31\end{array}$ tetrahydrobiopterin

Chapter 3 Tackling endothelial dysfunction by modulating NOS uncoupling: new insights into its pathogenesis and therapeutic possibilities

Chapter 4 Enhancing eNOS transcription: a new therapeutic option to tackle myocardial and endothelial dysfunction

Chapter 5 (Pharmacological) Enhancement of endothelial nitric oxide synthase activity prevents pressure overload-induced ventricular hypertrophy

Chapter 6 TNIP2: a novel regulator of inflammatory lymphangiogenesis in human atherosclerosis

Chapter 7 General discussion

Addendum Summary

Samenvatting

Valorization

List of abbreviations

Curriculum Vitae 

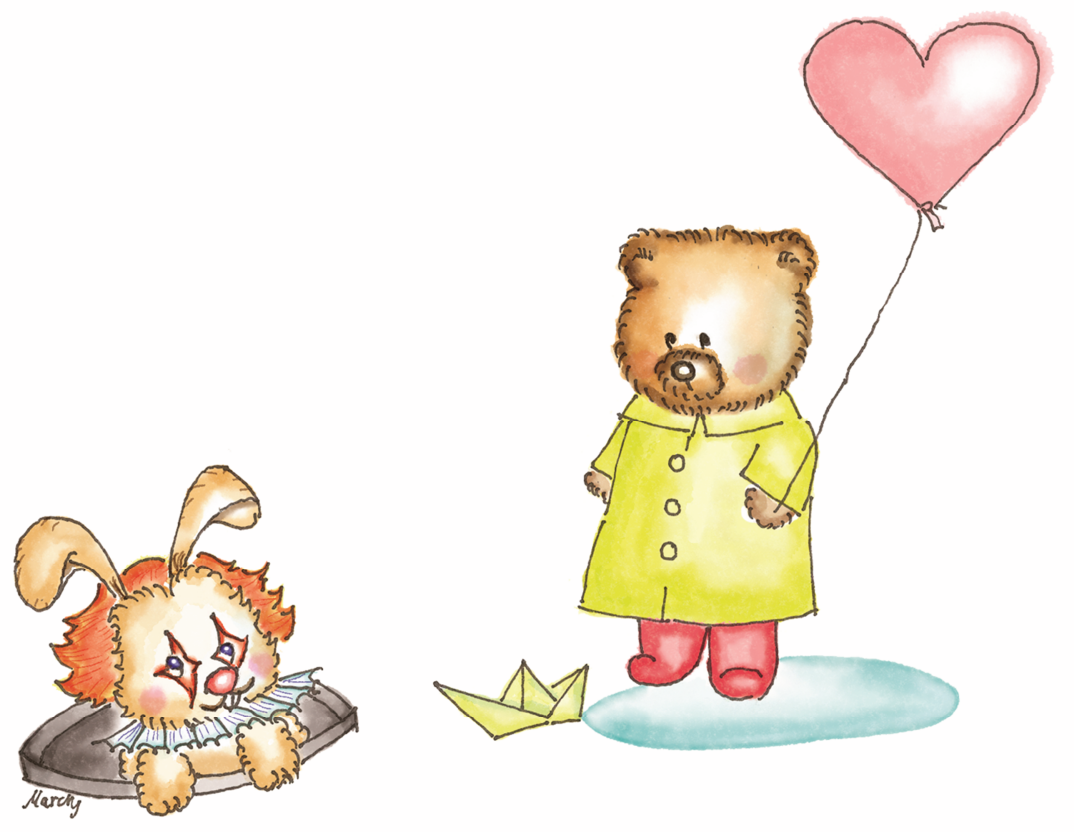
Chapter 1

General introduction 


\section{Current status of cardiovascular diseases}

Cardiovascular disease (CVD), such as heart disease (ischemic heart disease, IHD; coronary heart disease, CHD) and cerebrovascular disease (mainly ischemic stroke) collectively account for $45 \%$ and $31 \%$ of all deaths in Europe ${ }^{1}$ and worldwide $^{2}$, respectively, and are the two most common single causes of death. Major CVD risk factors fall into two groups: (I) behavioral risk factors (diet, low physical activity, smoking, alcohol use), and (II) medical risk factors (high systolic blood pressure, high total cholesterol, high fasting plasma glucose, and high body mass index $(\mathrm{BMI}))^{1}$.

Atherosclerosis, a chronic inflammatory disease of large- to medium-sized arteries, is the main underlying cause of $\mathrm{CVD}^{3}$. Failure of lymphatics in the mediation of drainage of interstitial fluids, the inflammatory response and in clearance of cholesterol from the arterial intima, may contribute to atherosclerosis ${ }^{4}$. In addition, the hallmark of endothelial dysfunction is the impaired nitric oxide (NO) bioavailability ${ }^{5}$, leading to increased expression of several inflammatory mediators and adhesion molecules; these processes contribute to increased plaque vulnerability ${ }^{6}$. The search for novel and improved treatments for atherosclerosis-related CVD remain one of the major challenges in the field of cardiology. To this end we need a better understanding of the relevant pathomechanisms. Importantly, the abnormal development of microvessels leads to their immaturity, fragility and leakage, and is associated with $C V D^{7}$. This introduction will present a short overview on the role of microvessels and lymphatics, as well as the regulation of their formation in CVD.

Atherosclerosis was first identified as a pathology of cholesterol storage, leading to artery obstruction, however, it is now additionally recognized as a lipiddriven chronic inflammatory disease ${ }^{8,9}$. Atherosclerotic plaques are composed of cholesterol, lipids and cellular debris, deposited in the artery walls, resulting in their narrowing. Usually, atherosclerotic lesions affect large and medium-sized elastic and muscular arteries and can lead to ischemia of the heart, brain, or extremities, resulting in infarction ${ }^{10}$. Thus, major manifestations of atherosclerosis include IHD, ischemic stroke, and peripheral arterial disease (PAD) ${ }^{11}$. Unlike IHD and stroke, PAD is rarely lethal and is a less prevalent complication of atherosclerosis ${ }^{11,12}$. Additionally, stenotic coronary arteries with stable atherosclerosis may cause stable angina, but this is rarely fatal. However, plaques that rupture play a major role in the pathogenesis of life-threatening acute coronary syndromes (ACS) and its manifestations include unstable angina, acute myocardial infarction (MI) and heart failure (HF) ${ }^{13}$.

Plaque rupture leads to thrombus formation, which is considered the main cause of acute cardiovascular events ${ }^{14,15}$. It has been suggested that plaque rupture occurs mainly in the weakest spots (i.e. the cap margin or shoulder region ${ }^{16}$ ) of 8 
lesions that contain a thin and inflamed fibrous cap covering the large necrotic core (thin-cap fibroatheromas (TFCA) or vulnerable plaques ${ }^{16}$ ). Rupture-prone caps are infiltrated by macrophage foam cells, and contain few smooth muscle cells (SMC), which are indeed absent at the actual site of rupture ${ }^{16}$. Notably, plaque macrophages exhibit impaired migratory capacity, which contributes to their failure to resolve inflammation within the plaque, and enhances lesion progression ${ }^{17}$. Inflammatory cells such as macrophages and T-cells are thought to be the main drivers of plaque rupture, releasing proteolytic metalloproteinases that inhibit collagen synthesis; causing the weakening of the cap and reducing plaque mechanical stability ${ }^{18,19}$. The continued inflammatory response ultimately leads to the destabilization of atherosclerotic plaques via the action of proinflammatory cytokines such as interferon gamma (IFNG/Y), tumor necrosis factor alpha (TNFA/ $\alpha$ ) and interleukin 1 beta (IL1B/ $\beta$ ) ${ }^{20}$. Moreover, dying macrophages release their lipid contents, along with tissue factor, leading to the formation of a pro-thrombotic necrotic core, a key component of unstable plaques which contributes to their rupture ${ }^{17}$. This process is even augmented, due to the reduced capacity of plaque macrophages to perform efferocytosis, the process of apoptotic cell internalization and degradation by phagocytic cells (e.g. macrophages). As a result, non-engulfed apoptotic cells eventually become leaky, resulting in secondary necrosis, which contributes to the formation and expansion of the necrotic core, and in turn, increases plaque vulnerability to rupture ${ }^{21}$. The risk of plaque rupture is also associated with angiogenesis and intraplaque haemorrhage (IPH) ${ }^{14}$. Indeed, plaque angiogenesis plays an important role in the pathogenesis of atherosclerosis. Plaque vasa vasorum (VV) exhibit abnormal morphology, have aberrant endothelial cell junctions and show increased leukocyte adherence; this immature microvascular network may contribute to plaque progression and vulnerability. The disruption and leakiness of incompetent $\mathrm{VV}$ is directly involved in leukocyte and erythrocyte extravasation and therefore in IPH $7,22,23$. Importantly, IPH plays a causal role in promoting the expansion of the necrotic core and enhancing plaque progression via deposition of free cholesterol derived from red blood cells ${ }^{22}$. IPH can elicit oxidative stress responses through the release of $\mathrm{Fe}^{++}$from entrapped hemoglobin after red blood cell lysis. In parallel, hemorrhages stimulate neutrophil recruitment. These neutrophils can then release pro-oxidant enzymes into the plaque, causing endothelial cytotoxicity, subsequent acceleration of disease progression, and ultimately plaque rupture ${ }^{23}$.

Interestingly, recent observations suggest that multiple TCFA coexist in patients, and that thrombotic rupture of TFCA is a rare event, especially in low risk subjects. This subsequently challenges the concept of the vulnerable plaque ${ }^{24,25}$. It may also imply that rupture is not solely dependent on plaque morphology; other local mechanical factors are probably involved. In this regard, wall (or endothelial) shear stress (WSS) and plaque structural stress (PSS) may determine plaque development, 
progression and rupture. WSS is the parallel frictional force exerted by blood flow on the endoluminal surface of the arterial wall. In principle, high (or physiological) WSS exerts atheroprotective property. However, supraphysiological (or very high) WSS, which occurs when blood flows through a stenotic atherosclerotic plaque, is associated with endothelial cell injury, inflammation and vascular remodeling. This further suggests that supraphysiological WSS is possibly involved with plaque rupture or thrombus generation, and can induce the erosion of the plaque surface. In addition, PSS is determined by plaque architecture and composition, as well as localisation, extent, and size of individual calcium deposits within the plaque. Increased PSS is associated with increased necrotic core thickness or size, as well as reduced fibrous cap thickness. High PSS levels that exceed the plaque's strength can damage fibrous caps and thus cause plaque rupture (see review ${ }^{25}$ ). Upon rupture, a pro-thrombotic necrotic core becomes exposed to circulating platelets, resulting in platelet aggregation (thrombus). Moreover, proinflammatory cytokines can also increase the expression of the potent procoagulant, tissue factor, which triggers thrombosis in the ruptured plaque ${ }^{26}$. Subsequently this leads to arterial blockage, which may result in MI or stroke ${ }^{21}$. The loss of cardiac function due to ACS can eventually lead to HF.

$\mathrm{HF}$, a complex clinical syndrome, is defined by a heart's inability to maintain workload, leading to oxygen and nutrient delivery that is insufficient to meet the requirements for tissue metabolism ${ }^{27}$. HF is the final common stage of all cardiac diseases and considerably increases the risk for morbidity and mortality ${ }^{28}$. HF can be categorized based on the left ventricular ejection fraction (LVEF), i.e. (I) HF with preserved EF (HFpEF, diastolic HF; normal LVEF; typically considered as $\geq 50 \%$ ), (II) HF with mid-range (HFmrEF; LVEF 40-49\%), and (III) HF with reduced EF (HFrEF, systolic HF; typically considered as $<40 \%)^{29}$. There are three causes of $\mathrm{HF}$ : dysfunctional myocardium (e.g. ischemic heart disease, drug-induced cardiomyopathy), prolonged abnormal loading conditions (e.g. hypertension, volume overload) and arrhythmias (e.g. tachyarrhythmia, bradyarrhythmias) ${ }^{29}$. MI secondary to ischemic heart disease is thought to be the most important risk factor for $\mathrm{HF}^{30}$. Although the risk of HF associated with hypertension is smaller than that associated with $\mathrm{MI}$, hypertension contributes considerably to the population burden of HF, as it is much more frequent than $\mathrm{MI}^{31}$. Left ventricular hypertrophy is both a major maladaptive response to chronic pressure overload and an important risk factor in patients with hypertension, which frequently progresses to $\mathrm{HF}^{32}$. Importantly, cardiac endothelial cells (EC) directly modulate performance of the subjacent cardiomyocytes, resulting in control of the onset of ventricular relaxation, and rapid filling of the heart. Thus, damage and/or dysfunction of the cardiac endothelium could have a serious impact on the development of cardiac diseases ${ }^{33,34}$. 
Together, the major cause of morbidity and mortality worldwide is atherosclerotic vascular disease, leading to stroke, MI and HF. Importantly, cardiovascular function is mediated by vascular endothelium. Endothelial cell activation and dysfunction attribute to pathogenesis of cardiovascular diseases.

\section{Vascular endothelium and cardiovascular diseases}

EC form a continuous monolayer, lining the blood luminal surface of vessels. This was originally thought to be an inert cellophane-like membrane in the vascular tree, with no function other than the maintenance of vessel wall permeability ${ }^{35,} 36$. However, EC are now recognized as a crucial player in maintaining a wide range of cardiovascular homeostatic functions. Indeed, EC regulate vascular tone and blood flow, through the release of vasodilators and vasoconstrictors; modulate hemostasis/thrombosis, through the secretion of pro- and anti-coagulant and fibrinolytic agents; mediate inflammatory responses, via release and reaction with various cytokines and adhesion molecules; generate angiogenic and angiostatic growth factors, and peptides, thus maintaining blood vessel homeostasis ${ }^{37,38}$.

In EC, endothelial nitric oxide synthase (eNOS) is the major source of NO, and is an important regulator of cardiovascular homeostasis. Normal function of eNOS requires dimerization of the enzyme and the presence of its cofactor tetrahydrobiopterin $(\mathrm{BH} 4)$. A functional eNOS oxidizes its substrate L-arginine to Lcitrulline and NO, the latter of which plays key role in cardiomyocyte contractility and vascular tone ${ }^{5,39}$. It is well documented that uncoupling eNOS is a prominent source of myocardial reactive oxygen species (ROS), contributing to pathogenesis of pressure overload-induced ventricular remodeling and cardiac dysfunction ${ }^{40,41}$. When eNOS uncouples and shifts from a dimer to a monomer state, it results in reduced $\mathrm{NO}$ production and increased ROS generation ${ }^{42}$. It has been suggested that $\mathrm{BH} 4$ deficiency is likely to represent the major cause for eNOS uncoupling ${ }^{43}$. In addition, the stoichiometry of intracellular $\mathrm{BH} 4 / \mathrm{eNOS}$ interactions as well as the ratio of $\mathrm{BH} 4$ and its oxidized from, dihydrobiopterin (BH2), are the key determinants of eNOS coupling ${ }^{43}$.

Endothelial dysfunction is defined by EC losing their ability to maintain this delicate balance, shifting the endothelium from an anti-thrombotic, anti-inflammatory, and vasodilation-prone surface, to conditions inclined to coagulation, inflammation and vasoconstriction ${ }^{44}$. The mechanisms underlying endothelial dysfunction involve decreased NO bioavailability, activation of the pathways of vascular smooth muscle contraction, vascular oxidative stress, and inflammation ${ }^{45,46}$. Additionally, decreased endothelium-dependent vasodilator capacity of coronary arteries in part contributes to reduced myocardial perfusion, and hence impaired ventricular function ${ }^{47}$. Endothelial dysfunction is associated with the process of plaque formation and atherosclerosis 
progression, resulting from increased vascular permeability, upregulation of adhesion molecules, cytokine secretion, leukocyte adherence, elevated oxidized-low density lipoprotein (oxLDL), platelet activation, and vascular smooth muscle cell (VSMC) proliferation and migration ${ }^{45}$. EC have a crucial role in the recruitment and adhesion of leukocytes, whose infiltration into lesions is a prominent feature of atherosclerosis. In response to normal laminar flow condition, EC generate low amounts of adhesion molecules, such as vascular cell adhesion molecule-1 (VCAM-1) and intracellular adhesion molecule-1 (ICAM-1). However, production of adhesion molecules is sharply increased in non-laminar or turbulent flow ${ }^{48}$. The flow disturbances that occur naturally, or are associated with vascular diseases and interventions, can lead to neointimal hyperplasia or thrombosis, causing pathological conditions, such as atherosclerosis, in-stent restenosis, and bypass graft occlusion ${ }^{38}$.

The hallmark of endothelial dysfunction is impairment of NO mediated endothelium-dependent vasodilation ${ }^{49}$. When endothelial dysfunction is present, the ability of the blood vessels to dilate and/or constrict can be assessed ${ }^{35}$. Although, measuring a patient's endothelial function is not routinely done, assessments of endothelial function is a good predictor of future cardiac events in individuals at risk of CVD and those with established CVD ${ }^{50,51}$. Endothelial function can be assessed by measuring dilation in response to stimuli such as hyperemia or after pharmacological stimuli. Impaired vasodilatation would be indicative of poor endothelial function ${ }^{51}$. To distinguish between endothelial dysfunction and SMC dysfunction as a cause for the vasodilation impairment, endothelium-dependent and -independent vasodilatation (i.e. acetylcholine and sodium nitroprusside, respectively) are typically assessed ${ }^{52}$. Several approaches can be used to evaluate endothelial function, including (I) invasive macrovascular techniques (e.g. iontophoresis), (II) noninvasive macrovascular techniques (e.g. flow-mediated dilatation and glyceryl trinitrate), or (III) measurement of morphologic and mechanical characteristics of the vascular wall (e.g. carotid intima-media thickness) ${ }^{52,53}$.

\section{General background of angiogenesis}

As previously mentioned, EC function in maintaining blood vessel formation, is characterized by four parameters; (I) de novo primary vessel formation involving the migration, differentiation and incorporation of endothelial progenitors (vasculogenesis), (II) the sprouting of new blood vessels from the pre-existing ones (angiogenesis), in which endothelial cells are responsible for the capillary growth, migration and organization of the vessel lumen, (III) the increase in the size of the lumen of preexisting arterioles by remodeling and growth (arteriogenesis), a process that is controlled by mural cells (i.e. pericytes and VSMC, and (IV) recruitment of bone marrow-derived cells and/or endothelial progenitor cells to the vascular wall for further 
incorporation into the endothelial lining during vascular repair or expansion of pathological vessels in adult (postnatal vasculogenesis) ${ }^{54}$.

When an existing vessel is stimulated with angiogenic signals, such as hypoxia, angiogenic factors (e.g. vascular endothelial growth factor (VEFG) -A, fibroblast growth factor (FGF)), or NO, it causes mural cells to detach from the vascular wall, and junctions between EC to loosen, resulting in increased vascular permeability. The extravasation of plasma protein allows the formation of a provisional matrix, onto which endothelial cells migrate. The microvascular sprout is guided by a specialized endothelial cell (tip cell), while the neighboring endothelial cell (stalk cell) proliferates to elongate the stalk. Ultimately, a vessel lumen is established, and mural cells are recruited to ensure neovessel stability ${ }^{54}$. Once the new vessel sprout matures, EC maintain in a quiescent, non-proliferative and non-migratory, cobblestone-like phenotype, named phalanx cells ${ }^{55}$. Subsequently, these EC become covered with pericytes, which suppress endothelial cell proliferation and release cellsurvival signals such as VEGF-A and angiopoetin (Ang)-1. A basement membrane is then established ${ }^{54}$. High vascular endothelial growth factor receptor (VEGFR)-1 levels and subsequent low VEGF-A responsiveness enable these cells to stay quiescent for years ${ }^{55}$. EC display the remarkable capability to switch rapidly from a quiescent state to a highly migratory and proliferative state during vessel sprouting, in response to injury or in pathological conditions ${ }^{55}$. This switch is mediated by the Ang-Tie system ${ }^{54}$. Ang1 is predominantly expressed by mural cells, and in binding with its receptor Tie2, it has a role in maintaining vascular stability, maturity, and integrity as well as inhibiting VEGF-A induced permeability ${ }^{56,57}$. In contrast, Ang2 is synthesized primarily by EC, and is traditionally thought to antagonize Ang1 signaling. Ang2 binds Tie2, allowing EC to respond to destabilizing and angiogenic signals. In addition, Ang2 generation is activated by hypoxia, VEGF-A, FGF, and various proinflammatory endothelial activators, and its expression is mainly restricted to sites of vascular remodeling ${ }^{56-58}$. Importantly, high levels of Ang2 have been observed in human atherosclerotic plaques, and are associated with increased plaque angiogenesis and potentially also with microvessel destabilization, suggesting increased leakage ${ }^{59}$.

Angiogenesis is both an essential adaptive response to physiological stress and an endogenous repair mechanism after ischemic injury ${ }^{60}$. Under physiological conditions, angiogenesis occurs during growth, physiological adaptation and tissue repair (e.g. gestation, exercise-induced skeleton and cardiac muscle hypertrophy, wound healing) ${ }^{61}$. Pathological angiogenesis on the other hand, contributes to chronic inflammation and cancer. Indeed, insufficient and excessive angiogenesis play determinant roles in the pathogenesis of $\mathrm{MI}$ and atherosclerosis, respectively. 


\section{The role of angiogenesis in myocardial infarction}

In the healthy heart, a dense network of capillaries ensures sufficient oxygen supply to meet the high energy demand of properly contracting myocytes. During physiological (adaptive) cardiac growth, myocytes release angiogenic growth factors in response to hypertrophic stimuli, which in part regulate the balance between cardiac hypertrophy and angiogenesis. Disruption of coordinated myocyte growth and angiogenesis, leads to contractile dysfunction, and promotes the progression from adaptive cardiac hypertrophy to heart failure ${ }^{62}$. This suggests that heart growth and function are angiogenesis dependent. Interestingly, it has been reported that newly formed blood vessels may secrete factors that promote the growth of cardiomyocytes ${ }^{63}$. Taken together, this suggests the crosstalk between the myocardium and the vasculature functions to promote the growth of each, in a paracrine fashion.

Myocardial ischemia is a primary cause for the loss of vital components such as cardiomyocytes in the heart, leading to $\mathrm{Ml}$ and eventually cardiac dysfunction or HF 64. In addition, endothelial dysfunction and/or decreased angiogenesis cause inadequate oxygen supply. Subsequently, this can result in progressive myocyte loss, replacement fibrosis and infarct extension, as well as hypertension, due to increased systemic resistance ${ }^{65,66}$. Early after MI, cardiomyocytes, EC and inflammatory cells express hypoxia-inducible transcription factors, such as hypoxia-inducible factor 1 alpha (HIF-1 $\alpha$ ), which can be expressed for up to 4 weeks after MI in rats ${ }^{67}$. In addition, various proangiogenic factors are expressed in ischemic heart, of which the VEGF-A and FGF families are the most studied growth factors in post-MI angiogenesis. VEGF-A is rapidly induced in the ischemic heart, in both human and animal studies, suggesting that VEGF-A is a likely mediator of ischemia-induced myocardial neovascularization ${ }^{68-70}$. Immunohistochemical analysis of heart tissue from patients with early or evolving infarction, or cardiac ischemia revealed HIF-1a expression in both myocardial and endothelial cells. In contrast, VEGF $-\mathrm{A}^{+}$cells were found only in the endothelium that lined small to medium arterioles and capillaries in the myocardium, suggesting that the angiogenic effects of HIF-1 and VEGF-A are limited to regions of terminal small vessels in the myocardium ${ }^{69}$.

In response to myocardial ischemia, HIF-1 $\alpha$ and HIF-2 $\alpha$ accumulate in cardiomyocytes and other cell types. HIF-1 transcriptional activation would upregulate angiogenic factor expression such as VEGF-A; however, the angiogenic capacity was seen to be suppressed rather than enhanced ${ }^{64}$. A study of chronic pressure overloadinduced cardiac hypertrophy in mice revealed that cardiac VEGF-A levels were increased in the early phase, but decreased in later phases of cardiac hypertrophy, and this downregulation was associated with suppressed myocardial angiogenesis ${ }^{71}$. Several studies have suggested that loss of copper, a HIF-1 cofactor, and 
accumulation of $\mathrm{p} 53$, are partially responsible for inhibition of HIF-1 activity -mediated VEGF-A expression. This thereby impairs cardiac angiogenesis in chronic ischemic heart and sustained pressure overload-induced cardiac hypertrophy ${ }^{64,71,72}$.

Therefore, maintenance of the microvasculature in a failing myocardium may preserve blood supply and preserve myocardial function. Angiogenesis has the potential to restore ischemic myocardium at early stages after $\mathrm{MI}$, and is also essential to prevent the transition to $\mathrm{HF}$ through the control of cardiomyocyte hypertrophy and contractility ${ }^{70,73}$.

\section{The role of angiogenesis in atherosclerosis}

The VV are specialized microvasculature, and play a major role in normal vessel wall biology and pathology. Under physiological conditions, VV originate from the adventitia and provide oxygen and nutrient to arterial and venous walls ${ }^{74,75}$. In normal human coronary arteries, VV is present in the adventitia and outer media layer, but absent in the intima ${ }^{76}$.

Plaque angiogenesis is a physiological response to cope with the increased oxygen demand in the plaque. It is proinflammatory and proatherogenic, and enhances plaque vulnerability ${ }^{77}$. It has been suggested that neovascularization in early plaques may provide an additional route for leukocyte and lipid accumulation relative to the arterial lumen. Hypoxic areas are known to be present in human atherosclerotic lesions ${ }^{78}$. During atherosclerosis, the intima increases in thickness, which results in regional limited oxygen exchange, and partly contributes to plaque hypoxia. Importantly, plaque macrophages, with their high metabolic demand, are a major contributor to hypoxia in human plaque. Hypoxic macrophages upregulate HIF$1 \alpha$ which induces angiogenesis, leading to plaque progression ${ }^{79}$. EC react to hypoxic conditions by becoming more angiogenic, apoptosis-prone, and proinflammatory. They also alter their metabolism - all processes that promote endothelial dysfunction and atherogenesis ${ }^{77,80}$. These effects may involve HIF-1 $\alpha$, a master regulator of hypoxic responses ${ }^{81,82}$. In early human plaque, the density of adventitial VV is much higher than that of intraplaque $\mathrm{VV}^{7}$. Most of the intraplaque $\mathrm{VV}$ are endothelialized, and only a few have mural pericytes and vascular smooth muscle cells. Lack of mural cells, poorly formed endothelial cell junctions, and the close proximity of inflammation, probably induce leakiness of the intraplaque $\mathrm{VV}^{7,76}$. In addition, VV density is correlated with atherosclerosis progression and morphology of atherosclerotic lesions ${ }^{7}$, as well as with intraplaque hemorrhage and plaque rupture ${ }^{76}$. Therefore, it is fair to assume that functional aberrations of plaque angiogenesis causes an exacerbation of the atherosclerotic process. 


\section{General background of lymphangiogenesis}

Under physiological conditions, excess interstitial fluid, stemming from leaky endothelium is drained via lymphatic vessels. Lymphatic vessels were first officially described in the 1600s, and named, after their milky fluid content: venae albae aut lacteae (lacteal vessels) ${ }^{83,84}$. In the late 1990s, the identification of molecular markers of lymphatics ${ }^{84,85}$, enabled researchers to investigate the (patho) physiological role of lymphatics and the molecular mechanisms of their formation in closer detail. Next to fluid homeostasis, lymphatic vessels have important functions in lipid absorption, and immune surveillance ${ }^{86,87}$, whilst recent studies have suggested additional functions of the lymphatic vasculature in fat metabolism, obesity, inflammation, and the regulation of salt storage in hypertension ${ }^{87,88}$.

The lymphatic vascular network consists of thin-walled, blind-ended capillarysized vessels, called "initial lymphatics", which serves for interstitial fluid absorption and its transport to "pre-collectors", with the final drainage via "collecting lymphatics" 89, 90. Initial lymphatics are hallmarked by LYmphatic VEssel hyaluronan receptor 1 (LYVE-1)-expressing lymphatic endothelial cells (LEC), the absence of SMC and the lack of pericyte coverage. Pre-collectors contain valves and have sparse smooth muscle cell coverage. Collecting lymphatics are characterized by podoplanin (PDPN) expression, with absent, or only very weak LYVE-1 expression, and are covered with continuous basement membrane and SMC. Collecting lymphatics are segmented by unidirectional valves into units called lymphangions ${ }^{91,92}$. This contractile unit propels lymph into the next lymphangion through the interposed valves, in a unidirectional manner ${ }^{93}$. These collecting lymphatics transport the protein-rich lymph to the proximal site, and return the lymph to the cardiovascular system via the thoracic duct.

Lymphangiogenesis is the formation of new lymphatic vessels from preexisting lymphatics ${ }^{90}$,essential in embryonic development. In adults, lymphangiogenesis is actively involved with pathological processes, including inflammatory diseases and tumor dissemination. In addition, insufficient lymphangiogenesis occurs in lymphedema, which is characterized by chronic tissue edema and impaired immunity ${ }^{86,90}$. The process of lymphangiogenesis is thought to be similar to angiogenesis, during which quiescent LEC become activated to degrade their surrounding extracellular matrix, directionally migrate towards the lymphangiogenic stimuli, proliferate and organize into new capillary networks ${ }^{85,94,}$ 95. It has been suggested that at cellular level, lymphangiogenesis also has similarities to angiogenesis, as it is characterized by tip and stalk cell differentiation, and involves similar regulators such as VEGF-C, neuropilin-2 (NRP2), Notch homolog 1, translocation associated (Drosophila); also known as Notch1, and Delta-like 4 (DLL4) ${ }^{85,96 .}$ 
During embryogenesis, the formation of lymphatics is initiated by the transcription factors; sex determining region $\mathrm{Y}$ box 18 (SOX18) / chicken ovalbumin upstream promoter-transcription factor II (COUP-TFII), inducing prospero homeobox 1 (PROX1) expression in a subset of venous EC (VEC) of the cardinal vein. Venous PROX1-expressing EC (referred to LEC progenitors) migrate away from the cardinal vein. This process requires the graded expression of VEGF-C in the surrounding mesenchyme. The budding LEC maintain the expression of VEGFR-3 and begin expressing PDPN, indicating that lymphatic differentiation is progressing. Subsequently, LEC assemble together and establish lymph sacs (primordial thoracic duct). Following LEC proliferation and sprouting, the majority of the lymphatic network arises from these sacs ${ }^{97}$. Lymphatic vessels undergo further remodeling and maturation, including valve formation; processes mediated by Ang2, PDPN, ephrin-B2 and Foxc2 (forkhead box C2), subsequently establishing a functional lymphatic vessel network ${ }^{98}$.

During adulthood, the majority of lymphatic vessels are quiescent, with the exception of reproductive organs during the ovarian cycle and gestation; however, lymphangiogenesis is often activated in several pathological conditions ${ }^{99,}{ }^{100}$. Adult lymphangiogenesis occurs primarily by sprouting from pre-existing vessels, although bone marrow-derived cells, such as macrophages, may transdifferentiate into lymphatic endothelium in some pathological conditions ${ }^{88,90}$. Importantly, physiological and pathological lymphangiogenesis likely share certain biological mechanisms, i.e. activation of the VEGF-C/VEGFR-3 signaling pathway ${ }^{100,101}$. Additionally, pathological lymphangiogenesis is also mediated by proinflammatory cytokines and/or growth factors such as VEGF-A. Moreover, activated macrophages are a major source of VEGF-C and/ or VEGF-D, and induce lymphangiogenesis during inflammation and tumor development ${ }^{88,100}$.

In summary, the mechanisms regulating lymphangiogenesis are poorly understood, when compared to angiogenesis. Physiological and pathological lymphangiogenesis is mediated by, in part, a similar molecular signaling pathway to that governing angiogenesis. Recent research has implicated the lymphatic system in the pathogenesis of cardiovascular diseases, including obesity and metabolic disease, dyslipidemia, inflammation, atherosclerosis, hypertension, and $\mathrm{MI}^{93}$.

\section{Role of lymphangiogenesis in myocardial infarction}

A pioneering investigation of the cardiac lymphatic system was performed in the $17^{\text {th }}$ century by Rudbeck, who described lymphatics in the dog heart ${ }^{102,} 103$ however, cardiac lymphatics have been relatively neglected in cardiovascular research for decades. Nevertheless, cardiac lymphatics have gained interest recently, as increasing evidence has revealed the important role of cardiac lymphatic 
vasculature in maintaining normal heart function ${ }^{104,105}$. Cardiac lymphatics function in draining myocardial interstitial fluid and thus play a role in controlling tissue pressure, and help to prevent myocardial edema ${ }^{106}$. In the adult heart, cardiac lymphatics are located most abundantly in the ventricles ${ }^{107}$. Although there are some species-specific anatomical variations, cardiac lymphatics of most species consist of (1) terminal capillaries, (2) a capillary plexus penetrating the subendocardium, myocardium, and the subepicardium, and (3) collecting vessels that lead the lymph out of the heart ${ }^{108,}$ 109. In animal studies, acute cardiac lymphatic obstruction caused epicardial lymphedema and lymphangiectasis. Also, chronic obstruction led to myocardial edema, subendocardial hemorrhages, endocardial fibrosis and myocardial fibrosis primarily involving the left ventricle ${ }^{106}$. In humans, impairment of lymph flow is associated with coronary artery injury ${ }^{105}$. Obstruction of cardiac lymphatics takes place during open-heart surgery and can cause atrial fibrillation, prolonged pericardial or pleural effusions, also known as "swollen heart" ${ }^{110}$. Only a few studies have demonstrated the role of lymphatic vessels in MI. A recent study has demonstrated that adverse remodeling of epicardial collector lymphatics in the infarcted area causes reduced cardiac lymphatic flow and persistent myocardial edema in rats ${ }^{111}$. In response to $\mathrm{MI}$, cardiac lymphatics substantially expanded in rodents ${ }^{111,112}$ as well as in postmortem human MI samples ${ }^{113}$. Intraperitoneal injection of VEGF-C $156 \mathrm{~S}^{112}$ or treatment with microparticle-based intramyocardial delivery VEGF-C 156 S protein ${ }^{111}$ promoted post-MI lymphangiogenesis, resulting in improved cardiac function and attenuated cardiac inflammation in rodent MI models. This suggests the beneficial effect of pro-lymphangiogenic therapy in MI.

\section{Role of lymphangiogenesis in atherosclerosis}

Lymphatic functions are related to a causal role in atherogenesis, including immune response and cholesterol metabolism ${ }^{4}$. Lymphatic vessels were first described in human aortic walls by Johnson in the late $1960 \mathrm{~s}^{114}$. Lymphatics can be observed in the arterial wall of a variety of animals (e.g. rabbits, dogs, rats and mice) and seem to be mostly present in the adventitial layer ${ }^{4}$. In human atherosclerotic arteries, lymphatic vessels were reported previously to exist predominantly in the adventitia ${ }^{115,116}$ while they are rarely present in the intima ${ }^{117}$. However, Kholova et al. ${ }^{116}$ have reported that lymphatics also are detectable in media and intima of progressive human coronary atherosclerotic lesions. This concurs with recent findings showing abundant lymphatics within the atherosclerotic lesion of human carotids ${ }^{4}$. In human atherosclerotic lesions, the number of adventitial lymphatics is correlated with disease progression ${ }^{115}$ and lymphatic dysfunction is correlated with atherogenesis ${ }^{118}$. Plaque lymphangiogenic vessels were often collapsed and seemed mostly associated with areas rich in extracellular matrix, whereas more inflamed areas displayed mostly angiogenesis ${ }^{116}$. Dilatation of adventitial lymphatics has been observed in animal ${ }^{119}$ 
and human ${ }^{116}$ atherosclerotic lesions, possibly as a result of an increased arterial wall permeability. Moreover, adventitial VV that expands in plaque lesion are often dysfunctional and leaky, potentially causing interstitial fluid buildup and local edema 120,121 . This may be similar to the lymphatic remodeling that has been observed in cancer, where lymphatics are often collapsed and enlarged due to the excessive interstitial pressure and edema, implying lymphatic dysfunction ${ }^{85,122}$. Interestingly, upon growth of the plaque and increasing plaque interstitial pressure, the LEC elongate, and this stretching activates $\beta 1$ integrin signaling mediated VEGFR-3 phosphorylation and subsequent induction of lymphangiogenesis ${ }^{123}$.

In addition, the functional consequences of adventitial lymphangiogenesis for atherosclerosis are largely unknown. In 1970 , Jellinek et al. ${ }^{119}$ proposed that sufficient lymphatic drainage was required for transporting excess plasma accumulation in aortic atherosclerotic lesions, and that disturbance of lymph drainage contributed to lipid accumulation, resulting in the aggravation of arteriosclerotic lesions. During 1970s to1980s, it was further suggested that the integrity of the lymphatic system draining the coronary arterial wall, might have an important role in the lipid efflux mechanism and the occurrence of atherosclerosis in humans ${ }^{118}$. More than 40 years ago it was postulated that the ingrowth of VV occurred in response of metabolic demand within arterial walls, and thus increased passage of materials to arterial walls. However, ingrowth of lymphatics did not occur in the media or intima, and subsequently led to lipid accumulation within intimal plaque due to the lack of escape route ${ }^{124}$. Recent studies have demonstrated that plaque lymphangiogenesis functions in lipoprotein metabolism ${ }^{125}$ and cholesterol clearance ${ }^{126}$. Moreover, lymphatic dysfunction precedes the onset of atherosclerosis ${ }^{120,127}$. Disruption of lymphatic drainage accelerates plaque progression due to cholesterol retention ${ }^{128}$ and T-cell accumulation ${ }^{120}$ in plaque lesions. Moreover, plaque lymphangiogenesis could exert atheroprotective functions by draining plaque-contained lipids during regression ${ }^{128}$. Systemic treatment with VEGF-C 152s, a selective VEGFR-3 agonist, improved lymphatic cellular transport in pre-atherosclerotic mice ${ }^{127}$.

Together, it is now becoming evident that the lymphatic system plays an active role in cardiovascular disease, and lymphatic dysfunction accelerates disease progression. Sufficient lymphatic drainage seems to protect against MI and atherosclerosis. However, many aspects of the lymphatic system remain unclear, and future studies are needed to fully understand the mechanism of lymphangiogenesis in cardiovascular disease. Recent advances in lymphatic research will potentially provide novel insights into the treatment of cardiovascular diseases. 


\section{Overall aim and hypothesis}

The general aim of this thesis is to investigate novel endothelium-targeted therapeutic approaches for pressure overload-induced heart failure, and for controlling lymphangiogenic functions in atherosclerosis.

We hypothesize that:

1. AVE3085, an eNOS transcription enhancer, can protect against pressure overload-induced left ventricular hypertrophy.

2. Gene network analysis will yield co-expressed genes correlating with human plaque lymphatic vessel density, which are be critical in the regulation of lymphangiogenesis-associated atherosclerosis.

\section{Outline of the thesis}

The pathogenesis of myocardial and endothelial dysfunction shows an important role for eNOS uncoupling. BH4 is an essential cofactor for eNOS, and decreased BH4-bioavailability, resulting in subsequent uncoupling of eNOS. In chapter 2 we discussed the pathophysiologic role of decreased BH4 bioavailability, molecular mechanisms regulating its metabolism, and its potential therapeutic use, as well as its pitfalls as an NOS-modulating drug. Chapter 3 reviewed the important role of eNOS uncoupling in the pathogenesis of endothelial dysfunction, and the potential therapeutic interventions to modulate eNOS for tackling endothelial dysfunction. Pharmacological approaches that prevent eNOS uncoupling are of therapeutic interest. Hence, in chapter $\mathbf{4}$ we discussed modulation of eNOS activity by novel small molecules AVE9488 and AVE3085, which concomitantly enhanced eNOS transcription and reversed the eNOS uncoupling. To investigate the potential protective effect of elevated eNOS expression in ventricular hypertrophy, in chapter 5 we investigated the protective effects of AVE3085. We determined whether eNOS modulation could reverse cardiac hypertrophy and dysfunction in pressure overloadinduced heart failure model. We subjected mice to severe transverse aortic constriction (TAC) for 1 week, as a model of acute onset of HF. It is well established that eNOS uncoupling plays a major role in TAC pathobiology. Moreover, mice that underwent severe, but not mild, TAC resulted in enhanced eNOS uncoupling, associated with increased eNOS-dependent oxidative stress, and consequent cardiac dysfunction and remodeling ${ }^{129,130}$. We used C57BL/6 mice because they develop rapid cardiac hypertrophy, myocyte hypertrophy and fibrosis within 7 days after TAC 131,132 , allowing us to examine the utility of pharmacological or molecular interventions that may limit hypertrophy. 
As discussed, another effective method to prevent the deleterious effects of vascular leakage is to induce the drainage of leaked fluids via lymphatics; as lymphatic vessels are pivotal for drainage of immune cells and lipids. As inflammation and lipid metabolism are causally related to atherogenesis, in chapter 6, we investigated the process of lymphangiogenesis and its main drivers in human atherosclerosis. This was done using a new systems medicine approach, where we correlated microarray data from stable and ruptured atherosclerotic lesions to plaque lymphangiogenesis to identify candidate genes. Subsequently, we performed deep bioinformatics interrogation of expression array data and in vitro loss-offunction screening to identify novel genetic regulators of lymphangiogenesisassocicated atherosclerosis. Finally, chapter 7 summarized and discussed the major findings of this thesis and future perspectives. 


\section{References}

1. European Cardiovascular Disease Statistics 2017 http://www.ehnheart.org/cvd-statistics/cvdstatistics-2017.html, Assessed 17 Jul 2017.

2. WHO: Cardiovascular diseases (CVDs) Fact sheets Updated May 2017 http://www.who.int/mediacentre/factsheets/fs317/en/ , Assessed 17 Jul 2017.

3. Libby P, Lichtman AH, Hansson GK. Immune Effector Mechanisms Implicated in Atherosclerosis: From Mice to Humans. Immunity 2013;38(6):1092-1104.

4. Kutkut I, Meens MJ, McKee TA, Bochaton-Piallat M-L, Kwak BR. Lymphatic vessels: an emerging actor in atherosclerotic plaque development. European Journal of Clinical Investigation 2015;45(1):100-108.

5. Kietadisorn R, Juni RP, Moens AL. Tackling endothelial dysfunction by modulating NOSuncoupling: new insights in pathogenesis and therapeutic possibilities. American Journal of Physiology - Endocrinology And Metabolism 2011.

6. Galkina E, Ley K. Immune and Inflammatory Mechanisms of Atherosclerosis. Annual review of immunology 2009;27:165-197.

7. Sluimer JC, Kolodgie FD, Bijnens APJJ, Maxfield K, Pacheco E, Kutys B, Duimel H, Frederik PM, van Hinsbergh VWM, Virmani R, Daemen MJAP. Thin-walled microvessels in human coronary atherosclerotic plaques show incomplete endothelial junctions: relevance of compromised structural integrity for intraplaque microvascular leakage. Journal of the American College of Cardiology 2009;53(17):1517-1527.

8. Ross R. Atherosclerosis - An Inflammatory Disease. New England Journal of Medicine 1999;340(2):115-126.

9. Libby P. History of Discovery: Inflammation in Atherosclerosis. Arteriosclerosis, thrombosis, and vascular biology 2012;32(9):2045-2051.

10. What Is Atherosclerosis? https://www.nhlbi.nih.gov/health/health-topics/topics/atherosclerosis , Assesed 13 Jul 2017.

11. Herrington W, Lacey B, Sherliker P, Armitage J, Lewington S. Epidemiology of Atherosclerosis and the Potential to Reduce the Global Burden of Atherothrombotic Disease. Circulation Research 2016;118(4):535.

12. Barquera S, Pedroza-Tobías A, Medina C, Hernández-Barrera L, Bibbins-Domingo K, Lozano R, Moran AE. Global Overview of the Epidemiology of Atherosclerotic Cardiovascular Disease. Archives of Medical Research 2016;46(5):328-338.

13. Falk E, Nakano M, Bentzon JF, Finn AV, Virmani R. Update on acute coronary syndromes: the pathologists' view. European Heart Journal 2013;34(10):719-728.

14. Sluimer JC, Daemen MJ. Novel concepts in atherogenesis: angiogenesis and hypoxia in atherosclerosis. The Journal of Pathology 2009;218(1):7-29.

15. van der Heiden K, Hoogendoorn A, Daemen MJ, Gijsen FJH. Animal models for plaque rupture: a biomechanical assessment. Thrombosis and Haemostasis 2016;115(3):501-508.

16. Bentzon JF, Otsuka F, Virmani R, Falk E. Mechanisms of Plaque Formation and Rupture. Circulation Research 2014;114(12):1852-1866.

17. Moore K, Sheedy F, Fisher E. Macrophages in atherosclerosis: a dynamic balance. Nature reviews Immunology 2013;13(10):709-721.

18. Hansson GK, Libby P, Tabas I. Inflammation and plaque vulnerability. Journal of internal medicine 2015;278(5):483-493.

19. Newby AC, George SJ, Ismail Y, Johnson JL, Sala-Newby GB, Thomas AC. Vulnerable atherosclerotic plaque metalloproteinases and foam cell phenotypes. Thrombosis and haemostasis 2009;101(6):1006-1011.

20. Ramji DP, Davies TS. Cytokines in atherosclerosis: Key players in all stages of disease and promising therapeutic targets. Cytokine \& Growth Factor Reviews 2015;26(6):673-685.

21. Tabas IRA. Death-defying plaque cells. Nature 2016;536(7614):32-33. 
22. Guo L, Harari E, Virmani R, Finn AV. Linking Hemorrhage, Angiogenesis, Macrophages, and Iron Metabolism in Atherosclerotic Vascular Diseases. Arteriosclerosis, Thrombosis, and Vascular Biology 2017;37(4):e33-e39.

23. Michel J-B, Virmani R, Arbustini E, Pasterkamp G. Intraplaque haemorrhages as the trigger of plaque vulnerability. European Heart Journal 2011;32(16):1977-1985.

24. Libby P, Pasterkamp G. Requiem for the 'vulnerable plaque'. European Heart Journal 2015;36(43):2984-2987.

25. Brown AJ, Teng Z, Evans PC, Gillard JH, Samady H, Bennett MR. Role of biomechanical forces in the natural history of coronary atherosclerosis. Nat Rev Cardiol 2016;13(4):210-220.

26. Quillard T, Franck G, Mawson T, Folco E, Libby P. Mechanisms of erosion of atherosclerotic plaques. Current Opinion in Lipidology 2017; Publish Ahead of Print.

27. McMurray JJV, Adamopoulos S, Anker SD, Auricchio A, Böhm M, al e. ESC Guidelines for the diagnosis and treatment of acute and chronic heart failure 2012. European Journal of Heart Failure 2012;14(8):803-869.

28. Martínez-Sellés M, Teresa Vidán M, López-Palop R, Rexach L, Sánchez E, Datino T, Cornide M, Carrillo P, Ribera JM, Díaz-Castro Ó, Bañuelos C. End-Stage Heart Disease in the Elderly. Revista Española de Cardiología (English Edition) 2009;62(04):409-421.

29. Ponikowski P, Voors AA, Anker SD, Bueno H, Cleland JGF, al. e. 2016 ESC Guidelines for the diagnosis and treatment of acute and chronic heart failure. European Journal of Heart Failure 2016;18(8):891-975.

30. Bui AL, Horwich TB, Fonarow GC. Epidemiology and risk profile of heart failure. Nature reviews Cardiology 2011;8(1):30-41.

31. Mosterd A, Hoes AW. Clinical epidemiology of heart failure. Heart 2007;93(9):1137-1146.

32. Katholi RE, Couri DM. Left Ventricular Hypertrophy: Major Risk Factor in Patients with Hypertension: Update and Practical Clinical Applications. International Journal of Hypertension $2011 ; 2011$.

33. Brutsaert DL. Cardiac Endothelial-Myocardial Signaling: Its Role in Cardiac Growth, Contractile Performance, and Rhythmicity. Physiological Reviews 2003;83(1):59-115.

34. Noireaud J, Andriantsitohaina R. Recent Insights in the Paracrine Modulation of Cardiomyocyte Contractility by Cardiac Endothelial Cells. BioMed Research International 2014;2014:10.

35. Rajendran P, Rengarajan T, Thangavel J, Nishigaki Y, Sakthisekaran D, Sethi G, Nishigaki I. The Vascular Endothelium and Human Diseases. International Journal of Biological Sciences 2013;9(10):1057-1069.

36. Cines DB, Pollak ES, Buck CA, Loscalzo J, Zimmerman GA, McEver RP, Pober JS, Wick TM, Konkle BA, Schwartz BS, Barnathan ES, McCrae KR, Hug BA, Schmidt A-M, Stern DM. Endothelial Cells in Physiology and in the Pathophysiology of Vascular Disorders. Blood 1998;91(10):3527-3561.

37. Michiels C. Endothelial cell functions. Journal of Cellular Physiology 2003;196(3):430-443.

38. Chiu J-J, Chien S. Effects of Disturbed Flow on Vascular Endothelium: Pathophysiological Basis and Clinical Perspectives. Physiological reviews 2011;91(1):10.1152/physrev.00047.2009.

39. Förstermann $\mathrm{U}, \mathrm{Li} \mathrm{H}$. Therapeutic effect of enhancing endothelial nitric oxide synthase (eNOS) expression and preventing eNOS uncoupling. British Journal of Pharmacology 2011;164(2):213223.

40. Takimoto E, Champion HC, Li M, Ren S, Rodriguez ER, Tavazzi B, Lazzarino G, Paolocci N, Gabrielson KL, Wang Y, Kass DA. Oxidant stress from nitric oxide synthase-3 uncoupling stimulates cardiac pathologic remodeling from chronic pressure load. The Journal of Clinical Investigation 2005;115(5):1221-1231.

41. Moens AL, Takimoto E, Tocchetti CG, Chakir K, Bedja D, Cormaci G, Ketner EA, Majmudar M, Gabrielson K, Halushka MK, Mitchell JB, Biswal S, Channon KM, Wolin MS, Alp NJ, Paolocci N, Champion HC, Kass DA. Reversal of Cardiac Hypertrophy and Fibrosis From Pressure Overload 
by Tetrahydrobiopterin: Efficacy of Recoupling Nitric Oxide Synthase as a Therapeutic Strategy. Circulation 2008;117(20):2626-2636.

42. Alp NJ, Channon KM. Regulation of Endothelial Nitric Oxide Synthase by Tetrahydrobiopterin in Vascular Disease. Arteriosclerosis, Thrombosis, and Vascular Biology 2004;24(3):413-420.

43. Bendall JK, Douglas G, McNeill E, Channon KM, Crabtree MJ. Tetrahydrobiopterin in Cardiovascular Health and Disease. Antioxidants \& Redox Signaling 2014;20(18):3040-3077.

44. Esper RJ, Nordaby RA, Vilariño JO, Paragano A, Cacharrón JL, Machado RA. Endothelial dysfunction: a comprehensive appraisal. Cardiovascular Diabetology 2006;5(1):4.

45. Favero G, Paganelli C, Buffoli B, Rodella LF, Rezzani R. Endothelium and Its Alterations in Cardiovascular Diseases: Life Style Intervention. BioMed Research International 2014;2014:28.

46. Widmer RJ, Lerman A. Endothelial dysfunction and cardiovascular disease. Global Cardiology Science \& Practice 2014;2014(3):291-308.

47. Bauersachs J, JD. W. Endothelial dysfunction in heart failure. Pharmacol Rep 2008;60(1):119126.

48. Rader DJ, Daugherty A. Translating molecular discoveries into new therapies for atherosclerosis. Nature 2008;451(7181):904-913.

49. Cai H, Harrison DG. Endothelial Dysfunction in Cardiovascular Diseases: The Role of Oxidant Stress. Circulation Research 2000;87(10):840-844.

50. Gokce N, Keaney JF, Hunter LM, Watkins MT, Nedeljkovic ZS, Menzoian JO, Vita JA. Predictive value of noninvasivelydetermined endothelial dysfunction for long-term cardiovascular events inpatients with peripheral vascular disease. Journal of the American College of Cardiology 2003;41(10):1769-1775.

51. Flammer AJ, Anderson T, Celermajer DS, Creager MA, Deanfield J, Ganz P, Hamburg N, Lüscher TF, Shechter M, Taddei S, Vita JA, Lerman A. The Assessment of Endothelial FunctionFrom Research into Clinical Practice. Circulation 2012;126(6):753-767.

52. Sandoo A, van Zanten JJCSV, Metsios GS, Carroll D, Kitas GD. The Endothelium and Its Role in Regulating Vascular Tone. The Open Cardiovascular Medicine Journal 2010;4:302-312.

53. Moens AL, Goovaerts I, Claeys MJ, Vrints CJ. Flow-Mediated Vasodilation. CHEST 2005;127(6):2254-2263.

54. Carmeliet P, Jain RK. Molecular mechanisms and clinical applications of angiogenesis. Nature 2011;473(7347):298-307.

55. Eelen $G$, de Zeeuw $P$, Simons $M$, Carmeliet $P$. Endothelial cell metabolism in normal and diseased vasculature. Circulation research 2015;116(7):1231-1244.

56. Goel S, Duda DG, Xu L, Munn LL, Boucher Y, Fukumura D, Jain RK. Normalization of the vasculature for treatment of cancer and other diseases. Physiological Reviews 2011;91(3):10711121.

57. Augustin HG, Young Koh G, Thurston G, Alitalo K. Control of vascular morphogenesis and homeostasis through the angiopoietin-Tie system. Nat Rev Mol Cell Biol 2009;10(3):165-177.

58. Whiteford JR, De Rossi G, Woodfin A. Mutually Supportive Mechanisms of Inflammation and Vascular Remodeling. International Review of Cell and Molecular Biology 2016;326:201-278.

59. Post S, Peeters W, Busser E, Lamers D, Sluijter JPG, Goumans MJ, de Weger RA, Moll FL, Doevendans PA, Pasterkamp G, Vink A. Balance between Angiopoietin-1 and Angiopoietin-2 Is in Favor of Angiopoietin-2 in Atherosclerotic Plaques with High Microvessel Density. Journal of Vascular Research 2008;45(3):244-250.

60. Lähteenvuo J, Rosenzweig A. Invited Review: The Role of Angiogenesis in Cardiovascular Aging. Circulation research 2012;110(9):1252-1264.

61. McLoughlin P, Keane MP. Physiological and Pathological Angiogenesis in the Adult Pulmonary Circulation. In. Comprehensive Physiology: John Wiley \& Sons, Inc.; 2011.

62. Walsh K, Shiojima I. Cardiac growth and angiogenesis coordinated by intertissue interactions. The Journal of Clinical Investigation 2007;117(11):3176-3179. 
63. Tirziu D, Chorianopoulos E, Moodie KL, Palac RT, Zhuang ZW, Tjwa M, Roncal C, Eriksson U, Fu Q, Elfenbein A, Hall AE, Carmeliet P, Moons L, Simons M. Myocardial hypertrophy in the absence of external stimuli is induced by angiogenesis in mice. The Journal of Clinical Investigation 2007;117(11):3188-3197.

64. He W, James Kang Y. Ischemia-induced Copper Loss and Suppression of Angiogenesis in the Pathogenesis of Myocardial Infarction. Cardiovascular Toxicology 2013;13(1):1-8.

65. de Boer RA, Pinto YM, van Veldhuisen DJ. The Imbalance Between Oxygen Demand and Supply as a Potential Mechanism in the Pathophysiology of Heart Failure: The Role of Microvascular Growth and Abnormalities. Microcirculation 2003;10(2):113-126.

66. Hilfiker-Kleiner D, Landmesser U, Drexler H. Molecular Mechanisms in Heart Failure. Journal of the American College of Cardiology 2006;48(9):A56-A66.

67. Jürgensen JS, Rosenberger C, Wiesener MS, Warnecke C, Hörstrup JH, Gräfe M, Philipp S, Griethe W, Maxwell PH, Frei U, Bachmann S, Willenbrock R, Eckardt K-U. Persistent induction of HIF-1 $\alpha$ and $-2 \alpha$ in cardiomyocytes and stromal cells of ischemic myocardium. The FASEB Journal 2004.

68. Zhang $\mathrm{H}$, van Olden $\mathrm{C}$, Sweeney $\mathrm{D}$, Martin-Rendon E. Blood vessel repair and regeneration in the ischaemic heart. Open Heart 2014;1(1).

69. Lee SH, Wolf PL, Escudero R, Deutsch R, Jamieson SW, Thistlethwaite PA. Early Expression of Angiogenesis Factors in Acute Myocardial Ischemia and Infarction. New England Journal of Medicine 2000;342(9):626-633.

70. Cochain C, Channon KM, Silvestre J-S. Angiogenesis in the Infarcted Myocardium. Antioxidants \& Redox Signaling 2013;18(9):1100-1113.

71. Jiang Y, Reynolds C, Xiao C, Feng W, Zhou Z, Rodriguez W, Tyagi SC, Eaton JW, Saari JT, Kang YJ. Dietary copper supplementation reverses hypertrophic cardiomyopathy induced by chronic pressure overload in mice. The Journal of Experimental Medicine 2007;204(3):657-666.

72. Sano M, Minamino T, Toko H, Miyauchi H, Orimo M, Qin Y, Akazawa H, Tateno K, Kayama Y, Harada M, Shimizu I, Asahara T, Hamada H, Tomita S, Molkentin JD, Zou Y, Komuro I. p53induced inhibition of Hif-1 causes cardiac dysfunction during pressure overload. Nature 2007;446(7134):444-448.

73. van der Laan AM, Piek JJ, van Royen N. Targeting angiogenesis to restore the microcirculation after reperfused MI. Nat Rev Cardiol 2009;6(8):515-523.

74. Ritman EL, Lerman A. The Dynamic Vasa Vasorum. Cardiovascular research 2007;75(4):649658.

75. Mulligan-Kehoe MJ, Simons M. Vasa Vasorum in Normal and Diseased Arteries. Circulation 2014;129(24):2557-2566.

76. Virmani R, Kolodgie FD, Burke AP, Finn AV, Gold HK, Tulenko TN, Wrenn SP, Narula J. Atherosclerotic Plaque Progression and Vulnerability to Rupture. Angiogenesis as a Source of Intraplaque Hemorrhage 2005;25(10):2054-2061.

77. de Vries MR, Quax PHA. Plaque angiogenesis and its relation to inflammation and atherosclerotic plaque destabilization. Current Opinion in Lipidology 2016;27(5):499-506.

78. Jeziorska M, Woolley DE. Neovascularization in early atherosclerotic lesions of human carotid arteries: Its potential contribution to plaque development. Human Pathology 1999;30(8):919-925.

79. Sluimer JC, Gasc J-M, van Wanroij JL, Kisters N, Groeneweg M, Sollewijn Gelpke MD, Cleutjens JP, van den Akker LH, Corvol P, Wouters BG, Daemen MJ, Bijnens A-PJ. Hypoxia, HypoxiaInducible Transcription Factor, and Macrophages in Human Atherosclerotic Plaques Are Correlated With Intraplaque Angiogenesis. Journal of the American College of Cardiology 2008:51(13):1258-1265.

80. Jain RK. Antiangiogenesis Strategies Revisited: From Starving Tumors to Alleviating Hypoxia. Cancer cell 2014;26(5):605-622.

81. Gao L, Chen Q, Zhou X, Fan L. The role of hypoxia-inducible factor 1 in atherosclerosis. Journal of Clinical Pathology 2012;65(10):872-876. 
82. Marsch E, Sluimer JC, Daemen MJAP. Hypoxia in atherosclerosis and inflammation. Current Opinion in Lipidology 2013;24(5):393-400.

83. Eales NB. The History of the Lymphatic System, with Special Reference to the Hunter-Monro Controversy. Journal of the History of Medicine and Allied Sciences 1974;XXIX(3):280-294.

84. Natale G, Bocci G, Ribatti D. Scholars and scientists in the history of the lymphatic system. Journal of Anatomy 2017:n/a-n/a.

85. Stacker SA, Williams SP, Karnezis T, Shayan R, Fox SB, Achen MG. Lymphangiogenesis and lymphatic vessel remodelling in cancer. Nat Rev Cancer 2014;14(3):159-172.

86. Zheng W, Aspelund A, Alitalo K. Lymphangiogenic factors, mechanisms, and applications. The Journal of Clinical Investigation 2014;124(3):878-887.

87. Wang $\mathrm{Y}$, Oliver $\mathrm{G}$. Current views on the function of the lymphatic vasculature in health and disease. Genes \& Development 2010;24(19):2115-2126.

88. Hirakawa S. Regulation of pathological lymphangiogenesis requires factors distinct from those governing physiological lymphangiogenesis. Journal of Dermatological Science 2011;61(2):85-93.

89. Baluk P, Fuxe J, Hashizume H, Romano T, Lashnits E, Butz S, Vestweber D, Corada M, Molendini C, Dejana E, McDonald DM. Functionally specialized junctions between endothelial cells of lymphatic vessels. The Journal of Experimental Medicine 2007;204(10):2349-2362.

90. Tammela T, Alitalo K. Lymphangiogenesis: Molecular Mechanisms and Future Promise. Cell 2010;140(4):460-476.

91. Dellinger M, Hunter R, Bernas M, Gale N, Yancopoulos G, Erickson R, Witte M. Defective remodeling and maturation of the lymphatic vasculature in Angiopoietin-2 deficient mice. Developmental Biology 2008;319(2):309-320.

92. Mäkinen T, Adams RH, Bailey J, Lu Q, Ziemiecki A, Alitalo K, Klein R, Wilkinson GA. PDZ interaction site in ephrinB2 is required for the remodeling of lymphatic vasculature. Genes \& Development 2005;19(3):397-410.

93. Aspelund A, Robciuc MR, Karaman S, Makinen T, Alitalo K. Lymphatic System in Cardiovascular Medicine. Circulation Research 2016;118(3):515.

94. Sleeman JP. Understanding the mechanisms of lymphangiogenesis: a hope for cancer therapy? Phlebolymphology 2010;17:99-107.

95. Blacher S, Erpicum C, Lenoir B, Paupert J, Moraes G, Ormenese S, Bullinger E, Noel A. Cell Invasion in the Spheroid Sprouting Assay: A Spatial Organisation Analysis Adaptable to Cell Behaviour. PLoS ONE 2014;9(5):e97019.

96. Xu Y, Yuan L, Mak J, Pardanaud L, Caunt M, Kasman I, Larrivée B, del Toro R, Suchting S, Medvinsky A, Silva J, Yang J, Thomas J-L, Koch AW, Alitalo K, Eichmann A, Bagri A. Neuropilin2 mediates VEGF-C-induced lymphatic sprouting together with VEGFR3. The Journal of Cell Biology 2010;188(1):115-130.

97. Yang Y, Oliver G. Development of the mammalian lymphatic vasculature. The Journal of Clinical Investigation 2014;124(3):888-897.

98. Vittet D. Lymphatic collecting vessel maturation and valve morphogenesis. Microvascular Research 2014;96:31-37.

99. Eklund L, Bry M, Alitalo K. Mouse models for studying angiogenesis and lymphangiogenesis in cancer. Molecular Oncology 2013;7(2):259-282.

100. Coso S, Bovay E, Petrova TV. Pressing the right buttons: signaling in lymphangiogenesis. Blood 2014;123(17):2614.

101. Kim H, Kataru RP, Koh GY. Regulation and implications of inflammatory lymphangiogenesis. Trends in Immunology 2012;33(7):350-356.

102. Patek PR. The morphology of the lymphactics of the mammalian heart. American Journal of Anatomy 1939;64(2):203-249.

103. Rudbeck O. Nova exervitatio anatomia exhibens ductus hepatico aquosos et vasa glandularum serosa, nunc primum inventa, aeneisque figures delineate. . Uppsala: Arosiae 1653. 
104. Dashkevich A, Hagl C, Beyersdorf F, Nykänen Al, Lemström KB. VEGF Pathways in the Lymphatics of Healthy and Diseased Heart. Microcirculation 2016;23(1):5-14.

105. Cui Y. Impact of Lymphatic Vessels on the Heart. Thorac cardiovasc Surg 2010;58(01):1-7.

106. Miller AJ. The grossly invisible and generally ignored lymphatics of the mammalian heart. Medical Hypotheses 2011;76(4):604-606.

107. Vuorio T, Tirronen A, Ylä-Herttuala S. Cardiac Lymphatics - A New Avenue for Therapeutics? Trends in Endocrinology \& Metabolism 2017;28(4):285-296.

108. Flaht-Zabost A, Gula G, Ciszek B, Czarnowska E, Jankowska-Steifer E, Madej M, NiderlaBielińska J, Radomska-Leśniewska D, Ratajska A. Cardiac Mouse Lymphatics: Developmental and Anatomical Update. The Anatomical Record 2014;297(6):1115-1130.

109. Ratajska A, Gula G, Flaht-Zabost A, Czarnowska E, Ciszek B, Jankowska-Steifer E, NiderlaBielinska J, Radomska-Lesniewska D. Comparative and Developmental Anatomy of Cardiac Lymphatics. The Scientific World Journal 2014;2014:9.

110. Lupinski RW. Aortic fat pad and atrial fibrillation: cardiac lymphatics revisited. ANZ Journal of Surgery 2009;79(1-2):70-74.

111. Henri O, Pouehe C, Houssari M, Galas L, Nicol L, Edwards-Lévy F, Henry J-P, Dumesnil A, Boukhalfa I, Banquet S, Schapman D, Thuillez C, Richard V, Mulder P, Brakenhielm E. Selective Stimulation of Cardiac Lymphangiogenesis Reduces Myocardial Edema and Fibrosis Leading to Improved Cardiac Function Following Myocardial Infarction. Circulation 2016;133(15):1484.

112. Klotz L, Norman S, Vieira JM, Masters M, Rohling M, Dubé KN, Bollini S, Matsuzaki F, Carr CA, Riley PR. Cardiac lymphatics are heterogeneous in origin and respond to injury. Nature 2015;522(7554):62-67.

113. Ishikawa $\mathrm{Y}$, Akishima-Fukasawa $\mathrm{Y}$, Ito K, Akasaka $\mathrm{Y}$, Tanaka M, Shimokawa R, KimuraMatsumoto M, Morita H, Sato S, Kamata I, Ishii T. Lymphangiogenesis in myocardial remodelling after infarction. Histopathology 2007;51(3):345-353.

114. Johnson R. Lymphatics of blood vessels. Lymphology 1969;2:44-56.

115. Drozdz K, Janczak D, Dziegiel P, Podhorska M, Patrzałek D, Ziółkowski P, Andrzejak R, Szuba A. Adventitial lymphatics of internal carotid artery in healthy and atherosclerotic vessels. Folia Histochem Cytobiol 2008;46(4):433-436.

116. Kholová I, Dragneva G, Čermáková P, Laidinen S, Kaskenpää N, Hazes T, Čermáková E, Šteiner I, Ylä-Herttuala S. Lymphatic vasculature is increased in heart valves, ischaemic and inflamed hearts and in cholesterol-rich and calcified atherosclerotic lesions. European Journal of Clinical Investigation 2011;41(5):487-497.

117. Nakano T, Nakashima Y, Yonemitsu Y, Sumiyoshi S, Chen Y-X, Akishima Y, Ishii T, lida M, Sueishi K. Angiogenesis and lymphangiogenesis and expression of lymphangiogenic factors in the atherosclerotic intima of human coronary arteries. Human Pathology 2005;36(4):330-340.

118. Eliska O EM, Miller AJ. The absence of lymphatics in normal and atherosclerotic coronary arteries in man: a morphologic study. Lymphology 2006;39(2):76-83.

119. Jellinek $H$, Veress $B$, Bálint A, Nagy Z. Lymph vessels of rat aorta and their changes in experimental atherosclerosis: An electron microscopic study. Experimental and Molecular Pathology 1970;13(3):370-376.

120. Rademakers T, van der Vorst EPC, Daissormont ITMN, Otten JJT, Theodorou K, Theelen TL, Gijbels M, Anisimov A, Nurmi H, Lindeman JHN, Schober A, Heeneman S, Alitalo K, Biessen EAL. Adventitial lymphatic capillary expansion impacts on plaque $\mathrm{T}$ cell accumulation in atherosclerosis. Scientific Reports 2017;7:45263.

121. Rademakers T, Douma K, Hackeng TM, Post MJ, Sluimer JC, Daemen MJAP, Biessen EAL, Heeneman S, van Zandvoort MAMJ. Plaque-Associated Vasa Vasorum in Aged Apolipoprotein E-Deficient Mice Exhibit Proatherogenic Functional Features In Vivo. Arteriosclerosis, Thrombosis, and Vascular Biology 2013;33(2):249-256.

122. Claesson-Welsh L. Vascular permeability-the essentials. Upsala Journal of Medical Sciences 2015;120(3):135-143. 
123. Planas-Paz L, Strilić B, Goedecke A, Breier G, Fässler R, Lammert E. Mechanoinduction of lymph vessel expansion. The EMBO Journal 2012;31(4):788-804.

124. Cliff W. Ancillary structures of blood vessel walls. Blood Vessels 1976:125-140.

125. Vuorio T, Nurmi H, Moulton K, Pikkarainen J, Robciuc MR, öhman M, Heinonen SE, Samaranayake H, Heikura T, Alitalo K, Ylä-Herttuala S. Lymphatic vessel insufficiency in hypercholesterolemic mice alters lipoprotein levels and promotes atherogenesis. Arteriosclerosis, thrombosis, and vascular biology 2014;34(6):1162-1170.

126. Lim Hwee Y, Thiam Chung H, Yeo Kim P, Bisoendial R, Hii Chung S, McGrath Kristine CY, Tan Kar W, Heather A, Alexander JSteven J, Angeli V. Lymphatic Vessels Are Essential for the Removal of Cholesterol from Peripheral Tissues by SR-BI-Mediated Transport of HDL. Cell Metabolism 2013;17(5):671-684.

127. Milasan A, Dallaire F, Mayer G, Martel C. Effects of LDL Receptor Modulation on Lymphatic Function. Scientific Reports 2016;6:27862.

128. Martel C, Li W, Fulp B, Platt AM, Gautier EL, Westerterp M, Bittman R, Tall AR, Chen S-H, Thomas MJ, Kreisel D, Swartz MA, Sorci-Thomas MG, Randolph GJ. Lymphatic vasculature mediates macrophage reverse cholesterol transport in mice. The Journal of Clinical Investigation 2013;123(4):1571-1579.

129. van Deel ED, Octavia Y, de Boer M, Juni RP, Tempel D, van Haperen R, de Crom R, Moens AL, Merkus D, Duncker DJ. Normal and high eNOS levels are detrimental in both mild and severe cardiac pressure-overload. Journal of Molecular and Cellular Cardiology 2015;88(Supplement C): $145-154$.

130. Takimoto E, Champion HC, Li M, Ren S, Rodriguez ER, Tavazzi B, Lazzarino G, Paolocci N, Gabrielson KL, Wang Y, Kass DA. Oxidant stress from nitric oxide synthase-3 uncoupling stimulates cardiac pathologic remodeling from chronic pressure load. Journal of Clinical Investigation 2005;115(5):1221-1231.

131. Souders CA, Borg TK, Banerjee I, Baudino TA. Pressure Overload Induces Early Morphological Changes in the Heart. The American Journal of Pathology 2012;181(4):1226-1235.

132. Patten RD, Hall-Porter MR. Small Animal Models of Heart Failure. Development of Novel Therapies, Past and Present 2009;2(2):138-144. 



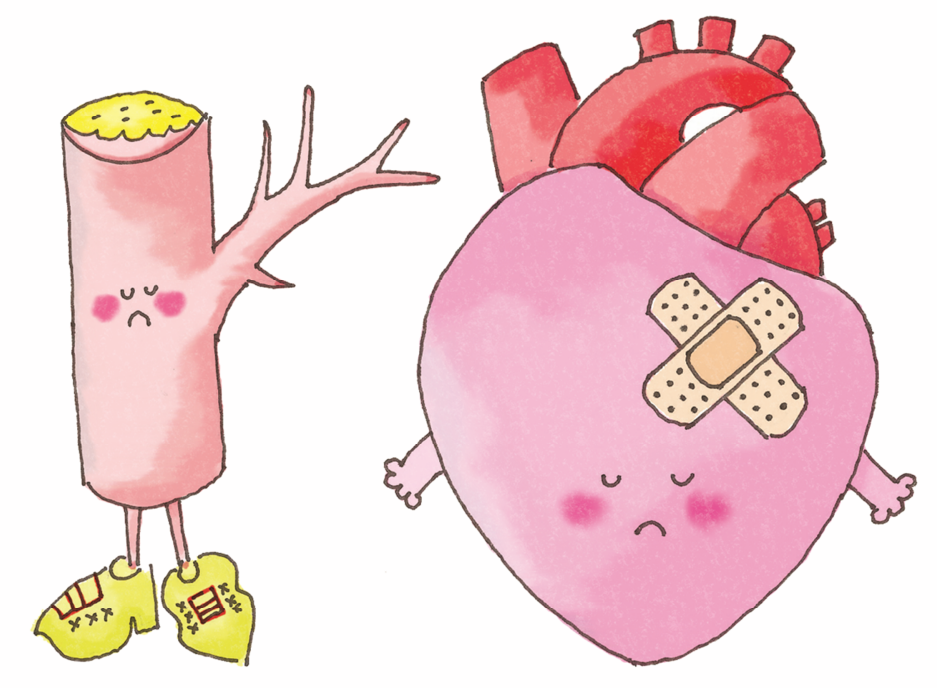




\section{Chapter 2}

\section{Targeting endothelial and myocardial dysfunction with tetrahydrobiopterin}

A. L. Moens, R. Kietadisorn, J. Y. Lin, D.Kass

J Mol Cell Cardiol. 2011 Oct;51(4):559-63. 


\begin{abstract}
Tetrahydrobiopterin (BH4) is an essential cofactor for aromatic amino acid hydroxylases and for all three nitric oxide synthase (NOS) isoforms. It also has a protective role in the cell as an antioxidant and scavenger of reactive nitrogen and oxygen species. Experimental studies in humans and animals demonstrate that decreased BH4-bioavailability, with subsequent uncoupling of endothelial NOS (eNOS) plays an important role in the pathogenesis of endothelial dysfunction, hypertension, ischemia/reperfusion injury, and pathologic cardiac remodeling. Synthetic BH4 is clinically approved for the treatment of phenylketonuria, and experimental studies support its capacity for ameliorating cardiovascular pathophysiologies. To date, however, the translation of these studies to human patients remains limited, and early results have been mixed. In this review, we discuss the pathophysiologic role of decreased $\mathrm{BH} 4$ bioavailability, molecular mechanisms regulating its metabolism, and its potential therapeutic use as well as pitfalls as an NOS-modulating drug. This article is part of a special issue entitled "Key Signaling Molecules in Hypertrophy and Heart Failure."
\end{abstract}




\section{Introduction}

Tetrahydrobiopterin $(\mathrm{BH} 4)$ is an essential cofactor for the three aromatic amino acid hydroxylase enzymes involved in the synthesis of neurotransmitters, as well as the nitric oxide synthase (NOS) isoforms. In the cardiovascular system, the NOS isozymes have a central role in mediating vascular tone, endothelial function, platelet aggregation, cardiac myocyte contraction and excitation-contraction coupling, and many other properties. NOS activity depends on several cofactors, including flavin adenine dinucleotide, flavin mononucleotide, a heme group, and $\mathrm{BH} 4$, as well as structural features such as a zinc-thiolate cluster. $\mathrm{BH} 4$ facilitates electron transfer from reductase to oxidase NOS domains, coupling this to the conversion of arginine to citrulline and NO generation. It also promotes and stabilizes NOS in its active homodimeric form ${ }^{1}$. Decreased $\mathrm{BH} 4$ bioavailability results in unstable NOS that becomes physically less compact and functionally uncoupled, reducing NO-production and enhancing the generation of superoxide. Though the ratio between "coupled" and "uncoupled" NOS in normal or pathological disease conditions remains unclear, uncoupling can be reversed by exogenous $\mathrm{BH} 4$ administration, igniting interest in $\mathrm{BH} 4$ as a potential cardiovascular therapeutic. Both a reduced bioavailability of the substrate L-arginine and the cofactor $\mathrm{BH} 4$ can lead to uncoupling of eNOS. However, in in vivo settings the latter is the most prominent factor. Recoupling of eNOS accounts for the majority of the benefits that result from $\mathrm{BH} 4$ administration in a model of pressure overload. Moens et al. ${ }^{2}$ have demonstrated that administration of the potent antioxidant Tempol (which did not recouple the uncoupled eNOS), did not had any significant effect on remodeling, except on myocyte dimensions (but still less than the effect of $\mathrm{BH} 4$ on myocyte dimensions).

However, despite encouraging experimental data, clinical translation studies remain limited, and those reported (largely preliminary data) have been less than encouraging. The basic science continues to drive efforts to understand the biochemistry better, and ultimately identify a pathway to successfully adjust decreased $\mathrm{BH} 4$-levels. Here, we review key background regarding $\mathrm{BH} 4$ chemistry and physiology, and highlight new insights and controversies in this area of research.

\subsection{Regulation of $\mathrm{BH} 4$ synthesis}

$\mathrm{BH} 4$ is synthesized by one of the two pathways, de novo, or salvaged from its oxidized forms. For de novo synthesis, the enzymes GTP cyclohydrolase (GTPCH), 6pyruvoyltetrahydropterin synthase and sepiapterin reductase convert GTP into $\mathrm{BH} 4^{3 \text {, }}$ ${ }^{4}$. GTPCH is the rate limiting enzymatic step and primary regulator for new synthesis (overview see Figure 1). GTPCH colocalizes with eNOS in caveolae, and upregulation of one enzyme requires matching upregulation of the other in order to maintain normal 
NOS-NO synthesis ${ }^{5}$. For example, eNOS overexpression in the absence of compensating GTPCH levels leads to excessive reactive oxygen species (ROS) generation by NOS rather than enhanced NO production ${ }^{5}$. Salvage of $\mathrm{BH} 4$ from $\mathrm{BH} 2$ is achieved by dihydrofolate reductase (DHFR), or by quinonoid dihydrobiopterin through dihydropteridine reductase (DHPR). DHFR is mainly involved in folate metabolism but also converts inactive $\mathrm{BH} 2$ back to $\mathrm{BH} 4$ and plays an important role in the metabolism of exogenously administered $\mathrm{BH} 4$. A study in bovine aortic endothelial cell (BAEC) culture showed that angiotensin II (AT2) downregulates DHFR expression via endothelial $\mathrm{NADPH}$-oxidase-derived $\mathrm{H}_{2} \mathrm{O}_{2}$, resulting in reduced $\mathrm{NO}$ production due to $\mathrm{BH} 4$ deficiency and the uncoupling of eNOS ${ }^{6}$. Overexpression of DHFR restores all of these abnormalities ${ }^{6}$. Seujange et al. demonstrated that renal ischemia/reperfusion injury significantly reduced renal DHFR mRNA and protein levels which were restored by administration of ACE-inhibitor or AT2 receptor type 1 blocker (ARB) ${ }^{7}$.

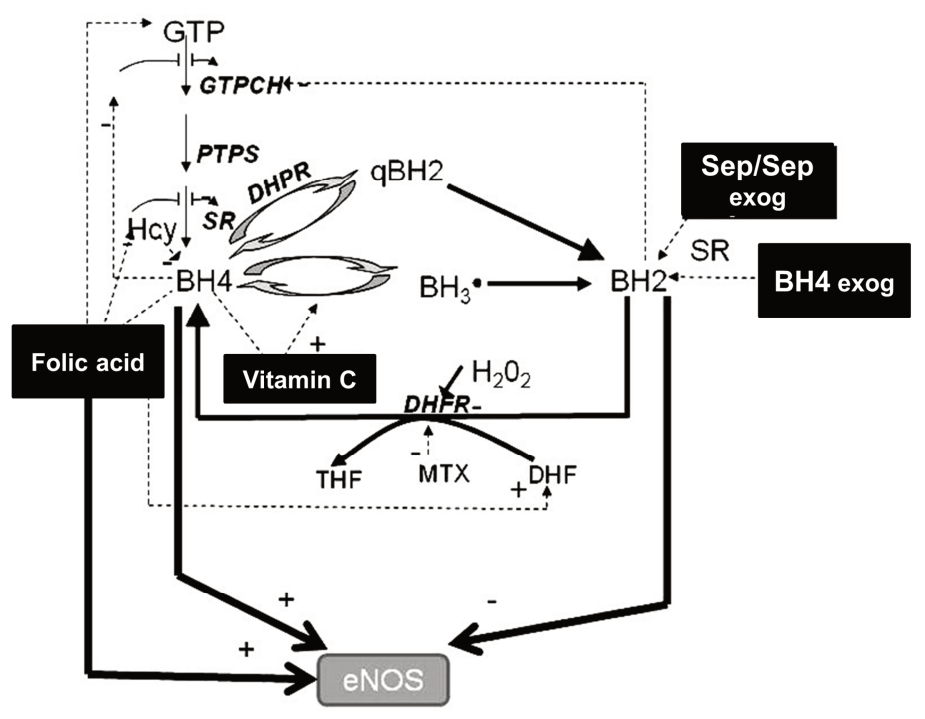

Figure 1. Biosynthesis of $\mathrm{BH} 4$ 


\subsection{NOS uncoupling}

The stoichiometry of intracellular BH4/eNOS interactions (or for that matter $\mathrm{BH} 4$ with other NOS isoforms) remains poorly defined, making it unclear whether intracellular $\mathrm{BH} 4$ deficiency alone is sufficient to induce eNOS uncoupling. Crabtree et al. ${ }^{8}$ found that the ratio of $\mathrm{BH} 4: \mathrm{BH} 2$ and absolute molar concentration of $\mathrm{BH} 4$ are the key determinants of eNOS coupling in vivo. Furthermore, they showed that eNOS:BH4 ratio and biopterin redox status are responsible for determining the degree of eNOS coupling even in the absence of vascular disease or oxidative stress. The degree of $\mathrm{BH} 4$ oxidation, $\mathrm{BH} 2$ accumulation, and superoxide production directly correlated with intracellular eNOS: $\mathrm{BH} 4$ ratio. $\mathrm{BH} 4$ can have substantial effects on the levels of cellular reactive oxygen species production through mechanisms independent of eNOS, such as direct reactive oxygen species scavenging. This suggests that general antioxidant properties of $\mathrm{BH} 4$ act in direct scavenging of superoxide and maintenance of intracellular redox balance. Moreover, they demonstrate that eNOS-dependent superoxide production occurs in addition to basal superoxide formation overwhelming antioxidant defenses. This is surprising as superoxide reacts with $\mathrm{BH} 4$ in vitro with a rate constant $>10,000$-fold slower $\left(3.9 \times 10^{5}\right.$ $\left.\mathrm{mol} \mathrm{I}^{-1} \mathrm{~s}^{-1}\right)$ than its near diffusion limited reaction with $\mathrm{NO}\left(6.7 \times 10^{9} \mathrm{~mol} \mathrm{I}^{-1} \mathrm{~s}^{-1}\right)^{9,10}$.

The role of $\mathrm{BH} 2$ in the pathogenesis of eNOS uncoupling has recently been elucidated. Before, $\mathrm{BH} 2$ was described as an inactive and oxidized form of $\mathrm{BH} 4$. Because the $K_{m}$ of $\mathrm{BH} 4$ and $\mathrm{BH} 2$ for eNOS are similar $(\sim 80 \mathrm{~nm})$, earlier studies speculated that $\mathrm{BH} 2$ competed with $\mathrm{BH} 4$ for eNOS binding, thus promoting NOS uncoupling and $\mathrm{O}_{2}^{-}$production ${ }^{11}$. This was recently shown, and the fall in $\mathrm{BH} 4: \mathrm{BH} 2$ ratio, rather than decline in absolute $\mathrm{BH} 4$, determined $\mathrm{NO}$ and $\mathrm{O}_{2}{ }^{-}$production by eNOS ${ }^{12}$. Thus, strategies to augment $\mathrm{BH} 4$ while suppressing $\mathrm{BH} 2$ may be required to optimally achieve therapeutic benefit.

Although GTPCH is the key regulator of the total amount of intracellular biopterins, DHFR is critical to eNOS function as it determines $\mathrm{BH} 4: \mathrm{BH} 2$ ratio and thus eNOS coupling. In particular, DHFR is important in preventing "self-propagated" eNOS uncoupling where there are low total biopterin levels, and eNOS-dependent oxidation of $\mathrm{BH} 4$ that would further exacerbate this state can be rescued by DHFR ${ }^{13}$. Inhibition of DHFR activity or reduction of DHFR protein (by methotrexate or DHFR-specific siRNA, respectively) resulted in $\mathrm{BH} 4$ oxidation to $\mathrm{BH} 2$, reducing $\mathrm{NO}$ generation and increasing eNOS-derived $\mathrm{O}_{2}^{-}$. This was particularly effective if $\mathrm{BH} 4$ was reduced. Sugiyama et al. ${ }^{14}$ showed in BAEC that while GTPCH knockdown reduced overall biopterin levels, lowering eNOS-NO synthesis, it did not enhance superoxide production. In contrast, DHFR knockdown yielded a marked increase in $\mathrm{BH}$, though no substantial effect on total biopterin, reducing NO generation while greatly 
enhancing ROS production. These data suggest that decreased NO production and increased ROS production are not intrinsically linked by $\mathrm{BH} 4$ depletion. Even if $\mathrm{BH} 4$ levels are lowered to the point of uncoupling $\mathrm{NO}$ synthesis, $\mathrm{BH} 2$ appears necessary to observe eNOS-dependent $\mathrm{H}_{2} \mathrm{O}_{2}$ synthesis. Taken together, these data imply that $\mathrm{BH} 2$ plays a key role in generating ROS from eNOS in cultured endothelial cells, and the ratio of $\mathrm{BH} 4: \mathrm{BH} 2$, rather than the absolute concentrations is the critical determinant.

Recently, it was suggested that $\mathrm{BH} 4$ also has a role in mediating cardiac mitochondrial NOS (mtNOS), though the exact identification of a mtNOS species remains controversial. Using permeabilized cat ventricular myocytes, Dedkova et al. showed that $\mathrm{BH} 4$ reduced mitochondrial ROS generation and mitochondrial permeability transition pore opening while increasing mitochondrial NO generation ${ }^{15}$.

\section{3. $\mathrm{BH} 4$ and vascular pathophysiology}

Endothelial dysfunction is defined by inability of endothelium to maintain vascular tone, increased platelet activation, leukocyte adhesion, and smooth muscle proliferation; and all can be linked to inadequate NO generation ${ }^{5}$. Patients with diabetes, heart failure, and hypertension, each conditions with excessive endothelial ROS, exhibit improved endothelium-dependent vasodilation after $\mathrm{BH} 4$ supplementation ${ }^{16}$ compared with general antioxidants. In smokers, endothelial dysfunction is partially due to increased lipid peroxidation and the increased formation of oxidized low-density lipoprotein (oxLDL). OxLDL inhibits the Akt survival pathways attenuating eNOS activity ${ }^{17-19}$. One study showed that cigarette smoke extract reduced eNOS activity in a concentration-dependent fashion ${ }^{20}$ due to $\mathrm{BH} 4$ depletion, possibly from $\mathrm{BH} 4$ oxidation ${ }^{21}$. Human studies have shown that $\mathrm{BH} 4$ administration via intra-arterial infusion at a dose of $500 \mu \mathrm{g} / \mathrm{min}$ for $30 \mathrm{~min}^{20}$, or oral administration of sapropterin hydrochloride at a dose of $2 \mathrm{mg} / \mathrm{kg}^{22}$, improves endothelial dependent relaxation in smokers. Administration of $\mathrm{BH} 4$ has also been described to eliminate accelerated atherosclerosis by recoupling eNOS in atherogenic apoE-deficient mice 23 .

Hyper-homocysteinemia has been emerged as an independent risk factor for atherosclerosis and vascular disease. Homocysteine diminishes the bioavailability of $\mathrm{BH} 4$ in vitro, and incubation of human umbilical vein endothelial cells with $\mathrm{BH} 4$ attenuates homocysteine-induced altered NOS activity and increased superoxide production ${ }^{24}$. 
Intra-arterial $\mathrm{BH} 4$ improves endothelial dysfunction in patients with hypercholesterolemia ${ }^{25}$. Cosentino et al. tested chronic oral BH4 (400 mg bid $x 4$ weeks) showing its reversed endothelial dysfunction and oxidative stress in hypercholesterolaemia. Hph-1 mice that have $90 \%$ deficiency in GTPCH develop hypertension ${ }^{26,27}$ and accelerated atherosclerosis ${ }^{28}$, and this can be ameliorated by exogenous $\mathrm{BH} 4$ administration ${ }^{29}$.

NOS is activated by shear stress, and recent studies have shown that $\mathrm{BH} 4$ biosynthesis is commensurately upregulated by this mechanical stimulation ${ }^{30,31}$. $\mathrm{Li}$ et al. revealed a mechanism for this response, showing that laminar shear caused dissociation of GTPCH from its inhibitory co-protein GFRP, and promoted GTPCH activation by phosphorylation via casein kinase2 $(C K 2)^{31,32}$, resulting in enhanced NO generation ${ }^{32}$. Oscillatory shear stress that generated no net shear had no impact on GTPCH-GFRP association, preventing GTPCH phosphorylation and leading to relatively reduced $\mathrm{BH} 4$ levels ${ }^{31,32}$.

Angiotensin (AT) type 1 receptor blockade improves eNOS coupling and reduces ROS production ${ }^{33}$, while AT2 itself stimulates hypertension in part by ROS generation via eNOS derived $\mathrm{O}_{2}^{-}$production ${ }^{6}$, an effect suppressed by administration of $\mathrm{BH} 4$. Endothelial NADPH oxidase-derived $\mathrm{H}_{2} \mathrm{O}_{2}$ downregulates DHFR expression that can impact $\mathrm{BH} 2$ levels, worsening eNOS uncoupling ${ }^{6}$. Recently, $\mathrm{Xu}$ et al. ${ }^{34}$ found $\mathrm{BH} 4$ levels declined in endothelial cells after exposure to low concentrations of AT2, associated with tyrosine nitration of PA700 and accelerated GTPCH degradation.

Compared to the normotensive controls, spontaneous hypertensive rats have reduced plasma $\mathrm{BH} 4$ levels ${ }^{35,36}$, and $\mathrm{BH} 4$ administration blunts the development of hypertension, improving endothelial function by increasing eNOS NO versus $\mathrm{O}_{2}^{-}$formation. In a low renin hypertension model, the DOCA-salt mouse, increased $\mathrm{NADPH}$ oxidase-derived superoxide was linked to increased $\mathrm{BH} 4$ oxidation, and oral $\mathrm{BH} 4$ supplementation reversed eNOS uncoupling and blunted hypertension. This did not occur in controls, showing how BH4 might have vasodilating efficacy but only if eNOS uncoupling was present ${ }^{37}$. This could impact translation to patients, since the diagnosis of eNOS uncoupling is difficult, so identifying responsive patients may be tricky. An overview of all relevant preclinical studies (vascular and myocardial dysfunction) and clinical trial is given in Table 1 and 2.

\section{BH4 and cardiac pathophysiology}

While the role of $\mathrm{BH} 4$ and NOS uncoupling in the vasculature was well established, as recently as 2005 , little was known as to its relevance for myocardial remodeling and dysfunction in heart disease. Takimoto et al. ${ }^{38}$ first revealed that 
eNOS was indeed an important source of myocardial ROS in a mouse model of pressure overload-induced by transverse aorta constriction. Mice developed myocardial and myocyte hypertrophy, interstitial fibrosis, and eventually cardiac dilatation and dysfunction. These changes occurred with concomitant oxidative stress generated largely and perhaps surprisingly from eNOS uncoupling. $\mathrm{BH} 4$ levels declined along with NOS-derived NO in hypertrophied myocardium. Mice lacking eNOS actually did better, with little oxidative stress and associated chamber dilation. Administration of $\mathrm{BH} 4$ to control mice improved the outcome, whereas this did not occur by administering the equally anti-oxidative yet non-NOS interactive tetrahydroneopterin. Moens et al. subsequently performed a more clinical translational study, showing that $\mathrm{BH} 4$ reversed hypertrophy, fibrosis, and chamber dysfunction, and suppressed myocardial ROS in mice in which pressure overload remodeling was already well established ${ }^{2}$. More recently, Silberman et al. ${ }^{39}$ reported that eNOS uncoupling may have a pathogenetic role in the diastolic dysfunction in mice with mild hypertension. This was ameliorated by $\mathrm{BH} 4$. Many heart failure patients have hypertrophy and diastolic dysfunction despite an apparently normal EF, and this study proposed $\mathrm{BH} 4$ as a potential treatment.

NOS uncoupling and altered $\mathrm{BH} 4$ biology have been identified as contributors to cardiac ischemia/reperfusion injury, though the focus has primarily been on vascular more than myocardial effects. Chronic $\mathrm{BH} 4$ improved functional recovery after global ischemia/reperfusion by preventing coronary endothelial dysfunction, decreasing malondialdehyde (MDA), a product of lipid peroxidation and index of tissue injury ${ }^{40}$, restoring NOS-NO production and improving postischemic recovery of NOSdependent coronary flow ${ }^{41}$. Other studies have shown $\mathrm{BH} 4$ improved contractile and metabolic abnormalities ${ }^{42,43}$ post reperfusion, and reduced polymorphonuclear cell adhesion and tissue infiltration possibly by inhibiting inter-cellular adhesion molecule-1 expression ${ }^{44,45}$. The role of NOS uncoupling in ischemic myocardium itself has not yet been clarified to date.

\subsection{Is there translational potential for $\mathrm{BH} 4$ ?}

As already noted, many small clinical trials have appeared supporting benefits of $\mathrm{BH} 4$ treatment in disorders involving vascular and in particular endothelial disease ${ }^{46}$. With the development of synthetic sapropterin hydrochloride (6R-BH4, Kuvan $\left.{ }^{\circledR}\right)$, larger trials were feasible with an FDA approved formulation, and hope was that similar efficacy would be observed. 6R-BH4 was studied in a number of phase I-II clinical trials for diseases including arterial (NCT00325962, concluded 2008) and pulmonary hypertension (NCT00435331, recruitment stopped in 4/09, no data reported), endothelial dysfunction (NCT00532844, study completed, data unpublished), peripheral vascular disease (NCT00403494, competed 1/09) and sickle 
cell disease (NCT00445978, completed 6/09). The results were disappointing, not because they revealed adverse effects, but for their lack of efficacy. There has been some evidence of improved endothelial function in sickle cell patients ${ }^{47}$, though the primary goal of reducing episodes of sickle cell crisis was unaltered. Given this history, clinical assessment of this particular compound for cardiovascular indications appears to have come to a halt.

What happened? There are many reasons by which one could hypothesize that administering excess oral $\mathrm{BH} 4$ might not be effective. If the stoichiometry with NOS isoforms has to be just right, too much might activate constitutive NOS (iNOS) in settings of inflammation, exacerbating pathophysiology. This has been observed in ischemic brain injury, where $\mathrm{BH} 4$ levels, GTPCH activity, and iNOS activity rise within $24 \mathrm{~h}$ due to action of proinflammatory cytokines, resulting in excessive NO production, increased peroxynitrite, and neuronal damage ${ }^{48}$. The human pathology is far less clean and uniform than that generated in animal models. Secondly, the relationship between plasma and target tissue $\mathrm{BH} 4$ levels remains unclear. $\mathrm{BH} 2$ can be more efficiently transported into cells over $\mathrm{BH} 4$, but must then be recycled back to $\mathrm{BH} 4{ }^{49}$. Oral $\mathrm{BH} 4$ is likely oxidized and must be re-reduced, so this biochemistry becomes very important for the net result. Some efforts have been made to enhance this rereduction process by combining $\mathrm{BH} 4$ with anti-oxidants such as vitamin $\mathrm{C}$, though evidence for clinical efficacy of this combination remains lacking. Recently, Suckling et al. ${ }^{50}$ revealed a novel $\mathrm{BH} 4$ analog 6-acetyl-7,7-dimethyl-5,6,7,8-tetrahydropterin (ADDP), a stable compound soluble in both polar and organic solvents. ADDP can diffuse from the plasma, across cell membranes, and cause vasodilatation by stimulating eNOS activity. This may provide another avenue for clinical translation.

In addition, the bioavailability of $\mathrm{BH} 4$ can be increased on several ways. Statins have been described to increase $\mathrm{BH} 4$ levels in vascular endothelial cells by potentiating GTPCH gene expression and $\mathrm{BH} 4$ synthesis, thereby increasing $\mathrm{NO}$ production and preventing relative shortages of $\mathrm{BH}^{51}{ }^{51}$. Another way to increase the bioavailability of $\mathrm{BH} 4$ in the vasculature has been the administration of folic acid. Folic acid increases the bioavailability of $\mathrm{BH} 4$ by (i) ameliorating the binding affinity of $\mathrm{BH} 4$ to eNOS, (ii) enhancing the regeneration of $\mathrm{BH} 4$ from the inactive form $\mathrm{BH} 2$ and (iii) chemically stabilizing $\mathrm{BH} 4{ }^{52}$. Furthermore Hyndman et al. ${ }^{53}$ demonstrated that 5MTHF is capable of binding the active site of nitric oxide synthase and mimicking the orientation of tetrahydrobiopterin.

While the actual preclinical studies regarding the effect of $\mathrm{BH} 4$ on myocardial and endothelial dysfunction are promising, some extra topics need to be investigated before extrapolation to the clinic takes place. There is a need to determine the doseresponse relation between $\mathrm{BH} 4$ and its effect on superoxide generation in a model of 
heart failure because of the tight stoichiometric relation between eNOS and $\mathrm{BH} 4$, with possible subsequent uncoupling. In addition, the uptake of $\mathrm{BH} 4$ and other eNOS modulators by myocytes of the failing or ischemic heart needs to be explored.

\section{Summary}

The biochemistry, molecular biology, and experimental translational evidence supporting an important role of $\mathrm{BH} 4$ to heart and vascular health by means of stabilizing NOS function and suppressing NOS-derived ROS seem compelling. Yet, the data also point to potential pitfalls that could easily limit the efficacy of this approach in clinical diseases. Most importantly, the instability of $\mathrm{BH} 4$ and thus likely requirement for robust intracellular re-reduction and the likely loss of benefit if this is not done just right, may have stymied recent efforts to test the translatability of $\mathrm{BH} 4$ supplementation for clinical disease. Whether alternative forms that cannot be oxidized, and/or are not dependent upon other enzyme systems to maintain stability can be generated and would work better is a question that remains open.

A major advantage is the fact that $\mathrm{BH} 4$ is already FDA approved as a therapeutic for the metabolic disorder phenylketonuria (PKU), a deficiency of phenylalanine hydroxylase that can be partially offset to by providing excessive $\mathrm{BH} 4$. Sapropterin dihydrochloride (Kuvan ${ }^{\circledR}$, BioMarin, Tiburon, $\mathrm{CA}$ ) is the synthetic version of $\mathrm{BH} 4$ that is currently used to treat PKU patients, and in many, the therapy lowers blood phenylalanine levels independent of dietary intake.

Given the many impressive results of $\mathrm{BH} 4$ as a new therapeutic strategy to tackle myocardial and endothelial dysfunction, one would hope that such efforts will continue, and some ultimate translational potential will be realized. 
Table 1. Overview of major vascular and myocardial preclinical in vivo studies with BH4.

\begin{tabular}{|c|c|c|c|}
\hline & Model & Major finding & Reference \\
\hline \multirow[t]{4}{*}{$\begin{array}{l}\text { Vascular } \\
\text { dysfunction }\end{array}$} & apoE-KO/eNOS-Tg mice & $\begin{array}{l}\mathrm{BH} 4 \text { reduced atherosclerotic lesion } \\
\text { size by improvement of eNOS } \\
\text { dysfunction apoE-KO/eNOS-Tg mice. }\end{array}$ & 23 \\
\hline & Hph-1 mice & $\begin{array}{l}\text { In vivo BH4 deficiency facilitates } \\
\text { neointimal formation after wire- } \\
\text { induced femoral artery injury. } \mathrm{BH} 4 \\
\text { prevented vascular injury-induced } \\
\text { increase in neointimal formation }\end{array}$ & 54 \\
\hline & $\begin{array}{l}\text { Spontaneously } \\
\text { hypertensive rats }\end{array}$ & $\mathrm{BH} 4$ blunts oxidative stress & 5 \\
\hline & $\begin{array}{l}\text { Deoxycorticosterone } \\
\text { acetate-salt (DOCA-salt) } \\
\text { hypertension-mice }\end{array}$ & $\begin{array}{l}\text { Increased NADPH oxidase-derived } \\
\text { superoxide was linked to increased } \\
\mathrm{BH} 4 \text { oxidation and } \mathrm{BH} 4 \\
\text { supplementation reversed eNOS } \\
\text { uncoupling and blunted hypertension }\end{array}$ & 37 \\
\hline \multirow[t]{3}{*}{$\begin{array}{l}\text { Myocardial } \\
\text { dysfunction }\end{array}$} & $\begin{array}{l}\text { Mice with de novo } \\
\text { pressure overload }\end{array}$ & $\begin{array}{l}\text { Uncoupling of eNOS due to } \\
\text { decreased } \mathrm{BH} 4 \text { bioavailability is a } \\
\text { major cause of ROS-generation in } \\
\text { pressure overload- induced heart } \\
\text { failure. Administration of } \mathrm{BH} 4 \text { from the } \\
\text { start of pressure overload blocks the } \\
\text { onset of ventricular remodeling }\end{array}$ & 38 \\
\hline & $\begin{array}{l}\text { Mice with pre-existing } \\
\text { pressure overload - } \\
\text { induced heart failure }\end{array}$ & $\begin{array}{l}\text { Administration of } \mathrm{BH} 4 \text { recouples the } \\
\text { uncoupled eNOS and reverses pre- } \\
\text { existing heart failure }\end{array}$ & 2 \\
\hline & $\begin{array}{l}\text { Cardiopulmonary bypass } \\
\text { (dog) }\end{array}$ & $\begin{array}{l}\text { Application of BH4 improves } \\
\text { myocardial, endothelial and } \\
\text { pulmonary function after } \\
\text { cardiopulmonary bypass with } \\
\text { hypothermic cardiac arrest }\end{array}$ & 55 \\
\hline
\end{tabular}


Table 2. Overview of relevant cardiovascular clinical trials with BH4-analogs.

\begin{tabular}{|c|c|c|c|}
\hline $\begin{array}{l}\text { Cardiovascular } \\
\text { disease }\end{array}$ & Dosage of BH4 & Outcome & Reference \\
\hline Hypertension & $\begin{array}{l}\text { Oral } 5 \mathrm{mg} / \mathrm{kg} \text {, twice daily, } \\
\text { eight-weeks }\end{array}$ & $\begin{array}{l}\text { Not statistically } \\
\text { significant drop of } \\
6.4 \mathrm{~mm} \mathrm{Hg} \text { in } \\
\text { patients' SBP }\end{array}$ & $\begin{array}{l}\text { 2008, BioMarin } \\
\text { Pharmaceutical } \\
\text { NCT00325962 }\end{array}$ \\
\hline $\begin{array}{l}\text { Pulmonary Arterial } \\
\text { Hypertension }\end{array}$ & $\begin{array}{l}2.5 \mathrm{mg} / \mathrm{kg} / \mathrm{day} \text { for two } \\
\text { weeks, } 5 \mathrm{mg} / \mathrm{kg} / \mathrm{day} \text { for } \\
\text { two weeks, } 10 \mathrm{mg} / \mathrm{kg} / \text { day } \\
\text { for four weeks, then } 20 \\
\mathrm{mg} / \mathrm{kg} / \mathrm{day} \text { for two days }\end{array}$ & $\mathrm{n} / \mathrm{a}$ & $\begin{array}{l}\text { Ongoing Vanderbilt } \\
\text { University, The } \\
\text { National Institutes of } \\
\text { Health, GCRC\& } \\
\text { BioMarin } \\
\text { Pharmaceutical } \\
\text { NCT00435331 }\end{array}$ \\
\hline Endothelial Dysfunction & $\begin{array}{l}5 \mathrm{mg} / \mathrm{kg} \text { oral, BID } 13.5 \\
\text { days }\end{array}$ & Not significant. & $\begin{array}{l}\text { 2009, BioMarin } \\
\text { Pharmaceutical } \\
\text { NCT00532844 }\end{array}$ \\
\hline Sickle Cell Disease & $\begin{array}{l}\text { 16-week dose escalation } \\
\text { phase oral, every } 4 \text { weeks } \\
\text { as follows: } 2.5,5,10 \text { (once- } \\
\text { daily), and } 20 \\
\mathrm{mg} / \mathrm{kg} / \mathrm{day} \text { (twice-daily), } \\
\text { continue in an optional } \\
\text { extension phase at the } \\
\text { highest tolerated dose for } \\
\text { up to a total of } 2 \text { years }\end{array}$ & $\begin{array}{l}\text { Improvement of } \\
\text { endothelial function }\end{array}$ & $\begin{array}{l}\text { 2009, BioMarin } \\
\text { Pharmaceutical } \\
\text { NCT00445978 }\end{array}$ \\
\hline $\begin{array}{l}\text { Peripheral Arterial } \\
\text { Disease }\end{array}$ & 400 mg oral, BID 24 weeks & Not significant. & $\begin{array}{l}\text { 2009, BioMarin } \\
\text { Pharmaceutical } \\
\text { NCT00403494 }\end{array}$ \\
\hline
\end{tabular}




\section{References}

1. Raman CS, Li H, Martásek P, Král V, Masters BSS, Poulos TL. Crystal Structure of Constitutive Endothelial Nitric Oxide Synthase. Cell 1998;95(7):939-950.

2. Moens AL, Takimoto E, Tocchetti CG, Chakir K, Bedja D, Cormaci G, Ketner EA, Majmudar M, Gabrielson K, Halushka MK, Mitchell JB, Biswal S, Channon KM, Wolin MS, Alp NJ, Paolocci N, Champion HC, Kass DA. Reversal of Cardiac Hypertrophy and Fibrosis From Pressure Overload by Tetrahydrobiopterin: Efficacy of Recoupling Nitric Oxide Synthase as a Therapeutic Strategy. Circulation 2008;117(20):2626-2636.

3. Takikawa S-I, Curtius H-C, Redweik U, Leimbacher W, Ghisla S. Biosynthesis of tetrahydrobiopterin. European Journal of Biochemistry 1986;161(2):295-302.

4. Thöny B, Auerbach G, Blau N. Tetrahydrobiopterin biosynthesis, regeneration and functions. Biochemical Journal 2000;347(Pt 1):1-16.

5. Alp NJ, Channon KM. Regulation of Endothelial Nitric Oxide Synthase by Tetrahydrobiopterin in Vascular Disease. Arteriosclerosis, Thrombosis, and Vascular Biology 2004;24(3):413-420.

6. Chalupsky K, Cai H. Endothelial dihydrofolate reductase: Critical for nitric oxide bioavailability and role in angiotensin II uncoupling of endothelial nitric oxide synthase. Proceedings of the National Academy of Sciences of the United States of America 2005;102(25):9056-9061.

7. Seujange Y, Eiam-Ong S, Tirawatnapong T, Eiam-Ong S. Role of Angiotensin II on Dihydrofolate Reductase, GTP-Cyclohydrolase 1 and Nitric Oxide Synthase Expressions in Renal IschemiaReperfusion. American Journal of Nephrology 2008;28(4):692-700.

8. Crabtree MJ, Tatham AL, Al-Wakeel Y, Warrick N, Hale AB, Cai S, Channon KM, Alp NJ. Quantitative Regulation of Intracellular Endothelial Nitric-oxide Synthase (eNOS) Coupling by Both Tetrahydrobiopterin-eNOS Stoichiometry and Biopterin Redox Status. Journal of Biological Chemistry 2009;284(2):1136-1144.

9. Vásquez-Vivar J, Whitsett J, Martásek $\mathrm{P}$, Hogg $\mathrm{N}$, Kalyanaraman B. Reaction of tetrahydrobiopterin with superoxide: EPR-kinetic analysis and characterization of the pteridine radical. Free Radical Biology and Medicine 2001;31(8):975-985.

10. Huie RE, Padmaja S. The Reaction of no With Superoxide. Free Radical Research Communications 1993;18(4):195-199.

11. Vásquez-Vivar J, Martásek $\mathrm{P}$, Whitsett $\mathrm{J}$, Joseph $\mathrm{J}$, Kalyanaraman B. The ratio between tetrahydrobiopterin and oxidized tetrahydrobiopterin analogues controls superoxide release from endothelial nitric oxide synthase: an EPR spin trapping study. Biochemical Journal 2002;362(Pt 3):733-739.

12. Crabtree MJ, Smith CL, Lam G, Goligorsky MS, Gross SS. Ratio of 5,6,7,8-tetrahydrobiopterin to 7,8-dihydrobiopterin in endothelial cells determines glucose-elicited changes in NO vs. superoxide production by eNOS. American Journal of Physiology - Heart and Circulatory Physiology 2008;294(4):H1530-H1540.

13. Crabtree MJ, Tatham AL, Hale AB, Alp NJ, Channon KM. Critical Role for Tetrahydrobiopterin Recycling by Dihydrofolate Reductase in Regulation of Endothelial Nitric-oxide Synthase Coupling: RELATIVE IMPORTANCE OF THE DE NOVO BIOPTERIN SYNTHESIS VERSUS SALVAGE PATHWAYS. The Journal of Biological Chemistry 2009;284(41):28128-28136.

14. Sugiyama T, Levy BD, Michel T. Tetrahydrobiopterin Recycling, a Key Determinant of Endothelial Nitric-oxide Synthase-dependent Signaling Pathways in Cultured Vascular Endothelial Cells. The Journal of Biological Chemistry 2009;284(19):12691-12700.

15. Dedkova EN, Blatter LA. Characteristics and function of cardiac mitochondrial nitric oxide synthase. The Journal of Physiology 2009;587(Pt 4):851-872.

16. Higashi Y, Sasaki S, Nakagawa K, Fukuda Y, Matsuura H, Oshima T, Chayama K. Tetrahydrobiopterin enhances forearm vascular response to acetylcholine in both normotensive and hypertensive individuals*. American Journal of Hypertension 2002;15(4):326-332. 
17. Dimmeler S, Fleming I, Fisslthaler B, Hermann C, Busse R, Zeiher AM. Activation of nitric oxide synthase in endothelial cells by Akt-dependent phosphorylation. Nature 1999;399(6736):601-605.

18. Fulton D, Gratton J-P, McCabe TJ, Fontana J, Fujio Y, Walsh K, Franke TF, Papapetropoulos A, Sessa WC. Regulation of endothelium-derived nitric oxide production by the protein kinase Akt. Nature 1999;399(6736):597-601.

19. Chavakis E, Dernbach E, Hermann C, Mondorf UF, Zeiher AM, Dimmeler S. Oxidized LDL Inhibits Vascular Endothelial Growth Factor-Induced Endothelial Cell Migration by an Inhibitory Effect on the Akt/Endothelial Nitric Oxide Synthase Pathway. Circulation 2001;103(16):21022107.

20. Heitzer T, Brockhoff C, Mayer B, Warnholtz A, Mollnau H, Henne S, Meinertz T, Münzel T. Tetrahydrobiopterin Improves Endothelium-Dependent Vasodilation in Chronic Smokers. Evidence for a Dysfunctional Nitric Oxide Synthase 2000;86(2):e36-e41.

21. Chen W, Druhan LJ, Chen C-A, Hemann C, Chen Y-R, Berka V, Tsai A-L, Zweier JL. Peroxynitrite induces destruction of the tetrahydrobiopterin and heme in endothelial nitric oxide synthase: transition from reversible to irreversible enzyme inhibition. Biochemistry 2010;49(14):3129-3137.

22. Ueda S, Matsuoka H, Miyazaki H, Usui M, Okuda S, Imaizumi T. Tetrahydrobiopterin restores endothelial function in long-term smokers. Journal of the American College of Cardiology 2000;35(1):71-75.

23. Ozaki M, Kawashima S, Yamashita T, Hirase T, Namiki M, Inoue N, Hirata K-i, Yasui H, Sakurai $H$, Yoshida Y, Masada M, Yokoyama M. Overexpression of endothelial nitric oxide synthase accelerates atherosclerotic lesion formation in apoE-deficient mice. The Journal of Clinical Investigation 2002;110(3):331-340.

24. Dhillon B, Badiwala MV, Maitland A, Rao V, Li S-H, Verma S. Tetrahydrobiopterin attenuates homocysteine induced endothelial dysfunction. Molecular and Cellular Biochemistry 2003;247(1):223-227.

25. Stroes E, Kastelein J, Cosentino F, Erkelens W, Wever R, Koomans H, Lüscher T, Rabelink T. Tetrahydrobiopterin restores endothelial function in hypercholesterolemia. Journal of Clinical Investigation 1997;99(1):41-46.

26. Cosentino F, Barker JE, Brand MP, Heales SJ, Werner ER, Tippins JR, West N, Channon KM, Volpe M, Lüscher TF. Reactive Oxygen Species Mediate Endothelium-Dependent Relaxations in Tetrahydrobiopterin-Deficient Mice. Arteriosclerosis, Thrombosis, and Vascular Biology 2001;21(4):496-502.

27. Kinoshita H, Milstien S, Wambi C, Katusic ZS. Inhibition of tetrahydrobiopterin biosynthesis impairs endothelium-dependent relaxations in canine basilar artery. American Journal of Physiology - Heart and Circulatory Physiology 1997;273(2):H718-H724.

28. Khoo JP, Bursill C, Alp NJ, McAteer MA, Channon KM. Endothelial tetrahydrobiopterin deficiency accelerates atherosclerotic progression by nitric oxide synthase uncoupling (Abstract). Circulation 2005;112:116.

29. Wang C-H, Li S-H, Weisel RD, Fedak PWM, Hung A, Li R-K, Rao V, Hyland K, Cherng W-J, Errett L, Leclerc Y, Bonneau D, Latter DA, Verma S. Tetrahydrobiopterin deficiency exaggerates intimal hyperplasia after vascular injury. American Journal of Physiology - Regulatory, Integrative and Comparative Physiology 2005;289(2):R299-R304.

30. Lam C-F, Peterson TE, Richardson DM, Croatt AJ, d'Uscio LV, Nath KA, Katusic ZS. Increased blood flow causes coordinated upregulation of arterial eNOS and biosynthesis of tetrahydrobiopterin. American Journal of Physiology - Heart and Circulatory Physiology 2006;290(2): H786-H793.

31. Widder JD, Chen W, Li L, Dikalov S, Thöny B, Hatakeyama K, Harrison DG. Regulation of Tetrahydrobiopterin Biosynthesis by Shear Stress. Circulation Research 2007;101(8):830-838.

32. Li L, Rezvan A, Salerno JC, Husain A, Kwon K, Jo H, Harrison DG, Chen W. GTP Cyclohydrolase I Phosphorylation and Interaction with GTP Cyclohydrolase Feedback Regulatory Protein Provide 
Novel Regulation of Endothelial Tetrahydrobiopterin and Nitric Oxide. Circulation research 2010;106(2):328.

33. Satoh M, Fujimoto S, Arakawa S, Yada T, Namikoshi T, Haruna Y, Horike H, Sasaki T, Kashihara $\mathrm{N}$. Angiotensin II type 1 receptor blocker ameliorates uncoupled endothelial nitric oxide synthase in rats with experimental diabetic nephropathy. Nephrology Dialysis Transplantation 2008;23(12):3806-3813.

34. $\mathrm{Xu} \mathrm{J,} \mathrm{Wang} \mathrm{S,} \mathrm{Wu} \mathrm{Y,} \mathrm{Song} \mathrm{P,} \mathrm{Zou} \mathrm{M-H.} \mathrm{Tyrosine} \mathrm{Nitration} \mathrm{of} \mathrm{PA700} \mathrm{Activates} \mathrm{the} \mathrm{26S}$ Proteasome to Induce Endothelial Dysfunction in Mice With Angiotensin II-Induced Hypertension. Hypertension 2009;54(3):625-632.

35. Cosentino F, Patton S, d'Uscio LV, Werner ER, Werner-Felmayer G, Moreau P, Malinski T, Lüscher TF. Tetrahydrobiopterin alters superoxide and nitric oxide release in prehypertensive rats. Journal of Clinical Investigation 1998;101(7):1530-1537.

36. Hong H-J, Hsiao G, Cheng T-H, Yen M-H. Supplemention With Tetrahydrobiopterin Suppresses the Development of Hypertension in Spontaneously Hypertensive Rats. Hypertension 2001;38(5):1044-1048.

37. Landmesser U, Dikalov S, Price SR, McCann L, Fukai T, Holland SM, Mitch WE, Harrison DG. Oxidation of tetrahydrobiopterin leads to uncoupling of endothelial cell nitric oxide synthase in hypertension. Journal of Clinical Investigation 2003;111(8):1201-1209.

38. Takimoto E, Champion HC, Li M, Ren S, Rodriguez ER, Tavazzi B, Lazzarino G, Paolocci N, Gabrielson KL, Wang Y, Kass DA. Oxidant stress from nitric oxide synthase-3 uncoupling stimulates cardiac pathologic remodeling from chronic pressure load. The Journal of Clinical Investigation 2005;115(5):1221-1231.

39. Silberman GA, Fan T-HM, Liu H, Jiao Z, Xiao HD, Lovelock JD, Boulden BM, Widder J, Fredd S, Bernstein KE, Wolska BM, Dikalov S, Harrison DG, Dudley SC. Uncoupled Cardiac Nitric Oxide Synthase Mediates Diastolic Dysfunction. Circulation 2010;121(4):519-528.

40. Verma S, Maitland A, Weisel RD, Fedak PWM, Pomroy NC, Li S-H, Mickle DAG, Li R-K, Rao V. Novel cardioprotective effects of tetrahydrobiopterin after anoxia and reoxygenation: Identifying cellular targets for pharmacologic manipulation. The Journal of Thoracic and Cardiovascular Surgery 2002;123(6):1074-1083.

41. Dumitrescu C, Biondi R, Xia Y, Cardounel AJ, Druhan LJ, Ambrosio G, Zweier JL. Myocardial ischemia results in tetrahydrobiopterin $(\mathrm{BH}(4))$ oxidation with impaired endothelial function ameliorated by $\mathrm{BH}(4)$. Proceedings of the National Academy of Sciences of the United States of America 2007;104(38):15081-15086.

42. Yamashiro S, Noguchi K, Matsuzaki T, Miyagi K, Nakasone J, Sakanashi M, Koja K, Sakanashi $M$. Beneficial effect of tetrahydrobiopterin on ischemia-reperfusion injury in isolated perfused rat hearts. The Journal of Thoracic and Cardiovascular Surgery 2002;124(4):775-784.

43. Yamashiro S, Noguchi K, Matsuzaki T, Miyagi K, Nakasone J, Sakanashi M. Role of tetrahydrobiopterin on ischemia-reperfusion injury in isolated perfused rat hearts. J Cardiovasc Surg (Torino) 2003; 44(1):37-49.

44. Chen Q, Kim EEJ, Elio K, Zambrano C, Krass S, Teng JC-w, Kay H, Perkins K-A, Pershad S, McGraw S, Emrich J, Adams JS, Young LH. The Role of Tetrahydrobiopterin and Dihydrobiopterin in Ischemia/Reperfusion Injury When Given at Reperfusion. Advances in Pharmacological Sciences 2010;2010:11.

45. Elio K, Kim EEJ, Chen Q, Kay HY, Adams J, Young LH. Tetrahydrobiopterin (BH4) attenuates neutrophil adhesion/transmigration in myocardial ischemia/reperfusion injury. The FASEB Journal 2007;21(6):A1145.

46. Katusic ZS, d'Uscio L, Nath KA. Vascular Protection by Tetrahydrobiopterin: Progress and Therapeutic Prospects. Trends in pharmacological sciences 2009;30(1):48-54.

47. Vásquez-Vivar J. Tetrahydrobiopterin, Superoxide and Vascular Dysfunction. Free radical biology \& medicine 2009;47(8):1108-1119. 
48. Kidd GA, Hong H, Majid A, Kaufman DI, Chen AF. Inhibition of Brain GTP Cyclohydrolase I and Tetrahydrobiopterin Attenuates Cerebral Infarction via Reducing Inducible NO Synthase and Peroxynitrite in Ischemic Stroke. Stroke 2005;36(12):2705-2711.

49. Hasegawa H, Sawabe K, Nakanishi N, Wakasugi OK. Delivery of exogenous tetrahydrobiopterin $(\mathrm{BH} 4)$ to cells of target organs: Role of salvage pathway and uptake of its precursor in effective elevation of tissue BH4. Molecular Genetics and Metabolism 2005;86:2-10.

50. Suckling CJ, Gibson CL, Huggan JK, Morthala RR, Clarke B, Kununthur S, Wadsworth RM, Daff S, Papale D. 6-Acetyl-7,7-dimethyl-5,6,7,8-tetrahydropterin is an activator of nitric oxide synthases. Bioorganic \& Medicinal Chemistry Letters 2008;18(5):1563-1566.

51. Hattori Y, Nakanishi N, Akimoto K, Yoshida M, Kasai K. HMG-CoA Reductase Inhibitor Increases GTP Cyclohydrolase I mRNA and Tetrahydrobiopterin in Vascular Endothelial Cells. Arteriosclerosis, Thrombosis, and Vascular Biology 2003;23(2):176-182.

52. Moens AL, Vrints CJ, Claeys MJ, Timmermans J-P, Champion HC, Kass DA. Mechanisms and potential therapeutic targets for folic acid in cardiovascular disease. American Journal of Physiology - Heart and Circulatory Physiology 2008;294(5):H1971-H1977.

53. Hyndman ME, Verma S, Rosenfeld RJ, Anderson TJ, Parsons HG. Interaction of 5methyltetrahydrofolate and tetrahydrobiopterin on endothelial function. American Journal of Physiology - Heart and Circulatory Physiology 2002;282(6):H2167-H2172.

54. Wang Y, Subudhi SK, Anders RA, Lo J, Sun Y, Blink S, Wang Y, Wang J, Liu X, Mink K, Degrandi D, Pfeffer K, Fu Y-X. The role of herpesvirus entry mediator as a negative regulator of $T$ cell-mediated responses. Journal of Clinical Investigation 2005;115(3):711-717.

55. Szabó G, Seres L, Soós P, Gorenflo M, Merkely B, Horkay F, Karck M, Radovits T. Tetrahydrobiopterin improves cardiac and pulmonary function after cardiopulmonary bypass. European Journal of Cardio-Thoracic Surgery 2011;40(3):695-700. 



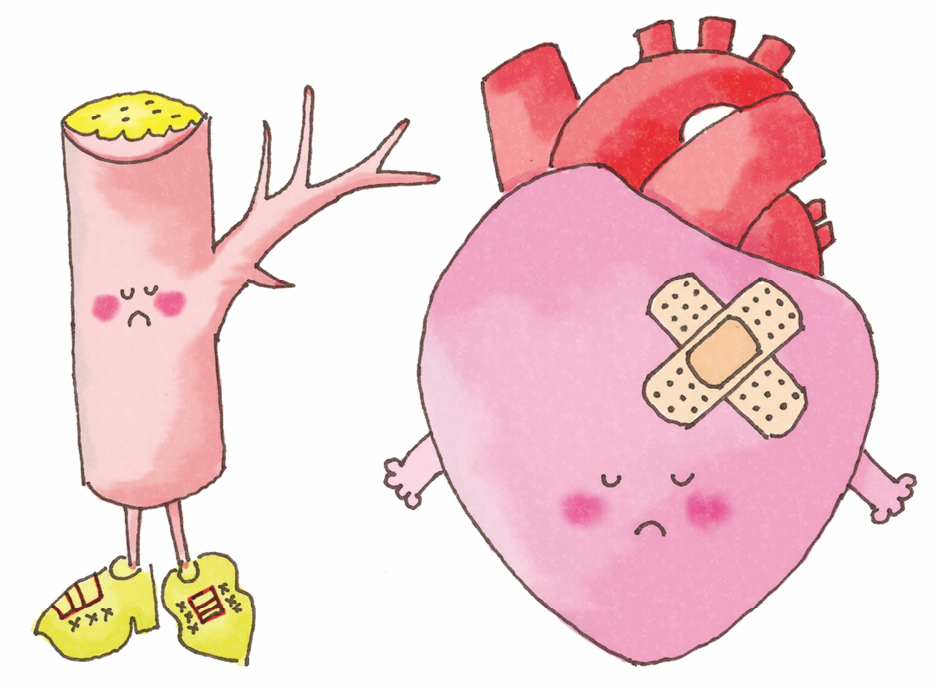




\title{
Chapter 3
}

\section{Tackling endothelial dysfunction by modulating NOS uncoupling: new insights into its pathogenesis and therapeutic possibilities}

\author{
R. Kietadisorn, R.P. Juni, A.L. Moens
} Am J Physiol Endocrinol Metab. 2012 Mar 1;302(5):E481-95 


\section{Abstract}

Endothelial nitric oxide synthase (eNOS) serves as a critical enzyme in maintaining vascular pressure by producing nitric oxide (NO); hence, it has a crucial role in the regulation of endothelial function. The bioavailability of eNOS-derived NO is crucial for this function and might be affected at multiple levels. Uncoupling of eNOS, with subsequently less $\mathrm{NO}$ and more superoxide generation, is one of the major underlying causes of endothelial dysfunction found in atherosclerosis, diabetes, hypertension, cigarette smoking, hyperhomocysteinemia, and ischemia/reperfusion injury. Therefore, modulating eNOS uncoupling by stabilizing eNOS activity, enhancing its substrate, cofactors, and transcription, and reversing uncoupled eNOS are attractive therapeutic approaches to improve endothelial function. This review provides an extensive overview of the important role of eNOS uncoupling in the pathogenesis of endothelial dysfunction and the potential therapeutic interventions to modulate eNOS for tackling endothelial dysfunction. 


\section{Introduction}

The endothelial layer of blood vessels is critical to vascular and myocardial health and plays an important role in the pathophysiology of hypertension and myocardial ischemia. It regulates the release of 1) endothelium-induced relaxing factors such as nitric oxide (NO) and endothelium-derived hyperpolarization factor (EDHF), 2) endothelium-derived contracting factors such as endothelin-1 and angiotensin, and 3) proinflamatory prothombolytic and 4) growth factors. Endothelial dysfunction is characterized by an impaired release of the aforementioned and has been defined as a blunting of the vasodilatory response to acetylcholine or hyperemia, both of which are known to produce NO-dependent vasodilatation. Disruption of the endothelium triggers a number of signaling cascades that converge on medial smooth muscle cells, which stimulates cell proliferation and migration and leads to pathological repair and development of neointimal hyperplasia ${ }^{1}$. Endothelial dysfunction causes $\mathrm{NO}$ deficiency ${ }^{2}$, which has been implicated in the underlying pathology of many cardiovascular diseases.

Endothelial nitric oxide synthase (eNOS) is the critical enzyme in the maintenance of vascular pressure by producing NO, a volatile gas that diffuses to the adjacent vascular smooth muscle. NO has a physiological role in the regulation of vascular tone, synaptic transmission, and cellular defense. In addition, it plays a major role in the relaxation of smooth muscle surrounding the arterioles ${ }^{3}$ and maintaining vascular function by inhibition of vasoconstriction ${ }^{4}$, platelet aggregation, leukocyte adhesion, and cell proliferation through the cGMP-dependent downstream signaling cascade. Moreover, NO limits oxidative phosphorylation in mitochondria ${ }^{5}$. NO functions not only as a physiological regulator of cell respiration but also augments the generation of mitochondria-derived reactive oxygen species (ROS). The majority of ROS generation in the vasculature is derived from NADPH oxidases (NOX) and eNOS uncoupling. The latter takes place when oxidative stress oxidizes the fragile eNOS cofactor tetrahydrobiopterin (BH4).

This review gives an extensive overview of the role of eNOS uncoupling in the pathogenesis of endothelial dysfunction and how modulating eNOS uncoupling can tackle endothelial dysfunction.

\section{Molecular Mechanism of eNOS Uncoupling}

Evidence has shown that eNOS uncoupling is the underlying cause of endothelial dysfunction in animal experiments such as deoxycorticosterone acetate (DOCA)-salt hypertension ${ }^{6}$, angiotensin II-induced hypertension ${ }^{7}$, myocardial ischemia/reperfusion (I/R) injury ${ }^{8}$, streptozotocin (STZ)-induced diabetes ${ }^{9}$, as well as 
essential hypertension ${ }^{10}$ and hypertension-induced heart failure ${ }^{11}$. Importantly, uncoupling of eNOS in the pathogenesis of endothelial dysfunction in vascular disease states has been linked to the decrease of $\mathrm{BH} 4$ bioavailability due to enhanced oxidation of $\mathrm{BH} 4$. As an essential cofactor, $\mathrm{BH} 4$ is necessary for optimal eNOS activity 12. It facilitates NADPH-derived electron transferring from the eNOS reductase to the oxygenase domain to convert L-arginine to $\mathrm{NO}$ and L-citrulline. When $\mathrm{BH} 4$ levels are inadequate, eNOS becomes unstable and uncoupled, leading to subsequently less NO production and more superoxide generation. Moreover, the interaction between $\mathrm{NO}$ and superoxide leads to the formation of peroxynitrite, a potent oxidant, which further oxidizes $\mathrm{BH} 4{ }^{13}$.

$\mathrm{BH} 4$ is synthesized by the de novo or the salvage pathway. Through de novo pathway, $\mathrm{BH} 4$ is generated from guanosine-5'-triphosphate (GTP) via the rate-limiting enzyme GTP cyclohydrolase (GTPCH), 6-pyruvoyltetrahydropterin synthase, and sepiapterin reductase ${ }^{14,15}$. In the salvage pathway, $\mathrm{BH} 4$ is regenerated by its oxidized form 7,8-dihydrobiopterin (BH2) via dihydrofolate reductase (DHFR) or quinonoid dihydrobiopterin (qBH2) through dihydropteridine reductase (DHPR) ${ }^{15,16}$. Interestingly, $\mathrm{BH} 2$ can promote eNOS uncoupling because $\mathrm{BH} 2$, which has no eNOS cofactor property, can competitively replace eNOS-bound $\mathrm{BH} 4{ }^{17}$. In addition, the relative abundance of eNOS vs. $\mathrm{BH} 4$, together with the intracellular $\mathrm{BH} 4: \mathrm{BH} 2$ ratio, rather than absolute concentrations of $\mathrm{BH} 4$, is the key determinant of eNOS uncoupling ${ }^{18}$. Recently, Crabtree et al. ${ }^{19}$ demonstrated in $\mathrm{BH} 4$ deficiency hph-1 mice that DHFR plays a vital role in regulating the $\mathrm{BH} 4: \mathrm{BH} 2$ ratio and eNOS coupling in vivo, particularly when total biopterin availability is diminished.

The bioavailability of NO produced by eNOS might be affected at multiple levels, including 1) eNOS mRNA or protein expression, 2) availability of its substrate L-arginine, which might be competed by asymmetric dimethylarginine (ADMA), 3) availability of its cofactors, 4) protein-protein interaction such as caveolin-1 (cav-1) and heat shock protein 90 (Hsp90), 5) posttransitional modifications, and 6) reaction of NO with superoxide to yield peroxynitrite, which further reduce the bioavailability of $\mathrm{BH} 4{ }^{20}$. Although many studies have shown that eNOS overexpression generates vasoprotective effects by increasing endothelium-derived $\mathrm{NO}^{21,22}$, the expression of eNOS protein in endothelial dysfunction remains at normal or even, in some cases, increased levels ${ }^{3}$. Indeed, elevated eNOS expression without further increase in $\mathrm{BH} 4$ levels, results in eNOS uncoupling because of the enzyme cofactor imbalance $^{23}$ (see Figure 1). 


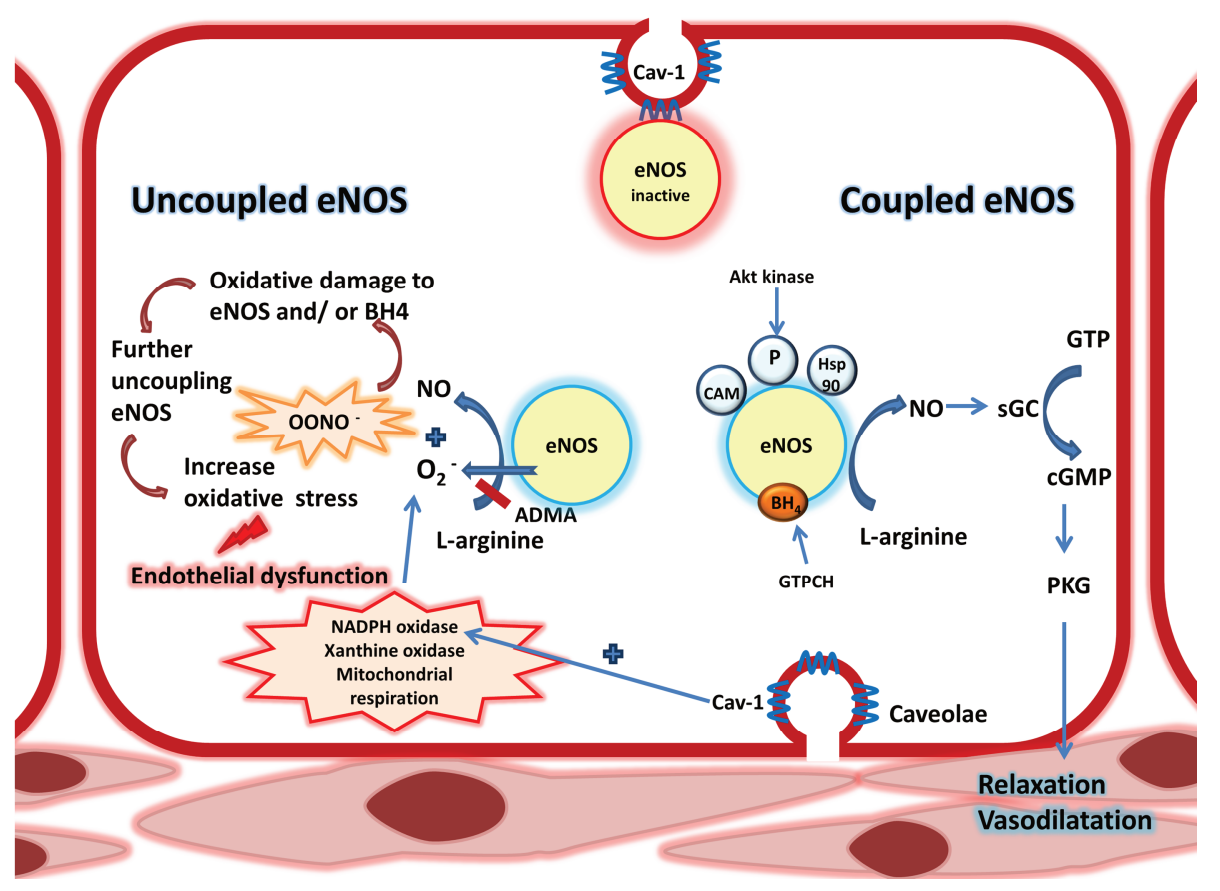

Figure 1. Central role of endothelial NO synthase (eNOS) uncoupling in the pathogenesis of endothelial dysfunction.

eNOS is localized at the plasma membrane caveolae. In endothelial cells, eNOS is inactive when it is bonded with caveolin 1 (cav-1). When it becomes active, eNOS disassociates from cav-1 and binds with calmodulin (CAM) and heat shock protein 90 (Hsp90) and together with phosphorylation of serine sites (e.g., Ser1177). The functional eNOS protein is a dimer (so-called coupled eNOS). Tetrahydrobiopterin $(\mathrm{BH} 4)$, an essential cofactor of eNOS, is necessary for optimal eNOS activity. BH4 facilitates NADPHderived electron transferring from the eNOS reductase to the oxygenase domain to convert $L$-arginine to $N O$ and L-citrulline. NO plays a major role in relaxation of smooth muscle surrounding arterioles and maintaining vascular function by inhibition of vasoconstriction, platelet aggregation, leukocyte adhesion, and cell proliferation through the CGMP-dependent downstream signaling cascade. Interaction between Larginine and asymmetric dimethylarginine (ADMA; endogenous competitive inhibitor of NOS) is likely direct competition for eNOS. When availability of L-arginine or BH4 levels are inadequate, eNOS becomes unstable and uncoupled, leading to subsequently less NO production and more superoxide generation. Moreover, interaction between NO and superoxide leads to formation of peroxynitrite, a potent oxidant, which further oxidizes $\mathrm{BH} 4$, resulting in eNOS uncoupling as a vicious cycle, with subsequent endothelial dysfunction. Outside arrows indicate adjacent endothelial cells. 
The availability of the substrate L-arginine is required as the nitrogen donor for eNOS-derived NO. Although it is unlikely that plasma L-arginine levels would drop below the concentrations required for eNOS activity, decreased intracellular L-arginine caused by arginase may also lead to eNOS uncoupling. The expression of arginase in endothelial cells (EC) can compete with eNOS for their common substrate ${ }^{24}$ and downregulate eNOS activity ${ }^{25}$. Furthermore, studies show that oxidized low-density lipoprotein (oxLDL) is able to reduce endothelial L-arginine uptake, resulting in decreased local L-arginine and eNOS uncoupling ${ }^{26}$. In addition, endogenous ADMA levels, a derivative of $L$-arginine, can act to competitively inhibit eNOS. The elevated levels of plasma ADMA are associated with oxidative stress within the vascular and development of endothelial dysfunction and cardiovascular diseases ${ }^{27,28}$.

\section{Atherosclerosis-Induced eNOS Uncoupling}

Endothelial dysfunction is considered to be an early marker for atherosclerosis, preceding angiographic or ultrasonic evidence of atherosclerotic plaque formation ${ }^{29}$. Atherosclerosis starts with an innate immune response involving the recruitment and activation of monocytes/macrophages that respond to an excessive accumulation of modified lipids within the arterial wall, followed by an adaptive immune response ${ }^{30}$. Wilcox et al. ${ }^{31}$ demonstrated that atherosclerosis is associated with enhanced expression of all forms of NOS in the intima and adventitia. Furthermore, NOS-derived NO plays a dual role, as both anti- and proatherosclerotic effects are based on the course of disease progression.

Endothelium-dependent vascular relaxation is impaired both in cholesterol-fed mice ${ }^{32}$ and in isolated human coronary arteries ${ }^{33}$, and this impairment is correlated with the degree of atherosclerosis ${ }^{34}$. Administration of L-arginine ${ }^{35,36}$ or $\mathrm{BH} 4^{37,38}$ attenuates atherosclerotic lesion progression, whereas administration of NOS inhibitors blocks this protective effect ${ }^{39}$, signifying a direct link between NO and atherosclerosis lesion formation. Recently, using an $\mathrm{apoE}^{-/-}$model of rapid atherosclerotic lesion formation after partial carotid ligation, Li et al. ${ }^{40}$ demonstrated that NOS uncoupling and $\mathrm{BH} 4$ deficiency contribute to the vascular inflammation and abnormal cytokine milieu induced by disturbed flow without affecting systemic immune cell numbers.

In apo $\mathrm{E}^{-/-}$mice, aortic superoxide production is diminished after administration of the NOS inhibitor L-NAME, suggesting that NOS is an important source of superoxide in this model ${ }^{41,42}$. In addition, $\mathrm{BH} 4$ deficiency is likely the major cause of eNOS uncoupling in atherosclerosis. apoE ${ }^{-/}$mice overexpressing eNOS $\left(\mathrm{apoE}^{-/-} / \mathrm{eNOS}-\mathrm{Tg}\right)$ showed eNOS dysfunction demonstrated by a decrease in NO production relative to eNOS expression, a marked reduction in vascular $\mathrm{BH} 4$, and an increase in superoxide formation, resulting in an acceleration of atherosclerotic lesion 54 
formation ${ }^{43}$. In addition, oral $\mathrm{BH} 4$ administration $\left(10 \mathrm{mg} \cdot \mathrm{kg}^{-1} \cdot \mathrm{day}^{-1}\right)$ to apoE $\mathrm{E}^{-/-} / \mathrm{eNOS}$ $\mathrm{Tg}$ mice reduced the formation of atherosclerotic lesion and vascular superoxide and increased eNOS-derived $\mathrm{NO}^{43}$, indicating that the increase in eNOS expression alone, but not together with vascular $\mathrm{BH} 4$ levels, may result in eNOS uncoupling due to the stoichiometric relationships between endothelial BH4 and NOS activity ${ }^{23}$. On the other hand, overexpression of GTPCH in $\mathrm{apoE}^{-/} / \mathrm{GTPCH}-\mathrm{Tg}$ mice is able to decrease endothelial superoxide production, increase aortic $\mathrm{BH} 4$ levels, and recouple eNOS. As a result, these double transgenic mice showed a significant decrease in aortic root atherosclerotic plaque compared with apoE ${ }^{-/}$controls $^{41}$. Takaya et al. ${ }^{44}$ demonstrated that, in the triple transgenic mice of eNOS- and GTPCH-overexpressing in $\mathrm{apoE}^{-/-}\left(\mathrm{apoE}^{-/-} / \mathrm{eNOS}-\mathrm{Tg} / \mathrm{GTPCH}-\mathrm{Tg}\right)$, increases in vascular $\mathrm{BH} 4$ levels are associated with decreased eNOS-dependent superoxide production and results in reduced atherosclerotic plaque area. This study indicates that eNOS-derived superoxide plays a crucial role in atherosclerosis and that upregulation of GTPCH is able to restore eNOS function.

Elevated levels of C-reactive protein (CRP), a proinflammatory marker, have been also associated with atherosclerosis. Many data are evolving to suggest that CRP also promotes atherothrombosis ${ }^{45,46}$. Interestingly, studies in human endothelial cells showed that CRP, a proinflammatory marker, caused downregulation of eNOS activity and NO bioavailability ${ }^{47,48}$. Moreover, expression of human CRP in transgenic mice resulted in decreased eNOS activity ${ }^{49-51}$. Singh et al. ${ }^{52}$ demonstrated in human aortic endothelial cells (HAEC) that CRP inhibited GTPCH and stimulated NOX, leading to a decrease in $\mathrm{BH} 4$ and an increase in ROS levels. These resulted in uncoupling of eNOS and decreased eNOS activity, which was associated with decreased phosphorylation of Ser ${ }^{177}$ and decreased eNOS binding to Hsp90.

In healthy vasculatures, eNOS-derived NO prevents oxidative modification of low-density lipoprotein (LDL) ${ }^{53}$. However, under oxidative stress, LDL is initially oxidized at the endothelial walls ${ }^{54,55}$. oxLDL has been known to indicate initiate the pathogenesis of atherosclerosis ${ }^{56,57}$. Moreover, oxLDL is also a potent inducer of superoxide; hence, it is a cause of oxidative stress ${ }^{58}$. oxLDL increases synthesis of caveolin-1 (cav-1) ${ }^{59}$ and inhibits the Akt survival pathways ${ }^{60-62}$ attenuating eNOS activity with subsequent decreases in NO bioavailability.

During the inflammatory process in atherosclerosis, inducible NOS (iNOS) in endothelial cells and macrophages is upregulated and produces excessive amount of $\mathrm{NO}{ }^{63}$. Deletion of iNOS decreases plaque development in $\mathrm{apoE}^{-/-}$mice, indicating that iNOS does have proatherogenic effects ${ }^{64}$. In addition, studies indicate that neuronal NOS (nNOS) also plays a role in protecting atherosclerotic plaque development in animal models ${ }^{65,66}$. This NOS isoform is upregulated in smooth 
muscle cells, macrophages, and endothelial cells in both early and advanced human atherosclerotic lesions ${ }^{31}$. Recently, Seddon et al. ${ }^{67}$ demonstrated in healthy humans that nNOS-derived NO is important for the control of blood pressure via regulation of basal vascular tone and blood flow, yet there are no data to indicate nNOS uncoupling is involved with atherosclerosis.

\section{Diabetes Mellitus-Induced eNOS Uncoupling}

Evidence indicates that endothelial dysfunction could play an initial and ultimately crucial role in the development of macrovascular and microvascular complications caused by diabetes mellitus (DM) in human and animal models of $\mathrm{DM}^{68}$ . Under hyperglycemic conditions, a hallmark of diabetes, eNOS-derived NO capacity is diminished ${ }^{69}$. In vitro experiments have shown that protein kinase $C$ (PKC)mediated phosphorylation of eNOS protein may elicit the enzyme catalytic activity ${ }^{70}$. Stimulation of endothelial cells with phorbol esters, direct activators of PKC ${ }^{71}$, or glucose ${ }^{72}$ elevates the expression of eNOS. Glucose also greatly enhances endothelial superoxide production ${ }^{72}$, leading to increased vascular formation of the $\mathrm{NO} /$ superoxide reaction product peroxynitrite ${ }^{73}$, which further promotes $\mathrm{BH} 4$ oxidation, with subsequent enhanced eNOS uncoupling ${ }^{74}$.

Insulin is an essential hormone of metabolic homeostasis that has vasodilator action via PI3K/Akt pathway-dependent eNOS activation ${ }^{75}$. In addition to the PI3K/Akt pathway, insulin can modulate eNOS activity by increasing BH4 synthesis via activation of GTPCH. Shinozaki et al. ${ }^{76}$ have demonstrated that the GTPCH activity is significantly decreased in a rat model of insulin resistance, which leads to attenuation of endothelial $\mathrm{BH} 4$ levels and substantial increased $\mathrm{BH} 2$ levels, resulting in impairment of endothelium-dependent vasodilatation. Alteration of insulin-mediated vasodilation has been associated with vascular insulin resistance, which is implicated in arterial hypertension and endothelial dysfunction. eNOS-derived NO regulates blood flow to insulin-sensitive tissues, including skeletal muscle ${ }^{77}$, liver ${ }^{78}$, and adipose tissue ${ }^{77}$, and its activity is impaired in insulin-resistant individuals. An increasing body of evidence has shown the role of eNOS in regulating tissue sensitivity to insulin. An increase in systemic insulin resistance has been demonstrated in $\mathrm{eNOS}^{-/-}$mice that received a hyperinsulinemic euglycemic clamp ${ }^{79}$, ${ }^{80}$. Furthermore, a study in normotensive and nondiabetic individuals demonstrated that insulin resistance, measured by insulin-mediated glucose disposal, significantly correlated with increased plasma levels of ADMA, a potent endogenous NOS inhibitor ${ }^{81}$. It was been demonstrated that NOS inhibition impaired microvascular recruitment and blunted muscle glucose uptake in response to insulin ${ }^{82}$ indicating that eNOS plays a major role in the regulation of insulin sensitivity. Interestingly, an increase in eNOS expression is not always beneficial. It was demonstrated in Goto-Kakizaki rats, 
a model of insulin resistance, that elevated eNOS expression in aortic tissue was associated with increased superoxide production and decreased NO bioavailability. Incubation with L-NAME or deendothelialization of the aortic segments significantly decreased superoxide production.

Increased superoxide production in diabetes is not restricted to EC and is demonstrably enhanced in the smooth muscle layer ${ }^{83}$. Interestingly, adenoviral transfection of eNOS to diabetic vessels improved endothelial-dependent relaxation without altering superoxide production of vascular smooth muscle cells, an observation that may point to an important contribution of an impaired NOS function to endothelial dysfunction in diabetes.

Importantly, downregulation of DHFR has been observed in aortas of STZinduced diabetic mice ${ }^{84}$. As a key enzyme responsible for salvaging $\mathrm{BH} 4$, DHFR downregulation can result in $\mathrm{BH} 4$ deficiency and $\mathrm{BH} 2$ accumulation, both of which worsen eNOS uncoupling. Crabtree et al. ${ }^{17}$ has demonstrated in hyperglycemic models of murine endothelial cells that eNOS uncoupling is due to the accumulation of $\mathrm{BH} 2$ in these cells. In addition, $\mathrm{BH} 2$ replaces $\mathrm{BH} 4-\mathrm{NNOS}$ binding and, hence, directly suppresses eNOS activity. This indicates that $\mathrm{BH}_{2}$-eNOS assembly does have a key role in the pathogenesis of diabetic vasculopathies. In STZ-diabetic rats, hyperglycemia-induced oxidative stress impairs the ability of dimethylarginine dimethylaminohydrolase (DDAH) to metabolize ADMA, leading to an elevation of ADMA and inhibition of endothelium-derived synthesis of $\mathrm{NO}^{85}$.

Leo et al. ${ }^{86}$ demonstrated in diabetic rats that hyperglycemia increased superoxide production, causing endothelial dysfunction, which was due to the impairment of both NO and EDHF-type relaxation. However, the degree of impairment in NO activity appears to be greater than the reduction in EDHF activity, as EDHF is able to elicit maximum relaxation when NO is inhibited, suggesting that $\mathrm{NO}$ is more susceptible to impairment by diabetes. Recent studies showed that attenuation of eNOS-derived NO in insulin-resistant C57BL/KsJ (diabetic, $+d b /+d b$ ) mice ${ }^{87}$ and rat models of type 1 and type $2 \mathrm{DM}^{88}$ could be due to an impairment of eNOS activity through the augmented cav-1 expression, which further indicates that cav-1 plays an important role in cardiovascular complications in both types of diabetes.

Recently, Jo et al. ${ }^{89}$ demonstrated in STZ-induced diabetic cardiomyopathy in $\mathrm{eNOS}^{-/-}, \mathrm{iNOS}^{-/-}, \mathrm{nNOS}^{-/-}$, and WT mice that iNOS uncoupling plays a major role in the pathophysiology of the diabetic heart. Although the oxidative/nitrosative stress markers, i.e., malondialdehyde (MDA), 4-hydroxynoneal (HNE), and nitrotyrosine (NT) are augmented in the diabetic mouse heart, this increase in oxidative/nitrosative stress was significantly repressed in the iNOS ${ }^{-/}$diabetic mouse heart. Importantly, oral administration of sepiapterin, a precursor of $\mathrm{BH} 4\left(10 \mathrm{mg} \cdot \mathrm{kg}^{-1} \cdot \mathrm{day}^{-1}\right.$ for 14 days $)$ 
significantly increases myocardial $\mathrm{BH} 4$ in the control and diabetic hearts. However, a significant increase in the ratio $\mathrm{BH} 4: \mathrm{BH} 2$ is observed only in the diabetic heart and is associated with the inhibition of uncoupling NOS, resulting in increasing iNOS-derived NO. Intriguingly, the absence of the increase in $\mathrm{BH} 2$ in the diabetic heart by administration of sepiapterin suggests that the salvage pathway of $\mathrm{BH} 4$ synthesis through DHFR is more activated in the diabetic heart than in the control heart. These findings may provide an important therapeutic implication in the treatment of NOS uncoupling-induced cardiovascular dysfunction by potentiating the salvage pathway of $\mathrm{BH} 4$ synthesis by sepiapterin administration. Furthermore, hyperglycemia significantly elicits the expression of iNOS both in in vitro ${ }^{90,91}$ and in vivo diabetic embryopathy mouse models associated with increased protein nitrosylation and enhanced NO and superoxide production, resulting in excess production of peroxynitrite, which stimulates the apoptosis pathway via c-Jun $\mathrm{NH}_{2}$-terminal kinase1/2 (JNK1/2) activation $^{91}$. Presently, no evidence demonstrates uncoupling of nNOS in DM.

\section{Hypertension-Induced eNOS Uncoupling}

It is broadly recognized that ROS contribute to the pathogenesis of hypertension. Increased levels of superoxide oxidize NO to peroxynitrite and subsequently to nitrite and nitrate. This results in a loss of "bioactive" NO-mediated vasodilatation, an increase in vasoconstriction, and subsequently an increase in systemic vascular resistance ${ }^{92}$. Angiotensin II is known to play a major role in the initiation and progression of hypertension ${ }^{93}$. It stimulates hypertension in part by ROS generation via eNOS uncoupling, leading to further increases in superoxide ${ }^{7,16}$. Furthermore, the reduction of NO caused by eNOS uncoupling promotes salt sensitivity and salt-induced hypertension ${ }^{94}$. Landmesser et al. ${ }^{6}$ demonstrated in DOCA salt hypertensive rats that uncoupled eNOS and NOX represent important sources of increased vascular ROS production that ultimately oxidize vascular $\mathrm{BH}$ 4. In addition, Takimoto et al. ${ }^{11}$ and Moens et al. ${ }^{95}$ revealed in a mouse model of transverse aortic constriction that eNOS uncoupling is a major source of superoxide in the pathogenesis of de novo and established pressure overload-induced heart failure. Compared with WT, eNOS ${ }^{-/}$mice showed no cardiac hypertrophy, dilatation, and myocardial fibrosis because there was no detrimental eNOS-derived superoxide production.

Higashi et al. ${ }^{10}$ demonstrated that $\mathrm{BH} 4$ augments endothelium-dependent vasodilatation in the forearm in normotensive as well as hypertensive individuals through the recoupling of eNOS and by increasing eNOS-derived NO production. Moreover, studies indicate that the use of NOS inhibitors with relative specificity for nNOS and iNOS ${ }^{96-98}$ implicates reduced NO production by these two NOS isoforms as possible contributors to salt-induced hypertension. Indeed, nNOS-derived NO 
generation in autonomic efferent nerves participates in vasodilatation, blood flow increase, and hypotension ${ }^{99,}{ }^{100}$. Silberman et al. ${ }^{101}$ demonstrated in a mild hypertensive mouse model (unilateral nephrectomy, with subcutaneous implantation of DOCA and saline feeding) increased cardiac oxidation, decreased NOS-derived NO generation and decreased cardiac $\mathrm{BH} 4$, resulting in NOS uncoupling. Interestingly, experiments of NOS inhibitors in this study revealed that nNOS is the largest contributor to cardiac superoxide production in diastolic dysfunction.

\section{Smoking-Induced eNOS Uncoupling}

Cigarette smoke (CS)-mediated oxidative stress downregulates eNOS levels, leading to reduced NO production and decreased endothelium-dependent vasodilatation in endothelial cells ${ }^{102,}{ }^{103}$. Edirisinghe et al. ${ }^{102}$ revealed that CSmediated downregulation of vascular endothelial growth factor receptor 2 expression and activation results in reduction of phosphorylated eNOS and total eNOS both in human lung microvascular endothelial cells and in mouse lungs. Decreased expression/activation levels of eNOS in response to CS have direct implications for endothelial functions such as cell migration, angiogenesis, and endotheliumdependent relaxation ${ }^{104}$. Importantly, deficit of $\mathrm{BH} 4$ bioavailability caused by $\mathrm{ROS}$ scavengers in CS may lead to NOS uncoupling, at least in part, contributing to endothelial dysfunction in chronic smokers ${ }^{105}$. In addition, CS has been shown to induce iNOS expression in pulmonary arteries ${ }^{106}$. Furthermore, Lowe et al. ${ }^{107}$ revealed that chemicals found in aqueous cigarette smoke extracts can directly affect eNOS by oxidizing $\mathrm{BH} 4$. Although both eNOS and nNOS are inhibited by cigarette smoke extracts, $\mathrm{BH} 4$ reactivates eNOS but not nNOS, whereas L-arginine protects nNOS but not eNOS. Thus, differential effects might be expected, and this may be the basis for isoform-selective inhibition of nNOS over eNOS in penile tissue from rats treated with cigarette smoke ${ }^{108}$.

\section{Homocysteine-Induced eNOS Uncoupling}

Increased plasma homocysteine (Hcy) has emerged as an independent risk factor for atherosclerosis and vascular disease ${ }^{109}$. The pathophysiological roles of hyperhomocysteinemia (HHcy) in endothelial dysfunction are associated with increased thrombogenicity ${ }^{110,111}$, increased oxidative stress ${ }^{112}$, overactivation of redox-sensitive inflammatory pathways ${ }^{113}$, and atherogenesis ${ }^{114}$. Uncoupling of eNOS is mainly responsible for Hcy-induced oxidative stress, because Hcy activates intracellular superoxide synthesis in human umbilical vein endothelial cells (HUVEC), and treatment with L-NAME markedly decreases superoxide generation, indicating that Hcy-induced oxidative stress is dependent mainly on NOS activity ${ }^{115}$. In cultured porcine endothelial cells incubated with Hcy, it has been described that eNOS uncoupling contributes to Hcy-induced superoxide formation ${ }^{116}$. The interaction 
between Hcy and eNOS uncoupling can be explained in several ways. First, Hcy has been shown to decrease L-arginine uptake in endothelial cell cultures, with a subsequent uncoupling of eNOS ${ }^{117}$. Second, Hcy elicits the cellular transport of Larginine without altering eNOS activity, and eNOS generates superoxide rather than $\mathrm{NO}$ and forms peroxynitrite which later oxidizes $\mathrm{BH} 4$, leading to eNOS uncoupling ${ }^{115}$. Third, studies with HUVEC have revealed that Hcy induces eNOS uncoupling through increasing superoxide and diminishing intracellular $\mathrm{BH} 4$ bioavailability ${ }^{115,}{ }^{118}$. Recently, He et al. ${ }^{119}$ provided the first evidence that Hcy impairs coronary artery endothelial function. In addition, plasma levels of $\mathrm{NO}$ and $\mathrm{BH} 4$ are positively correlated and significantly decreased in patients with $\mathrm{HHcy}$ compared with controls. This suggests that the uncoupling of eNOS induced by HHcy in patients with chronic $\mathrm{HHcy}$ due to reduced $\mathrm{BH} 4$ levels may explain in part this adverse effect ${ }^{120}$. Fourth, Hcy inhibits catabolic degradation activity of DDAH, causing ADMA accumulation; thus, it inhibits eNOS activity in vascular endothelium ${ }^{121}$. Importantly, ADMA is associated with the increased eNOS uncoupling found in endothelium of patients with coronary artery disease (CAD) ${ }^{122}$. Recently, Lemarie et al. ${ }^{123}$ demonstrated in the endothelial progenitor cells (EPC) of heterozygous methylenetetrahydrofolate reductase-deficient $\left(\mathrm{Mthfr}^{+/}\right)$mice, which are mildly HHcy, and that ROS production is significantly increased and the eNOS dimer-to-monomer ratio significantly decreased compared with EPC from wild-type mice, demonstrating eNOS uncoupling. This study indicates that eNOS uncoupling is a main cause of increased ROS formation in these mildly HHcy mice. Interestingly, the expression of sirtuin-1 (SIRT1), a NAD+dependent protein deacetylase, is impaired at both mRNA and protein levels by $\mathrm{Mthfr}^{+/}$mice. SIRT1 has been shown to exert protective effects against endothelial dysfunction by preventing stress-induced senescence ${ }^{124}$ and, at vascular levels, to promote endothelium-dependent vasodilation by deacetylating eNOS and increasing NO bioavailability ${ }^{125}$. These results suggest that, in mildly HHcy mice, the uncoupling of eNOS increases ROS production, which leads to inhibition of SIRT1, then to premature senescence of EPC, and thus eventually to endothelial dysfunction.

On the other hand, although there are no data showing that Hcy induces nNOS or iNOS uncoupling, Hcy has also been shown to upregulate iNOS, which may contribute to the inflammatory response that characterizes atherogenesis and may account for the adverse effects of $\mathrm{Hcy}{ }^{126}$. In addition, an increase in iNOS activity is a key contributor to a HHcy-mediated collagen/elastin switch and a resulting decline in aortic compliance ${ }^{127}$.

\section{I/R Injury-Induced eNOS Uncoupling}

One of the events occurring in the early phase of $I / R$ is vascular dysfunction associated with impaired endothelial function. ROS production has been implicated in 
endothelial damage, leading to endothelial dysfunction after I/R injury ${ }^{128}$. ROS generation has been shown to be significantly increased during reperfusion. The largest increase in ROS level has been observed 15 min after reperfusion ${ }^{129-131}$. This increase in reactive oxygen burst coincides with the development of endothelial dysfunction. Indeed, while 90 or $120 \mathrm{~min}$ of ischemia did not change vascular reactivity, vascular response to acetylcholine (ACh) was attenuated as early as 2.5 min after the onset of reperfusion ${ }^{132,133}$. A reduction in endothelial-dependent vasorelaxation after $\mathrm{I} / \mathrm{R}$ injury has been associated with a decrease in NO bioavailability due to alteration of eNOS. Furthermore, endothelial-dependent vasorelaxation in response to serotonin was also impaired in pig carotid artery exposed to I/R, which was again improved with $\mathrm{BH} 4$ supplementation ${ }^{134}$.

Several ROS generators during $\mathrm{I} / \mathrm{R}$ injury have been determined. These include mitochondria ${ }^{135}$, xanthine oxidase ${ }^{136}$, NOX ${ }^{137}$, neutrophils ${ }^{138}$, and eNOS ${ }^{139}$. eNOS uncoupling has been demonstrated to have a significant role in the occurrence of tissue damage after I/R injury. In the early phase of cardiac ischemia, there is an increase in $\mathrm{Ca}^{2+}$ uptake by cardiomyocytes and endothelial cells, leading to activation of eNOS with subsequent rapid and short-lived aggravation of NO concentration. This is followed not only by rapid consumption of L-arginine (the substrate of the enzymes) but also $\mathrm{BH} 4$ (the cofactor), triggering eNOS uncoupling and a decrease in NO bioavailability, which has been shown especially in the onset of reperfusion ${ }^{140,141}$.

It has been demonstrated that isolated rat hearts subjected to ischemia showed reduced $\mathrm{BH} 4$ levels with subsequent decreased eNOS activity and increased superoxide production ${ }^{142}$. BH4 supplementation could restore impaired epicardial coronary epithelial function; moreover, it attenuated lipid peroxidation and improved cardiac functional recovery in rat models of global cardiac $\mathrm{I} / \mathrm{R}^{143}$. In accordance with that, impaired coronary flow during reperfusion phase could be improved by $\mathrm{BH} 4$ infusion, which was associated with increased eNOS activity and decreased NOSdependent superoxide production ${ }^{142}$. Moreover, a study in rat femoral artery also showed that $\mathrm{BH} 4$ increased $\mathrm{NO}$ production and decreased $\mathrm{H}_{2} \mathrm{O}_{2}$ release after $\mathrm{l} / \mathrm{R}$.

In addition to $\mathrm{BH} 4, \mathrm{Hsp} 90$, another posttranslational modulator of eNOS, has also been implicated in I/R injury. Hsp90 was proposed to prevent eNOS uncoupling and eNOS-derived superoxide production after chronic myocardial ischemia ${ }^{144}$. It has been demonstrated that an Hsp90-transfected pig model of myocardial I/R showed reduction in infarct size and improved myocardial function. This effect was abrogated by administration of L-NAME and was associated with the ability of Hsp90 to act as an adaptor for Akt and phosphatase calcineurin, thereby promoting eNOS $\mathrm{Ser}^{1177}$ phosphorylation and $\mathrm{Thr}^{495}$ dephosphorylation ${ }^{145}$. All these findings enhance 
the essential role of eNOS in I/R injury and provide evidence for the potential of this protein as a therapeutic target.

\section{Atrial Fibrillation-Induced eNOS Uncoupling}

The association of eNOS and atrial fibrillation (AF) has been derived from the study of Minamino et al. ${ }^{146}$, showing significantly reduced plasma levels of nitrite and nitrate and platelet cGMP in patients with AF compared with patients with sinus rhythm. Furthermore, Takahashi et al. ${ }^{147}$ demonstrated that, compared with control patients with sinus rhythm, the increase of $\mathrm{ACh}$-induced forearm blood flow was considerably smaller in patients with AF and was improved after cardioversion to sinus rhythm. These two studies proposed a correlation between AF and endothelial dysfunction with eNOS as a link. Altered hemodynamic condition has been implicated as an underlying mechanism that translates $A F$ to endothelial dysfunction ${ }^{147,148}$. Cai et al. ${ }^{148}$ suggested that decreased endocardial eNOS expression in a dog model of AF was due to turbulent blood flow occurring during AF. In an in vitro setting, it was demonstrated that HUVEC produce lower levels of NO when exposed to turbulent flow compared with when in laminar flow conditions. An increase in NO generation after laminar flow exposure appeared to be due to an upregulation of eNOS expression ${ }^{149}$. Regulation of eNOS expression and NO generation by shear stress involves the opening of ion channels followed by eNOS protein phosphorylation and gene upregulation, leading to an increase in NO bioavailability ${ }^{150}$. Although experimental animal studies have shown reduced eNOS expression in fibrillating atria ${ }^{148,151}$, a human study showed no difference in eNOS gene and protein expression in the atrium of $\mathrm{AF}$ and sinus rhythm (SR) patients ${ }^{152}$.

In addition to eNOS, iNOS has been implicated in AF. Han et al. ${ }^{153}$ reported an increased level of $\mathrm{NO}$ in the right atrium of $\mathrm{AF}$ patients, with subsequent generation of peroxynitrite, which was associated with an increase in iNOS expression. In addition, Nishijima et al. ${ }^{154}$ reported increased expression of iNOS in a dog model of heart failure-induced AF. Despite some concerns about the methodology used ${ }^{155,156}$, the authors demonstrated that increased expression of iNOS in heart failure (HF) is accompanied by low $\mathrm{NO}$ and high superoxide production, which can be reversed by administration of $\mathrm{BH} 4$, suggesting the occurrence of iNOS uncoupling. Furthermore, 6wk oral administration of $50 \mathrm{mg} \mathrm{BH} 4$ plus $3 \mathrm{~g} \mathrm{~L}$-arginine twice daily reduced inducible $\mathrm{AF}$ and normalized heart failure-induced shortening of the left atrial myocyte action potential duration in this model ${ }^{154}$.

Investigating the source of superoxide in the atrium of patients with AF, Kim et al. ${ }^{157}$ demonstrated that gp91 phox containing NOX in atrial myocytes was the main source of atrial superoxide production in SR and in AF patients. NOS was shown to contribute significantly to superoxide generation in fibrillating atria but not in patients 
with sinus rhythm, suggesting that increased levels of NOX-dependent oxidative stress induce eNOS uncoupling with a consequence of increased production of superoxide. Moreover, Reilly et al. ${ }^{158}$ demonstrated that different atrial sources of ROS varied with the duration and substrate of AF. The authors reported that NOX was the main source of superoxide production in the left atrium of goats after $2 \mathrm{wk}$ of $A F$ and in patients who developed postoperative AF. Conversely, after 6 mo of AF, NOX showed no production of superoxide. Instead, NOS was the main source of oxidative stress in the presence of this long-standing AF. Interestingly, NOS-dependent superoxide production was associated with decreased $\mathrm{BH} 4$ level and $\mathrm{BH} 4 \mathrm{BH} 2$ ratio, suggesting that NOX-dependent superoxide generation during early periods of $\mathrm{AF}$ induces oxidation of $\mathrm{BH} 4$ as a cofactor of NOS leading to uncoupling of this enzyme. These results imply that AF treatments may be differentiated according to duration and substrate of AF. Whether agents that modulate eNOS will be able to alter AF in patients with atrial structural remodeling remain to be elucidated.

\section{Endothelial Dysfunction and Endothelial Progenitor Cells}

EPC are circulating cells with the ability to differentiate into mature endothelium and have a role in endothelial repair and maintenance. Under certain pathophysiological conditions, for instance in CAD patients, this process seems to be blunted, resulting in reduced levels and migratory capacity of EPC for neovascularization of ischemic tissue ${ }^{159}$. In addition, both NO and oxidative stress, and in particular the balance between them, regulate the number and function of EPC by direct and indirect mechanisms ${ }^{160}$. Increasing evidence suggests that a damaged endothelial lining can be restored by circulating EPC derived from bone marrow ${ }^{161-163}$. A decrease in the number and function of EPC has been associated with a large number of risk factors for atherosclerosis ${ }^{164,165}$. There is strong evidence that EPCexpressed eNOS is regulated under various physiological and pathophysiological conditions. Moreover, compounds or molecules that increase eNOS expression improve EPC function, whereas eNOS inhibitory substances have deleterious effects ${ }^{166}$. By upregulating eNOS expression of EPC, statins, estrogen, and erythropoietin (EPO) could enhance reendothelialization or augment neovascularization ${ }^{167-170}$. On the contrary, oxLDL or CRP attenuates EPCs' survival, differentiation, and function by reducing eNOS expression of EPC ${ }^{171,172}$.

It has been demonstrated that several substances affect the number and function of EPC via an Akt/eNOS-related pathway. Indeed, the PI3K/Akt pathway is vital for regulating EPC recruitment, mobilization, and proliferation ${ }^{173}$. Compounds that stimulate the PI3K/Akt protein kinase pathway can also activate eNOS ${ }^{62}$. This association between eNOS and EPC count and activity appears to be crucial, because the expression of eNOS is essential for the mobilization of stem and progenitor cells 
${ }^{174}$, and perturbations in the $\mathrm{PI} 3 \mathrm{~K} / \mathrm{Akt} / \mathrm{eNOS} / \mathrm{NO}$ signaling pathway or one of its members may result in EPC dysfunction ${ }^{156}$. Recently, Cui et al. ${ }^{1}$ demonstrated that transplantation of EPC overexpressing eNOS can repair balloon-caused carotid artery injury in a rat model by inhibiting neointimal hyperplasia and restoring vascular function.

\section{Diagnosis of Endothelial Dysfunction}

The ability to detect endothelial dysfunction before overt cardiovascular disease manifests makes the diagnostic modalities attractive clinical tools for prevention and rehabilitation ${ }^{175}$. In humans, endothelium-derived vasodilatation can be assessed by measuring increases in the diameter of large arteries (forearm or coronary) after 1) release of ischemia (e.g., arrested forearm circulation), 2) intraarterial infusion of $\mathrm{ACh}$, or 3 ) a sudden blood pressure elevation by placing the hands in ice water (cold pressure test). These measurements are based on the fact that conduit vessels can respond to alterations in blood flow by increasing vessel diameter via an endothelial-dependent mechanism ${ }^{176,177}$. These responses have been shown to reflect local bioactivity of endothelium-dependent $\mathrm{NO}$ generation and NO inactivation. These measurements are very sensitive to external conditions (room temperature, caffeine intake, etc.); hence, these measurements need to be performed under standard conditions ${ }^{178}$.

Quantitative coronary angiography (QCA) measures the changes in the diameters of the coronary arteries in baseline conditions compared with vasodilatation induced by endothelium-dependent drugs. More recently, noninvasive QCA has been developed using computed tomography imaging ${ }^{179}$ or magnetic resonance imaging (MRI) ${ }^{180}$.

\section{Therapeutic Effects of eNOS Modulators}

\section{L-arginine}

L-arginine, a semiessential amino acid found in large quantities in fish, chicken, and beans, is the substrate for the production of NO. L-arginine deficiency or the presence of its endogenous inhibitors, i.e., ADMA, may lead to eNOS uncoupling ${ }^{181}$. L-arginine activates oxygen uptake by eNOS ${ }^{182}$ and prevents superoxide generation within uncoupled eNOS by electron interaction with heme-bound oxygen ${ }^{183}$. In addition, L-arginine may be able to restore the physiological status by normalizing the extracellular L-arginine:ADMA ratio ${ }^{184}$. Although $L$-arginine improves both endothelium-dependent vasodilation and abnormal interactions of vascular cells, platelets, and monocytes, clinical studies with L-arginine have shown inconsistent effects on endothelial function. Acute and subacute L-arginine administration improves 
NO-dependent vasodilatation in a study of healthy elderly individuals ${ }^{185}$ and patients with hypercholesterolemia ${ }^{186}$ and coronary artery disease ${ }^{187}$. On the other hand, chronic administration may not show the beneficial effect of L-arginine. The VINTAGE $\mathrm{Ml}$ study demonstrated that 6 mo of oral L-arginine administration ( $3 \mathrm{~g} 3$ times a day) does not improve clinical outcome and possibly increases risk of death in older patients with CAD ${ }^{188}$. In addition, L-arginine supplementation also leads to an increase in Hcy production, which can result in worsening, not improving, endothelial function and atherosclerosis ${ }^{189}$. Oral administration of L-arginine $(9 \mathrm{~g} / \mathrm{day})$ to healthy postmenopausal women for 1 month has no affect on major endocrine hormones or lipid profile. Although L-arginine could be the key to future treatment of cardiovascular disorders, it has not been possible to draw any general conclusion supporting the use of L-arginine for improving the clinical treatment in patients with endothelial dysfunction. In addition, it is not completely clear which types of endothelial dysfunction are related to L-arginine deficiency.

\section{$\mathrm{BH} 4$}

Since uncoupled eNOS can increase the production of ROS, promote $\mathrm{BH} 4$ oxidation, and self-limit its NO biosynthesis, modulating eNOS uncoupling is an attractive therapeutic approach in endothelial dysfunction. The most straightforward way to modulate eNOS is administration of its essential cofactor $\mathrm{BH} 4{ }^{120}$.

$\mathrm{BH} 4$ is an FDA-approved therapy for some forms of phenylketonuria (PKU), in which there is a deficiency in the hepatic enzyme phenylalanine hydroxylase. Supplementating with $\mathrm{BH} 4$ increases NOS activity by recoupling uncoupled eNOS in mice with hypertension-induced heart failure with subsequent reversal of cardiac hypertrophy and fibrosis ${ }^{95}$. In vitro administration of $\mathrm{BH} 4$, or its physiological precursor sepiapterin, restored endothelium-dependent relaxation of resistance arteries in diabetic $d b / d b$ mice ${ }^{190}$, atherosclerotic vessels of humans and pigs ${ }^{38}$, and patients with endothelial dysfunction ${ }^{105,191}$. Chronic oral administration of $\mathrm{BH} 4$ has been reported to improve endothelium function ${ }^{6,192}$, decrease vascular superoxide production, and increase vascular NO production. As a result, it blunts the increase in blood pressure in a hypertensive mice model ${ }^{6}$. Recently, Li et al. ${ }^{40}$ demonstrated in $\mathrm{apoE}^{-/-}$mice by using partial carotid ligation that oral $\mathrm{BH} 4$ supplementation in drinking water (10 $\mathrm{mg} \cdot \mathrm{kg}^{-1} \cdot \mathrm{day}^{-1}$ for $\left.1 \mathrm{wk}\right)$ prevents NOS uncoupling and improves endothelial function associated with diminished monocyte adhesion and T-cell activation as well as blunted cytokine production from the vessel wall. In addition, short-term administration of $\mathrm{BH} 4$ (intra-arterial infusion $500 \mu \mathrm{g} / \mathrm{min}$ ) improves endothelialdependent vasodilatation to ACh in type 2 diabetes ${ }^{105}$. Porkert et al. ${ }^{193}$ demonstrated in subjects with poorly controlled hypertension that orally administering $(400 \mathrm{mg}$ or higher) $\mathrm{BH} 4$ daily has a significant and sustained antihypertensive effect. Importantly, 
this effect is associated with reversing the uncoupling of NOS and improving NO bioavailability ${ }^{80}$. Although studies suggest that $\mathrm{BH} 4$ administration shows beneficial results for endothelial dysfunction, it may have limited long-term benefit in improving eNOS coupling ${ }^{17}$. Chronic $\mathrm{BH} 4$ administration may result in endothelial $\mathrm{BH} 2$ accumulation and consequent eNOS uncoupling because $\mathrm{BH} 2$ can replace eNOSbound BH4 competitively ${ }^{17,194}$. Recently, Moens et al. ${ }^{195}$ studied the therapeutic efficacy of $\mathrm{BH} 4$ in hypertension-induced heart failure in a mouse model of pressure overload, demonstrating a bimodal dose-dependent relationship, first rising and then declining at higher doses. Importantly, this study indicates that, at higher doses of exogenous $\mathrm{BH} 4$ (and thus $\mathrm{BH} 2$ ), the intrinsic capacity to maintain $\mathrm{BH} 4: \mathrm{BH} 2$ ratios may become compromised, limiting net efficacy. These results expose a potential limitation for the clinical use of $\mathrm{BH} 4$ in diseases characterized by oxidative stress, as defining the oral dose that would optimally provide $\mathrm{BH} 4$ rather than $\mathrm{BH} 2$ may be difficult and vary from individual to individual. Inadequate conversion of $\mathrm{BH} 2$ to $\mathrm{BH} 4$ may pose a limitation to its therapeutic use, and coadministration of agents that stimulate such conversion may be valuable to enhance its therapeutic benefits in in vivo. Albeit, the benefit of a $\mathrm{BH} 4$ supplement, i.e., synthetic sapropterin hydrochloride ( $6 \mathrm{R}-\mathrm{BH}_{4}$, Kuvan) on endothelial function seems promising, the results from clinical trials were disappointing, not because they revealed adverse effects but for their lack of efficacy. Future studies are needed to determine the dose-response relation between $\mathrm{BH}_{4}$ and its effect on superoxide generation in models of cardiovascular diseases because of the tight stoichiometric relation between eNOS and $\mathrm{BH}_{4}$, with possible subsequent uncoupling.

\section{Folic acid}

Folic acid (FA) is a chemically stable and inexpensive vitamin (Vit B9), which has direct and indirect superoxide scavenging effects. Although the best-known biological function of FA is to reduce plasma Hcy, the major effects of FA in the cardiovascular system are independent of Hcy lowering ${ }^{196}$. Moat et al. ${ }^{197}$ demonstrated in patients with CAD that FA dose-dependently improves endothelial function through a mechanism independent of Hcy lowering. Clinically, FA and 5methyltetrahydrofolate (5-MTHF), the active form of FA, have been shown to restore endothelial function in patients with hypercholesterolemia ${ }^{198}$, diabetes ${ }^{199,} 200$, and atherosclerosis ${ }^{201}$. FA increases the vascular bioavailability of $\mathrm{BH} 4$ and subsequently reduces eNOS-derived superoxide generation ${ }^{201}$. FA restores the function of uncoupled eNOS by improving $\mathrm{BH} 4$ bioavailability in the vasculature by preventing its oxidation, enhancing the regeneration of $\mathrm{BH} 4$ from $\mathrm{BH} 2$, and chemically stabilizing $\mathrm{BH} 4{ }^{95,202}$. Furthermore, Hyndman et al. ${ }^{203}$ demonstrated that 5-MTHF is capable of binding the active site of NOS and mimicking the orientation of $\mathrm{BH} 4$. In addition, van Etten et al. ${ }^{199}$ demonstrated that administration of 5-MTHF ameliorates endothelial 
dysfunction found in patients with type 2 diabetes by restoring impaired NO-mediated vasodilatation. Moreover, administration of FA improves EPC function by normalizing gene expression profiles in type 1 diabetes patients ${ }^{200}$. However, recent clinical trials have failed to demonstrate a benefit of long-term use of FA in lowering the risk of recurrent cardiovascular disease or death after an acute myocardial infarction 204, 205, which can be explained by too low of a dosage ${ }^{206}$. Therefore, an important distinction must be made between FA as a long-term, low-dose fortification or dietary supplement and as a short-term, high-dose treatment.

\section{eNOS transcription enhancers}

The novel small molecules AVE9488 and AVE3085 are eNOS transcription enhancers. AVE9488 has proven in vivo effects improving left ventricular remodeling in a rat model of myocardial infarction ${ }^{207}$ and a mouse model of cardiac I/R injury ${ }^{208}$. Wohlfart et al. ${ }^{42}$ demonstrated in a model of experimental atherosclerosis that both AVE9488 and AVE3085 have vasoprotective properties, i.e., the increased endothelial NO generation associated with reduced cuff-induced neointima formation and reduced formation of atherosclerotic plaques in $\mathrm{apoE}^{-/-}$mice. This study indicates that both compounds showed the concomitant increase in eNOS transcription and eNOS protein levels; BH4 levels also increased, although GTPCH mRNA levels did not. In addition, the mechanisms for the increase in $\mathrm{BH} 4$ by these eNOS enhancers still remain unknown. Recently, Yang et al. ${ }^{209}$ demonstrated that AVE3085 restored impaired endothelial function in a hypertensive model by upregulated expression of eNOS protein and mRNA, enhanced eNOS phosphorylation, and decreased formation of nitrotyrosine. While these preclinical data are very promising, no clinical studies are initiated at the moment.

\section{Statins}

Statins, hydroxymethylglutaryl-CoA reductase inhibitors, improve endothelial function by increasing eNOS stability ${ }^{210}$ and bioavailability of $\mathrm{NO}^{211}$, and in part by lowering $L D L^{212}$. In animal experiments, statins have been shown to reduce platelet activation and thrombus formation, which in part, are influenced by eNOS upregulation ${ }^{213}$. Moreover, statins increase $\mathrm{BH} 4$ levels in vascular endothelial cells by potentiating GTPCH gene expression and $\mathrm{BH} 4$ synthesis, thereby preventing relative shortages of $\mathrm{BH} 4{ }^{214}$. Some statins, such as atorvastatin, decrease cav- 1 expression in EC, thereby allowing for the activation of eNOS by cofactors, resulting in promoting NO production ${ }^{215}$. Wenzel et al. ${ }^{216}$ demonstrated in STZ diabetic rats that chronic administration of atorvastatin $\left(20 \mathrm{mg} \cdot \mathrm{kg}^{-1} \cdot \mathrm{day}^{-1}\right.$ for $\left.7 \mathrm{wk}\right)$ improves endothelial function by normalizing endothelial $\mathrm{BH} 4$ level and GTPCH expression, reducing oxidative stress, preventing NOX upregulation, and preventing and reversing eNOS uncoupling. 


\section{Conclusions}

In this review, we have discussed how eNOS uncoupling is one of the major underlying causes of endothelial dysfunction found in atherosclerosis, diabetes, hypertension, cigarette smoking, HHcy, and I/R injury. Evidence suggests that modulating of eNOS by stabilizing eNOS function and suppressing eNOS-derived $R O S$ is a promising therapeutic target for endothelial dysfunction. Therapeutics, such as L-arginine, BH4, FA, eNOS transcription enhancers (AVE9488 and AVE 3085), and statins have achieved vascular protection, improving endothelial function and ameliorating cardiovascular diseases in animal and/or human studies (Figure 2), yet this experimental evidence needs to be confirmed in clinical trials. Further understanding of the pathophysiology and the molecular biology of endothelial dysfunction is required to understand this discrepancy. Importantly, future efforts may be directed at identifying signaling pathways regulating NOS on oxidative/nitrosative stress and providing possible mechanisms that can recouple the uncoupled eNOS and other NOS isoforms. These new studies will provide us with a comprehensive understanding of the molecular basis of eNOS uncoupling, thereby identifying potential novel therapeutic approaches targeting the underlying signaling pathways for the prevention and treatment of progressive endothelial dysfunction in cardiovascular diseases. 


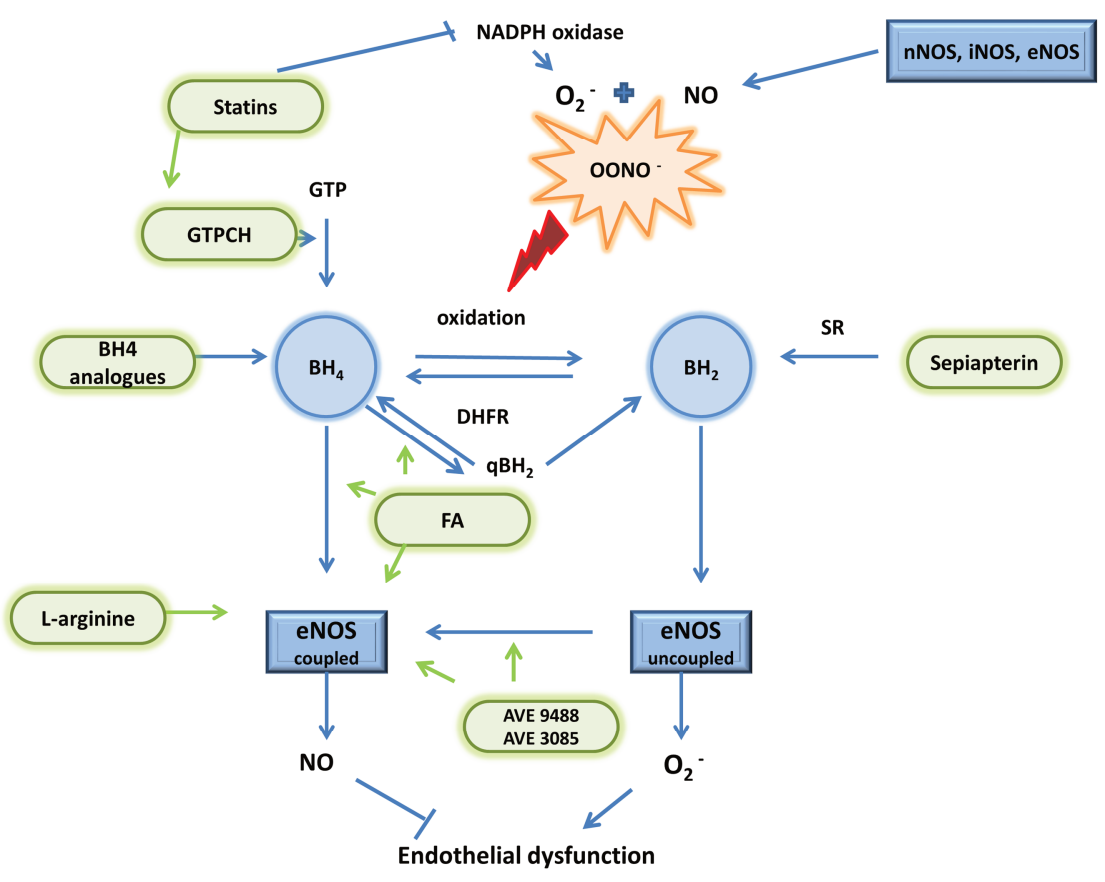

Figure 2. Potential therapeutic options for treating endothelial dysfunction by modulating eNOS.

The most straightforward way to modulate eNOS is administration of its substrate L-arginine or its essential cofactor $\mathrm{BH} 4$ or $\mathrm{BH} 4$ analogs. Folic acid (FA) can modulate eNOS by improving BH4 bioavailability in the vasculature by preventing its oxidation, enhancing regeneration of $\mathrm{BH} 4$ from $\mathrm{BH} 2$, and chemically stabilizing BH4. Novel small molecules AVE9488 and AVE3085 are eNOS transcription enhancers. Statins can improve endothelial function by increasing eNOS stability and inhibiting NADPH oxidase upregulation. Also, statins can increase $\mathrm{BH} 4$ levels in vascular endothelial cells by potentiating GTPCH gene expression and $\mathrm{BH} 4$ synthesis. 


\section{References}

1. Cui B, Huang L, Fang Y, Guo R, Yin Y, Zhao X. Transplantation of endothelial progenitor cells overexpressing endothelial nitric oxide synthase enhances inhibition of neointimal hyperplasia and restores endothelium-dependent vasodilatation. Microvascular Research 2011;81(1):143150.

2. Ignarro LJ, Cirino G, Casini A, Napoli C. Nitric Oxide as a Signaling Molecule in the Vascular System: An Overview. Journal of Cardiovascular Pharmacology 1999;34(6):879-886.

3. Channon K. Tetrahydrobiopterin: Regulator of Endothelial Nitric Oxide Synthase in Vascular Disease. Trends in Cardiovascular Medicine 2004;14(8):323-327.

4. Zanzinger J, Czachurski J, Seller $\mathrm{H}$. Inhibition of sympathetic vasoconstriction is a major principle of vasodilation by nitric oxide in vivo. Circulation Research 1994;75(6):1073-1077.

5. Moncada S, Erusalimsky JD. Does nitric oxide modulate mitochondrial energy generation and apoptosis? 2002;3:214.

6. Landmesser U, Dikalov S, Price SR, McCann L, Fukai T, Holland SM, Mitch WE, Harrison DG. Oxidation of tetrahydrobiopterin leads to uncoupling of endothelial cell nitric oxide synthase in hypertension. Journal of Clinical Investigation 2003;111(8):1201-1209.

7. Mollnau H, Wendt M, Szöcs K, Lassègue B, Schulz E, Oelze M, Li H, Bodenschatz M, August M, Kleschyov AL, Tsilimingas N, Walter U, Förstermann U, Meinertz T, Griendling K, Münzel T. Effects of Angiotensin II Infusion on the Expression and Function of $\mathrm{NAD}(\mathrm{P}) \mathrm{H}$ Oxidase and Components of Nitric Oxide/cGMP Signaling. Circulation Research 2002;90(4):e58-e65.

8. Moens AL, Champion HC, Claeys MJ, Tavazzi B, Kaminski PM, Wolin MS, Borgonjon DJ, Van Nassauw L, Haile A, Zviman M, Bedja D, Wuyts FL, Elsaesser RS, Cos P, Gabrielson KL, Lazzarino G, Paolocci N, Timmermans J-P, Vrints CJ, Kass DA. High-Dose Folic Acid Pretreatment Blunts Cardiac Dysfunction During Ischemia Coupled to Maintenance of HighEnergy Phosphates and Reduces Postreperfusion Injury. Circulation 2008;117(14):1810-1819.

9. Hink U, Li H, Mollnau H, Oelze M, Matheis E, Hartmann M, Skatchkov M, Thaiss F, Stahl RAK, Warnholtz A, Meinertz T, Griendling K, Harrison DG, Forstermann U, Munzel T. Mechanisms Underlying Endothelial Dysfunction in Diabetes Mellitus. Circulation Research 2001;88(2):e14e22.

10. Higashi $\mathrm{Y}$, Sasaki S, Nakagawa K, Fukuda Y, Matsuura H, Oshima T, Chayama K. Tetrahydrobiopterin enhances forearm vascular response to acetylcholine in both normotensive and hypertensive individuals*. American Journal of Hypertension 2002;15(4):326-332.

11. Takimoto E, Champion HC, Li M, Ren S, Rodriguez ER, Tavazzi B, Lazzarino G, Paolocci N, Gabrielson KL, Wang Y, Kass DA. Oxidant stress from nitric oxide synthase-3 uncoupling stimulates cardiac pathologic remodeling from chronic pressure load. Journal of Clinical Investigation 2005;115(5):1221-1231.

12. Alp NJ, Channon KM. Regulation of Endothelial Nitric Oxide Synthase by Tetrahydrobiopterin in Vascular Disease. Arteriosclerosis, Thrombosis, and Vascular Biology 2004;24(3):413-420.

13. Kuzkaya N, Weissmann N, Harrison DG, Dikalov S. Interactions of Peroxynitrite, Tetrahydrobiopterin, Ascorbic Acid, and Thiols: implications for uncoupling endothelial nitric-oxide synthase. Journal of Biological Chemistry 2003;278(25):22546-22554.

14. Takikawa S-I, Curtius H-C, Redweik U, Leimbacher W, Ghisla S. Biosynthesis of tetrahydrobiopterin. European Journal of Biochemistry 1986;161(2):295-302.

15. Thöny B, Auerbach G, Blau N. Tetrahydrobiopterin biosynthesis, regeneration and functions. Biochemical Journal 2000;347(Pt 1):1-16.

16. Chalupsky K, Cai H. Endothelial dihydrofolate reductase: Critical for nitric oxide bioavailability and role in angiotensin II uncoupling of endothelial nitric oxide synthase. Proceedings of the National Academy of Sciences of the United States of America 2005;102(25):9056-9061.

17. Crabtree MJ, Smith CL, Lam G, Goligorsky MS, Gross SS. Ratio of 5,6,7,8-tetrahydrobiopterin to 7,8-dihydrobiopterin in endothelial cells determines glucose-elicited changes in NO vs. 
superoxide production by eNOS. American Journal of Physiology - Heart and Circulatory Physiology 2008;294(4):H1530-H1540.

18. Crabtree MJ, Tatham AL, Al-Wakeel Y, Warrick N, Hale AB, Cai S, Channon KM, Alp NJ. Quantitative Regulation of Intracellular Endothelial Nitric-oxide Synthase (eNOS) Coupling by Both Tetrahydrobiopterin-eNOS Stoichiometry and Biopterin Redox Status. Journal of Biological Chemistry 2009;284(2):1136-1144.

19. Crabtree MJ, Hale AB, Channon KM. Dihydrofolate reductase protects endothelial nitric oxide synthase from uncoupling in tetrahydrobiopterin deficiency. Free Radical Biology \& Medicine 2011;50(11):1639-1646.

20. Huang PL. eNOS, metabolic syndrome and cardiovascular disease. Trends in endocrinology and metabolism: TEM 2009;20(6):295-302.

21. Kawashima S, Yamashita T, Ozaki M, Ohashi Y, Azumi H, Inoue N, Hirata K-i, Hayashi Y, Itoh H, Yokoyama M. Endothelial NO Synthase Overexpression Inhibits Lesion Formation in Mouse Model of Vascular Remodeling. Arteriosclerosis, Thrombosis, and Vascular Biology 2001;21(2):201.

22. Ozaki M, Kawashima S, Yamashita T, Ohashi Y, Rikitake Y, Inoue N, Hirata K-I, Hayashi Y, Itoh $\mathrm{H}$, Yokoyama M. Reduced Hypoxic Pulmonary Vascular Remodeling by Nitric Oxide From the Endothelium. Hypertension 2001;37(2):322-327.

23. Bendall JK, Alp NJ, Warrick N, Cai S, Adlam D, Rockett K, Yokoyama M, Kawashima S, Channon KM. Stoichiometric Relationships Between Endothelial Tetrahydrobiopterin, Endothelial NO Synthase (eNOS) Activity, and eNOS Coupling in Vivo: Insights From Transgenic Mice With Endothelial-Targeted GTP Cyclohydrolase 1 and eNOS Overexpression. Circ Res 2005;97(9):864-871.

24. Bachetti T, Comini L, Francolini G, Bastianon D, Valetti B, Cadei M, Grigolato P, Suzuki H, Finazzi D, Albertini A, Curello S, Ferrari R. Arginase pathway in human endothelial cells in pathophysiological conditions. Journal of Molecular and Cellular Cardiology 2004;37(2):515-523.

25. Xu W, Kaneko FT, Zheng S, Comhair SAA, Janocha AJ, Goggans T, Thunnissen FBJM, Farver C, Hazen SL, Jennings C, Dweik RA, Arroliga AC, Erzurum SC. Increased arginase II and decreased NO synthesis in endothelial cells of patients with pulmonary arterial hypertension. The FASEB Journal 2004.

26. Vergnani L, Hatrik S, Ricci F, Passaro A, Manzoli N, Zuliani G, Brovkovych V, Fellin R, Malinski T. Effect of Native and Oxidized Low-Density Lipoprotein on Endothelial Nitric Oxide and Superoxide Production : Key Role of I-Arginine Availability. Circulation 2000;101(11):1261-1266.

27. Achan V, Broadhead M, Malaki M, Whitley G, Leiper J, MacAllister R, Vallance P. Asymmetric Dimethylarginine Causes Hypertension and Cardiac Dysfunction in Humans and Is Actively Metabolized by Dimethylarginine Dimethylaminohydrolase. Arteriosclerosis, Thrombosis, and Vascular Biology 2003;23(8):1455-1459.

28. Sydow K, Schwedhelm E, Arakawa N, Bode-Böger SM, Tsikas D, Hornig B, Frölich JC, Böger $\mathrm{RH}$. ADMA and oxidative stress are responsible for endothelial dysfunction in hyperhomocyst(e)inemia: effects of I-arginine and B vitamins. Cardiovascular Research 2003;57(1):244-252.

29. Lüscher T, Barton M. Biology of the endothelium. Clin Cardiol 1997;20(11):Suppl II: II-3-II-10.

30. Libby P. Inflammation in atherosclerosis. Nature 2002;420(6917):868-874.

31. Wilcox JN, Subramanian RR, Sundell CL, Tracey WR, Pollock JS, Harrison DG, Marsden PA. Expression of Multiple Isoforms of Nitric Oxide Synthase in Normal and Atherosclerotic Vessels. Arteriosclerosis, Thrombosis, and Vascular Biology 1997;17(11):2479-2488.

32. Kojda G, Hüsgen B, Hacker A, Perings D, Schnaith EM, Kottenberg E, E N. Impairment of endothelium-dependent vasorelaxation in experimental atherosclerosis is dependent on gender. Cardiovasc Res 1998;37(3):738-47. 
33. Förstermann U, Mügge A, Bode SM, Frölich JC. Response of human coronary arteries to aggregating platelets: importance of endothelium-derived relaxing factor and prostanoids. Circulation Research 1988;63(2):306-312.

34. Otsuji S, Nakajima O, Waku S, Kojima S, Hosokawa H, Kinoshita I, Okubo T, Tamoto S, Takada $\mathrm{K}$, Tadashi I, Osawa N. Attenuation of acetylcholine-induced vasoconstriction by L-arginine is related to the progression of atherosclerosis. American Heart Journal 1995;129(6):1094-1100.

35. Aji W, Ravalli S, Szabolcs M, Jiang X-c, Sciacca RR, Michler RE, Cannon PJ. L-Arginine Prevents Xanthoma Development and Inhibits Atherosclerosis in LDL Receptor Knockout Mice. Circulation 1997;95(2):430-437.

36. Böger RH, Bode-Böger SM, Brandes RP, Phivthong-ngam L, Böhme M, Nafe R, Mügge A, Frölich JC. Dietary L-Arginine Reduces the Progression of Atherosclerosis in Cholesterol-Fed Rabbits. Comparison With Lovastatin 1997;96(4):1282-1290.

37. Hattori $\mathrm{Y}$, Hattori S, Wang X, Satoh H, Nakanishi N, Kasai K. Oral Administration of Tetrahydrobiopterin Slows the Progression of Atherosclerosis in Apolipoprotein E-Knockout Mice. Arteriosclerosis, Thrombosis, and Vascular Biology 2007;27(4):865-870.

38. Tiefenbacher CP, Bleeke T, Vahl C, Amann K, Vogt A, Kübler W. Endothelial Dysfunction of Coronary Resistance Arteries Is Improved by Tetrahydrobiopterin in Atherosclerosis. Circulation 2000;102(18):2172-2179.

39. Wang B-Y, Candipan RC, Arjomandi M, Hsiun PTC, Tsao PS, Cooke JP. Arginine restores nitric oxide activity and inhibits monocyte accumulation after vascular injury in hypercholesterolemic rabbits. Journal of the American College of Cardiology 1996;28(6):1573-1579.

40. Li L, Chen W, Rezvan A, Jo H, Harrison DG. Tetrahydrobiopterin Deficiency and Nitric Oxide Synthase Uncoupling Contribute to Atherosclerosis Induced by Disturbed Flow. Arteriosclerosis, Thrombosis, and Vascular Biology 2011;31(7):1547-1554.

41. Alp NJ, McAteer MA, Khoo J, Choudhury RP, Channon KM. Increased Endothelial Tetrahydrobiopterin Synthesis by Targeted Transgenic GTP-Cyclohydrolase I Overexpression Reduces Endothelial Dysfunction and Atherosclerosis in ApoE-Knockout Mice. Arteriosclerosis, Thrombosis, and Vascular Biology 2004;24(3):445-450.

42. Wohlfart P, Xu H, Endlich A, Habermeier A, Closs El, Hubschle T, Mang C, Strobel H, Suzuki T, Kleinert H, Forstermann U, Ruetten H, Li H. Antiatherosclerotic Effects of Small-Molecular-Weight Compounds Enhancing Endothelial Nitric-Oxide Synthase (eNOS) Expression and Preventing eNOS Uncoupling. Journal of Pharmacology and Experimental Therapeutics 2008;325(2):370379.

43. Ozaki M, Kawashima S, Yamashita T, Hirase T, Namiki M, Inoue N, Hirata K-i, Yasui H, Sakurai $H$, Yoshida Y, Masada M, Yokoyama M. Overexpression of endothelial nitric oxide synthase accelerates atherosclerotic lesion formation in apoE-deficient mice. The Journal of Clinical Investigation 2002;110(3):331-340.

44. Takaya T, Hirata K-i, Yamashita T, Shinohara M, Sasaki N, Inoue N, Yada T, Goto M, Fukatsu A, Hayashi T, Alp NJ, Channon KM, Yokoyama M, Kawashima S. A Specific Role for eNOS-Derived Reactive Oxygen Species in Atherosclerosis Progression. Arteriosclerosis, Thrombosis, and Vascular Biology 2007;27(7):1632-1637.

45. Jialal I, Devaraj S, Venugopal SK. C-Reactive Protein: Risk Marker or Mediator in Atherothrombosis? Hypertension 2004;44(1):6-11.

46. Paul A, Ko KWS, Li L, Yechoor V, McCrory MA, Szalai AJ, Chan L. C-Reactive Protein Accelerates the Progression of Atherosclerosis in Apolipoprotein E-Deficient Mice. Circulation 2004;109(5):647-655.

47. Venugopal SK, Devaraj S, Yuhanna I, Shaul P, Jialal I. Demonstration That C-Reactive Protein Decreases eNOS Expression and Bioactivity in Human Aortic Endothelial Cells. Circulation 2002;106(12):1439-1441. 
48. Verma S, Wang C-H, Li S-H, Dumont AS, Fedak PWM, Badiwala MV, Dhillon B, Weisel RD, Li RK, Mickle DAG, Stewart DJ. C-Reactive Protein Attenuates Nitric Oxide Production and Inhibits Angiogenesis. Circulation 2002;106(8):913-919.

49. Grad E, Golomb M, Mor-Yosef I, Koroukhov N, Lotan C, Edelman ER, Danenberg HD. Transgenic expression of human C-reactive protein suppresses endothelial nitric oxide synthase expression and bioactivity after vascular injury. American Journal of Physiology - Heart and Circulatory Physiology 2007;293(1):H489-H495.

50. Mineo C, Gormley AK, Yuhanna IS, Osborne-Lawrence S, Gibson LL, Hahner L, Shohet RV, Black S, Salmon JE, Samols D, Karp DR, Thomas GD, Shaul PW. FcyRIIB Mediates C-Reactive Protein Inhibition of Endothelial NO Synthase. Circulation Research 2005;97(11):1124-1131.

51. Schwartz R, Osborne-Lawrence S, Hahner L, Gibson LL, Gormley AK, Vongpatanasin W, Zhu W, Word RA, Seetharam D, Black S, Samols D, Mineo C, Shaul PW. C-Reactive Protein Downregulates Endothelial NO Synthase and Attenuates Reendothelialization In Vivo in Mice. Circulation Research 2007;100(10):1452-1459.

52. Singh U, Devaraj S, Vasquez-Vivar J, Jialal I. C -Reactive Protein Decreases Endothelial Nitric Oxide Synthase Activity via Uncoupling. Journal of molecular and cellular cardiology 2007;43(6):780-791.

53. Rubbo H, Trostchansky A, Botti H, Batthyány C. Interactions of Nitric Oxide and Peroxynitrite with Low-Density Lipoprotein. In. Biological Chemistry; 2002, 547.

54. Davignon J, Ganz P. Role of Endothelial Dysfunction in Atherosclerosis. Circulation 2004;109(23 suppl 1):III-27-III-32.

55. Victor MV, Milagros R, Eva S, Celia B, Katherine G-M, Antonio Hernandez M. Oxidative Stress, Endothelial Dysfunction and Atherosclerosis. Current Pharmaceutical Design 2009;15(26):29883002.

56. Steinberg D, Parthasarathy S, Carew TE, Khoo JC, Witztum JL. Beyond Cholesterol. New England Journal of Medicine 1989;320(14):915-924.

57. Steinberg D, Witztum JL. Is the Oxidative Modification Hypothesis Relevant to Human Atherosclerosis? Do the Antioxidant Trials Conducted to Date Refute the Hypothesis? 2002;105(17):2107-2111.

58. Rueckschloss U, Galle J, Holtz J, Zerkowski H-R, Morawietz H. Induction of NAD(P)H Oxidase by Oxidized Low-Density Lipoprotein in Human Endothelial Cells. Antioxidative Potential of Hydroxymethylglutaryl Coenzyme A Reductase Inhibitor Therapy 2001;104(15):1767-1772.

59. Kinlay S, Libby P, Ganz P. Endothelial function and coronary artery disease. Current Opinion in Lipidology 2001;12(4):383-389.

60. Chavakis E, Dernbach E, Hermann C, Mondorf UF, Zeiher AM, Dimmeler S. Oxidized LDL Inhibits Vascular Endothelial Growth Factor-Induced Endothelial Cell Migration by an Inhibitory Effect on the Akt/Endothelial Nitric Oxide Synthase Pathway. Circulation 2001;103(16):21022107.

61. Dimmeler S, Fleming I, Fisslthaler B, Hermann C, Busse R, Zeiher AM. Activation of nitric oxide synthase in endothelial cells by Akt-dependent phosphorylation. Nature 1999;399(6736):601-605.

62. Fulton D, Gratton J-P, McCabe TJ, Fontana J, Fujio Y, Walsh K, Franke TF, Papapetropoulos A, Sessa WC. Regulation of endothelium-derived nitric oxide production by the protein kinase Akt. Nature 1999;399(6736):597-601.

63. Boyle JJ, Weissberg PL, Bennett MR. Human Macrophage-Induced Vascular Smooth Muscle Cell Apoptosis Requires NO Enhancement of Fas/Fas-L Interactions. Arteriosclerosis, Thrombosis, and Vascular Biology 2002;22(10):1624-1630.

64. Kuhlencordt PJ, Chen J, Han F, Astern J, Huang PL. Genetic Deficiency of Inducible Nitric Oxide Synthase Reduces Atherosclerosis and Lowers Plasma Lipid Peroxides in Apolipoprotein EKnockout Mice. Circulation 2001;103(25):3099-3104. 
65. Kuhlencordt PJ, Hötten S, Schödel J, Rützel S, Hu K, Widder J, Marx A, Huang PL, Ertl G. Atheroprotective Effects of Neuronal Nitric Oxide Synthase in Apolipoprotein E Knockout Mice. Arteriosclerosis, Thrombosis, and Vascular Biology 2006;26(7):1539-1544.

66. Tsutsui M. Neuronal Nitric Oxide Synthase as a Novel Anti-Atherogenic Factor. Journal of Atherosclerosis and Thrombosis 2004;11(2):41-48.

67. Seddon MD, Chowienczyk PJ, Brett SE, Casadei B, Shah AM. Neuronal Nitric Oxide Synthase Regulates Basal Microvascular Tone in Humans In Vivo. Circulation 2008;117(15):1991-1996.

68. Vanhoutte PM, Shimokawa H, Tang EHC, Feletou M. Endothelial dysfunction and vascular disease. Acta Physiologica 2009;196(2):193-222.

69. Kersten JR, Toller WG, Tessmer JP, Pagel PS, Warltier DC. Hyperglycemia reduces coronary collateral blood flow through a nitric oxide-mediated mechanism. American Journal of Physiology - Heart and Circulatory Physiology 2001;281(5):H2097-H2104.

70. Hirata K-i, Kuroda R, Sakoda T, Katayama M, Inoue N, Suematsu M, Kawashima S, Yokoyama M. Inhibition of Endothelial Nitric Oxide Synthase Activity by Protein Kinase C. Hypertension 1995;25(2):180-185.

71. Li H, Oehrlein SA, Wallerath T, Ihrig-Biedert I, Wohlfart $\mathrm{P}$, Ulshöfer $\mathrm{T}$, Jessen $\mathrm{T}$, Herget $\mathrm{T}$, Förstermann U, Kleinert H. Activation of Protein Kinase Ca and/or $\varepsilon$ Enhances Transcription of the Human Endothelial Nitric Oxide Synthase Gene. Molecular Pharmacology 1998;53(4):630637.

72. Cosentino F, Hishikawa K, Katusic ZS, Lüscher TF. High Glucose Increases Nitric Oxide Synthase Expression and Superoxide Anion Generation in Human Aortic Endothelial Cells. Circulation 1997;96(1):25-28.

73. Kossenjans W, Eis A, Sahay R, Brockman D, Myatt L. Role of peroxynitrite in altered fetalplacental vascular reactivity in diabetes or preeclampsia. American Journal of Physiology - Heart and Circulatory Physiology 2000;278(4):H1311-H1319.

74. Milstien S, Katusic Z. Oxidation of Tetrahydrobiopterin by Peroxynitrite: Implications for Vascular Endothelial Function. Biochemical and Biophysical Research Communications 1999;263(3):681684.

75. Montagnani M, Chen H, Barr VA, Quon MJ. Insulin-stimulated Activation of eNOS Is Independent of $\mathrm{Ca} 2+$ but Requires Phosphorylation by Akt at Ser1179. Journal of Biological Chemistry 2001;276(32):30392-30398.

76. Shinozaki K, Kashiwagi A, Nishio Y, Okamura T, Yoshida Y, Masada M, Toda N, Kikkawa R Abnormal biopterin metabolism is a major cause of impaired endothelium-dependent relaxation through nitric oxide/O2- imbalance in insulin-resistant rat aorta. Diabetes 1999;48(12):2437-2445.

77. Kapur S, Bédard S, Marcotte B, Côté CH, Marette A. Expression of Nitric Oxide Synthase in Skeletal Muscle: A Novel Role for Nitric Oxide as a Modulator of Insulin Action. Diabetes 1997;46(11):1691-1700.

78. Shah V, Haddad FG, Garcia-Cardena G, Frangos JA, Mennone A, Groszmann RJ, Sessa WC. Liver sinusoidal endothelial cells are responsible for nitric oxide modulation of resistance in the hepatic sinusoids. Journal of Clinical Investigation 1997;100(11):2923-2930.

79. Duplain H, Burcelin R, Sartori C, Cook S, Egli M, Lepori M, Vollenweider P, Pedrazzini T, Nicod $\mathrm{P}$, Thorens B, Scherrer U. Insulin Resistance, Hyperlipidemia, and Hypertension in Mice Lacking Endothelial Nitric Oxide Synthase. Circulation 2001;104(3):342-345.

80. Shankar RR, Wu Y, Shen HQ, Zhu JS, Baron AD. Mice with gene disruption of both endothelial and neuronal nitric oxide synthase exhibit insulin resistance. Diabetes 2000;49(5):684-687.

81. Stühlinger MC, Abbasi F, Chu JW, et al. Relationship between insulin resistance and an endogenous nitric oxide synthase inhibitor. JAMA 2002;287(11):1420-1426.

82. Vincent MA, Barrett EJ, Lindner JR, Clark MG, Rattigan S. Inhibiting NOS blocks microvascular recruitment and blunts muscle glucose uptake in response to insulin. American Journal of Physiology - Endocrinology And Metabolism 2003;285(1):E123-E129. 
83. Lund DD, Faraci FM, Miller FJ, Heistad DD. Gene Transfer of Endothelial Nitric Oxide Synthase Improves Relaxation of Carotid Arteries From Diabetic Rabbits. Circulation 2000;101(9):10271033.

84. Oak J-H, Cai H. Attenuation of Angiotensin II Signaling Recouples eNOS and Inhibits Nonendothelial NOX Activity in Diabetic Mice. Diabetes 2007;56(1):118-126.

85. Lin KY, Ito A, Asagami T, Tsao PS, Adimoolam S, Kimoto M, Tsuji H, Reaven GM, Cooke JP. Impaired Nitric Oxide Synthase Pathway in Diabetes Mellitus. Role of Asymmetric Dimethylarginine and Dimethylarginine Dimethylaminohydrolase 2002;106(8):987-992.

86. Leo $\mathrm{CH}$, Hart JL, Woodman OL. Impairment of both nitric oxide-mediated and EDHF-type relaxation in small mesenteric arteries from rats with streptozotocin-induced diabetes. British Journal of Pharmacology 2011;162(2):365-377.

87. Lam TY, Seto SW, Lau YM, Au LS, Kwan YW, Ngai SM, Tsui KW. Impairment of the vascular relaxation and differential expression of caveolin-1 of the aorta of diabetic $+\mathrm{db} /+\mathrm{db}$ mice. European Journal of Pharmacology 2006;546(1):134-141.

88. Elçioğlu KH, Kabasakal L, Çetinel Ş, Conturk G, Sezen SF, Ayanoğlu-Dülger G. Changes in caveolin-1 expression and vasoreactivity in the aorta and corpus cavernosum of fructose and streptozotocin-induced diabetic rats. European Journal of Pharmacology 2010;642(1):113-120.

89. Jo H, Otani H, Jo F, Shimazu T, Okazaki T, Yoshioka K, Fujita M, Kosaki A, Iwasaka T. Inhibition of nitric oxide synthase uncoupling by sepiapterin improves left ventricular function in streptozotocin-induced diabetic mice. Clinical and Experimental Pharmacology and Physiology 2011;38(8):485-493.

90. Gong L, Liu F-q, Wang J, Wang X-p, Hou X-g, Sun Y, Qin W-d, Wei S-j, Zhang Y, Chen L, Zhang $M-X$. Hyperglycemia induces apoptosis of pancreatic islet endothelial cells via reactive nitrogen species-mediated Jun N-terminal kinase activation. Biochimica et Biophysica Acta (BBA) Molecular Cell Research 2011;1813(6):1211-1219.

91. Yang $\mathrm{P}, \mathrm{CaO} \mathrm{Y}, \mathrm{Li} \mathrm{H}$. Hyperglycemia induces iNOS gene expression and consequent nitrosative stress via JNK activation. American journal of obstetrics and gynecology 2010;203(2):185.e5185.e11.

92. Harrison DG, Gongora MC, Guzik TJ, Widder J. Oxidative stress and hypertension. Journal of the American Society of Hypertension 2007;1(1):30-44.

93. Mehta PK, Griendling KK. Angiotensin II cell signaling: physiological and pathological effects in the cardiovascular system. American Journal of Physiology - Cell Physiology 2007;292(1):C82C97.

94. Leonard AM, Chafe LL, Montani J-P, Van Vliet BN. Increased Salt-Sensitivity in Endothelial Nitric Oxide Synthase-Knockout Mice*. American Journal of Hypertension 2006;19(12):1264-1269.

95. Moens AL, Takimoto E, Tocchetti CG, Chakir K, Bedja D, Cormaci G, Ketner EA, Majmudar M, Gabrielson K, Halushka MK, Mitchell JB, Biswal S, Channon KM, Wolin MS, Alp NJ, Paolocci N, Champion HC, Kass DA. Reversal of Cardiac Hypertrophy and Fibrosis From Pressure Overload by Tetrahydrobiopterin: Efficacy of Recoupling Nitric Oxide Synthase as a Therapeutic Strategy. Circulation 2008;117(20):2626-2636.

96. Mattson DL, Maeda CY, Bachman TD, Cowley AW. Inducible Nitric Oxide Synthase and Blood Pressure. Hypertension 1998;31(1):15-20.

97. Rudd MA, Trolliet M, Hope S, Scribner AW, Daumerie G, Toolan G, Cloutier T, Loscalzo J. Saltinduced hypertension in Dahl salt-resistant and salt-sensitive rats with NOS II inhibition. American Journal of Physiology - Heart and Circulatory Physiology 1999;277(2):H732-H739.

98. Tan DY, Meng S, Cason GW, Manning RD. Mechanisms of salt-sensitive hypertension: role of inducible nitric oxide synthase. American Journal of Physiology - Regulatory, Integrative and Comparative Physiology 2000;279(6):R2297-R2303.

99. Toda N, Ayajiki K, Okamura T. Cerebral Blood Flow Regulation by Nitric Oxide: Recent Advances. Pharmacological Reviews 2009;61(1):62-97. 
100. Toda N, Ayajiki K, Okamura T. Control of systemic and pulmonary blood pressure by nitric oxide formed through neuronal nitric oxide synthase. Journal of Hypertension 2009;27(10):1929-1940.

101. Silberman GA, Fan T-HM, Liu H, Jiao Z, Xiao HD, Lovelock JD, Boulden BM, Widder J, Fredd S, Bernstein KE, Wolska BM, Dikalov S, Harrison DG, Dudley SC. Uncoupled Cardiac Nitric Oxide Synthase Mediates Diastolic Dysfunction. Circulation 2010;121(4):519-528.

102. Edirisinghe I, Yang S-R, Yao H, Rajendrasozhan S, Caito S, Adenuga D, Wong C, Rahman A, Phipps RP, Jin Z-G, Rahman I. VEGFR-2 inhibition augments cigarette smoke-induced oxidative stress and inflammatory responses leading to endothelial dysfunction. The FASEB Journal 2008;22(7):2297-2310.

103. Su Y, Cao W, Han Z, Block ER. Cigarette smoke extract inhibits angiogenesis of pulmonary artery endothelial cells: the role of calpain. American Journal of Physiology - Lung Cellular and Molecular Physiology 2004;287(4):L794-L800.

104. Edirisinghe I, Rahman I. Cigarette smoke-mediated oxidative stress, shear stress, and endothelial dysfunction: role of VEGFR2. Annals of the New York Academy of Sciences 2010;1203(1):66-72.

105. Heitzer T, Brockhoff C, Mayer B, Warnholtz A, Mollnau H, Henne S, Meinertz T, Münzel T. Tetrahydrobiopterin Improves Endothelium-Dependent Vasodilation in Chronic Smokers. Evidence for a Dysfunctional Nitric Oxide Synthase 2000;86(2):e36-e41.

106. Wright JL, Tai H, Dai J, A C. Cigarette smoke induces rapid changes in gene expression in pulmonary arteries. Lab Invest 2002;82(10):1391-8.

107. Lowe ER, Everett AC, Lee AJ, Lau M, Dunbar AY, Berka V, Tsai A-I, Osawa Y. Time-dependent inhibition and tetrahydrobiopterin depletion of endothelial nitric-oxide synthase caused by cigarettes. Drug Metabolism and Disposition 2005;33(1):131-138.

108. Xie Y, Garban H, Ng C, Rajfer J, Gonzalez-Cadavid NF. Effect of Long-term Passive Smoking on Erectile Function and Penile Nitric Oxide Synthase in the Rat. The Journal of Urology 1997;157(3):1121-1126.

109. Christen WG, Ajani UA, Glynn RJ, Hennekens $\mathrm{CH}$. Blood levels of homocysteine and increased risks of cardiovascular disease: Causal or casual? Archives of Internal Medicine 2000;160(4):422434.

110. Ebbesen LS, Christiansen K, Ingerslev J. Hyperhomocysteinemia Due to Folate Deficiency Is Thrombogenic in Rats. The Journal of Nutrition 2003;133(7):2250-2255.

111. Nishinaga M, Ozawa T, Shimada K. Homocysteine, a thrombogenic agent, suppresses anticoagulant heparan sulfate expression in cultured porcine aortic endothelial cells. Journal of Clinical Investigation 1993;92(3):1381-1386.

112. Tyagi N, Sedoris KC, Steed M, Ovechkin AV, Moshal KS, Tyagi SC. Mechanisms of homocysteine-induced oxidative stress. American Journal of Physiology - Heart and Circulatory Physiology 2005;289(6):H2649-H2656.

113. Weiss N, Heydrick Stanley J, Postea O, Keller C, Keaney John F, Loscalzo J. Influence of Hyperhomocysteinemia on the Cellular Redox State - Impact on Homocysteine-Induced Endothelial Dysfunction. In. Clinical Chemistry and Laboratory Medicine; 2003, 1455.

114. Hofmann MA, Lalla E, Lu Y, Gleason MR, Wolf BM, Tanji N, Ferran LJ, Kohl B, Rao V, Kisiel W, Stern DM, Schmidt AM. Hyperhomocysteinemia enhances vascular inflammation and accelerates atherosclerosis in a murine model. Journal of Clinical Investigation 2001;107(6):675-683.

115. Topal G, Brunet A, Millanvoye E, Boucher J-L, Rendu F, Devynck M-A, David-Dufilho M. Homocysteine induces oxidative stress by uncoupling of no synthase activity through reduction of tetrahydrobiopterin. Free Radical Biology and Medicine 2004;36(12):1532-1541.

116. Doshi SN, McDowell IFW, Moat SJ, Lang D, Newcombe RG, Kredan MB, Lewis MJ, Goodfellow J. Folate Improves Endothelial Function in Coronary Artery Disease. An Effect Mediated by Reduction of Intracellular Superoxide? 2001;21(7):1196-1202.

117. Jin L, Caldwell RB, Li-Masters T, RW. C. Homocysteine induces endothelial dysfunction via inhibition of arginine transport. J Physiol Pharmacol 2007;58(2):191-206. 
118. Dhillon B, Badiwala MV, Maitland A, Rao V, Li S-H, Verma S. Tetrahydrobiopterin attenuates homocysteine induced endothelial dysfunction. Molecular and Cellular Biochemistry 2003;247(1):223-227.

119. He L, Zeng H, Li F, Feng J, Liu S, Liu J, Yu J, Mao J, Hong T, Chen AF, Wang X, Wang G. Homocysteine impairs coronary artery endothelial function by inhibiting tetrahydrobiopterin in patients with hyperhomocysteinemia. American Journal of Physiology - Endocrinology And Metabolism 2010;299(6):E1061-E1065.

120. Kietadisorn R, Kietselaer BL, Schmidt HHHW, Moens AL. Role of tetrahydrobiopterin (BH4) in hyperhomocysteinemia-induced endothelial dysfuction: new indication for this orphan-drug? American Journal of Physiology - Endocrinology And Metabolism 2011;300(6):E1176-E1176.

121. Stühlinger MC, Tsao PS, Her J-H, Kimoto M, Balint RF, Cooke JP. Homocysteine Impairs the Nitric Oxide Synthase Pathway. Role of Asymmetric Dimethylarginine 2001;104(21):2569-2575.

122. Antoniades C, Shirodaria C, Leeson P, Antonopoulos A, Warrick N, Van-Assche T, Cunnington C, Tousoulis D, Pillai R, Ratnatunga C, Stefanadis C, Channon KM. Association of plasma asymmetrical dimethylarginine (ADMA) with elevated vascular superoxide production and endothelial nitric oxide synthase uncoupling: implications for endothelial function in human atherosclerosis. European Heart Journal 2009;30(9):1142-1150.

123. Lemarié CA, Shbat L, Marchesi C, Angulo OJ, Deschênes M-E, Blostein MD, Paradis P, Schiffrin EL. Mthfr deficiency induces endothelial progenitor cell senescence via uncoupling of eNOS and downregulation of SIRT1. American Journal of Physiology - Heart and Circulatory Physiology 2011;300(3):H745-H753.

124. Ota H, Akishita M, Eto M, lijima K, Kaneki M, Ouchi Y. Sirt1 modulates premature senescencelike phenotype in human endothelial cells. Journal of Molecular and Cellular Cardiology 2007;43(5):571-579.

125. Mattagajasingh I, Kim C-S, Naqvi A, Yamamori T, Hoffman TA, Jung S-B, DeRicco J, Kasuno K, Irani K. SIRT1 promotes endothelium-dependent vascular relaxation by activating endothelial nitric oxide synthase. Proceedings of the National Academy of Sciences 2007;104(37):1485514860.

126. Welch GN UGJ, Farivar RS, Pigazzi A, Vu K, Brecher P, Keaney JF Jr, Loscalzo J. Homocysteine-induced nitric oxide production in vascular smooth-muscle cells by NF-kappa Bdependent transcriptional activation of Nos2. Proc Assoc Am Physicians 1998;110(1):22-31.

127. Steed MM, Tyagi N, Sen U, Schuschke DA, Joshua IG, Tyagi SC. Functional consequences of the collagen/elastin switch in vascular remodeling in hyperhomocysteinemic wild-type, eNOS-/-, and iNOS-/- mice. American Journal of Physiology - Lung Cellular and Molecular Physiology 2010;299(3):L301-L311.

128. Szocs K. Endothelial dysfunction and reactive oxygen species production in ischemia/reperfusion and nitrate tolerance. Gen Physiol Biophys 2004;23(3):265-95.

129. Bertuglia S, Giusti A. Microvascular oxygenation, oxidative stress, NO suppression and superoxide dismutase during postischemic reperfusion. American Journal of Physiology - Heart and Circulatory Physiology 2003;285(3):H1064-H1071.

130. Büttemeyer R, Philipp AW, Mall JW, Ge B, Scheller FW, Lisdat F. In vivo measurement of oxygen-derived free radicals during reperfusion injury. Microsurgery 2002;22(3):108-113.

131. Kim KS, Takeda K, Sethi R, Pracyk JB, Tanaka K, Zhou YF, Yu ZX, Ferrans VJ, Bruder JT, Kovesdi I, Irani K, Goldschmidt-Clermont P, Finkel T. Protection from reoxygenation injury by inhibition of rac1. Journal of Clinical Investigation 1998;101(9):1821-1826.

132. Hayward R, Lefer AM. Time course of endothelial-neutrophil interaction in splanchnic artery ischemia-reperfusion. American Journal of Physiology - Heart and Circulatory Physiology 1998;275(6):H2080-H2086.

133. Tsao PS, Aoki N, Lefer DJ, Johnson G, Lefer AM. Time course of endothelial dysfunction and myocardial injury during myocardial ischemia and reperfusion in the cat. Circulation 1990;82(4):1402-1412. 
134. Tiefenbacher CP, Chilian WM, Mitchell M, DeFily DV. Restoration of Endothelium-Dependent Vasodilation After Reperfusion Injury by Tetrahydrobiopterin. Circulation 1996;94(6):1423-1429.

135. Chen Q, Camara AKS, Stowe DF, Hoppel CL, Lesnefsky EJ. Modulation of electron transport protects cardiac mitochondria and decreases myocardial injury during ischemia and reperfusion. American Journal of Physiology - Cell Physiology 2007;292(1):C137-C147.

136. Adkins WK, Taylor AE. Role of xanthine oxidase and neutrophils in ischemia-reperfusion injury in rabbit lung. Journal of Applied Physiology 1990;69(6):2012-2018.

137. Fisher AB. Reactive Oxygen Species and Cell Signaling in Lung Ischemia. In: Bhattacharya J, ed. Cell Signaling in Vascular Inflammation. Totowa, NJ: Humana Press; 2005, p 125-135.

138. Wickersham NE, Johnson JJ, Meyrick BO, Gilroy RJ, Loyd JE. Lung ischemia-reperfusion injury in awake sheep: protection with verapamil. Journal of Applied Physiology 1991;71(4):1554-1562.

139. Moens AL, Kass DA. Tetrahydrobiopterin and Cardiovascular Disease. Arteriosclerosis, Thrombosis, and Vascular Biology 2006;26(11):2439-2444.

140. Hallström S, Gasser H, Neumayer C, Fügl A, Nanobashvili J, Jakubowski A, Huk I, Schlag G, Malinski T. S-Nitroso Human Serum Albumin Treatment Reduces Ischemia/Reperfusion Injury in Skeletal Muscle via Nitric Oxide Release. Circulation 2002;105(25):3032-3038.

141. Huk I, Nanobashvili J, Neumayer C, Punz A, Mueller M, Afkhampour K, Mittlboeck M, Losert U, Polterauer P, Roth E, Patton S, Malinski T. I-Arginine Treatment Alters the Kinetics of Nitric Oxide and Superoxide Release and Reduces Ischemia/Reperfusion Injury in Skeletal Muscle. Circulation 1997;96(2):667-675.

142. Dumitrescu C, Biondi R, Xia Y, Cardounel AJ, Druhan LJ, Ambrosio G, Zweier JL. Myocardial ischemia results in tetrahydrobiopterin $(\mathrm{BH}(4))$ oxidation with impaired endothelial function ameliorated by $\mathrm{BH}(4)$. Proceedings of the National Academy of Sciences of the United States of America 2007;104(38):15081-15086.

143. Verma S, Maitland A, Weisel RD, Fedak PWM, Pomroy NC, Li S-H, Mickle DAG, Li R-K, Rao V. Novel cardioprotective effects of tetrahydrobiopterin after anoxia and reoxygenation: Identifying cellular targets for pharmacologic manipulation. The Journal of Thoracic and Cardiovascular Surgery 2002;123(6):1074-1083.

144. Chen Q, Kim EEJ, Elio K, Zambrano C, Krass S, Teng JC-w, Kay H, Perkins K-A, Pershad S, McGraw S, Emrich J, Adams JS, Young LH. The Role of Tetrahydrobiopterin and Dihydrobiopterin in Ischemia/Reperfusion Injury When Given at Reperfusion. Advances in Pharmacological Sciences 2010;2010:11.

145. Kupatt C, Dessy C, Hinkel R, Raake P, Daneau G, Bouzin C, Boekstegers P, Feron O. Heat Shock Protein 90 Transfection Reduces Ischemia-Reperfusion-Induced Myocardial Dysfunction via Reciprocal Endothelial NO Synthase Serine 1177 Phosphorylation and Threonine 495 Dephosphorylation. Arteriosclerosis, Thrombosis, and Vascular Biology 2004;24(8):1435-1441.

146. Minamino T, Kitakaze M, Sato H, Asanuma H, Funaya H, Koretsune Y, Hori M. Plasma Levels of Nitrite/Nitrate and Platelet cGMP Levels Are Decreased in Patients With Atrial Fibrillation. Arteriosclerosis, Thrombosis, and Vascular Biology 1997;17(11):3191-3195.

147. Takahashi N, Ishibashi $\mathrm{Y}$, Shimada T, Sakane T, Ohata S, Sugamori T, Ohta Y, Inoue S-i, Nakamura K, Shimizu H, Katoh H, Sano K, Murakami Y, Hashimoto M. Atrial fibrillation impairs endothelial function of forearm vessels in humans. Journal of Cardiac Failure 2001;7(1):45-54.

148. Cai H, Li Z, Goette A, Mera F, Honeycutt C, Feterik K, Wilcox JN, Dudley SC, Harrison DG, Langberg JJ. Downregulation of Endocardial Nitric Oxide Synthase Expression and Nitric Oxide Production in Atrial Fibrillation. Potential Mechanisms for Atrial Thrombosis and Stroke 2002;106(22):2854-2858.

149. Noris M, Morigi M, Donadelli R, Aiello S, Foppolo M, Todeschini M, Orisio S, Remuzzi G, Remuzzi A. Nitric Oxide Synthesis by Cultured Endothelial Cells Is Modulated by Flow Conditions. Circulation Research 1995;76(4):536-543.

150. Vallance $P$, Chan $N$. Endothelial function and nitric oxide: clinical relevance. Heart $2001 ; 85(3): 342-350$. 
151. Goette A, Hammwöhner M, Bukowska A, Scalera F, Martens-Lobenhoffer J, Dobrev D, Ravens U, Weinert S, Medunjanin S, Lendeckel U, Bode-Böger SM. The impact of rapid atrial pacing on ADMA and endothelial NOS. International Journal of Cardiology 2012;154(2):141-146.

152. Bukowska A, Röcken C, Erxleben M, Röhl F-W, Hammwöhner M, Huth C, Ebert MPA, Lendeckel $\mathrm{U}$, Goette A. Atrial expression of endothelial nitric oxide synthase in patients with and without atrial fibrillation. Cardiovascular Pathology 2010;19(3):e51-e60.

153. Han W, Fu S, Wei N, Xie B, Li W, Yang S, Li Y, Liang Z, Huo H. Nitric oxide overproduction derived from inducible nitric oxide synthase increases cardiomyocyte apoptosis in human atrial fibrillation. International Journal of Cardiology 2008;130(2):165-173.

154. Nishijima Y, Sridhar A, Bonilla I, Velayutham M, Khan M, Terentyeva R, Li C, Kuppusamy P, Elton TS, Terentyev D, Györke S, Zweier JL, Cardounel AJ, Carnes CA. Tetrahydrobiopterin depletion and NOS2 uncoupling contribute to heart failure-induced alterations in atrial electrophysiology. Cardiovascular Research 2011;91(1):71-79.

155. Crijns HJ, Schotten U, Moens AL. Is NOS uncoupling the missing link between atrial fibrillation and chronic non-ischaemic cardiomyopathy? Cardiovascular Research 2011;91(3):556-556.

156. Hamed S, Brenner B, Roguin A. Nitric oxide: a key factor behind the dysfunctionality of endothelial progenitor cells in diabetes mellitus type-2. Cardiovascular Research 2011;91(1):9-15.

157. Kim YM, Guzik TJ, Zhang YH, Zhang MH, Kattach H, Ratnatunga C, Pillai R, Channon KM, Casadei B. A Myocardial Nox2 Containing NAD(P)H Oxidase Contributes to Oxidative Stress in Human Atrial Fibrillation. Circulation Research 2005;97(7):629-636.

158. Reilly SN, Jayaram R, Nahar K, Antoniades C, Verheule S, Channon KM, Alp NJ, Schotten U, Casadei B. Atrial Sources of Reactive Oxygen Species Vary With the Duration and Substrate of Atrial Fibrillation. Implications for the Antiarrhythmic Effect of Statins 2011;124(10):1107-1117.

159. Vasa M, Fichtlscherer S, Aicher A, Adler K, Urbich C, Martin H, Zeiher AM, Dimmeler S. Number and Migratory Activity of Circulating Endothelial Progenitor Cells Inversely Correlate With Risk Factors for Coronary Artery Disease. Circulation Research 2001;89(1):e1-e7.

160. Fleissner F, Thum T. Critical Role of the Nitric Oxide/Reactive Oxygen Species Balance in Endothelial Progenitor Dysfunction. Antioxidants \& Redox Signaling 2011;15(4):933-948.

161. Dimmeler S, Zeiher AM. Vascular repair by circulating endothelial progenitor cells: the missing link in atherosclerosis? Journal of Molecular Medicine 2004;82(10):671-677.

162. Schroeter MR, Leifheit M, Sudholt P, Heida N-M, Dellas C, Rohm I, Alves F, Zientkowska M, Rafail S, Puls M, Hasenfuss G, Konstantinides S, Schäfer K. Leptin Enhances the Recruitment of Endothelial Progenitor Cells Into Neointimal Lesions After Vascular Injury by Promoting IntegrinMediated Adhesion. Circulation Research 2008;103(5):536-544.

163. Walter DH, Rittig K, Bahlmann FH, Kirchmair R, Silver M, Murayama T, Nishimura H, Losordo DW, Asahara T, Isner JM. Statin Therapy Accelerates Reendothelialization. A Novel Effect Involving Mobilization and Incorporation of Bone Marrow-Derived Endothelial Progenitor Cells 2002;105(25):3017-3024.

164. Loomans CJM, de Koning EJP, Staal FJT, Rookmaaker MB, Verseyden C, de Boer HC, Verhaar MC, Braam B, Rabelink TJ, van Zonneveld A-J. Endothelial Progenitor Cell Dysfunction. A Novel Concept in the Pathogenesis of Vascular Complications of Type 1 Diabetes 2004;53(1):195-199.

165. Michowitz Y, Goldstein E, Wexler D, Sheps D, Keren G, George J. Circulating endothelial progenitor cells and clinical outcome in patients with congestive heart failure. Heart 2007;93(9):1046-1050.

166. Thum T, Bauersachs J. Spotlight on endothelial progenitor cell inhibitors: short review. Vascular Medicine 2005;10(2_suppl):S59-S64.

167. d'Uscio LV, Smith LA, Santhanam AV, Richardson D, Nath KA, Katusic ZS. Essential Role of Endothelial Nitric Oxide Synthase in Vascular Effects of Erythropoietin. Hypertension 2007;49(5):1142-1148.

168. Iwakura A, Luedemann C, Shastry S, Hanley A, Kearney M, Aikawa R, Isner JM, Asahara T, Losordo DW. Estrogen-Mediated, Endothelial Nitric Oxide Synthase-Dependent Mobilization of 
Bone Marrow-Derived Endothelial Progenitor Cells Contributes to Reendothelialization After Arterial Injury. Circulation 2003;108(25):3115-3121.

169. Landmesser U, Engberding N, Bahlmann FH, Schaefer A, Wiencke A, Heineke A, Spiekermann S, Hilfiker-Kleiner D, Templin C, Kotlarz D, Mueller M, Fuchs M, Hornig B, Haller H, Drexler H. Statin-Induced Improvement of Endothelial Progenitor Cell Mobilization, Myocardial Neovascularization, Left Ventricular Function, and Survival After Experimental Myocardial Infarction Requires Endothelial Nitric Oxide Synthase. Circulation 2004;110(14):1933-1939.

170. Urao N, Okigaki M, Yamada H, Aadachi Y, Matsuno K, Matsui A, Matsunaga S, Tateishi K, Nomura T, Takahashi T, Tatsumi T, Matsubara H. Erythropoietin-Mobilized Endothelial Progenitors Enhance Reendothelialization via Akt-Endothelial Nitric Oxide Synthase Activation and Prevent Neointimal Hyperplasia. Circulation Research 2006;98(11):1405-1413.

171. Ma FX, Zhou B, Chen Z, Ren Q, Lu SH, Sawamura T, Han ZC. Oxidized low density lipoprotein impairs endothelial progenitor cells by regulation of endothelial nitric oxide synthase. Journal of Lipid Research 2006;47(6):1227-1237.

172. Verma S, Kuliszewski MA, Li S-H, Szmitko PE, Zucco L, Wang C-H, Badiwala MV, Mickle DAG, Weisel RD, Fedak PWM, Stewart DJ, Kutryk MJB. C-Reactive Protein Attenuates Endothelial Progenitor Cell Survival, Differentiation, and Function. Further Evidence of a Mechanistic Link Between C-Reactive Protein and Cardiovascular Disease 2004;109(17):2058-2067.

173. Morello F, Perino A, Hirsch E. Phosphoinositide 3-kinase signalling in the vascular system. Cardiovascular Research 2009;82(2):261-271.

174. Aicher A, Heeschen C, Mildner-Rihm C, Urbich C, Ihling C, Technau-Ihling K, Zeiher AM, Dimmeler S. Essential role of endothelial nitric oxide synthase for mobilization of stem and progenitor cells. Nat Med 2003;9(11):1370-1376.

175. Lekakis J, Abraham P, Balbarini A, Blann A, Boulanger CM, Cockcroft J, Cosentino F, Deanfield J, Gallino A, Ikonomidis I, Kremastinos D, Landmesser U, Protogerou A, Stefanadis C, Tousoulis D, Vassalli G, Vink H, Werner N, Wilkinson I, Vlachopoulos C. Methods for evaluating endothelial function: a position statement from the European Society of Cardiology Working Group on Peripheral Circulation. European Journal of Cardiovascular Prevention \& Rehabilitation 2011;18(6):775-789.

176. Anderson EA, Mark AL. Flow-mediated and reflex changes in large peripheral artery tone in humans. Circulation 1989;79(1):93-100.

177. Pohl U, Holtz J, Busse R, Bassenge E. Crucial role of endothelium in the vasodilator response to increased flow in vivo. Hypertension 1986;8(1):37-44.

178. Moens AL, Goovaerts I, Claeys MJ, Vrints CJ. Flow-Mediated Vasodilation. CHEST 2005;127(6):2254-2263.

179. Husmann L, Gaemperli O, Schepis T, Scheffel H, Valenta I, Hoefflinghaus T, Stolzmann P, Desbiolles L, Herzog BA, Leschka S, Marincek B, Alkadhi H, Kaufmann PA. Accuracy of quantitative coronary angiography with computed tomography and its dependency on plaque composition. The International Journal of Cardiovascular Imaging 2008;24(8):895-904.

180. Terashima M, Nguyen PK, Rubin GD, Iribarren C, Courtney BK, Go AS, Fortmann SP, McConnell MV. Impaired Coronary Vasodilation by Magnetic Resonance Angiography Is Associated With Advanced Coronary Artery Calcification. JACC: Cardiovascular Imaging 2008;1(2):167-173.

181. Sydow K, Münzel T. ADMA and oxidative stress. Atherosclerosis Supplements 2003;4(4):41-51.

182. Gao YT, Roman LJ, Martásek P, Panda SP, Ishimura Y, Masters BSS. Oxygen Metabolism by Endothelial Nitric-oxide Synthase. Journal of Biological Chemistry 2007;282(39):28557-28565.

183. Berka V, Wu G, Yeh H-C, Palmer G, Tsai A-I. Three Different Oxygen-induced Radical Species in Endothelial Nitric-oxide Synthase Oxygenase Domain under Regulation by L-Arginine and Tetrahydrobiopterin. Journal of Biological Chemistry 2004;279(31):32243-32251.

184. Bode-Böger SM, Scalera F, Ignarro LJ. The I-arginine paradox: Importance of the Iarginine/asymmetrical dimethylarginine ratio. Pharmacology \& Therapeutics 2007;114(3):295306. 
185. Bode-Böger SM, Muke J, Surdacki A, Brabant G, Böger RH, Frölich JC. Oral L-arginine improves endothelial function in healthy individuals older than 70 years. Vascular Medicine 2003;8(2):7781.

186. Clarkson P, Adams MR, Powe AJ, Donald AE, McCredie R, Robinson J, McCarthy SN, Keech A, Celermajer DS, Deanfield JE. Oral L-arginine improves endothelium-dependent dilation in hypercholesterolemic young adults. Journal of Clinical Investigation 1996;97(8):1989-1994.

187. Adams MR, McCredie R, Jessup W, Robinson J, Sullivan D, Celermajer DS. Oral I-arginine improves endothelium-dependent dilatation and reduces monocyte adhesion to endothelial cells in young men with coronary artery disease. Atherosclerosis 1997;129(2):261-269.

188. Schulman SP, Becker LC, Kass DA, et al. L-arginine therapy in acute myocardial infarction: The vascular interaction with age in myocardial infarction (vintage mi) randomized clinical trial. JAMA 2006;295(1):58-64.

189. Loscalzo J. What We Know and Don't Know About <span class="sc"> $></$ span $>$-Arginine and NO. Circulation 2000;101(18):2126-2129.

190. Pannirselvam M, Simon V, Verma S, Anderson T, Triggle CR. Chronic oral supplementation with sepiapterin prevents endothelial dysfunction and oxidative stress in small mesenteric arteries from diabetic (db/db) mice. British Journal of Pharmacology 2003;140(4):701-706.

191. Higashi Y, Sasaki S, Nakagawa K, Kimura M, Noma K, Hara K, Jitsuiki D, Goto C, Oshima T, Chayama K, Yoshizumi M. Tetrahydrobiopterin improves aging-related impairment of endothelium-dependent vasodilation through increase in nitric oxide production. Atherosclerosis 2006;186(2):390-395.

192. Cosentino F, Hürlimann D, Delli Gatti C, Chenevard R, Blau N, Alp NJ, Channon KM, Eto M, Lerch P, Enseleit F, Ruschitzka F, Volpe M, Lüscher TF, Noll G. Chronic treatment with tetrahydrobiopterin reverses endothelial dysfunction and oxidative stress in hypercholesterolaemia. Heart 2008;94(4):487-492.

193. Porkert M, Sher S, Reddy U, Cheema F, Niessner C, Kolm P, Jones DP, Hooper C, Taylor WR, Harrison D, Quyyumi AA. Tetrahydrobiopterin: a novel antihypertensive therapy. J Hum Hypertens 2008;22(6):401-407.

194. Vásquez-Vivar J, Duquaine D, Whitsett J, Kalyanaraman B, Rajagopalan S. Altered Tetrahydrobiopterin Metabolism in Atherosclerosis. Implications for Use of Oxidized Tetrahydrobiopterin Analogues and Thiol Antioxidants 2002;22(10):1655-1661.

195. Moens AL, Ketner EA, Takimoto E, Schmidt TS, O'Neill CA, Wolin MS, Alp NJ, Channon KM, Kass DA. Bi-modal Dose-dependent Cardiac Response to Tetrahydrobiopterin in Pressureoverload Induced Hypertrophy and Heart Failure. Journal of Molecular and Cellular Cardiology 2011;51(4):564-569.

196. Moens AL, Vrints CJ, Claeys MJ, Timmermans J-P, Champion HC, Kass DA. Mechanisms and potential therapeutic targets for folic acid in cardiovascular disease. American Journal of Physiology - Heart and Circulatory Physiology 2008;294(5):H1971-H1977.

197. Moat SJ, Madhavan A, Taylor SY, Payne N, Allen RH, Stabler SP, Goodfellow J, McDowell IFW, Lewis MJ, Lang D. High- but not low-dose folic acid improves endothelial function in coronary artery disease. European Journal of Clinical Investigation 2006;36(12):850-859.

198. Verhaar MC, Wever RMF, Kastelein JJP, van Loon D, Milstien S, Koomans HA, Rabelink TJ. Effects of Oral Folic Acid Supplementation on Endothelial Function in Familial Hypercholesterolemia. A Randomized Placebo-Controlled Trial 1999;100(4):335-338.

199. van Etten R, de Koning E, Verhaar M, Gaillard C, Rabelink T. Impaired NO-dependent vasodilation in patients with Type II (non-insulin-dependent) diabetes mellitus is restored by acute administration of folate. Diabetologia 2002;45(7):1004-1010.

200. van Oostrom O, de Kleijn DPV, Fledderus JO, Pescatori M, Stubbs A, Tuinenburg A, Lim SK, Verhaar MC. Folic acid supplementation normalizes the endothelial progenitor cell transcriptome of patients with type 1 diabetes: a case-control pilot study. Cardiovascular Diabetology 2009;8:4747. 
201. Antoniades C, Shirodaria C, Warrick N, Cai S, de Bono J, Lee J, Leeson P, Neubauer S, Ratnatunga C, Pillai R, Refsum H, Channon KM. 5-Methyltetrahydrofolate Rapidly Improves Endothelial Function and Decreases Superoxide Production in Human Vessels. Effects on Vascular Tetrahydrobiopterin Availability and Endothelial Nitric Oxide Synthase Coupling 2006;114(11):1193-1201.

202. Moens AL, Claeys MJ, Wuyts FL, Goovaerts I, Van Hertbruggen E, Wendelen LC, Van Hoof VO, Vrints CJ. Effect of Folic Acid on Endothelial Function Following Acute Myocardial Infarction. American Journal of Cardiology 2007;99(4):476-481.

203. Hyndman ME, Verma S, Rosenfeld RJ, Anderson TJ, Parsons HG. Interaction of 5methyltetrahydrofolate and tetrahydrobiopterin on endothelial function. American Journal of Physiology - Heart and Circulatory Physiology 2002;282(6):H2167-H2172.

204. Bønaa KH, Njølstad I, Ueland PM, Schirmer H, Tverdal A, Steigen T, Wang H, Nordrehaug JE, Arnesen E, Rasmussen K. Homocysteine Lowering and Cardiovascular Events after Acute Myocardial Infarction. New England Journal of Medicine 2006;354(15):1578-1588.

205. Investigators THOPE. Homocysteine Lowering with Folic Acid and B Vitamins in Vascular Disease. New England Journal of Medicine 2006;354(15):1567-1577.

206. Loscalzo J. Homocysteine Trials - Clear Outcomes for Complex Reasons. New England Journal of Medicine 2006;354(15):1629-1632.

207. Fraccarollo D, Widder JD, Galuppo P, Thum T, Tsikas D, Hoffmann M, Ruetten H, Ertl G, Bauersachs J. Improvement in Left Ventricular Remodeling by the Endothelial Nitric Oxide Synthase Enhancer AVE9488 After Experimental Myocardial Infarction. Circulation 2008;118(8):818-827.

208. Frantz S, Adamek A, Fraccarollo D, Tillmanns J, Widder J, Dienesch C, Schäfer A, Podolskaya A, Held M, Ruetten H, Ertl G, Bauersachs J. The eNOS enhancer AVE 9488: a novel cardioprotectant against ischemia reperfusion injury. Basic Research in Cardiology 2009;104(6):773-779.

209. Yang Q, Xue H-M, Wong W-T, Tian X-Y, Huang Y, Tsui SKW, Ng PKS, Wohlfart P, Li H, Xia N, Tobias S, Underwood MJ, He G-W. AVE3085, an enhancer of endothelial nitric oxide synthase, restores endothelial function and reduces blood pressure in spontaneously hypertensive rats. British Journal of Pharmacology 2011;163(5):1078-1085.

210. Laufs U, La Fata V, Plutzky J, Liao JK. Upregulation of Endothelial Nitric Oxide Synthase by HMG CoA Reductase Inhibitors. Circulation 1998;97(12):1129-1135.

211. Anderson TJ, Meredith IT, Yeung AC, Frei B, Selwyn AP, Ganz P. The Effect of CholesterolLowering and Antioxidant Therapy on Endothelium-Dependent Coronary Vasomotion. New England Journal of Medicine 1995;332(8):488-493.

212. Martínez-González J, Raposo B, Rodríguez C, Badimon L. 3-Hydroxy-3-Methylglutaryl Coenzyme A Reductase Inhibition Prevents Endothelial NO Synthase Downregulation by Atherogenic Levels of Native LDLs. Balance Between Transcriptional and Posttranscriptional Regulation 2001;21(5):804-809.

213. Laufs U, Gertz K, Huang P, Nickenig G, Böhm M, Dirnagl U, Endres M. Atorvastatin Upregulates Type III Nitric Oxide Synthase in Thrombocytes, Decreases Platelet Activation, and Protects From Cerebral Ischemia in Normocholesterolemic Mice. Stroke 2000;31(10):2442-2449.

214. Hattori Y, Nakanishi N, Akimoto K, Yoshida M, Kasai K. HMG-CoA Reductase Inhibitor Increases GTP Cyclohydrolase I mRNA and Tetrahydrobiopterin in Vascular Endothelial Cells. Arteriosclerosis, Thrombosis, and Vascular Biology 2003;23(2):176-182.

215. Feron O, Dessy C, Desager J-P, Balligand J-L. Hydroxy-Methylglutaryl-Coenzyme A Reductase Inhibition Promotes Endothelial Nitric Oxide Synthase Activation Through a Decrease in Caveolin Abundance. Circulation 2001;103(1):113-118.

216. Wenzel P, Daiber A, Oelze M, Brandt M, Closs E, Xu J, Thum T, Bauersachs J, Ertl G, Zou M-H, Förstermann U, Müunzel T. Mechanisms underlying recoupling of eNOS by HMG-CoA reductase 
Endothelial dysfuction and NOS uncoupling | 3

inhibition in a rat model of streptozotocin-induced diabetes mellitus. Atherosclerosis 2008;198(1):65-76. 


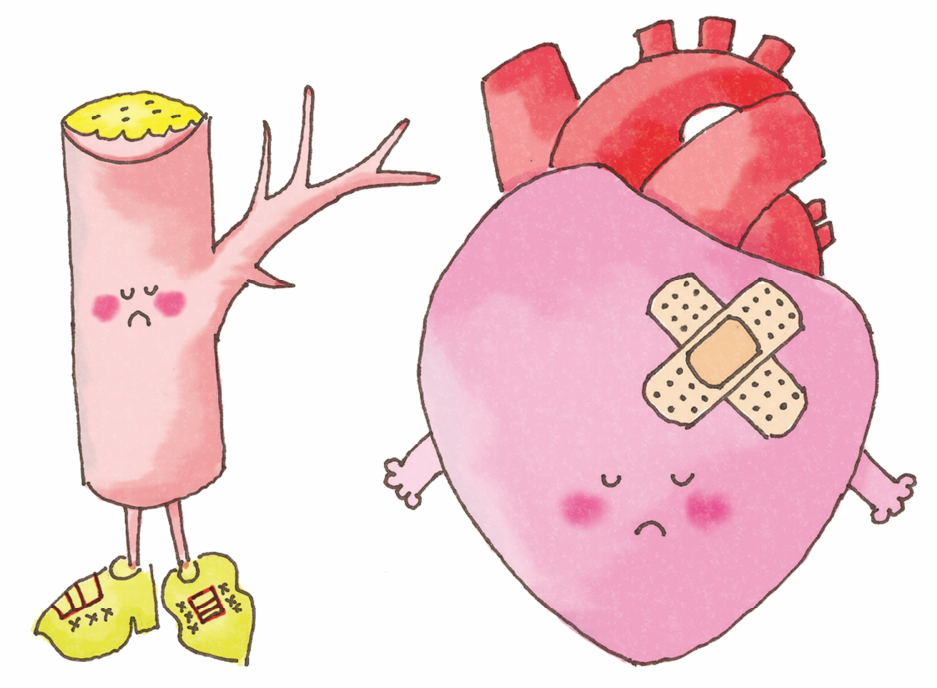


Chapter 4

\section{Enhancing eNOS transcription: a new therapeutic option to tackle myocardial and endothelial dysfunction}

R.Kietadisorn, J.C. Sluimer A.L. Moens, E.A.L. Biessen

(In preparation) 


\section{Abstract}

Nitric oxide (NO) generated by endothelial nitric oxide synthase (eNOS) has antithrombotic, antiatherosclerotic, antihypertensive, and antihypertrophic effects under physiological conditions. Normal function of eNOS requires dimerization of the enzyme and the presence of its cofactor tetrahydrobiopterin (BH4). A functional eNOS oxidizes its substrate L-arginine to L-citrulline and NO. As a consequence of eNOS uncoupling, eNOS generates superoxide rather than NO, contributing to the pathogenesis of cardiovascular diseases. The development of novel pharmacological approaches targeting eNOS is challenging, especially the search for compounds that have multiple, simultaneous actions: 1) increase eNOS expression and/or activity, 2) augment its cofactor $\mathrm{BH} 4$ and 3 ) reverse eNOS uncoupling. Importantly, compounds that increase eNOS protein levels are only beneficial if eNOS functionality is guaranteed. AVE9488 and AVE3085 are novel small molecule compounds that transcriptionally enhance eNOS gene expression, which are aimed to increase signaling $\mathrm{NO}$ and bioavailability. In this review we have outlined the mechanisms and therapeutic benefits of these novel eNOS transcription enhancers in cardiovascular disease. 


\section{Introduction}

Nitric oxide (NO) generated by endothelial nitric oxide synthase (eNOS) has antithrombotic, antiatherogenic, and antihypertensive properties ${ }^{1}$. Moreover, eNOSdependent NO has antihypertrophic effects via downstream NO-cyclic guanosine monophosphate (GMP)-protein kinase G (PKG) signaling cascades ${ }^{2}$. Impairment of NO bioavailability leads to altered regulation of key physiological and cellular processes, such as vasodilatation, platelet function, angiogenesis, apoptosis and smooth muscle cell proliferation. Hence, it plays a crucial role in the pathogenesis of cardiovascular diseases, hallmarked by endothelial dysfunction and/or arterial or cardiac hyperplasia ${ }^{3}$. Inadequate eNOS-dependent NO bioavailability may result from: 1) a decrease in eNOS expression and/or its activity, 2) deficiency in eNOS substrate (L-arginine) or its cofactor (tetrahydrobiopterin; $\mathrm{BH} 4$ ), 3) the presence of endogenous inhibitors (asymmetric dimethylarginine; ADMA), and 5) eNOS uncoupling and accelerated NO degradation by reactive oxygen species (ROS) (see reviews $\left.{ }^{3,4}\right)$. Therefore, therapeutic enhancement of NO bioavailability holds promise as cardiovascular-protective strategy.

A straightforward method to increase NO bioavailability are exogenous NO donors, such as nitroglycerin and sodium nitroprusside. However, this approach is limited by drug tolerance development after long-term treatment and toxicity issues. This indicates that alternative strategies are required ${ }^{5}$. One such alternative are agents that modulate endogenous NO bioactivity, such as angiotensin-converting enzyme (ACE) inhibitors, calcium channel blockers, statins, phosphodiesterase inhibitors and $\beta$-blockers ${ }^{6}$.These agents are primarily targeting distinct processes, but have been reported to indirectly increase eNOS gene expression, eNOS activity or to stabilize eNOS mRNA ${ }^{7-11}$.

A more direct approach that is widely explored are inducers of eNOS protein expression. However, these only are beneficial if the ensuing eNOS protein is functional ${ }^{12}$, in other words able to oxidize its substrate L-arginine to L-citrulline and $\mathrm{NO}^{13}$. Appropriate eNOS function requires dimerization of the enzyme and abundant presence of its cofactor tetrahydrobiopterin (BH4). This renders the development of novel drugs that induce eNOS activity challenging. This particularly holds when aiming at compounds that display multiple eNOS enhancing functions, and simultaneously 1) increase eNOS expression and/or activity, 2) augment bioavailability of its cofactor $\mathrm{BH} 4$, and 3) recouple eNOS. Screening of compound libraries for eNOS transcriptional upregulation yielded two structurally related indan-based smallmolecular-weight compounds: AVE9488 (4-fluoro- $N$-indan-2-yl-benzamide; CAS no. 291756-32-6; empirical formula $\mathrm{C}_{16} \mathrm{H}_{14} \mathrm{FNO}$; earlier designation C2431) and AVE3085 (2,2-difluoro-benzo[1,3]dioxole-5-carboxylic acid indan-2-ylamide; CAS no. 450348- 
85-3; empirical formula $\mathrm{C}_{17} \mathrm{H}_{13} \mathrm{~F}_{2} \mathrm{NO}_{3}$ ). These small molecule compounds display a high potency for transcriptional enhancement of eNOS gene expression, and could potentially increase signaling $\mathrm{NO}$ and bioavailability ${ }^{14,15}$. In this review we shall outline the mechanisms and therapeutic benefits of these novel eNOS transcription enhancers in cardiovascular diseases.

\section{AVE mechanism of action}

\section{1 eNOS transcription-dependent effects of AVE}

The mode of action of AVE 9488 and AVE 3085 capacity to enhance eNOS expression has been explored in vitro in a human endothelial cell line (EA.hy 926) and in human umbilical vein endothelial cells (HUVEC). Both compounds enhanced eNOS promoter activity in a concentration-dependent manner, without affecting eNOS mRNA stability ${ }^{15}$. Thus, AVE compounds seem to act at eNOS transcriptional level ${ }^{15}$. Silencing of transcription factors Sp1, GATA2 and PEA3, which are critical in controlling eNOS promotor activity, resulted in decreased basal activity of eNOS promoter, but did not impact eNOS transcription activity ${ }^{15}$.Thus, the responsible transcription factors/cis-elements still remain to be identified. The efficacy of AVE9488 to increase eNOS expression was comparable to that of simvastatin ${ }^{15}$, which was seen to elevate eNOS stability by prolonging half-life of eNOS mRNA, but had little effect on eNOS transcription ${ }^{9}$.

\section{2 eNOS activity-dependent effects of AVE}

A potential secondary mode of action of AVE compounds involves direct regulation of eNOS activity. Phosphorylation of serine (Ser) ${ }^{1177}$ (corresponding to $\operatorname{Ser}^{1176}$ in rodents) is associated with increased eNOS activity, whereas phosphorylation at threonine $(\mathrm{Thr})^{495}$ inhibits eNOS activity ${ }^{16-19}$. In homocysteine induced endothelial dysfunction, AVE3085 increased eNOS phosphorylation at Ser ${ }^{1177}$ in a phosphoinositide $(\mathrm{PI}) 3$ kinase-protein kinase $B(A k t)$-dependent manner ${ }^{20}$. AVE 3085 increased eNOS activity in reoxygenation after cadioplegia-induced hypoxia ${ }^{21}$ and in ADMA-induced endothelial dysfunction ${ }^{22}$ in porcine coronary small arteries studies. This was achieved through enhanced phosphorylation of eNOS ( $p$-eNOS) at $\operatorname{Ser}^{1177}{ }^{21,22}$ and decreasing $\mathrm{Thr}^{495}$ phosphorylation ${ }^{22}$. Conversely, AVE 3085 treatment did not alter the ratio of phosphorylation at $\mathrm{Thr}^{495}$ or Ser $^{1176}$ to total eNOS in aortas of diabetic mice, indicating that AVE3085 did not affect eNOS activity ${ }^{23}$. These discrepancies may be due to p-eNOS quantification methods i.e. p-eNOS/ glyceraldehyde 3-phosphate dehydrogenase (GAPDH) versus p-eNOS/total eNOS. The latter study suggested that the increase in phosphorylated eNOS mainly reflected a proportional increase in eNOS synthesis upon AVE treatment ${ }^{23}$. 


\section{3 eNOS transcription-independent effects of AVE}

\subsection{1 eNOS uncoupling and BH4 bioavailibility}

Next to altering eNOS transcription and activity, AVE9488 and AVE3085 were also shown to reverse eNOS uncoupling ${ }^{15,20,22}$. Although this notion has been challenged for AVE3085, where the increased eNOS activity resulted in increased NO production. However, this was accompanied by an overproduction of peroxynitrite in diabetic CD34+ stem cells ${ }^{24}$. This further suggested that NADPH oxidase, but not eNOS uncoupling, was a major source of ROS generation in this study, and thus increasing eNOS expression without correcting oxidative stress was not effective.

Uncoupling of eNOS activity may in part be ascribed to AVE's effect on BH4 availability. Treatment of AVE9488 in a model of cuff-induced neointima formation in mice resulted in increased vascular $\mathrm{BH} 4$ levels, without altering the expression of the rate limiting enzyme in de novo synthesis of $\mathrm{BH} 4$, i.e. guanosine triphosphate cyclohydrolase I (GTPCH) ${ }^{15}$. In contrast, AVE9488 treatment did not alter myocardial $\mathrm{BH} 4$ levels in a cardiac ischemia/reperfusion (I/R) mouse model ${ }^{25}$. Of note, AVE9488 increased vascular $\mathrm{BH} 4$ contents when administered in vivo, but not in endothelial cells in vitro, suggesting that the elevation of $\mathrm{BH} 4$ in vivo may be indirect, e.g. by AVE9488 effects on cell types other than endothelial cells ${ }^{15}$.

It is unclear how AVE9488 exactly induced intravascular BH4 levels. It did not protect from $\mathrm{ROS}$-induced $\mathrm{BH} 4$ oxidation though regulation of superoxide-generating NADPH oxidases (NOX), including NOX1-4 and p22phox and superoxide-scavenging enzymes, i.e. superoxide dismutase $1-3$ (SOD) ${ }^{15,25}$. In contrast, AVE3085 may protect oxidative degradation of $\mathrm{BH} 4$ by ROS through downregulation of NOX subunits p22phox and gp91phox ${ }^{26}$ and iNOS gene expression ${ }^{20,26}$, suggesting AVE3085 reduced ROS generation through regulation of these oxidant enzymes. Moreover, both AVE compounds did not have superoxide and peroxynitrite scavenging activity by themselves ${ }^{23,25}$.

\subsubsection{Arginase activity}

AVE may also act indirectly by influencing substrate availability. eNOS activity can be affected by the endogenous inhibitor ADMA, and indirectly by the activity of arginase, which competes with eNOS for L-arginine as substrate. Induction of expression level or activity of arginase I or ADMA will compromise substrate levels and thus NO production at the expense of a rise in superoxide generation ${ }^{27,28}$. It has been demonstrated in homocysteine (Hcy)-induced endothelial dysfunction that AVE3085 reversed iNOS upregulation and arginase activation ${ }^{20,27}$. However, by what 
mechanisms AVE3085 inhibits Hcy-induced iNOS upregulation remains to be elucidated.

\section{4 eNOS-dependent effector pathways in AVE therapeutic activity}

\subsubsection{Regulation of endothelial dysfunction}

AVE 3085 was reported to improve endothelial function in both conduit ${ }^{29}$ and resistance vessels ${ }^{23}$, and has blood pressure lowering properties ${ }^{29}$. This suggested that improved endothelial function might be related to its anti-hypertensive effect, indicating a cardiovascular protective effect. Moreover, AVE 9488 and AVE3085 have shown to protect against cardiac and vascular remodeling through downregulation of TGF- $\beta$, connective tissue growth factor (CTGF) ${ }^{26}$, A-type and B-type natriuretic peptide (ANP and BNP, respectively) ${ }^{30}$, b- major histocompatibility complex (b-MHC) expression, as well as mothers against decapentaplegic (Smad) $2 / 3$ signaling ${ }^{31}$. In addition, bone marrow-derived mononuclear cells from patients with ischemic cardiomyopathy (ICMP) have increased NO/cGMP/PKG signaling, which is accompanied by impaired stromal cell-derived factor 1 (SDF-1) dependent migratory capacity. SDF-1 migratory responses could be normalized by AVE9488 treatment ${ }^{14}$. In contrast, AVE3085 did not improve CD34+ cell migration in response to SDF-1a in diabetics $^{32}$.

\subsubsection{Vasodilator-stimulated phosphoprotein (VASP)}

NO-dependent phosphorylation of VASP is an essential regulatory step in VASP-dependent inhibition of platelet activation. Therefore, VASP phosphorylation is positively correlated with NO bioavailability, and can thus be used as a sensitive (albeit indirect) measure of defective NO/cGMP signaling ${ }^{33}$. Treatment with AVE9488 increased platelet VASP- phosphorylation at $\operatorname{Ser}^{157}$ and $\operatorname{Ser}^{239}$ in $\mathrm{l} / \mathrm{R}$ mice ${ }^{25}$, myocardial infarction $(\mathrm{MI})$ rats ${ }^{30}$ and severe congestive heart failure rats ${ }^{34}$, indicating that AVE9488 exerts inhibitory effects on platelet activation.

\subsubsection{Mobilization of progenitor cells}

Cell therapy with bone marrow-derived stem/progenitor cells is a novel therapeutic strategy for improving neovascularization and cardiac function in peripheral arterial disease, ischemic heart disease, and ICMP ${ }^{35-37}$, which has been associated with eNOS/NO function. Indeed, the expression of eNOS is vital for the mobilization of stem and progenitor cells ${ }^{38}$.Moreover, increased eNOS expression of endothelial progenitor cells (EPC) by statins, estrogen or erythropoietin improved EPC function, was associated with enhanced re-endothelialization or augmented neovascularization ${ }^{39-42}$. 
Sasaki et al. ${ }^{14}$ reported that ex vivo pretreatment with AVE9488 (5 $\mu \mathrm{M}$ for 18 $24 \mathrm{~h}$ ) of bone marrow-derived mononuclear cells (BMC) derived from patients with ICMP resulted in increased eNOS mRNA expression in peripheral blood-derived EPC, $\mathrm{CD}_{3} 4^{+}$cells and $\mathrm{BMC}$ as well as increased NO production in lineage-negative CD105+ bone marrow-derived cells (i.e. circulating endothelial progenitor cells). Moreover, AVE-pretreated BMC from patients restored the impaired stromal cellderived factor 1 (SDF-1) mediated migratory capacity and this effect was abolished following administration of antibodies directed against the SDF-1 receptor, C-X-C chemokine receptor type 4 (CXCR4), or L-NAME. In addition, AVE 9488 did not improved the impairment of SDF-1 mediated migratory capacity in BMC derived from either eNOS deficient mice or cGMP-dependent protein kinase I deficient mice ( $\mathrm{PKGl}^{-1-}$ , also termed $\mathrm{GKI}^{--}$). This indicated that AVE9488 effects were mediated by eNOS, and increased NO/cGMP/PKG signaling activity was associated with the improvement of SDF-1 mediated migratory capacity.

Intravenous infusion of BMC derived from ICMP patients in mouse model of unilateral hind limb ischemia in vivo resulted in decreased recovery of limb perfusion after induction of hind limb ischemia, highlighting the importance of stem cell quality and functional activity. AVE-pretreated BMC derived from ICMP patients enhanced recovery of limb perfusion and increased neovascularization, associated with increased physical activity as assessed by swimming test. In addition, injection with AVE-treated patient-derived BMC in a mouse model of $\mathrm{Ml}$ resulted in improvement of ejection fraction and stroke work. In summary, AVE9488 increased eNOS expression enhances the regenerative capacity of EPC isolated from ICMP patients suggesting a synergistic effect between cell and gene therapy.

In conclusion, both AVE compounds have largely similar cardioprotective effects by reversing eNOS uncoupling, without affecting superoxide and peroxynitrite scavenging activity. In addition, they impact on $\mathrm{BH} 4$ bioavailability and arginase activity, as well as the expression of oxidant enzymes and superoxide inducers, while eNOS activity upon AVE 3085 or AVE9488 treatment is diverging or opposite. The broad spectrum of cardioprotective activities of the AVE compounds are summarized in Figure1. 


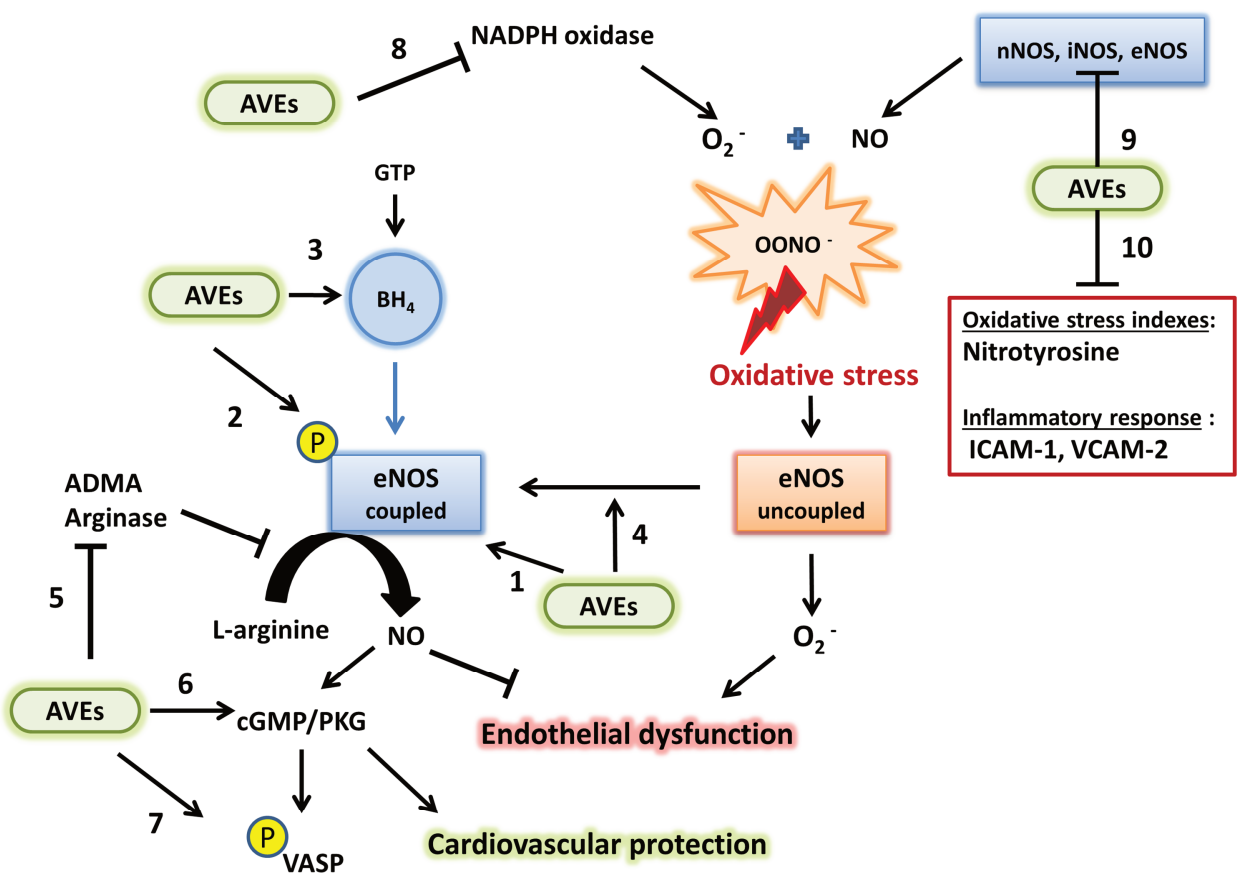

Figure 1. The potential mechanisms for the cardiovascular protective effect of AVE9488 and AVE3085, the eNOS transcription enhancers.

AVE compounds (AVEs) increase eNOS mRNA and protein expression (1), increase eNOS catalytic activity (by promoting phosphorylation of eNOS (p-eNOS) at Ser1177 and decreasing of p-eNOS at Thr495 (2) and by increasing $\mathrm{BH} 4$ bioavailability (3), and in addition can reverse eNOS uncoupling amongst others (4). Finally, AVEs promote eNOS mediated NO production indirectly by downregulating arginase and ADMA activity, (5). In turn, the elevated NO production will inhibit endothelial dysfunction, and provide cardiovascular protection via cGMP-dependent PKG signaling pathway (6). In parallel, NO can increase phosphorylation of vasodilator-stimulated phosphoprotein (VASP), platelet activation (7). Finally, AVEs decrease superoxide generation through downregulation of NADPH oxidase (8) and iNOS expression (9), and decrease oxidative stress and inflammatory responses (10). Abbreviations explained in main text.

\section{Preclinical studies of AVE's cardiovascular protective activity}

\subsection{Hypertension and associated endothelial dysfunction}

Loss of NO production and/ or bioavailability results in increased vasoconstriction, and subsequently increased systemic vascular resistance and hypertension ${ }^{43}$. AVE compounds has shown to increased eNOS expression and activity, and subsequently increased NO generated by eNOS ${ }^{15,23}$. Targeting endogenous eNOS production instead of directly relaxing vascular smooth muscle may represent an alternative therapeutic approach to the traditional treatment strategy 92 
by preventing the pathological changes in endothelial cells in hypertension. Yang et al. ${ }^{29}$ demonstrated that treatment of AVE3085 $(10 \mathrm{mg} / \mathrm{kg} / \mathrm{day}, 4 \mathrm{wks})$ in spontaneously hypertensive rats (SHR) resulted in reduced systolic blood pressure, restored the impaired endothelium-dependent relaxations SHR aortae in vitro, and increased aortic eNOS mRNA and protein expression, and phosphorylation. In addition, AVE3085 blunted the increased formation of nitrotyrosine, a marker of NO-dependent oxidative stress, in SHR rats. This suggests that AVE3085 might exert anti-hypertensive effects, possibly through increased eNOS expression and activity, and inhibited vascular oxidative stress.

\subsection{Diabetes mellitus}

Evidence showed that eNOS uncoupling was associated with diabetes mellitus (DM), causing reduced NO bioavailability and increased superoxide production ${ }^{44}$. Under hyperglycemic conditions, eNOS-derived NO capacity was diminished ${ }^{45}$. Moreover, studies suggested that the re-endothelialization capacity of EPC derived from diabetic patients, including the migration capacity in response to SDF-1 and vascular endothelial growth factor (VEGF), were severely impaired ${ }^{46-48}$.

Jarajapu et al. ${ }^{24}$ demonstrated that diabetic CD34+ cells exhibited impairment of migratory response to SDF-1 $\alpha$. Treatment with AVE3085 $(10 \mu \mathrm{M}, 24 \mathrm{~h})$ in diabetic CD34+ cells resulted in increased eNOS mRNA expression without improving migration in response to SDF-1a in vitro, while improving CD34+ cells homing functions in a mouse model of retinal $\mathrm{I} / \mathrm{R}$ injury in vivo. Interestingly, diabetic CD34+ cells treated with AVE3085 displayed increased peroxynitrite generation, which was further increased following SDF-1a stimulation. Pretreatment with peroxynitrite scavenger ebselen abolished this increase, suggesting that the AVE3085-mediated effect was dependent on overproduction of peroxynitrite. In addition, diabetic CD34+ cells displayed increased NOX2 mRNA expression, increased NADPH oxidase activity, as well as increased superoxide generation. Coinbubation with L-NAME did not alter superoxide levels, suggesting that superoxide generation was not caused by eNOS uncoupling. Importantly, treatment with NOX inhibitors improved vasoreparative functions in the dysfunctional diabetic CD34+ cells in vitro and in vivo, resulting in enhanced NO bioavailability. Taken together, this suggested that NOX2 was a major source of superoxide generation over uncoupled eNOS in this particular diabetes study, and targeting NOX activity might thus be suitable for diabetes treatment. While these findings are intriguing, it is difficult to draw a conclusion on the role of eNOS-generated superoxide in diabetic EPC due to inadequate details of patient characteristics. Indeed, the differences in stages and/or severity of diabetes, and antidiabetic treatments such as insulin, have shown different outcomes of the sources of superoxide generation ${ }^{49}$. Activation of NOX likely occurs 
early in diabetes and/or in mild diabetic forms ${ }^{50}$, whereas eNOS uncoupling with an even stronger subsequent production of ROS predominantly exists in advanced diabetes ${ }^{51}$.

Cheang et al. ${ }^{23}$ demonstrated that co-treatment with AVE3085 (1 $\left.\mu \mathrm{mol} / \mathrm{L}\right)$ restored the reduction of endothelium-dependent relaxation (EDR) to acetylcholine ( $\mathrm{ACh}$ ) in aortas of diabetic $\mathrm{db} / \mathrm{db}$ and in aortas of wild-type (WT) mice exposed to high glucose. This effect was abolished either by co-incubation with the transcription inhibitor actinomycin D, by L-NAME as well as in eNOS deficient mouse aortas, suggesting that AVE 3085-induced improvement of vascular relaxation was mediated by eNOS and its transcription process. In addition, treatment with AVE 3085 (1 $\mu \mathrm{mol} / \mathrm{L}$ ) reversed the reduction of NO bioavailability the primary endothelial cells from mouse aortas-exposed caused by high glucose. Moreover, co-treatment with AVE3085 $(1 \mu \mathrm{mol} / \mathrm{L})$ reversed eNOS downregulation, and inhibited ROS generation in high glucose-exposed WT aortas, as well as in diabetic mouse aortas. Interesting, high glucose-exposed WT aortas exhibited eNOS uncoupling, assessed by a decrease in eNOS dimer to monomer ratio and treatment with AVE3085 remained unaffected. In addition, AVE3085 treatment was unaffected in attenuation of the increased aortic ROS generation induced by hypoxanthine and xanthine oxidase in WT mice, suggesting that AVE3085 did not have a direct ROS-scavenging effect. In an in vivo study, oral administration of AVE3085 (10 mg/kg/day for 7 days) restored endothelial dysfunction in diabetic mouse arteries and inhibited aortic superoxide generation. While AVE3085 treatment increased aortic eNOS protein expression, it did not alter the ratio of phosphorylation at $\mathrm{Thr}^{495}$ or $\mathrm{Ser}^{1176}$ to total eNOS in diabetic mice. This suggested that the effect of AVE3085 to reduce ROS was unlikely mediated through inhibiting eNOS uncoupling, but by increasing eNOS expression and endothelial-derived NO generation.

\subsection{Atherosclerosis}

Endothelial dysfunction is generally considered to be a key process in atherogenesis, and concordant with this notion, atherosclerotic lesions have been shown to exhibit decreased eNOS mRNA and protein expression and eNOS enzymatic dysfunction ${ }^{43,52,53}$. This suggests that normalizing eNOS function might be beneficial in atherosclerosis. Adenoviral overexpression of eNOS, but not iNOS, in a rabbit model of atherosclerosis resulted in improved endothelial NO-mediated vasorelaxation in atherosclerotic arteries, and blunted plaque progression ${ }^{54}$. In contrast, apolipoprotein deficient $\left(\mathrm{apoE}^{-1}\right)$ atherosclerotic mice overexpressing eNOS (apoE ${ }^{-/}$/eNOS-Tg) displayed markedly reduced aortic BH4 levels as well as increased eNOS uncoupling, leading to accelerated plaque formation. Such statements raise a note of caution concerning the aimed level of increase in eNOS 
expression, without concordant increases in vascular $\mathrm{BH} 4$ levels. This may will result in eNOS uncoupling due to the stoichiometric relationships between endothelial $\mathrm{BH} 4$ and NOS activity ${ }^{55}$ (Table 1).

AVE may perform better in that regard. Wohlfart et al. ${ }^{15}$ demonstrated that sub-chronic administration of AVE $9488(30 \mathrm{mg} / \mathrm{kg} /$ day) for 17 days to WT mice significantly increased eNOS protein expression in healthy aortas (50\%) and femoral arteries (48\%). AVE9488 treatment (10 mg/kg/day, gavage b.i.d. for 17 days) in cuffinduced neointima formation in apo $\mathrm{E}^{-/}$mice resulted in increased aortic eNOS protein expression and decreased neointima formation. Similarly, chronic administration of AVE9488 or AVE3085 (30 mg/kg/day) for $12 \mathrm{wks}$ in apoE ${ }^{-/-}$mice-fed Western diet resulted in decreased plaque formation and increased eNOS protein expression without altering plasma lipid profiles or heart rate. Importantly, AVE compounds were ineffective in inhibiting neointima formation and atherosclerosis in $\mathrm{eNOS}^{-/}$mice or apoE $\mathrm{E}^{-/} / \mathrm{eNOS}^{-/-}$mice, respectively, indicating that the effects of AVE compounds were strictly eNOS-dependent. In addition, untreated atherosclerotic apo $^{-/}$mice exhibited increased aortic ROS production compared to AVE9488-treated group. This was partly inhibited by NOS inhibitor L-NAME suggesting that ROS was partly produced by an uncoupled eNOS. In contrast, AVE9488-treated apoE ${ }^{-/-}$mice ( $30 \mathrm{mg} / \mathrm{kg} /$ day, $2 w \mathrm{ks}$ ) displayed increased aortic BH4 levels. Also, AVE9488 reduced aortic ROS production to levels that could not be lowered any further by L-NAME, indicating effective recoupling of eNOS. Notably, the increase of vascular $\mathrm{BH} 4$ levels may be an important role for the reversal of eNOS uncoupling. Taken together, AVE compounds exert overt vasoprotective effects through upregulating eNOS expression and reversing eNOS uncoupling.

\subsection{Vascular endothelium impairment}

\subsubsection{Asymmetric dimethylarginine (ADMA) induced vascular endothelium impairment}

Evidence has shown that the increased concentrations of circulating ADMA is associated with increased risk of cardiovascular disease, suggesting ADMA as an independent risk marker for all-cause mortality and cardiovascular disease ${ }^{56,57}$. Indeed, ADMA, a derivative of L-arginine, can competitively inhibit eNOS and thus diminish endothelium-derived synthesis of $N O{ }^{58}$. Elevated ADMA levels cause a reduction of $\mathrm{NO}$ production and could consequently lead to endothelial dysfunction and cardiovascular events. In human studies, infusion of ADMA in healthy individuals led to reduced cardiac output and renal plasma flow, and to increased vascular resistance ${ }^{59}$. Moreover, increased plasma ADMA levels were associated with increased oxidative stress ${ }^{60,61}$. In patients with coronary artery disease (CAD), serum 
ADMA levels were positively correlated with eNOS uncoupling found in endothelium 62.

Xue et al. ${ }^{22}$ investigated in porcine coronary small arteries function in vitro that pre-incubation with ADMA $(100 \mu \mathrm{mol} / \mathrm{L}, 1 \mathrm{~h})$ diminished bradykinin-induced relaxation, and reduced the NO release in response to bradykinin, and such reductions were restored by co-incubation with AVE3085 (10 $\mu \mathrm{mol} / \mathrm{L}, 1 \mathrm{~h})$. Furthermore, co-incubation of NOS inhibitor, Nw-nitro-I-arginine (L-NNA; with selectivity for eNOS and nNOS over iNOS), markedly decreased ADMA-induced superoxide generation in porcine arteries, suggesting ADMA induced eNOS uncoupling. In addition, co-incubation of AVE3085 attenuated ADMA-induced ROS and reactive nitrogen species formation. Importantly, coronary small arteries preincubated with ADMA and AVE3085, L-NNA did not further inhibit superoxide generation, suggesting the reversal of eNOS uncoupling was mediated by AVE3085. Interestingly co-incubation with AVE3085 in ADMA-treated arteries did not alter eNOS protein levels. However, AVE3085 increased eNOS activity by reversing the downregulation of $\mathrm{p}$-eNOS ${ }^{\mathrm{Ser} 1177}$ and the upregulation of $\mathrm{p}$-eNOS ${ }^{\text {Thr495 }}$ induced by ADMA.

In contrast, Xuan et al. ${ }^{63}$ demonstrated in left internal thoracic artery segments from patients undergoing coronary artery bypass grafting that 1 -hr exposure to ADMA (100 $\mu \mathrm{mol} / \mathrm{L})$ resulted in impaired ACh-induced endothelium-dependent relaxation, decreased eNOS protein expression and increased superoxide production. Co-incubation with AVE3085 (30 $\mu \mathrm{mol} / \mathrm{L})$ restored endothelium-dependent relaxation, enhanced eNOS expression and reduced superoxide formation caused by ADMA.

The discrepancies between these two studies regarding AVE3085-mediated increased vascular eNOS expression may be due the difference of pathological condition of arteries (non-pathological porcine arteries vs arteries from patients with coronary artery disease) and dosage (10 vs $30 \mu \mathrm{mol} / \mathrm{L}$ ). Thus, further studies are warranted to draw firm conclusions on the role of eNOS enhancement in ADMAinduced endothelial dysfunction.

\subsubsection{Homocysteine (Hcy) induced vascular endothelium impairment}

Increased plasma homocysteine (Hcy) has emerged as an independent risk factor for cardiovascular diseases ${ }^{64}$. Evidence indicated that Hcy-induced oxidative stress was dependent on NOS activity, which was mainly attributed to uncoupled eNOS ${ }^{65}$. Studies demonstrated that Hcy induced eNOS uncoupling through increasing superoxide generation and diminishing intracellular BH4 bioavailability ${ }^{65,66}$, subsequently resulting in endothelial dysfunction. 
Yang et al. ${ }^{20}$ demonstrated in porcine coronary arteries-exposed Hcy that cotreatment with AVE3085 (10 $\mu \mathrm{mol} / \mathrm{L}, 24 \mathrm{~h})$ resulted in improved impairment of EDR to bradykinin, restored NO release, decreased superoxide generation, upregulated eNOS mRNA and protein expression, increased phosphorylation of eNOS at Ser1177 $\left(p-e N O S^{S e r 1177}\right)$, downregulated iNOS protein expression and normalized arginase activity. This beneficial effect of AVE3085 was attenuated when co-incubated with either Akt inhibitor (1L6-Hydroxymethyl-chiro-inositol-2-(R)-2-O-methyl-3-O-octadecylsn-glycerocarbonate) or phosphoinositide (PI) 3 kinase inhibitors (LY294002 or wortmannin). These inhibitors did not affect eNOS expression that was upregulated by AVE3085, suggesting that the PI3 kinase/Akt pathway was involved in the eNOS activation related endothelial protection of AVE3085. In addition, co-incubation either with iNOS inhibitor ( $1400 \mathrm{~W}$ ) or arginase inhibitor (nor- NOHA) in arteries-exposed to Hcy partially improved relaxation and NO release as well as normalized arginase activity. This was associated with blunted superoxide generation, suggesting that iNOS and arginase contributed to Hcy-induced endothelial dysfunction and superoxide formation. The NOS inhibitor, L-NNA, also lowered the superoxide level elevated by Hcy, suggesting the contribution of eNOS uncoupling to Hcy-induced superoxide generation. Importantly, co-treatment with AVE3085 in arteries-exposed to Hcy also blunted superoxide generation and this could not be reduced any further by L-NNA, indicating that AVE3085 reversed Hcy-induced eNOS uncoupling. Taken together, AVE3085 ameliorated Hcy-induced endothelial dysfunction by reversal eNOS uncoupling, downregulation of iNOS and inhibition of arginase activity and thus inhibited superoxide generation. AVE3085 enhanced NO production by upregulation of eNOS expression and by activation of eNOS activity through PI3 kinase/Aktdependent pathway.

\subsection{Cardiac ischemic injury}

\subsubsection{Ischemia-reperfusion (I/R)}

Myocardial infarct is caused by the occlusion of coronary arteries due to plaque rupture. If this occlusion is temporary, a period of cardiac ischemia is followed by reperfusion and associated damage. Changes in eNOS expression and function are causal in this process. Decreased eNOS-derived NO presented in experimental MI ${ }^{67}$ and patients with ischemic cardiomyopathy ${ }^{68,69}$. Also, genetic overexpression of eNOS in mice attenuated myocardial infarction after myocardial $I / R^{70}$, whereas eNOSdeficient mice showed an increased infarct size in such a model ${ }^{71}$, all signifying the important role of eNOS dysfunction in $\mathrm{MI}$ and $\mathrm{I} / \mathrm{R}$. Perkins et al. ${ }^{72}$ revealed in experimental I/R that co-treatment with an eNOS activity enhancer, protein kinase $\mathrm{C}$ epsilon type( $\mathrm{PKC} \varepsilon$ ), and with $\mathrm{BH} 4$ restored the post-reperfused cardiac function. In contrast, co-treatment with $\mathrm{PKC} \varepsilon$ and $\mathrm{BH} 2$ resulted in enhanced uncoupled eNOS 
activity, cardiac contractile dysfunction and increased ROS generation. Indeed, BH2, which lacks the capacity to act as eNOS cofactor, can competitively replace eNOSbound $\mathrm{BH} 4$ and subsequently promote eNOS uncoupling ${ }^{43}$. Together, this suggests that presence of $\mathrm{BH} 4$ is a prerequisite for therapeutic target eNOS activity enhancer, and increasing eNOS activity when eNOS is uncoupled, will result in deleterious consequences.

Frantz et al. ${ }^{25}$ demonstrated in a mice model of coronary l/R (30 min/24h) that $7 \mathrm{~d}$ pretreatment with AVE 9488 (30 mg/kg/day as dietary supplement) significantly increased eNOS expression levels and enhanced vasodilator- stimulated phosphoprotein (VASP) phosphorylation at Serine ${ }^{157}$, a measure of NO bioavailability and NO/cGMP signaling pathway ${ }^{73}$ ). This was associated with significantly decreased I/R injury, displayed by a smaller myocardial infarct size compared with the placebo group. In addition, levels of malondialdehyde (MDA), a lipid peroxidation marker, were reduced in mice that received AVE9488 pretreatment. Interestingly, AVE9488 did not alter myocardial BH4 levels in this study. Taken together, AVE9488 protects against cardiac I/R injury through augmentation of myocardial eNOS expression and activity.

\subsubsection{Myocardial infarction (MI)}

$\mathrm{MI}$ is typified by myocardial cell death due to prolonged ischemia. Long-term effects of MI are cardiac inflammatory and remodeling responses, including LV dilation, myocyte hypertrophy and interstitial fibrosis ${ }^{74}$. Uncoupling of eNOS caused by $\mathrm{BH} 4$ oxidation is the main source of superoxide generation in the ventricular remodeling process after MI in a rats ${ }^{32}$. eNOS- deficient mice exhibited left ventricular dysfunction and modeling after $\mathrm{MI}$, suggesting that enhancing cardiac eNOS expression may be beneficial to ameliorate $\mathrm{MI}^{75}$. This observation was confirmed in mice with transgenic eNOS overexpression by the improved LV systolic and diastolic function, and attenuation of LV, myocyte hypertrophy ${ }^{76}$, and myocardial infarct size ${ }^{70}$ after experimental MI.

Likewise, the eNOS enhancer compounds improved cardiac function. Fraccarollo et al. ${ }^{30}$ demonstrated in a rat model of MI that chronic AVE9488 treatment via dietary supplementation (approx. 1.25/kg/d, starting 7 days post Ml for 9 wks) led to increased eNOS expression, restored eNOS activity, diminished vascular superoxide production, collectively translating in improved global cardiac function, and reduced pathological hypertrophy and pulmonary edema. AVE9488-treated MI rats displayed decreased ANP and BNP expression, markers of the hypertrophic response to Ml. The AVE9488-mediated increase in eNOS-derived NO production may contribute to the antihypertrophic effects. Indeed, NO was seen to inhibit cardiomyocyte hypertrophy, via cGMP-dependent PKG activation ${ }^{77}$, and to play an important role in the antihypertrophic effect of bradykinin ${ }^{78}$. Besides, AVE9488-treated 98 
$\mathrm{Ml}$ in rats led to downregulated myocardial endothelin-1 (ET-1), possibly due to the inhibitory effect of NO on ET-1 expression and production ${ }^{79,80}$. Interestingly, in both studies AVE did not alter myocardial BH4 levels and eNOS dimer-to-monomer ratio. Thus, eNOS activity and the enhancer compounds ameliorate cardiac function after $\mathrm{Ml}$ by preventing the increased cardiac fetal genes expression, augmenting NO production and improving endothelial vasomotor dysfunction, independent of eNOS uncoupling.

\subsection{Heart failure}

\subsubsection{Diastolic heart failure (DHF)}

DHF refers to heart failure with normal left ventricular (LV) ejection fraction, which features slow LV relaxation and increased LV stiffness ${ }^{81}$. It has been known that NOS-derived NO is also a crucial mediator of cardiac diastolic function ${ }^{82}$. Mice with triple deletion of all NOS isoforms show impaired diastolic function and cardiac hypertrophy ${ }^{83}$. Importantly, diastolic dysfunction was found in mild hypertensive deoxycorticosterone acetate (DOCA)-salt treated mice and this was associated with marked eNOS uncoupling, as witness by increased ROS generation, decreased NOS-derived $\mathrm{NO}$ and depleted cardiac $\mathrm{BH} 4$ levels $^{84}$.

Westermann et al. ${ }^{26}$ have demonstrated that oral administration of AVE3085 in a Dahl salt-sensitive rat model of DHF (10 mg/kg/day for 8 weeks) led to restored diastolic dysfunction, to reduced cardiac hypertrophy and fibrosis and to decreased myocardial oxidative stress. AVE3085 displayed clear anti-fibrotic effects. This was attributable to 1) dampening of calcineurin activation, 2) impairing extracellular ERK/Akt-mediated collagen production, and 3) by blunting the production of profibrotic mediators, including transforming growth factor beta (TGF- $\beta$ ), connective tissue growth factor (CTGF). Moreover, AVE3085-treated DHF rats show downregulated iNOS and NOX subunits p22phox and gp91 phox mRNA expression, possibly explaining the observed decrease in cardiac ROS generation.

Although the authors have shown enhanced eNOS in this particular study, it is unclear if AVE3085 attenuated the development of hypertension through a vascular action or has any independent effect on systolic and/or diastolic function of the falling heart ${ }^{85}$. Besides, it would be interesting if further experiments investigate whether AVE3085 is able to recouple the uncoupled eNOS by measuring eNOS-dependent NO generation, eNOS dimer stability and enzymatic activity, and BH4/ dihydrobiopterin (BH2) levels. 


\subsubsection{Left ventricular hypertrophy}

It is well documented that uncoupling of eNOS is a prominent source of reactive oxygen species (ROS) generated in myocardium in pressure overloadinduced ventricular remodeling and cardiac dysfunction ${ }^{86,87}$. Chen et al. ${ }^{31}$ demonstrated in a mouse model of pressure overload-induced left ventricular hypertrophy that oral administration of AVE3085 $(10 \mathrm{mg} / \mathrm{kg} /$ day for $4 \mathrm{wks})$ resulted in increased cardiac eNOS mRNA and protein expression, leading to improved cardiac function, protected against cardiac hypertrophy and fibrosis, blunted the increases ANP and b-MHC mRNA expression and this was associated with attenuated the increases Smad2/3 protein expression and activation. This study suggests that AVE3085 inhibited Smad signaling pathway and thus attenuated cardiac remodeling. Taken together, AVE acts protective in both forms of heart failure, but the precise mode of action needs to be delineated further.

\subsection{Arterial thrombosis and platelet activation}

It has been suggested that the increased risk of thrombo-embolic events in congestive heart failure (CHF) is attributed to a hypercoagulable state ${ }^{88}$, associated with abnormal platelet activity ${ }^{89}$, impaired endothelium-dependent vasodilation and diminished release of endothelium-derived $\mathrm{NO}^{90}$. Elevated levels of P-selectin ${ }^{91}$ and, interestingly, uncoupling of platelet eNOS ${ }^{92}$ have been found in patients with congestive heart failure. In in vitro study, overexpression of eNOS in bovine aortic endothelial cells (BAEC) inhibited platelet aggregation and this effect was abolished when treated with L-NAME, suggesting platelet aggregation was mediated by eNOSdependent $\mathrm{NO}^{93}$. Indeed, eNOS-derived NO plays an important role in inhibiting platelet activation through SGC-cGMP-PKG dependent signaling pathway (reviewed in ${ }^{94}$ ). The activation of PKG by cGMP caused VASP-phosphorylation at $\mathrm{Ser}^{239}$, the cGMP/PKG preferred site, and further phosphorylate VASP at $\operatorname{Ser}^{1577} 73$. In platelets, phosphorylation of VASP correlated with vasodilator-induced inhibition of platelet activation and aggregation, as well as with inhibition of fibrinogen receptor activation ${ }^{95,96}$.

Schafer et al. ${ }^{34}$ demonstrated in a rat model of chronic MI-induced severe congestive heart failure that long-term oral administration of AVE9488 25 ppm/day improved and normalized aortic NO generation, as assessed by the additional constriction of isometrically pre-constricted aortic rings in response to L-NNA. In addition, AVE9488-treated severe CHF rats displayed increased platelet VASPphosphorylation at $\mathrm{Ser}^{157}$ and $\mathrm{Ser}^{239}$, indicating the improvement of the activity of platelet inhibitors/inhibitory pathways and NO/cGMP pathway ${ }^{73,95,97}$. Treatment with AVE9488 in severe CHF rats resulted in decreased platelet surface expression of $P$ selectin and glycoprotein 53, markers of platelet degranulation. The effect of AVE9488 100 
mediated VASP- phosphorylation at $\mathrm{Ser}^{157}$ was abolished in eNOS ${ }^{-/-}$mice, suggesting that AVE 9488 was specific for eNOS. Thus, AVE9488 normalized the impaired platelet VASP-phosphorylation and in this way prevents platelet activation, suggesting a therapeutic benefit in thrombo-embolic complications in patients.

\section{General conclusions}

The key role of $\mathrm{NO}$ in cardiovascular protection is well established. The variety of NO effects in vivo mirrors its complex downstream signaling cascades, as NO can signal by cGMP-dependent and -independent pathways ${ }^{98,99}$. NO generated by eNOS regulates blood pressure, vascular tone, leucocyte adhesion, cell proliferation and platelet aggregation, all critical processes in the pathogenesis of cardiovascular diseases. Therefore, agents that increase the bioavailability of eNOS-derived NO are attractive candidate therapeutics for the treatment of cardiovascular diseases. AVE9488 and AVE3085 have been identified as two novel structurally related smallmolecular-weight compounds. Both act protective in cardiovascular disease by effecting eNOS up-regulation and by reversing eNOS uncoupling. Recent studies revealed clear beneficial effects of AVE compounds (table 2) in atherogenesis, in cardiac diseases and in vascular function, including improved endothelium-dependent relaxation, enhanced vascular barrier function, increased circulating EPC, reduced ADMA levels, inhibited MDA (oxidative stress index and inflammation), and disrupted superoxide levels generated by NOX and iNOS. These promising preclinical results merit further study of the long-term therapeutic benefit of AVE9488 and AVE 3085 in human disease. 
Table 1. Phenotypic comparison of increased eNOS transgene expression vs AVE9488 treatment in a mouse model of atherosclerosis

\begin{tabular}{|c|c|c|}
\hline Parameters & apoE $^{-\alpha} /$ eNOS Tg mice & $\begin{array}{l}\text { AVE } 9488 \text { treatment of apoE } \\
\text { mice }^{-15}\end{array}$ \\
\hline Expression of eNOS & $\begin{array}{l}\text { Upregulation (+238\%, aortic } \\
\text { eNOS protien levels, Western } \\
\text { blotting) }\end{array}$ & $\begin{array}{l}\text { ( } 10 \mathrm{mg} / \mathrm{kg} / \mathrm{day} \text { b.i.d. for } 17 \text { days) } \\
\text { Upregulation (+109\%), aortic } \\
\text { eNOS protien levels, Western } \\
\text { blotting) }\end{array}$ \\
\hline Functional status of eNOS & eNOS uncoupling & Recoupling of uncoupled eNOS \\
\hline NO production & Increase $(+50 \%)$ & $\mathrm{n} / \mathrm{a}$ \\
\hline $\mathrm{BH} 4$ levels & $\begin{array}{l}\text { No effect ( } 52 \% \text { decrease } \\
\text { compared with WT) }\end{array}$ & Increase $(+80 \%)$ \\
\hline Superoxide formation & $\begin{array}{l}\text { Increase }(+75 \% \text { (non- } \\
\text { atherosclerotic artery segment } \\
) ;+30 \% \text { in plaque }\end{array}$ & Decrease $(-33 \%)$ \\
\hline Atherosclerotic lesion formation & $\begin{array}{l}\text { Increase }(+50 \%) \\
12 \text { wk of high cholesterol diet } \\
(1.25 \% \text { cholesterol, } 7.5 \% \text { cocoa } \\
\text { butter, } 7.5 \% \text { casein, } 0.5 \% \\
\text { sodium cholate) }\end{array}$ & 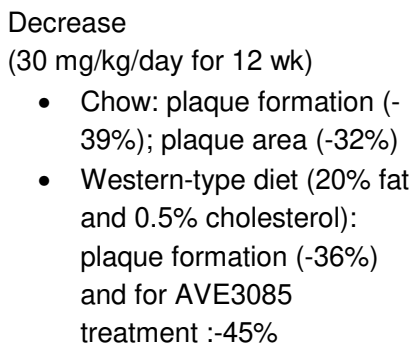 \\
\hline
\end{tabular}


Table 2. Overview of major vascular and myocardial preclinical studies with AVE compounds.*

\begin{tabular}{|c|c|c|c|c|}
\hline $\begin{array}{l}\text { Cardiovascular } \\
\text { dysfunction }\end{array}$ & Model & $\begin{array}{l}\text { Dosage of AVE } \\
\text { compounds }\end{array}$ & Major findings & Ref. \\
\hline \multirow[t]{3}{*}{$\begin{array}{l}\text { Hypertension } \\
\text { and } \\
\text { hypertension- } \\
\text { induced } \\
\text { endothelial } \\
\text { dysfunction. }\end{array}$} & $\begin{array}{l}\text { SHR rats } \\
\text { (in vivo) }\end{array}$ & $\begin{array}{l}\text { AVE3085 } \\
(10 \mathrm{mg} / \mathrm{kg} / \text { day; } \\
\text { 4wks; oral } \\
\text { gavage })\end{array}$ & $\begin{array}{ll}\text { - } & \text { Improved endothelium- } \\
\text { dependent relaxation (EDR) in } \\
\text { aortas } \\
\text { - } \quad \text { Up-regulated eNOS mRNA } \\
\text { and protein } \\
\text { - } \quad \text { Enhanced eNOS } \\
\text { phosphorylation } \\
\text { - } \quad \text { Decreased nitrotyrosine } \\
\text { formation } \\
\text { - } \quad \text { Reduced blood pressure }\end{array}$ & \multirow[t]{3}{*}{29} \\
\hline & $\begin{array}{l}\text { SHR rats } \\
\text { (ex vivo- aorta) }\end{array}$ & $\begin{array}{l}\text { AVE3085 } \\
10 \mu \mathrm{M} ; 2 \mathrm{hr} \\
\text { incubation }\end{array}$ & $\begin{array}{ll}\text { - } & \text { Improved EDR in aortas } \\
\text { - } & \text { Up-regulated eNOS mRNA } \\
\text { - } & \text { Enhanced eNOS } \\
& \text { phosphorylation }\end{array}$ & \\
\hline & $\begin{array}{l}\text { SHR rats } \\
\text { (in vitro; primary } \\
\text { endothelial cells } \\
\text { from aortas) }\end{array}$ & $\begin{array}{l}\text { AVE3085 } \\
10 \mu \mathrm{M} ; 12 \mathrm{hr} \\
\text { incubation }\end{array}$ & - Up-regulated eNOS mRNA & \\
\hline \multirow[t]{2}{*}{$\begin{array}{l}\text { Vasoreperative } \\
\text { dysfunction in } \\
\text { diabetic EPC }\end{array}$} & $\begin{array}{l}\text { CD34+ isolated } \\
\text { from peripheral } \\
\text { blood from diabetic } \\
\text { patients }\end{array}$ & $\begin{array}{l}\text { AVE3085 } \\
(10 \mu \mathrm{M} ; 24 \mathrm{hr} \\
\text { incubation) }\end{array}$ & $\begin{array}{l}\text { - Increased eNOS mRNA } \\
\text { expression resulted in } \\
\text { increased peroxynitrite levels } \\
\text { and, therefore, did not } \\
\text { enhance NO-mediated } \\
\text { function in vitro and in vivo } \\
\text { - } \quad \text { Migration in response to SDF- } \\
\text { 1a remained impaired } \\
\text { - No improvements of } \\
\text { vasoreparative function in } \\
\text { diabetic CD34+cells. }\end{array}$ & \multirow[t]{2}{*}{24} \\
\hline & $\begin{array}{l}\text { A mouse model of } \\
\text { retinal } I / R\end{array}$ & $\begin{array}{l}\text { AVE3085 } \\
(10 \mu \mathrm{M} ; 24 \mathrm{hr}) \\
\text { AVE-treated } \\
\text { diabetic } \\
\text { CD34+cells }\end{array}$ & $\begin{array}{l}\text { AVE3085-treated diabetic } \\
\text { cells did not migrate to areas } \\
\text { of vascular injury when } \\
\text { injected within the vitreous of } \\
\text { mice undergoing I/R of retinal } \\
\text { injury. }\end{array}$ & \\
\hline
\end{tabular}




\begin{tabular}{|c|c|c|c|c|}
\hline $\begin{array}{l}\text { Cardiovascular } \\
\text { dysfunction }\end{array}$ & Model & $\begin{array}{l}\text { Dosage of AVE } \\
\text { compounds }\end{array}$ & Major findings & Ref. \\
\hline \multirow[t]{2}{*}{$\begin{array}{l}\text { Endothelial } \\
\text { dysfunction in } \\
\text { diabetes }\end{array}$} & $\begin{array}{l}\text { Diabetic } \mathrm{db} / \mathrm{db} \\
\text { mice }\end{array}$ & $\begin{array}{l}\text { AVE3085 } \\
(10 \mathrm{mg} / \mathrm{kg} / \text { day; } \\
\text { 7days; p.o.) }\end{array}$ & $\begin{array}{l}\text { - Increased eNOS level but did } \\
\text { not change the level of p- } \\
\text { eNOSSer1176 to total eNOS. } \\
\text { The ratio of p-eNOSThr495 to } \\
\text { eNOS was not changed in } \\
\text { db/db mice when compared } \\
\text { with control or by AVE3085 } \\
\text { treatment } \\
\text { - } \quad \text { Reduced blood pressure } \\
\text { - Improved EDR to ACh in } \\
\text { aortas, mesenteric and renal } \\
\text { arteries } \\
\text { - Lowered ROS generation } \\
\text { - Augmented the attenuated } \\
\text { flow- dependent dilatation in } \\
\text { mesenteric resistance arteries }\end{array}$ & \multirow[t]{2}{*}{23} \\
\hline & $\begin{array}{l}\text { High-glucose- } \\
\text { incubated mouse } \\
\text { aortas } \\
\text { (HG 30mmol/L; } \\
48 \mathrm{hrs} \text { ) }\end{array}$ & $\begin{array}{l}\text { AVE3085 } \\
(1 \mu \mathrm{M} ; \\
\text { incubation) }\end{array}$ & $\begin{array}{ll}\text { - } & \text { Increased eNOS expression } \\
\text { - } & \text { Improved EDR to ACh in } \\
\text { aortas, mesenteric and renal } \\
\text { arteries } \\
\text { - } & \text { Inhibited ROS generation } \\
\end{array}$ & \\
\hline \multirow[t]{4}{*}{ Atherosclerosis } & EA.hy 926 cells & $\begin{array}{l}\text { AVE9488 and } \\
\text { AVE3085 } \\
10 \mu \mathrm{M} ; 18 \mathrm{~h} ; \\
\text { incubation }\end{array}$ & $\begin{array}{l}\text { Stimulated eNOS promoter } \\
\text { activity in a concentration- } \\
\text { dependent manner without } \\
\text { changing eNOS mRNA } \\
\text { stability }\end{array}$ & \multirow[t]{4}{*}{15} \\
\hline & $\begin{array}{l}\text { primary human } \\
\text { umbilical vein } \\
\text { endothelial cells }\end{array}$ & $\begin{array}{l}\text { AVE9488 } \\
2 \mu \mathrm{M} ; 18 \mathrm{~h} \\
\text { incubation }\end{array}$ & $\begin{array}{ll}\text { - } & \text { Increased eNOS mRNA and } \\
\text { protein expression } \\
\text { - } & \text { Enhanced bradykinin- } \\
\text { stimulated release of NO }\end{array}$ & \\
\hline & $\begin{array}{l}\text { C57BL/6J } \\
\text { apoE }{ }^{-1} \text { mice }\end{array}$ & $\begin{array}{l}\text { AVE } 9488 \\
(30 \mathrm{mg} / \mathrm{kg} / \mathrm{day} ; \\
17 \text { days; } \\
\text { pressed in } \\
\text { chow })\end{array}$ & $\begin{array}{l}\text { Enhanced vascular eNOS } \\
\text { expression (femoral arteries) }\end{array}$ & \\
\hline & $\begin{array}{l}\text { apoE }{ }^{-/-} \text {mice with } \\
\text { cuff-induced } \\
\text { neointima } \\
\text { formation }\end{array}$ & $\begin{array}{l}\text { AVE9488 } \\
\text { (10 mg/kg/day; } \\
\text { b.i.d. starting } 3 \\
\text { days before the } \\
\text { cuff placement } \\
17 \text { days;) }\end{array}$ & $\begin{array}{l}\text { - } \quad \text { Reduced neointima formation } \\
\text { - Enhanced aortic eNOS } \\
\text { expression }\end{array}$ & \\
\hline
\end{tabular}




\begin{tabular}{|c|c|c|c|c|}
\hline $\begin{array}{l}\text { Cardiovascular } \\
\text { dysfunction }\end{array}$ & Model & $\begin{array}{l}\text { Dosage of AVE } \\
\text { compounds }\end{array}$ & Major findings & Ref. \\
\hline \multirow[t]{3}{*}{$\begin{array}{l}\text { Atherosclerosis } \\
\text { (continued) }\end{array}$} & $\begin{array}{l}\text { apoE } E^{-/} \text {mice } \\
\text { (standard rodent } \\
\text { chow) }\end{array}$ & $\begin{array}{l}\text { AVE } 948810 \\
(30 \mathrm{mg} / \mathrm{kg} / \text { day; } \\
12 \mathrm{wks})\end{array}$ & $\begin{array}{ll}\text { - } & \text { Reduced aortic plaque } \\
& \text { formation } \\
\text { - } & \text { Enhanced eNOS protein } \\
& \text { expression (femoral arteries) }\end{array}$ & \\
\hline & $\begin{array}{l}\text { apoE } E^{-/-} \text {mice } \\
\text { (western type diet) }\end{array}$ & $\begin{array}{l}\text { AVE9488 or } \\
\text { AVE3085 } \\
\text { (30mg/kg/day; } \\
\text { each; } 12 \text { wks) }\end{array}$ & $\begin{array}{l}\text { Reduced aortic plaque } \\
\text { formation }\end{array}$ & \\
\hline & $\mathrm{apoE}^{-/-}$mice & $\begin{array}{l}\text { AVE9488 } \\
(30 \mathrm{mg} / \mathrm{kg} / \text { day; } \\
2 \mathrm{wks})\end{array}$ & $\begin{array}{ll}\text { - } & \text { Increase aortic BH4 levels } \\
\text { - } & \text { Decreased aortic ROS } \\
& \text { production } \\
\text { - } & \text { Reversed eNOS uncoupling }\end{array}$ & \\
\hline $\begin{array}{l}\text { Asymmetric } \\
\text { dimethylarginine } \\
\text { (ADMA) } \\
\text { induced } \\
\text { vascular } \\
\text { endothelium } \\
\text { impairment. }\end{array}$ & $\begin{array}{l}\text { Left internal } \\
\text { thoracic artery } \\
\text { segments from } \\
\text { patients } \\
\text { undergoing } \\
\text { coronary artery } \\
\text { bypass grafting } \\
\text { incubated with } \\
\text { ADMA } 100 \mu \mathrm{mol} / \mathrm{L}\end{array}$ & $\begin{array}{l}\text { AVE3085 } \\
\text { ( } 30 \mu \mathrm{M} ; \\
\text { incubation) }\end{array}$ & $\begin{array}{ll}- & \text { Improved EDR } \\
- & \text { Increased vascular eNOS } \\
& \text { expression } \\
- & \text { Decreased ADMA- induced } \\
& \text { ROS production }\end{array}$ & 22 \\
\hline $\begin{array}{l}\text { Homocysteine } \\
\text { (Hcy) induced } \\
\text { vascular } \\
\text { endothelium } \\
\text { impairment }\end{array}$ & $\begin{array}{l}\text { Porcine Coronary } \\
\text { Small Arteries } \\
\text { (PCAs) incubated } \\
\text { with Hcy } 50 \mu \mathrm{mol} / \mathrm{L}\end{array}$ & $\begin{array}{l}\text { AVE3085 } \\
(10 \mu \mathrm{M} ; 24 \mathrm{~h} ; \\
\text { incubation) }\end{array}$ & $\begin{array}{ll}- & \text { Improved EDR to bradykinin } \\
- & \text { Increased bradykinin- } \\
\text { stimulated NO release } \\
\text { - } & \text { Decreased ROS generation } \\
- & \text { Increased eNOS expression } \\
\text { both mRNA and protein levels } \\
\text { and p-eNOS } \text { Ser1177, increased }^{\text {Ser1177. }} \text { eNOS ratio } \\
\text { p-eNOS } \\
\text { - } \quad \text { Blunted the increased iNOS } \\
\text { protein expression } \\
\text { - Normalized the arginase } \\
\text { activity }\end{array}$ & 20 \\
\hline $\begin{array}{l}\text { Cardiac } \\
\text { ischemia injury }\end{array}$ & $\begin{array}{l}\text { Ischemia } \\
\text { reperfusion: } \\
\text { mice model of } \\
\text { coronary } \mathrm{l} / \mathrm{R}\end{array}$ & $\begin{array}{l}\text { AVE9488 } \\
\text { (30 mg/kg/day; } \\
7 \text { days; dietary } \\
\text { supplement) }\end{array}$ & $\begin{array}{ll}\text { - } & \text { Increased eNOS expression } \\
\text { - } & \text { Increased VASP } \\
\text { phosphorylation } \\
\text { - } & \text { Decreased myocardial } \\
\text { infarctions (infarct/ area at } \\
\text { risk) } \\
\text { - } \quad \text { Decreased malondialdehyde- } \\
\text { thiobarbituric acid (MDA) }\end{array}$ & 25 \\
\hline
\end{tabular}




\begin{tabular}{|c|c|c|c|c|}
\hline $\begin{array}{l}\text { Cardiovascular } \\
\text { dysfunction }\end{array}$ & Model & $\begin{array}{l}\text { Dosage of AVE } \\
\text { compounds }\end{array}$ & Major findings & Ref. \\
\hline \multirow[t]{2}{*}{$\begin{array}{l}\text { Cardiac } \\
\text { ischemia injury } \\
\text { (continued) }\end{array}$} & $\begin{array}{l}\text { Chronic myocardial } \\
\text { infarction: } \\
\text { rat model of Ml }\end{array}$ & $\begin{array}{l}\text { AVE9488 } \\
\text { (25 ppm AVE } \\
9488 \text { as a } \\
\text { dietary } \\
\text { supplement ; } \\
\text { average dose is } \\
1.25 / \mathrm{kg} / \mathrm{d} \text {, } \\
\text { starting } 7 \text { days } \\
\text { after coronary } \\
\text { artery ligation for } \\
\text { a period of } 9 \\
\text { wks) }\end{array}$ & $\begin{array}{ll}\text { - } & \text { Increased aortic and } \\
\text { myocardial eNOS protein } \\
\text { levels } \\
\text { - } \quad \text { Increased calcium-dependent } \\
\text { NOS activity in left venticular } \\
\text { myocardium } \\
-\quad \text { Improved EDR in aortas } \\
-\quad \text { Prevented LV dilatation, } \\
\text { - hypertrophy, fibrosis } \\
\text { Blunted the increased in } \\
\text { cardiac gene expression } \\
\text { (ANP, BNP and ET-1) } \\
-\quad \text { Decrease ROS generation } \\
-\quad \text { Reduced myocardial } \\
\text { nitrotyrosine levels } \\
-\quad \text { Increase p-VASP at Ser } 239 \\
-\quad \text { Increased circulating EPC } \\
\end{array}$ & 30 \\
\hline & $\begin{array}{l}\text { Hypoxia } \\
\text { reoxygenation: } \\
\text { porcine coronary } \\
\text { small arteries } \\
\text { incubated with St. } \\
\text { Thomas solution }\end{array}$ & $\begin{array}{l}\text { AVE3085 } \\
(10 \mu \mathrm{M} ; \\
\text { incubation) }\end{array}$ & $\begin{array}{ll}\text { - } & \text { Preserved the bradykinin } \\
\text { induced EDR } \\
\text { - } & \text { Enhanced eNOS expression } \\
\text { - } & \text { Increased phosphorylated } \\
\text { eNOS at Ser } 1177 \text { ( } p \text {-eNOS } \\
\text { Ser1177 ) }\end{array}$ & 21 \\
\hline \multirow[t]{3}{*}{$\begin{array}{l}\text { Impairment of } \\
\text { bone marrow } \\
\text { mononuclear } \\
\text { cells (BMC) in } \\
\text { ischemic } \\
\text { cardiomyopathy } \\
\text { (ICMP) and cell } \\
\text { therapy }\end{array}$} & $\begin{array}{l}\text { BMC derived from } \\
\text { patients with ICMP } \\
\text { (ex vivo and in } \\
\text { vitro) }\end{array}$ & $\begin{array}{l}\text { AVE9488 } \\
(5 \mu \mathrm{M} 18-24 \mathrm{hr} \\
\text { incubation) }\end{array}$ & $\begin{array}{l}\text { Increased eNOS mRNA } \\
\text { expression in peripheral } \\
\text { blood-derived EPC, CD34+ } \\
\text { and BMC } \\
\text { - } \\
\text { Increased eNOS protein } \\
\text { expression and activity, and } \\
\text { NO production in Lin-CD105+ } \\
\text { - Increased migratory capacity } \\
\text { of BMC in response to stromal } \\
\text { cell-derived factor } 1 \text { (SDF-1) }\end{array}$ & \multirow[t]{3}{*}{14} \\
\hline & Murine BMC & $\begin{array}{l}\text { AVE9488 } \\
(5 \mu \mathrm{M} 18 \mathrm{hr} \\
\text { incubation) }\end{array}$ & $\begin{array}{l}\text { - Increased migratory capacity } \\
\text { of BMC in response to SDF-1 } \\
\text { in WT }\end{array}$ & \\
\hline & $\begin{array}{l}\text { A nude mouse } \\
\text { model of unilateral } \\
\text { hind limb ischemia } \\
\text { (in vivo) }\end{array}$ & $\begin{array}{l}\text { AVE9488 } \\
(5 \mu \mathrm{M} 18 \mathrm{hr} \text {; } \\
\text { incubation; AVE- } \\
\text { treated BMC } \\
\text { from patients } \\
\text { with ICMP; i.v. } \\
\text { infusion) }\end{array}$ & $\begin{array}{l}\text { - Improved neovascularization } \\
\text { capacity } \\
\text { - } \quad \text { Enhanced recovery of limb } \\
\text { perfusion } \\
\text { - Increased the swimming time } \\
\text { ratio }\end{array}$ & \\
\hline
\end{tabular}




\begin{tabular}{|c|c|c|c|c|}
\hline $\begin{array}{l}\text { Cardiovascular } \\
\text { dysfunction }\end{array}$ & Model & $\begin{array}{l}\text { Dosage of AVE } \\
\text { compounds }\end{array}$ & Major findings & Ref. \\
\hline \multirow[t]{2}{*}{ Heart failure } & $\begin{array}{l}\text { DAHL salt- } \\
\text { sensitive induced } \\
\text { Diastolic heart } \\
\text { failure (DHF) rats }\end{array}$ & $\begin{array}{l}\text { AVE3085 } \\
(10 \mathrm{mg} / \mathrm{kg} / \mathrm{day} ; \\
8 w \mathrm{ks} ; \text { p.o. })\end{array}$ & 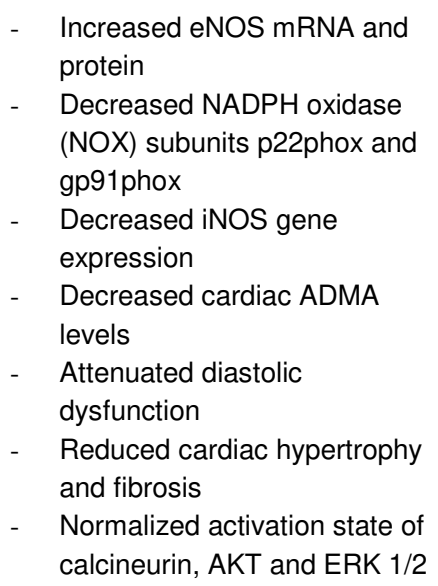 & 26 \\
\hline & $\begin{array}{l}\text { Pressure overload- } \\
\text { induced left } \\
\text { ventricular } \\
\text { hypertrophy mice }\end{array}$ & $\begin{array}{l}\text { AVE3085 (10 } \\
\text { mg/ kg /day, } 4 \\
\text { wks; p.o.) }\end{array}$ & $\begin{array}{ll}\text { - } & \text { Increased eNOS expression } \\
\text { - } & \text { improved cardiac function } \\
- & \text { Alleviated cardiac remodeling } \\
- & \text { Downregulated ANP and b- } \\
\text { MHC mRNA expression } \\
\text { - } \quad \text { Inhibited Smad } 1 / 2 \text { signaling } \\
\quad \text { pathway }\end{array}$ & 31 \\
\hline $\begin{array}{l}\text { Arterial } \\
\text { thrombosis and } \\
\text { platelet } \\
\text { activation }\end{array}$ & $\begin{array}{l}\text { congestive heart } \\
\text { failure rats }(\mathrm{CHF} ; \\
\text { left ventricular end- } \\
\text { diastolic pressure } \\
>15 \mathrm{mmHg})\end{array}$ & $\begin{array}{l}\text { AVE9488 ( } 25 \\
\text { ppm/day); } 10 \\
\text { wks; p.o. as diet } \\
\text { supplements) }\end{array}$ & $\begin{array}{l}\text { normalized platelet VASP } \\
\text { phosphorylation at serine } 157 \\
\text { and } 293 \text { in eNOS-dependent } \\
\text { manner } \\
\text { - } \quad \text { reduced expression of } \\
\text { markers of platelet } \\
\text { degranulation (i.e. P-selection } \\
\text { and glycoprotein 53) }\end{array}$ & 34 \\
\hline
\end{tabular}

$\left({ }^{*}\right)$ Of note, the beneficial effects in enhancing eNOS expression and activity of AVE compounds are absent in the presence of NOS inhibitor substances (L-NAME and L-NNA), transcription inhibitor (actinomycin D), endothelium-denuded rat aorta, and in $\mathrm{eNOS}^{-/-}$mice) 


\section{References}

1. Förstermann U, Sessa WC. Nitric oxide synthases: regulation and function. European Heart Journal 2012;33(7):829-837.

2. Takimoto E, Kass DA. Role of Oxidative Stress in Cardiac Hypertrophy and Remodeling. Hypertension 2007;49(2):241-248.

3. Naseem KM. The role of nitric oxide in cardiovascular diseases. Molecular Aspects of Medicine 2005;26(1-2):33-65.

4. Huang PL. eNOS, metabolic syndrome and cardiovascular disease. Trends in Endocrinology \& Metabolism 2009;20(6):295-302.

5. Miller MR, Megson IL. Recent developments in nitric oxide donor drugs. British Journal of Pharmacology 2007;151(3):305-321.

6. Ignarro LJ, Napoli C, Loscalzo J. Nitric Oxide Donors and Cardiovascular Agents Modulating the Bioactivity of Nitric Oxide: An Overview. Circulation Research 2002;90(1):21-28.

7. Zhuo JL, Mendelsohn FAO, Ohishi M. Perindopril Alters Vascular Angiotensin-Converting Enzyme, AT1 Receptor, and Nitric Oxide Synthase Expression in Patients With Coronary Heart Disease. Hypertension 2002;39(2):634-638.

8. Ding Y, Vaziri ND. Nifedipine and Diltiazem but Not Verapamil Up-Regulate Endothelial NitricOxide Synthase Expression. Journal of Pharmacology and Experimental Therapeutics 2000;292(2):606-609.

9. Laufs U, La Fata V, Plutzky J, Liao JK. Upregulation of Endothelial Nitric Oxide Synthase by HMG CoA Reductase Inhibitors. Circulation 1998;97(12):1129-1135.

10. Das A, Xi L, Kukreja RC. Phosphodiesterase-5 Inhibitor Sildenafil Preconditions Adult Cardiac Myocytes against Necrosis and Apoptosis: ESSENTIAL ROLE OF NITRIC OXIDE SIGNALING. Journal of Biological Chemistry 2005;280(13):12944-12955.

11. Aragón JP, Condit ME, Bhushan S, Predmore BL, Patel SS, Grinsfelder DB, Gundewar S, Jha S, Calvert JW, Barouch LA, Lavu M, Wright HM, Lefer DJ. Beta3-Adrenoreceptor Stimulation Ameliorates Myocardial Ischemia-Reperfusion Injury Via Endothelial Nitric Oxide Synthase and Neuronal Nitric Oxide Synthase Activation. Journal of the American College of Cardiology;58(25):2683-2691.

12. Förstermann U, Li H. Therapeutic effect of enhancing endothelial nitric oxide synthase (eNOS) expression and preventing eNOS uncoupling. British Journal of Pharmacology 2011;164(2):213223.

13. Förstermann U, Münzel T. Endothelial Nitric Oxide Synthase in Vascular Disease. Circulation 2006;113(13):1708

14. Sasaki K-i, Heeschen C, Aicher A, Ziebart T, Honold J, Urbich C, Rossig L, Koehl U, Koyanagi M, Mohamed A, Brandes RP, Martin H, Zeiher AM, Dimmeler S. Ex vivo pretreatment of bone marrow mononuclear cells with endothelial NO synthase enhancer AVE9488 enhances their functional activity for cell therapy. Proceedings of the National Academy of Sciences 2006;103(39):14537-14541.

15. Wohlfart $\mathrm{P}, \mathrm{Xu} \mathrm{H}$, Endlich A, Habermeier A, Closs El, Hubschle T, Mang C, Strobel H, Suzuki T, Kleinert H, Forstermann U, Ruetten H, Li H. Antiatherosclerotic Effects of Small-Molecular-Weight Compounds Enhancing Endothelial Nitric-Oxide Synthase (eNOS) Expression and Preventing eNOS Uncoupling. Journal of Pharmacology and Experimental Therapeutics 2008;325(2):370379.

16. Chen C-A, Druhan LJ, Varadharaj S, Chen Y-R, Zweier JL. Phosphorylation of Endothelial Nitricoxide Synthase Regulates Superoxide Generation from the Enzyme. Journal of Biological Chemistry 2008;283(40):27038-27047.

17. Dimmeler S, Fleming I, Fisslthaler B, Hermann C, Busse R, Zeiher AM. Activation of nitric oxide synthase in endothelial cells by Akt-dependent phosphorylation. Nature 1999;399(6736):601-605. 
18. Michell BJ, Chen Z-p, Tiganis T, Stapleton D, Katsis F, Power DA, Sim AT, Kemp BE. Coordinated Control of Endothelial Nitric-oxide Synthase Phosphorylation by Protein Kinase C and the cAMP-dependent Protein Kinase. Journal of Biological Chemistry 2001;276(21):1762517628.

19. Fleming I, Fisslthaler B, Dimmeler S, Kemp BE, Busse R. Phosphorylation of Thr495 Regulates $\mathrm{Ca} 2+/$ Calmodulin-Dependent Endothelial Nitric Oxide Synthase Activity. Circulation Research 2001;88(11):e68.

20. Yang Q, Xue H-M, Underwood M, Yu C-M. Mechanistic Studies of AVE3085 Against Homocysteine in Endothelial Protection. Cardiovascular Drugs and Therapy 2013;27(6):511-520.

21. Hong-Mei Xue, Guo-Wei He, Jun-Hao Huang, Yang Q. New Strategy of Endothelial Protection in Cardiac Surgery: Use of Enhancer of Endothelial Nitric Oxide Synthase. World Journal of Surgery 2010;34(7):1461-1469.

22. Xue H-M, Yu C-M, Underwood M, Huang J-H, Yang Q. AVE3085 Protects Coronary Endothelium from the Impairment of Asymmetric Dimethylarginine by Activation and Recoupling of eNOS. Cardiovasc Drugs Ther 2012;26(5):383-392.

23. Cheang WS, Wong WT, Tian XY, Yang Q, Lee HK, He G-W, Yao X, Huang Y. Endothelial nitric oxide synthase enhancer reduces oxidative stress and restores endothelial function in $\mathrm{db} / \mathrm{db}$ mice. Cardiovascular Research 2011;92(2):267-275.

24. Jarajapu Y, Caballero S, Verma A, Nakagawa T, Lo M, Li Q, Grant M. Blockade of NADPH oxidase restores vasoreparative function in diabetic CD34+ cells. Invest Ophthalmol Vis Sci 2011;52(8):5093-5104.

25. Frantz S, Adamek A, Fraccarollo D, Tillmanns J, Widder J, Dienesch C, Schäfer A, Podolskaya A Held M, Ruetten H, Ertl G, Bauersachs J. The eNOS enhancer AVE 9488: a novel cardioprotectant against ischemia reperfusion injury. Basic Research in Cardiology 2009;104(6):773-779.

26. Westermann D, Riad A, Richter U, Jäger S, Savvatis K, Schuchardt M, Bergmann N, Tölle M, Nagorsen D, Gotthardt M, Schultheiss H-P, Tschöpe C. Enhancement of the endothelial NO synthase attenuates experimental diastolic heart failure. Basic Research in Cardiology 2009;104(5):499-509.

27. Kim JH, Bugaj LJ, Oh YJ, Bivalacqua TJ, Ryoo S, Soucy KG, Santhanam L, Webb A, Camara A, Sikka G, Nyhan D, Shoukas AA, llies M, Christianson DW, Champion HC, Berkowitz DE. Arginase inhibition restores NOS coupling and reverses endothelial dysfunction and vascular stiffness in old rats. Journal of Applied Physiology 2009;107(4):1249-1257.

28. Dobrian AD. ADMA and NOS regulation in chronic renal disease: beyond the old rivalry for Larginine. Kidney International 2012;81(8):722-724.

29. Yang Q, Xue H-M, Wong W-T, Tian X-Y, Huang Y, Tsui SKW, Ng PKS, Wohlfart P, Li H, Xia N, Tobias S, Underwood MJ, He G-W. AVE3085, an enhancer of endothelial nitric oxide synthase, restores endothelial function and reduces blood pressure in spontaneously hypertensive rats. British Journal of Pharmacology 2011;163(5):1078-1085.

30. Fraccarollo D, Widder JD, Galuppo P, Thum T, Tsikas D, Hoffmann M, Ruetten H, Ertl G, Bauersachs J. Improvement in Left Ventricular Remodeling by the Endothelial Nitric Oxide Synthase Enhancer AVE9488 After Experimental Myocardial Infarction. Circulation 2008;118(8):818-827.

31. Chen Y, Chen C, Feng C, Tang A, Ma Y, He X, Li Y, He J, Dong Y. AVE 3085, a novel endothelial nitric oxide synthase enhancer, attenuates cardiac remodeling in mice through the Smad signaling pathway. Archives of Biochemistry and Biophysics 2015;570:8-13.

32. Masano T, Kawashima S, Toh R, Satomi-Kobayashi S, Shinohara M, Takaya T, Sasaki N, Takeda M, Tawa H, Yamashita T, Yokoyama M, Hirata K-i. Beneficial Effects of Exogenous Tetrahydrobiopterin on Left Ventricular Remodeling After Myocardial Infarction in Rats. The Possible Role of Oxidative Stress Caused by Uncoupled Endothelial Nitric Oxide Synthase. Circulation Journal 2008;72(9):1512-1519. 
33. Schäfer A, Wiesmann F, Neubauer S, Eigenthaler M, Bauersachs J, Channon KM. Rapid Regulation of Platelet Activation In Vivo by Nitric Oxide. Circulation 2004;109(15):1819-1822.

34. Schäfer A, Fraccarollo D, Widder J, Eigenthaler M, Ertl G, Bauersachs J. Inhibition of platelet activation in rats with severe congestive heart failure by a novel endothelial nitric oxide synthase transcription enhancer. European Journal of Heart Failure 2009;11(4):336-341.

35. Perin EC, Geng Y-J, Willerson JT. Adult Stem Cell Therapy in Perspective. Circulation 2003;107(7):935-938.

36. Tateishi-Yuyama E, Matsubara H, Murohara T, Ikeda U, Shintani S, Masaki H, Amano K, Kishimoto Y, Yoshimoto K, Akashi H, Shimada K, Iwasaka T, Imaizumi T. Therapeutic angiogenesis for patients with limb ischaemia by autologous transplantation of bone-marrow cells: a pilot study and a randomised controlled trial. The Lancet 2002;360(9331):427-435.

37. Assmus B, Schächinger V, Teupe C, Britten M, Lehmann R, Döbert N, Grünwald F, Aicher A, Urbich C, Martin H, Hoelzer D, Dimmeler S, Zeiher AM. Transplantation of Progenitor Cells and Regeneration Enhancement in Acute Myocardial Infarction (TOPCARE-AMI). Circulation 2002;106(24):3009-3017.

38. Aicher A, Heeschen C, Mildner-Rihm C, Urbich C, Ihling C, Technau-Ihling K, Zeiher AM, Dimmeler S. Essential role of endothelial nitric oxide synthase for mobilization of stem and progenitor cells. Nat Med 2003;9(11):1370-1376.

39. Landmesser U, Engberding N, Bahlmann FH, Schaefer A, Wiencke A, Heineke A, Spiekermann S, Hilfiker-Kleiner D, Templin C, Kotlarz D, Mueller M, Fuchs M, Hornig B, Haller H, Drexler H. Statin-Induced Improvement of Endothelial Progenitor Cell Mobilization, Myocardial Neovascularization, Left Ventricular Function, and Survival After Experimental Myocardial Infarction Requires Endothelial Nitric Oxide Synthase. Circulation 2004;110(14):1933-1939.

40. Iwakura A, Luedemann C, Shastry S, Hanley A, Kearney M, Aikawa R, Isner JM, Asahara T, Losordo DW. Estrogen-Mediated, Endothelial Nitric Oxide Synthase-Dependent Mobilization of Bone Marrow-Derived Endothelial Progenitor Cells Contributes to Reendothelialization After Arterial Injury. Circulation 2003;108(25):3115-3121.

41. d'Uscio LV, Smith LA, Santhanam AV, Richardson D, Nath KA, Katusic ZS. Essential Role of Endothelial Nitric Oxide Synthase in Vascular Effects of Erythropoietin. Hypertension 2007;49(5):1142-1148.

42. Urao N, Okigaki M, Yamada H, Aadachi Y, Matsuno K, Matsui A, Matsunaga S, Tateishi K, Nomura T, Takahashi T, Tatsumi T, Matsubara H. Erythropoietin-Mobilized Endothelial Progenitors Enhance Reendothelialization via Akt-Endothelial Nitric Oxide Synthase Activation and Prevent Neointimal Hyperplasia. Circulation Research 2006;98(11):1405-1413.

43. Kietadisorn R, Juni RP, Moens AL. Tackling endothelial dysfunction by modulating NOSuncoupling: new insights in pathogenesis and therapeutic possibilities. American Journal of Physiology - Endocrinology And Metabolism 2011.

44. Hink U, Li H, Mollnau H, Oelze M, Matheis E, Hartmann M, Skatchkov M, Thaiss F, Stahl RAK, Warnholtz A, Meinertz T, Griendling K, Harrison DG, Forstermann U, Munzel T. Mechanisms Underlying Endothelial Dysfunction in Diabetes Mellitus. Circulation Research 2001;88(2):e14e22.

45. Kersten JR, Toller WG, Tessmer JP, Pagel PS, Warltier DC. Hyperglycemia reduces coronary collateral blood flow through a nitric oxide-mediated mechanism. American Journal of Physiology - Heart and Circulatory Physiology 2001;281(5):H2097-H2104.

46. Stepanovic V, Awad O, Jiao C, Dunnwald M, Schatteman GC. Leprdb Diabetic Mouse Bone Marrow Cells Inhibit Skin Wound Vascularization but Promote Wound Healing. Circulation Research 2003;92(11):1247-1253.

47. Tepper OM, Galiano RD, Capla JM, Kalka C, Gagne PJ, Jacobowitz GR, Levine JP, Gurtner GC. Human Endothelial Progenitor Cells From Type II Diabetics Exhibit Impaired Proliferation, Adhesion, and Incorporation Into Vascular Structures. Circulation 2002;106(22):2781-2786. 
48. Segal MS, Shah R, Afzal A, Perrault CM, Chang K, Schuler A, Beem E, Shaw LC, Li Calzi S, Harrison JK, Tran-Son-Tay R, Grant MB. Nitric Oxide Cytoskeletal-Induced Alterations Reverse the Endothelial Progenitor Cell Migratory Defect Associated With Diabetes. Diabetes 2006;55(1):102-109.

49. Thum T, Bauersachs J. Letter by Thum et al Regarding Article, "Oxidant Stress Impairs In Vivo Reendothelialization Capacity of Endothelial Progenitor Cells From Patients With Type 2 Diabetes Mellitus: Restoration by the Peroxisome Proliferator- Activated Receptor- $\gamma$ Agonist Rosiglitazone". Circulation 2008;117(10):e185.

50. Sorrentino SA, Bahlmann FH, Besler C, Müller M, Schulz S, Kirchhoff N, Doerries C, Horváth T, Limbourg A, Limbourg F, Fliser D, Haller H, Drexler H, Landmesser U. Oxidant Stress Impairs In Vivo Reendothelialization Capacity of Endothelial Progenitor Cells From Patients With Type 2 Diabetes Mellitus: Restoration by the Peroxisome Proliferator-Activated Receptor- $\gamma$ Agonist Rosiglitazone. Circulation 2007;116(2):163-173.

51. Thum T, Fraccarollo D, Schultheiss M, Froese S, Galuppo P, Widder JD, Tsikas D, Ertl G, Bauersachs J. Endothelial Nitric Oxide Synthase Uncoupling Impairs Endothelial Progenitor Cell Mobilization and Function in Diabetes. Diabetes 2007;56(3):666-674.

52. Oemar BS, Tschudi MR, Godoy N, Brovkovich V, Malinski T, Luscher TF. Reduced Endothelial Nitric Oxide Synthase Expression and Production in Human Atherosclerosis. Circulation 1998;97(25):2494-2498.

53. Wilcox JN, Subramanian RR, Sundell CL, Tracey WR, Pollock JS, Harrison DG, Marsden PA. Expression of Multiple Isoforms of Nitric Oxide Synthase in Normal and Atherosclerotic Vessels. Arteriosclerosis, Thrombosis, and Vascular Biology 1997;17(11):2479-2488.

54. Hayashi T, Sumi D, Juliet PAR, Matsui-Hirai H, Asai-Tanaka Y, Kano H, Fukatsu A, Tsunekawa T, Miyazaki A, Iguchi A, Ignarro LJ. Gene transfer of endothelial NO synthase, but not eNOS, plus inducible NOS regressed atherosclerosis in rabbits. Cardiovascular Research 2004;61(2):339351.

55. Bendall JK, Alp NJ, Warrick N, Cai S, Adlam D, Rockett K, Yokoyama M, Kawashima S, Channon KM. Stoichiometric Relationships Between Endothelial Tetrahydrobiopterin, Endothelial NO Synthase (eNOS) Activity, and eNOS Coupling in Vivo: Insights From Transgenic Mice With Endothelial-Targeted GTP Cyclohydrolase 1 and eNOS Overexpression. Circ Res 2005;97(9):864-871.

56. Sibal L, Agarwal SC, Home PD, Boger RH. The Role of Asymmetric Dimethylarginine (ADMA) in Endothelial Dysfunction and Cardiovascular Disease. Current Cardiology Reviews 2010;6(2):8290.

57. Schlesinger S, Sonntag SR, Lieb W, Maas R. Asymmetric and Symmetric Dimethylarginine as Risk Markers for Total Mortality and Cardiovascular Outcomes: A Systematic Review and MetaAnalysis of Prospective Studies. PLoS ONE 2016;11(11):e0165811.

58. Vallance P, Leiper J. Cardiovascular Biology of the Asymmetric Dimethylarginine:Dimethylarginine Dimethylaminohydrolase Pathway. Arteriosclerosis, Thrombosis, and Vascular Biology 2004;24(6):1023-1030.

59. Kielstein JT, Impraim B, Simmel S, Bode-Böger SM, Tsikas D, Frölich JC, Hoeper MM, Haller H, Fliser D. Cardiovascular Effects of Systemic Nitric Oxide Synthase Inhibition With Asymmetrical Dimethylarginine in Humans. Circulation 2004;109(2):172-177.

60. Achan V, Broadhead M, Malaki M, Whitley G, Leiper J, MacAllister R, Vallance P. Asymmetric Dimethylarginine Causes Hypertension and Cardiac Dysfunction in Humans and Is Actively Metabolized by Dimethylarginine Dimethylaminohydrolase. Arteriosclerosis, Thrombosis, and Vascular Biology 2003;23(8):1455-1459.

61. Sydow K, Schwedhelm E, Arakawa N, Bode-Böger SM, Tsikas D, Hornig B, Frölich JC, Böger $\mathrm{RH}$. ADMA and oxidative stress are responsible for endothelial dysfunction in hyperhomocyst(e)inemia: effects of I-arginine and B vitamins. Cardiovascular Research 2003;57(1):244-252. 
62. Antoniades C, Shirodaria C, Leeson P, Antonopoulos A, Warrick N, Van-Assche T, Cunnington C, Tousoulis D, Pillai R, Ratnatunga C, Stefanadis C, Channon KM. Association of plasma asymmetrical dimethylarginine (ADMA) with elevated vascular superoxide production and endothelial nitric oxide synthase uncoupling: implications for endothelial function in human atherosclerosis. European Heart Journal 2009;30(9):1142-1150.

63. Xuan C, Chang F-J, Liu X-C, Bai X-Y, Liao X-L, He G-W, Ou J-S. Endothelial nitric oxide synthase enhancer for protection of endothelial function from asymmetric dimethylarginineinduced injury in human internal thoracic artery. The Journal of Thoracic and Cardiovascular Surgery 2012;144(3):697-703.

64. Christen WG, Ajani UA, Glynn RJ, Hennekens CH. Blood levels of homocysteine and increased risks of cardiovascular disease: Causal or casual? Archives of Internal Medicine 2000;160(4):422434.

65. Topal G, Brunet A, Millanvoye E, Boucher J-L, Rendu F, Devynck M-A, David-Dufilho M. Homocysteine induces oxidative stress by uncoupling of no synthase activity through reduction of tetrahydrobiopterin. Free Radical Biology and Medicine 2004;36(12):1532-1541.

66. Dhillon B, Badiwala M, Maitland A, Rao V, Li S-H, Verma S. Tetrahydrobiopterin attenuates homocysteine induced endothelial dysfunction. Mol Cell Biochem 2003;247(1-2):223-227.

67. Wiemer G, Itter G, Malinski T, Linz W. Decreased Nitric Oxide Availability in Normotensive and Hypertensive Rats With Failing Hearts After Myocardial Infarction. Hypertension 2001;38(6):13671371.

68. Hornig B, Arakawa N, Kohler C, Drexler H. Vitamin C improves endothelial function of conduit arteries in patients with chronic heart failure. Circulation 1998;97(4):363-368.

69. Zeiher AM, Drexler H, Saurbier B, Just H. Endothelium-mediated coronary blood flow modulation in humans. Effects of age, atherosclerosis, hypercholesterolemia, and hypertension. The Journal of clinical investigation 1993;92(2):652-662.

70. Jones SP, Greer JJM, Kakkar AK, Ware PD, Turnage RH, Hicks M, van Haperen R, de Crom R, Kawashima S, Yokoyama M, Lefer DJ. Endothelial nitric oxide synthase overexpression attenuates myocardial reperfusion injury. American Journal of Physiology - Heart and Circulatory Physiology 2004;286(1):H276-H282.

71. Sharp BR, Jones SP, Rimmer DM, Lefer DJ. Differential response to myocardial reperfusion injury in eNOS-deficient mice. American Journal of Physiology - Heart and Circulatory Physiology 2002;282(6):H2422-H2426.

72. Perkins K-A, Pershad S, Chen Q, McGraw S, Adams J, Zambrano C, Krass S, Emrich J, Bell B, lyamu M, Prince C, Kay H, Teng J, Young L. The effects of modulating eNOS activity and coupling in ischemia/reperfusion (I/R). Naunyn-Schmiedeberg's Archives of Pharmacology 2012;385(1):27-38.

73. Schäfer A, Burkhardt M, Vollkommer T, Bauersachs J, Münzel T, Walter U, Smolenski A. Endothelium-dependent and -independent relaxation and VASP serines 157/239 phosphorylation by cyclic nucleotide-elevating vasodilators in rat aorta. Biochemical Pharmacology 2003;65(3):397-405.

74. Thygesen K, Alpert JS, Jaffe AS, Simoons ML, Chaitman BR, White HD. Third Universal Definition of Myocardial Infarction. Circulation 2012;126(16):2020-2035.

75. Scherrer-Crosbie M, Ullrich R, Bloch KD, Nakajima H, Nasseri B, Aretz HT, Lindsey ML, Vançon A-C, Huang PL, Lee RT, Zapol WM, Picard MH. Endothelial Nitric Oxide Synthase Limits Left Ventricular Remodeling After Myocardial Infarction in Mice. Circulation 2001;104(11):1286-1291.

76. Janssens S, Pokreisz P, Schoonjans L, Pellens M, Vermeersch P, Tjwa M, Jans P, ScherrerCrosbie M, Picard MH, Szelid Z, Gillijns H, Van de Werf F, Collen D, Bloch KD. CardiomyocyteSpecific Overexpression of Nitric Oxide Synthase 3 Improves Left Ventricular Performance and Reduces Compensatory Hypertrophy After Myocardial Infarction. Circulation Research 2004;94(9):1256-1262. 
77. Wollert KC, Fiedler B, Gambaryan S, Smolenski A, Heineke J, Butt E, Trautwein C, Lohmann SM, Drexler H. Gene Transfer of cGMP-Dependent Protein Kinase I Enhances the Antihypertrophic Effects of Nitric Oxide in Cardiomyocytes. Hypertension 2002;39(1):87-92.

78. Ritchie RH, Schiebinger RJ, Lapointe MC, Marsh JD. Angiotensin II-induced hypertrophy of adult rat cardiomyocytes is blocked by nitric oxide. American Journal of Physiology - Heart and Circulatory Physiology 1998;275(4):H1370-H1374.

79. Boulanger C, Lüscher TF. Release of endothelin from the porcine aorta. Inhibition by endothelium-derived nitric oxide. The Journal of Clinical Investigation 1990;85(2):587-590.

80. Vanhoutte PM. Say NO to ET. Journal of the Autonomic Nervous System 2000;81(1):271-277.

81. Paulus WJ, Tschope C, Sanderson JE, Rusconi C, Flachskampf FA, Rademakers FE, Marino P, Smiseth OA, De Keulenaer G, Leite-Moreira AF, Borbely A, Edes I, Handoko ML, Heymans S, Pezzali N, Pieske B, Dickstein K, Fraser AG, Brutsaert DL. How to diagnose diastolic heart failure: a consensus statement on the diagnosis of heart failure with normal left ventricular ejection fraction by the Heart Failure and Echocardiography Associations of the European Society of Cardiology. European Heart Journal 2007;28(20):2539-2550.

82. Paulus WJ, Shah AM. NO and cardiac diastolic function. Cardiovascular Research 1999;43(3):595-606.

83. Shibata K, Yatera Y, Furuno Y, Sabanai K, Morisada N, Nakata S, Morishita T, Yamazaki F, Tanimoto A, Sasaguri Y, Tasaki H, Nakashima Y, Shimokawa H, Yanagihara N, Otsuji Y, Tsutsui M. Spontaneous Development of Left Ventricular Hypertrophy and Diastolic Dysfunction in Mice Lacking All Nitric Oxide Synthases. Circulation Journal 2010;74(12):2681-2692.

84. Silberman GA, Fan T-HM, Liu H, Jiao Z, Xiao HD, Lovelock JD, Boulden BM, Widder J, Fredd S, Bernstein KE, Wolska BM, Dikalov S, Harrison DG, Dudley SC. Uncoupled Cardiac Nitric Oxide Synthase Mediates Diastolic Dysfunction. Circulation 2010;121(4):519-528.

85. Heusch G. Diastolic heart failure: a misNOmer. Basic Research in Cardiology 2009;104(5):465467.

86. Takimoto E, Champion HC, Li M, Ren S, Rodriguez ER, Tavazzi B, Lazzarino G, Paolocci N, Gabrielson KL, Wang Y, Kass DA. Oxidant stress from nitric oxide synthase-3 uncoupling stimulates cardiac pathologic remodeling from chronic pressure load. The Journal of Clinical Investigation 2005;115(5):1221-1231.

87. Moens AL, Takimoto E, Tocchetti CG, Chakir K, Bedja D, Cormaci G, Ketner EA, Majmudar M, Gabrielson K, Halushka MK, Mitchell JB, Biswal S, Channon KM, Wolin MS, Alp NJ, Paolocci N, Champion HC, Kass DA. Reversal of Cardiac Hypertrophy and Fibrosis From Pressure Overload by Tetrahydrobiopterin: Efficacy of Recoupling Nitric Oxide Synthase as a Therapeutic Strategy. Circulation 2008;117(20):2626-2636.

88. Lip GY, Gibbs CR. Does heart failure confer a hypercoagulable state? Virchow's triad revisited. Journal of the American College of Cardiology 1999;33(5):1424-1426.

89. Chung I, Lip GYH. Platelets and heart failure. European Heart Journal 2006;27(22):2623-2631.

90. Kubo SH, Rector TS, Bank AJ, Williams RE, Heifetz SM. Endothelium-dependent vasodilation is attenuated in patients with heart failure. Circulation 1991;84(4):1589-96.

91. O'Connor CM, Gurbel PA, Serebruany VL. Usefulness of soluble and surface-bound P-selectin in detecting heightened platelet activity in patients with congestive heart failure. The American Journal of Cardiology 1999;83(9):1345-1349.

92. Dixon LJ, Morgan DR, Hughes SM, McGrath LT, El-Sherbeeny NA, Plumb RD, Devine A, Leahey W, Johnston GD, McVeigh GE. Functional Consequences of Endothelial Nitric Oxide Synthase Uncoupling in Congestive Cardiac Failure. Circulation 2003;107(13):1725-1728.

93. Kader KN, Akella R, Ziats NP, Lakey LA, Harasaki H, Ranieri JP, RV B. eNOS-Overexpressing Endothelial Cells Inhibit Platelet Aggregation and Smooth Muscle Cell Proliferation in Vitro. Tissue Engineering 2000;6(3):241-251.

94. Loscalzo J. Nitric Oxide Insufficiency, Platelet Activation, and Arterial Thrombosis. Circulation Research 2001;88(8):756-762. 
95. Horstrup K, Jablonka B, Hönig-Liedl P, Just M, Kochsiek K, Walter U. Phosphorylation of Focal Adhesion Vasodilator-Stimulated Phosphoprotein at Ser157 in Intact Human Platelets Correlates with Fibrinogen Receptor Inhibition. European Journal of Biochemistry 1994;225(1):21-27.

96. Aszodi A, Pfeifer A, Ahmad M, Glauner M, Zhou X-H, Ny L, Andersson K-E, Kehrel B, Offermanns S, Fassler R. The vasodilator-stimulated phosphoprotein (VASP) is involved in cGMP-and CAMP-mediated inhibition of agonist-induced platelet aggregation, but is dispensable for smooth muscle function. EMBO J 1999;18(1):37-48.

97. Oelze M, Mollnau H, Hoffmann N, Warnholtz A, Bodenschatz M, Smolenski A, Walter U, Skatchkov M, Meinertz T, Münzel T. Vasodilator-Stimulated Phosphoprotein Serine 239 Phosphorylation as a Sensitive Monitor of Defective Nitric Oxide/cGMP Signaling and Endothelial Dysfunction. Circulation Research 2000;87(11):999-1005.

98. Arnold WP, Mittal CK, Katsuki S, Murad F. Nitric oxide activates guanylate cyclase and increases guanosine $3^{\prime}: 5^{\prime}$-cyclic monophosphate levels in various tissue preparations. Proceedings of the National Academy of Sciences 1977;74(8):3203-3207.

99. López-Rivera E, Lizarbe TR, Martínez-Moreno M, López-Novoa JM, Rodríguez-Barbero A, Rodrigo J, Fernández AP, Álvarez-Barrientos A, Lamas S, Zaragoza C. Matrix metalloproteinase 13 mediates nitric oxide activation of endothelial cell migration. Proceedings of the National Academy of Sciences of the United States of America 2005;102(10):3685-3690.

100. Ozaki M, Kawashima S, Yamashita T, Hirase T, Namiki M, Inoue N, Hirata K-i, Yasui H, Sakurai $H$, Yoshida Y, Masada M, Yokoyama M. Overexpression of endothelial nitric oxide synthase accelerates atherosclerotic lesion formation in apoE-deficient mice. The Journal of Clinical Investigation 2002;110(3):331-340. 



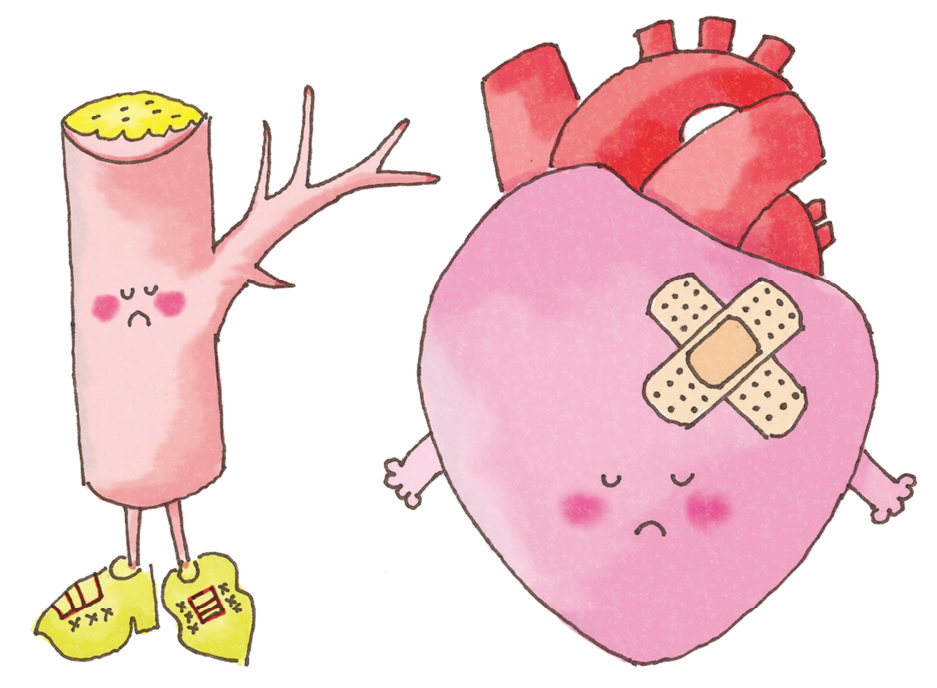




\section{Chapter 5}

\section{(Pharmacological) Enhancement of endothelial nitric oxide synthase activity prevents pressure overload-induced ventricular hypertrophy}

R.Kietadisorn, Y. Octavia, R. Juni, A.L. Moens, P. Wohlfart, J.C. Sluimer, E.A.L. Biessen (In preparation) 


\begin{abstract}
Aims: Endothelial nitric oxide synthase (eNOS) has a central role in the pathogenesis of pressure overload-induced ventricular remodeling. The small molecule AVE3085 can enhance transcription of eNOS and interference with eNOS-uncoupling has been suggested. In this study, we tested if AVE3085 can prevent pressure overload-induced cardiac hypertrophy.
\end{abstract}

Methods and results: Mice C57BL/6 ( $n=12 /$ group) underwent severe transverse aortic constriction (TAC) for one week to develop cardiac hypertrophy and remodeling. Oral AVE3085 (30 mg/kg/day) or placebo ( $0.5 \%$ methyl hydroxyeythylcellulose) were given from the day of surgery for 7 days. AVE3085 treatment reversed TAC-induced cardiac hypertrophy indices, including heart weight/body weight ratio (HW/BW; -21\%), heart weight/ tibia length ratio (HW/TL; $-13 \%)$, myocyte dimension $(-9 \%)$ and relative fibrosis area (-60\%). Also, hypertrophic markers B-type natriuretic peptide (BNP) and beta myosin heavy chain (bMHC) expression were normalized by $-6 \%$ and $-3 \%$ respectively compared to control TAC mice. This was associated with improved cardiac function, including left ventricular end-systolic diameter (LVESD; -34\%), wall thickness (-24\%), calculated LV mass $(-76 \%)$, fraction shortening (FS; $15 \%)$, and ejection fraction (EF; 7\%). Moreover, a reduction in cardiac reactive oxygen species (ROS) compared to control TAC mice was not reduced further by the NOS inhibitor LNAME. Interestingly, eNOS homodimer stability was also improved. Together this suggests AVE3084 reversed eNOS uncoupling, while eNOS mRNA and protein levels only showed a trend to increase after AVE3084 treatment.

Conclusion: AVE308 treatment reversed pressure overload-induced ventricular remodeling, which was likely mediated by a reversal of eNOS uncoupling through protection of tetrahydrobiopterin oxidation by ROS. 


\section{Introduction}

Sustained pressure overload can lead to pathologic cardiac hypertrophy and dysfunction ${ }^{1}$, and prevention or delay of this maladaptative response has emerged as an important therapeutic goal ${ }^{2}$. Under physiological conditions, nitric oxide (NO) generated by endothelial nitric oxide synthase (eNOS) plays a key role in cardiomyocyte contractility and vascular tone ${ }^{3,4}$. Proper function of eNOS requires dimerization of the enzyme and the presence of its cofactor tetrahydrobiopterin (BH4). Functional eNOS is able to oxidize its substrate L-arginine to produce L-citrulline and NO. It is well documented that uncoupling of eNOS is a prominent source of reactive oxygen species (ROS) generated in myocardium in pressure overload-induced ventricular remodeling and cardiac dysfunction ${ }^{5,6}$. eNOS uncoupling involves a shift from dimeric to monomeric state, resulting in reduced NO production and increased ROS generation ${ }^{7}$. The production of ROS in turn enhances oxidation of $\mathrm{BH} 4$, leading to decrease bioavailability of this cofactor, creating a vicious cycle of progressive eNOS uncoupling. Although BH4 deficiency is a major cause for eNOS function loss ${ }^{8}$, diminished eNOS transcription, mRNA stability and translation were proposed to be instrumental in this process (see reviews ${ }^{9}$ ). Because uncoupled eNOS generates not only NO, but also ROS, increasing eNOS transcription, translation or activity does not guarantee improved endothelial function ${ }^{10}$. Hence pharmacological approaches to preserve or restore eNOS functionality and prevent eNOS uncoupling are thus warranted. Indan compounds AVE9488 and AVE3085 were designed to enhance eNOS gene expression, with the eventual aim to increase NO signaling and bioavailability ${ }^{11,12}$. Surprisingly, AVE 9488 has also been shown to enhance endothelial $\mathrm{BH} 4$ levels and reverse eNOS uncoupling in experimental atherosclerosis ${ }^{12}$. This favorable activity profile suggests that AVE compounds could be effective in eNOS dysfunction induced cardiac diseases. While AVE3085 was seen to prevent cardiac remodeling in experimental compensated left ventricular dilation ${ }^{13}$, its effect on eNOS dysfunction and myocardial ROS formation in a mouse model of left ventricular hypertrophy is unknown. To investigate the potential role of AVE3085, a novel pharmacological modulator of eNOS, in cardiac stress remodeling associated with pressure overload, we subjected mice to severe transverse aortic constriction (TAC) for 1 week as a model of acute onset of HF. It is well established that eNOS uncoupling plays a major role in TAC pathobiology. Moreover, mice undergoing severe, but not mild, TAC show enhanced eNOS uncoupling associated with increased eNOS-dependent oxidative stress, and consequent cardiac dysfunction and remodeling ${ }^{5,6}$. We used C57BL/6 mice because they develop rapid cardiac hypertrophy, myocyte hypertrophy and fibrosis within 7 days after $\operatorname{TAC}^{7,8}$, allowing us to examine the utility of pharmacological or molecular interventions that may limit hypertrophy. In this study we therefore investigated the effects of AVE3085 on 
pressure overload induced eNOS uncoupling, and subsequent prevention and/or reversion of left ventricular hypertrophy.

\section{Materials and Methods}

All experiments were approved by the Animal Experiment Committee of Maastricht University and were performed in accordance with institutional and international guidelines.

\section{TAC and Study Protocols}

36 Male C57BL/ 6 mice ( $n=12$ per group; age, 9 to 11 weeks; weight, 22 to 24 g; Charles River, Maastricht, the Netherlands) underwent sham or severe transverse aortic constriction (TAC) surgery as previously described ${ }^{5}$. The mice were randomized to receive AVE3085 $(30 \mathrm{mg} / \mathrm{kg} / \mathrm{d}$; in $0.5 \%$ methyl hydroxyeythylcellulose (vehicle)) or placebo as a 7-day p.o. treatment, starting at the day of surgery. Animals were sacrificed at day 7 and organs were harvested for molecular, cellular, and superoxide anion generation. The experimental setup of this study is depicted in figure $1 \mathrm{~A}$.

\section{Cardiac Function}

In vivo cardiac morphology and function was assessed by transthoracic echocardiography; using a Hewlett-Packard $15 \mathrm{MHz}$ linear array transducer (15-6L) interfaced with a Sonos 5500 echocardiography system (Phillips, Eindhoven, The Netherlands) in conscious mice at baseline and at the end of the experiment. M-mode left ventricular (LV) end-systolic and end-diastolic dimensions were averaged from 3 to 5 beats, and data were analyzed by investigators blinded to the heart condition as described ${ }^{5}$.

\section{Histology}

The myocardium was fixed in $10 \%$ formalin, dehydrated in alcohol, embedded in paraffin, and $5 \mu \mathrm{M}$ sections were made. Subsequently, hematoxylin and eosin (HE) staining was performed. Images were taken with a Leica microscope at 20x magnification using QwinV3 software. Myocyte cross-sectional diameter was measured at the level of the nucleus in the longitudinally sectioned slides and analyzed with Adobe Photoshop 7.0.1 (3 slices in 4 different hearts in each group, averaging results from $60-90$ cells per group). Interstitial fibrosis was measured using picro-sirius red $(0.05 \%$ in saturated picric acid solution, Sigma). Images of nonvascular areas were randomly captured (4-5 fields per heart; $n=4$ per group; 20x magnification). Relative fibrosis areas were quantified by ImageJ MRI fibrosis tool (http://dev.mri.cnrs.fr/projects/imagej-macros/wiki/Fibrosis_Tool). 


\section{Gene expression analysis}

Total mRNA was extracted from 4-5 frozen LV samples per group using the RNeasy kit (Qiagen, The Netherlands) according to the manufacturer's protocol. RTqPCR was performed for specific genes of using SensiMix SYBR Green (Bio-Rad) on a Bio-Rad CFX96 Real-Time System, C1000 Thermal Cycler. Primer sequences for myocardial hypertrophy marker genes A- and B-type natriuretic peptide (ANP and $\mathrm{BNP}$ ), alpha and beta myosin heavy chain ( $\mathrm{aMHC}$ and bMHC), and phospholamban (PLB) are shown in table 1. mRNA expression were expressed relative to that of the housekeeping gene glyceraldehyde-3-phosphate dehydrogenase (GAPDH) and normalized to placebo-treated expression values.

mRNA expression of eNOS and guanosine triphosphate cyclohydrolase I (GCH1) was analyzed with the QuantiTect Probe RT-PCR kit (QIAGEN GmbH). TaqMan gene expression assays (predesigned probe and primer sets) were obtained from Applied Biosystems (Foster City, CA): eNOS (nos3; assay ID Mm00435204_m1), GCH1 (assay ID Mm00514993_m1) and GAPDH (assay ID 4352339E). Relative expression was calculated using the $2^{-\Delta \Delta C T}$ method.

\section{eNOS protein expression and dimer to monomer ratio}

Protein expression of eNOS was determined in homogenates of myocardium samples ( $n=5-6$ per group) as previously described ${ }^{14}$. Low temperature sodium dodecyl sulfate polyacrylamide gel electrophoresis (SDS-PAGE) was performed for detection of eNOS monomer and dimer as previous described ${ }^{6}$. Cold SDS-PAGE Western blot analysis was performed in $7 \%$ to $4 \%$ SDS-Tris gels run overnight on ice and then transferred for 3 hours to nitrocellulose membranes. Primary eNOS antibody (1:1000, Santa Cruz Technology, Inc, Santa Cruz, Calif) was detected by enhanced chemiluminescence (Pierce, Rockford, III) using a LAS 3000 imaging system. All protein bands were quantified using ImageJ $(\mathrm{NIH})$.

\section{Superoxide detection}

Superoxide generation in homogenized LV ( $n=3$ per group) was evaluated by low concentration lucigenin-enhanced chemiluminescence $(5 \mu \mathrm{mol} / \mathrm{L})$ using a singletube luminometer (Berthold FB12) as previously described ${ }^{15}$. Besides total superoxide production, NOS-dependent ROS production was determined by incubation of the same homogenized LV samples for $30 \mathrm{~min}$ with the NOS inhibitor LNAME (Sigma-Aldrich) $(1 \mathrm{mmol} / \mathrm{l})$. During the entire experiment the temperature was maintained at $37^{\circ} \mathrm{C}$; light emission was recorded and expressed as relative light units (RLU) per mg per second ${ }^{16}$. 


\subsection{Statistical Analysis}

All data are expressed as mean \pm SEM. Following the Kolmogorov-Smirnov test for normal distribution, the two groups were compared with student's t-test (Gaussian distribution) or Mann-Whitney test (non-Gaussian distribution). Parameters with more than two groups were analysed using one way ANOVA in combination with a Bonferroni post-hoc analysis, or Kruskal-Wallis Test, followed by Dunn's post-hoc testing. Analyses were performed using GraphPad Prism 5.0 (La Jolla, CA, USA). $P<0.05$ was considered to be statistically significant.

\section{Results}

\section{AVE3085 reversed cardiac hypertrophic remodeling and fibrosis}

To assess the effect of AVE3085 on left ventricular hypertrophy, histological analysis of the heart tissue was performed and cardiac myocyte dimension and interstitial fibrosis were measured (Figure1B-I). As expected, one week after TAC surgery in the placebo treated group we observed overt signs of cardiac hypertrophy, including heart weight /body weight ratio ( HW/BW; 70\%), heart weight/ tibia length ratio (HW/TL; $49 \%)$, myocyte dimension (37\%) and relative fibrosis area (1870\%), compared to the sham-operated group. As shown in Figure1B-I, hypertrophy reversed and heart function improved in TAC mice that had received AVE3085, as evidenced by a decreased hypertrophic response, including HW/BW (-21\%), HW/TL (-13\%), myocyte dimension $(-9 \%)$ and relative fibrosis area $(-60 \%)$. Treatment with AVE3085 decreased the TAC associated induction of the expression of hypertrophic markers Btype natriuretic peptide (BNP) and beta myosin heavy chain (bMHC) (Figure 11). Together, these findings indicated that AVE3085 was able to reversed cardiac hypertrophy and remodeling after pressure overload. 


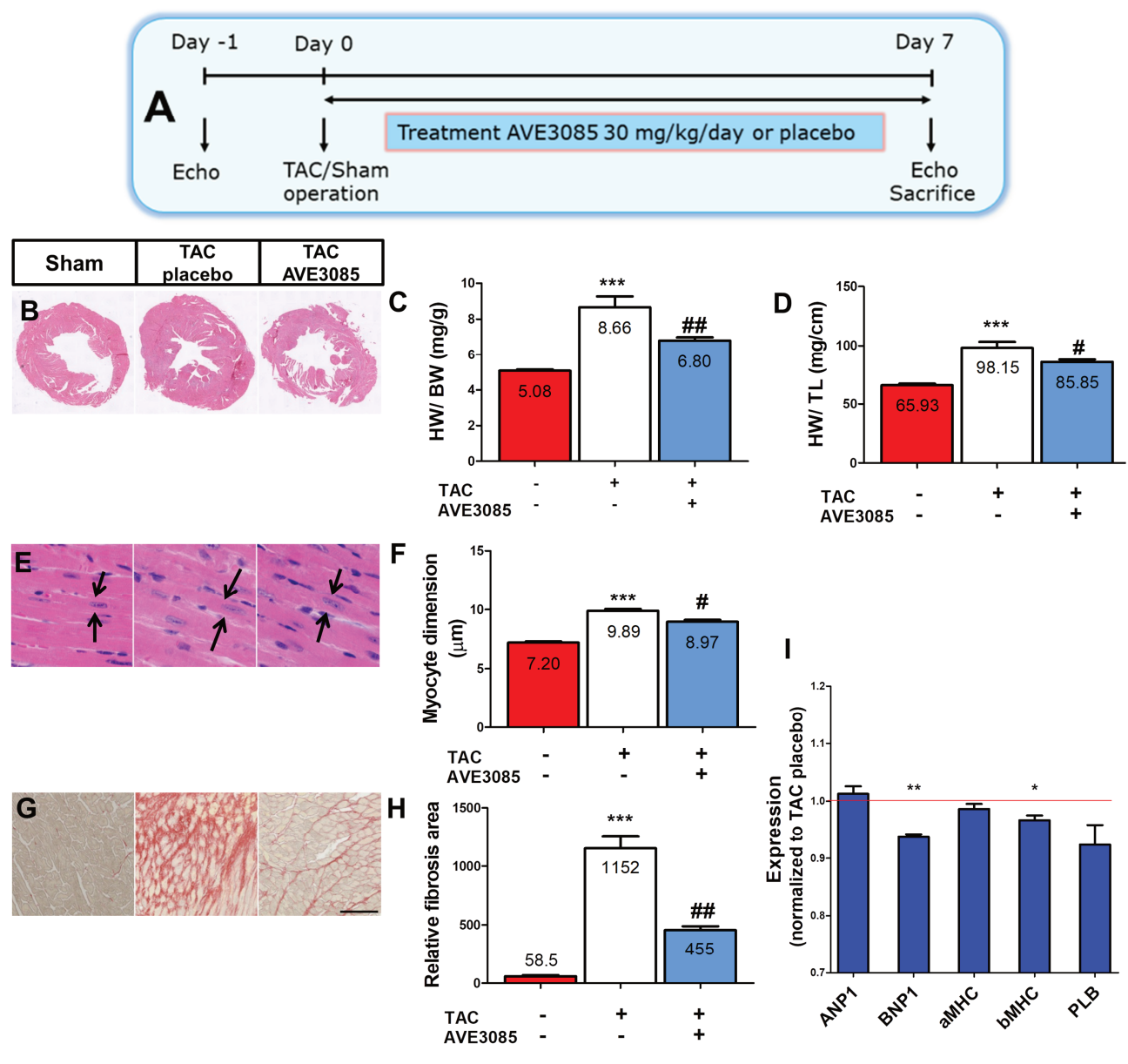

Figure 1. AVE3085 reverses cardiac hypertrophic remodeling and fibrosis

A. Schematic representation of experimental procedure for pressure overload-induced acute onset of heart failure in mice. B. Representative haematoxylin and eosin (HE) stained cross-sections of the murine heart 1 week after sham, TAC operation and/or AVE treatment (magnification $=1 x$ ), and corresponding quantifications of $\boldsymbol{C}$. Mean data for heart weight to body weight ratio (HW/BW), and $\boldsymbol{D}$. Heart weight to tibia length ratio (HW/TL). E. Representative HE staining showing myocyte dimensions (black arrows indicate dimensions; Magnification $=20 \mathrm{x}$ ) and $\boldsymbol{F}$. corresponding quantifications $(n=4$ group; 3 regions per heart averaging results from 60-90 cells per group). G. Picro-sirius red (PSR) staining revealed increased interstitial fibrosis in placebo-treated TAC heart (red staining; $n=4$ per group; 4-5 fields per heart; $20 x$ magnification scale bar $50 \mu \mathrm{M}$ ). $\boldsymbol{H}$. Quantification of relative fibrosis area, showing reversed interstitial fibrosis in AVE3085-treated TAC mice. ${ }^{* *} p<0.001$ vs. sham placebo; $\# p<0.05, \# \# p<0.01$ vs. TAC placebo. I. Analysis of fetal gene mRNA expression in TAC hearts, normalized by TAC placebo group ( $n=5$ per group). ${ }^{*} p<0.05,{ }^{* *} p<0.01$ vs TAC placebo. A- and B-type natriuretic peptide (ANP and BNP), alpha and beta myosin heavy chain (aMHC and bMHC), and phospholamban (PLB). 


\section{AVE3085 improved cardiac function}

Cardiac function was assessed by M-mode echocardiography in conscious mice. As shown in (Figure 2A-H), one week TAC resulted in increased left ventricular end-systolic diameter (LVESD; 110\%), end-diastolic wall thickness (90\%) and calculated left ventricular (LV) mass $(208 \%)$, while reducing cardiac contractility as assessed by fraction shortening (FS; -19\%) and ejection fraction (EF; -9\%), compared to sham operated placebo treatment. Treatment with AVE3085 attenuated all these deleterious changes (Figure $2 \mathrm{~A}-\mathrm{H})$, with marked decreases in LVESD $(-34 \%)$, wall thickness (-24\%) and calculated LV mass (-76\%) compared to placebo-treated TAC mice. A minor but significant increase in cardiac contractility parameters was detected (FS: $15 \%$ and EF: $7 \%$ ), compared to placebo-treated TAC mice. Thus, AVE3085 diminished pathological LV remodeling and myocardial contractile dysfunction caused by pressure overload- induced LV hypertrophy.

A

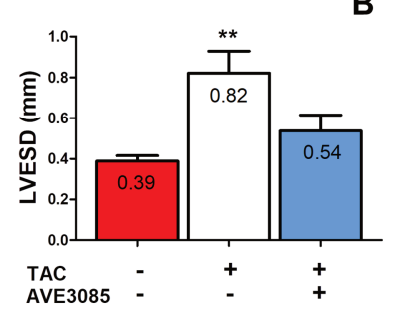

D

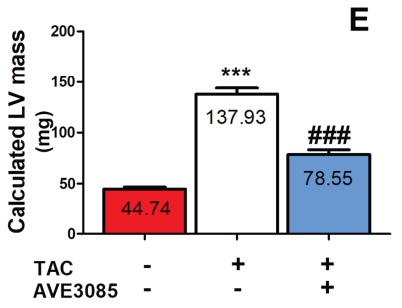

B
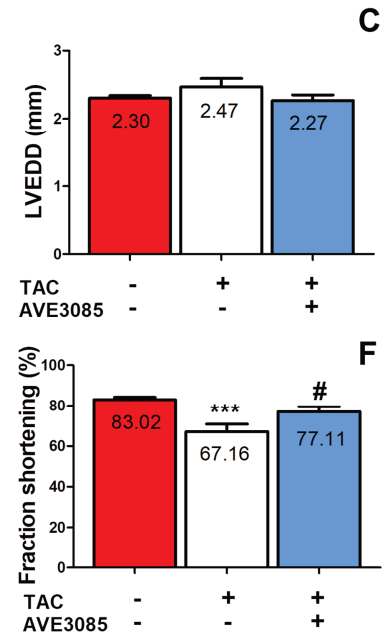

C
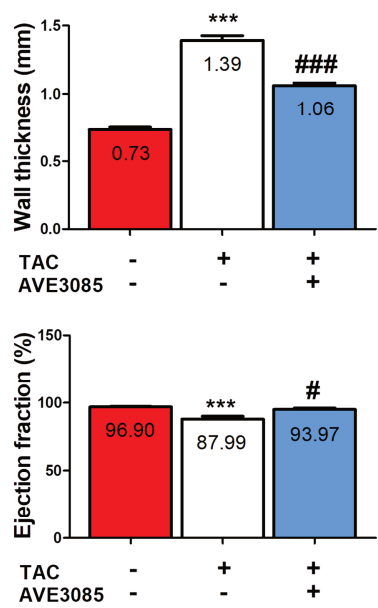

\section{G}

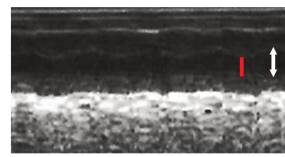

\section{1}

TAC placebo

H

TAC AVE3085 
Figure 2. AVE3085 improves cardiac function

AVE3085 improves cardiac function assessed by M-mode echocardiography in conscious mice, as shown by $\boldsymbol{A}$. left ventricular end-systolic diameter (LVESD; mm), B. left ventricular end-diastolic diameter (LVEDD; $\mathrm{mm}), \boldsymbol{C}$. end-diastolic wall thickness $(\mathrm{mm}), \boldsymbol{D}$. calculated left ventricular (LV) mass (mg); $\boldsymbol{E}$. fraction shortening (FS; \%), and F. ejection fraction (EF; \%). ${ }^{* *} p<0.01,{ }^{* *} p<0.001$ vs. sham placebo; $\# p<0.05$, $\# \# p<0.01, \# \#$ $\#<0.001$ vs. TAC placebo. G,H. Representative example of M-mode echocardiography in conscious animals, showing LVESD (red line) and LVEDD (white arrow)

\section{AVE3085 enhanced functional eNOS dimer formation and reversed myocardial eNOS uncoupling.}

To dissect AVE's mode of action, we determined eNOS mRNA expression levels (RT-qPCR) and protein expression (Western blotting) in homogenized heart. As shown in figure 3A-B, treatment with AVE3085 in TAC mice tended to increase eNOS mRNA and protein expression compared to placebo-treated TAC mice, albeit it that these effects were not significant. It has been suggested that eNOS homodimer instability, reflected by a lower ratio of dimers to monomers, may indicate eNOS uncoupling ${ }^{5,6}$. Surprisingly, although treatment with AVE3085 did not change total eNOS protein levels, it led to elevated eNOS dimer-to-monomer ratio (Figure $3 \mathrm{C}$ ). This suggests that AVE3085 has promoted eNOS dimerization and thus enhanced functional eNOS expression in TAC mice. In contrast, placebo-treated TAC group exhibited a lower dimer-to-monomer ratio, suggestive of eNOS uncoupling and elevation of the ROS producing eNOS monomer. 
A

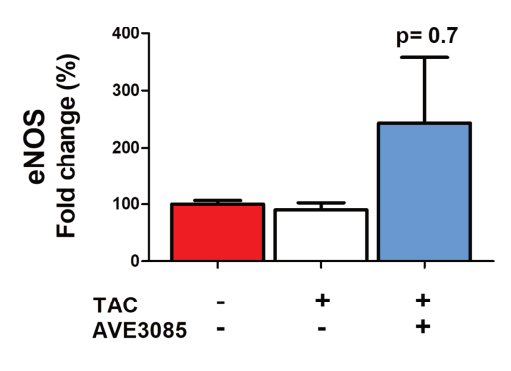

B $\underset{\substack{\text { 130 } \\ \text { TAC } \\ \text { AVE3085 }}}{\mathrm{kDa}}=\frac{- \text { - }}{+} \frac{\text { - }}{+}$

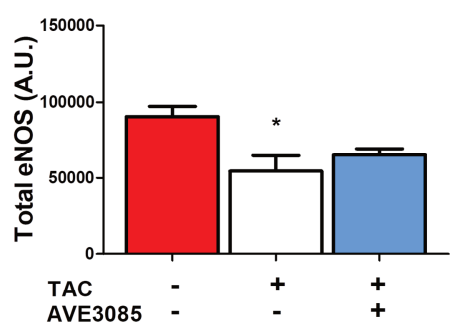

C
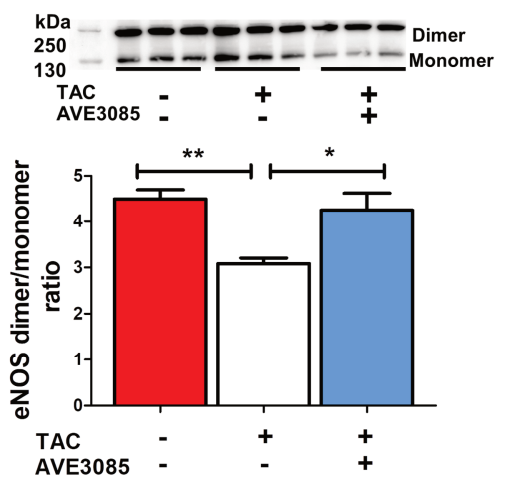

Figure 3. AVE3085 enhances functional eNOS dimer formation

A. The eNOS mRNA level 1 week after TAC was normalized to the reference gene (GAPDH) using the $2^{-\triangle \Delta C T}$ method ( $n=5-6$ per group). B. Representative western blot and quantification of total eNOS protein expression (n=5-6 per group). C. Representative western blot and quantification of eNOS dimer and monomer protein expression (dimer to monomer ratio; $n=5$ per group).

Indeed, AVE3085 enhanced myocardial superoxide generation, as assessed by lucigenin-enhanced chemiluminescent in LV homogenates. As shown in figure $4 \mathrm{~A}$, one week TAC substantially stimulated basal myocardial ROS formation in the placebo-treated group. Co-incubation of LV homogenates with the NOS inhibitor, LNAME resulted in a significant decrease in ROS generation, suggesting that cardiac ROS were at least partially attributable to eNOS uncoupling. These findings were supported by our observation in placebo-treated TAC mice, which displayed a decrease dimer-to-monomer ratio and thus monomeric eNOS contributed to increases ROS production. In contrast, treatment TAC mice with AVE3085 led to lowered myocardial ROS production. Under these conditions, L-NAME did not further reduce myocardial ROS production in AVE3085-treated group, indicating that AVE3085 reversed eNOS uncoupling. 
We further studied if eNOS uncoupling was dependent on $\mathrm{BH} 4{ }^{6}$.The ratelimiting step of $\mathrm{BH}_{4}$ biosynthesis is initial guanosine triphosphate (GTP) modification, catalyzed by the enzyme GTP cyclohydrolase I $(\mathrm{GCH} 1)^{12}$. Indeed, treatment with AVE3085 tended to induce GCH1 mRNA expression in TAC mice (Figure 4B) vs placebo-treated TAC group, suggestive of enhanced BH4 biosynthesis. Taken together, these findings suggested the AVE3085 maintained eNOS homodimer stability, reduced myocardial ROS production and subsequently prevented or reversed eNOS uncoupling induced by pressure overload.
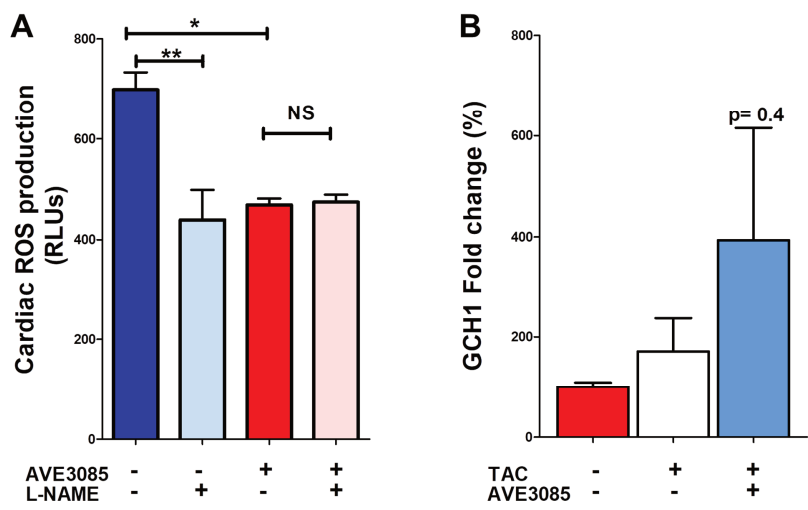

Figure 4. AVE3085 reverses myocardial eNOS uncoupling

A. Cardiac superoxide anion production was measured by lucigenin-enhanced chemiluminescence and expressed as the relative light unit (RLUs). Experiments were performed in the absence or presence of the NOS inhibitor $1 \mathrm{mmol} / \mathrm{l}$ L-NAME ( $n=3$ per group). ${ }^{*} p<0.05,{ }^{* *} p<0.01$, NS not significant. $\boldsymbol{B}$. The GCH1 mRNA level 1 week after TAC was normalized to the reference gene (GAPDH) using the $2^{-\triangle \Delta C T}$ method ( $n$ $=5-6$ per group). 


\section{Discussion}

In the present study, we are the first to investigate the role of AVE3085 in modulating eNOS functionality in pressure overload-induced acute onset of LV hypertrophy in mice. Our main findings suggested clear beneficial effects of AVE3085 treatment as it (1) reverses cardiac hypertrophy, interstitial fibrosis and blunted reexpression of fetal genes, 2) attenuates the pathological LV remodeling and myocardial contractile dysfunction, assessed by M-mode echocardiography, and 3) mechanistically, preserves eNOS homodimer stability even in the absence of transcriptional enhanced eNOS, and reduces myocardial ROS production. Taken together this suggests AVE3085 prevents and/or reverses eNOS uncoupling induced by pressure overload.

The observation that, AVE 3085 attenuated the pathological LV changes associated pressure overload, in the absence of transcriptionally enhanced eNOS protein and mRNA expression is surprising as AVE3085 treatment $(10 \mathrm{mg} / \mathrm{kg} / \mathrm{day}$ for 7days) was previously shown to increase aortic eNOS expression in diabetic mice ${ }^{17}$. At the same dose, AVE3085 led to increased cardiac eNOS mRNA and protein expression in mice subjected to pressure overload for 4 week ${ }^{13}$. A potential explanation for AVE3085's failure to enhance eNOS expression is a compensatory increase in eNOS levels in the early stages of hypertension due to decreased NO production, resulting from increased ROS production ${ }^{18}$. Therefore, eNOS protein levels may be similar between groups. Alternatively, AVE3085 may not have penetrated the intracellular compartments of cardiac tissue. Therefore, pharmacokinetics analysis and intracellular AVE3085 handling in myocardium in TAC mice is warranted. If myocardial bioavailability of AVE3085 is compromised, AVE3085 may exert its pleiotropic effects ectopically by lowering blood pressure, improving arterial endothelium-dependent relaxation ${ }^{19}$, and/or by downregulation oxidant enzymes ${ }^{20}$ as it has demonstrated in spontaneously hypertensive rats and experimental diastolic heart failure, respectively. AVE3085 mediated peripheral vascular function improvement may thus have led to an improvement of cardiac function in TAC mice.

Interestingly, instead of transcriptional upregulation, our study has unveiled a beneficial effect of AVE3085 treatment on eNOS functional stability, demonstrated by a concomitant increase in eNOS dimer-to-monomer ratio and by decreased myocardial ROS generation. The observation that AVE3080 lowered TAC-induced ROS generation independent of NOS inhibitor L-NAME further supports such reversal of eNOS uncoupling. Our findings were in line with previous studies those demonstrated that AVE9488 and AVE3085 can reverse eNOS uncoupling ${ }^{12,21,22}$. It is well documented that uncoupling of eNOS, but not iNOS, is a prominent source of 
myocardial ROS and contributes in this way to cardiac dysfunction and remodeling ${ }^{5}$. Indeed in severe and sustained pressure overload ( $\geq 3$ weeks), lack of eNOS ameliorated $^{5,16}$, whereas eNOS overexpression exacerbated, TAC-induced cardiac remodeling and dysfunction. The latter was associated with increased myocardial ROS production and enhanced eNOS uncoupling ${ }^{16}$. In line with our studies, this indicates that while functional eNOS generally acts protective against maladaptive stress responses, once uncoupled, it becomes a major ROS generator, contributing to the pathophysiology.

Since BH4 is highly susceptible to oxidative degradation caused by $\mathrm{ROS}^{8}$ and AVE3085 treatment attenuated myocaridial ROS generation in TAC mice, suggesting the beneficial effect of AVE3084 is likely the result of protection of $\mathrm{BH} 4$ oxidation by ROS. It is indeed known that $\mathrm{BH} 4$ increases the stability of the eNOS homodimer, and the stoichiometry of $\mathrm{BH} 4-\mathrm{eNOS}$ interaction is directly related to eNOS coupling ${ }^{23,24}$. Exogenous administration of $\mathrm{BH} 4$ has been shown to reverse pre-established advanced hypertrophy and decompensated dilation, which aligns with our AVE3085 findings for cardiac hypertrophy ( 1 week treatment).

In contrast, $\mathrm{BH} 4$ administration from TAC onset or cardiomyocyte specific guanosine triphosphate cyclohydrolase I $(\mathrm{GCH})$-overexpression did not restore cardiac function, assessed by echocardiogram analysis after 1 week of TAC ${ }^{6,25}$. The former may be due to eNOS coupling by overexpressed or supplemental BH4 ${ }^{25}$. Previous studies have demonstrated that 1 week of TAC did not alter endogenous cardiac $\mathrm{BH} 4$ levels ${ }^{26}$ or affect eNOS activity ${ }^{6}$. This suggests that eNOS is functional and can still generate $\mathrm{NO}$ production in the presence of sufficient $\mathrm{BH} 4^{8,27}$. Together, this might explain why $\mathrm{BH} 4$ treatments do not show beneficial effect after 1 week.

Although the capacity of AVE3085 to reverse pre-existing disease remains to be investigated, AVE3085 appears to protect $\mathrm{BH} 4$ from oxidation by ROS, when administered at the onset of pressure overload-induced cardiac hypertrophy. The mechanisms for the increase dimeric eNOS and $\mathrm{BH} 4$ mediated eNOS homodimer stability still remain to be addressed.

We are aware of the limitations of our study. First, we have not included a sham-operated group that received AVE3085, as previous studies had already demonstrated that AVE3085 treatment of control mice without surgery did not impact relevant hemodynamics, blood pressure and body weight ${ }^{20,28}$. Second, cardiac $\mathrm{BH} 4$ and $\mathrm{BH} 2$ levels remain to be assessed to fully underpin that $\mathrm{BH} 4$ dependent recoupling of eNOS was the underlying mechanism of AVE3085 treatment. However, as we did show that AVE3085 reduced myocardial ROS generation, this may suggest AVE3085 prevents oxidation of BH4 by ROS. Finally, it is necessary to investigate the 
protective effect of AVE3085 in eNOS knockout mice following TAC to confirm that it is eNOS-dependent effect.

In conclusion, AVE3085 treatment showed pronounced cardioprotective activity in experimental pressure overload remodeling. As we demonstrate, the ameliorating effects of this compound likely results from reversal of eNOS uncoupling and prevention of $\mathrm{BH} 4$ oxidation by ROS. Hence, AVE compounds have clear therapeutic potential for the treatment of heart failure, which warrants further study.

Supplemental Table 1. List of primers used in this study

\begin{tabular}{|l|l|l|}
\hline Gene & Forward primer & Reverse primer \\
\hline ANP1 & TTCCTCGTCTTGGCCTTTTG & CCTCATCTTCTACCGGCATCTTC \\
\hline BNP1 & GGGAGAACACGGCATCATTG & ACAGCACCTTCAGGAGATCCA \\
\hline aMHC & GGCACAGAAACACCTGAAGA & CATTGGCATGGACAGCATCATC \\
\hline bMHC & GCCCTTTGACCT CAAGAAAG & CTTCACAGTCACCGTCTTGC \\
\hline PLB & CCCAGCTAAGCTCCCATAAG & AACAGGCAGCCAAATGTGA \\
\hline GADPH & ACAGCAACAGGGTGGTGGAC & TTTGAGGGTGCAGCGAACTT \\
\hline
\end{tabular}




\section{References}

1. Heineke J, Molkentin JD. Regulation of cardiac hypertrophy by intracellular signalling pathways. Nat Rev Mol Cell Biol 2006;7(8):589-600.

2. McKinsey TA, Kass DA. Small-molecule therapies for cardiac hypertrophy: moving beneath the cell surface. Nat Rev Drug Discov 2007;6(8):617-635.

3. Kietadisorn R, Juni RP, Moens AL. Tackling endothelial dysfunction by modulating NOSuncoupling: new insights in pathogenesis and therapeutic possibilities. American Journal of Physiology - Endocrinology And Metabolism 2011.

4. Förstermann $\mathrm{U}, \mathrm{Li} \mathrm{H}$. Therapeutic effect of enhancing endothelial nitric oxide synthase (eNOS) expression and preventing eNOS uncoupling. British Journal of Pharmacology 2011;164(2):213223.

5. Takimoto E, Champion HC, Li M, Ren S, Rodriguez ER, Tavazzi B, Lazzarino G, Paolocci N, Gabrielson KL, Wang Y, Kass DA. Oxidant stress from nitric oxide synthase-3 uncoupling stimulates cardiac pathologic remodeling from chronic pressure load. The Journal of Clinical Investigation 2005;115(5):1221-1231.

6. Moens AL, Takimoto E, Tocchetti CG, Chakir K, Bedja D, Cormaci G, Ketner EA, Majmudar M, Gabrielson K, Halushka MK, Mitchell JB, Biswal S, Channon KM, Wolin MS, Alp NJ, Paolocci N, Champion HC, Kass DA. Reversal of Cardiac Hypertrophy and Fibrosis From Pressure Overload by Tetrahydrobiopterin: Efficacy of Recoupling Nitric Oxide Synthase as a Therapeutic Strategy. Circulation 2008;117(20):2626-2636.

7. Alp NJ, Channon KM. Regulation of Endothelial Nitric Oxide Synthase by Tetrahydrobiopterin in Vascular Disease. Arteriosclerosis, Thrombosis, and Vascular Biology 2004;24(3):413-420.

8. Bendall JK, Douglas G, McNeill E, Channon KM, Crabtree MJ. Tetrahydrobiopterin in Cardiovascular Health and Disease. Antioxidants \& Redox Signaling 2014;20(18):3040-3077.

9. Branko B, Marianne CV. Understanding eNOS for Pharmacological Modulation of Endothelial Function: A Translational View. Current Pharmaceutical Design 2007;13(17):1727-1740.

10. Huang PL. eNOS, metabolic syndrome and cardiovascular disease. Trends in endocrinology and metabolism: TEM 2009;20(6):295-302.

11. Sasaki K-i, Heeschen C, Aicher A, Ziebart T, Honold J, Urbich C, Rossig L, Koehl U, Koyanagi M, Mohamed A, Brandes RP, Martin H, Zeiher AM, Dimmeler S. Ex vivo pretreatment of bone marrow mononuclear cells with endothelial NO synthase enhancer AVE9488 enhances their functional activity for cell therapy. Proceedings of the National Academy of Sciences 2006;103(39):14537-14541.

12. Wohlfart P, Xu H, Endlich A, Habermeier A, Closs El, Hubschle T, Mang C, Strobel H, Suzuki T, Kleinert H, Forstermann U, Ruetten H, Li H. Antiatherosclerotic Effects of Small-Molecular-Weight Compounds Enhancing Endothelial Nitric-Oxide Synthase (eNOS) Expression and Preventing eNOS Uncoupling. Journal of Pharmacology and Experimental Therapeutics 2008;325(2):370379.

13. Chen Y, Chen C, Feng C, Tang A, Ma Y, He X, Li Y, He J, Dong Y. AVE 3085, a novel endothelial nitric oxide synthase enhancer, attenuates cardiac remodeling in mice through the Smad signaling pathway. Archives of Biochemistry and Biophysics 2015;570:8-13.

14. Moens AL, Leyton-Mange JS, Niu X, Yang R, Cingolani O, Arkenbout EK, Champion HC, Bedja D, Gabrielson KL, Chen J, Xia Y, Hale AB, Channon KM, Halushka MK, Barker N, Wuyts FL, Kaminski PM, Wolin MS, Kass DA, Barouch LA. Adverse ventricular remodeling and exacerbated NOS uncoupling from pressure-overload in mice lacking the $\beta 3$-adrenoreceptor. Journal of Molecular and Cellular Cardiology 2009;47(5):576-585.

15. Kim YM, Guzik TJ, Zhang YH, Zhang MH, Kattach H, Ratnatunga C, Pillai R, Channon KM, Casadei B. A Myocardial Nox2 Containing NAD(P)H Oxidase Contributes to Oxidative Stress in Human Atrial Fibrillation. Circulation Research 2005;97(7):629-636. 
16. van Deel ED, Octavia Y, de Boer M, Juni RP, Tempel D, van Haperen R, de Crom R, Moens AL, Merkus D, Duncker DJ. Normal and high eNOS levels are detrimental in both mild and severe cardiac pressure-overload. Journal of Molecular and Cellular Cardiology 2015;88(Supplement C):145-154.

17. Cheang WS, Wong WT, Tian XY, Yang Q, Lee HK, He G-W, Yao X, Huang Y. Endothelial nitric oxide synthase enhancer reduces oxidative stress and restores endothelial function in $\mathrm{db} / \mathrm{db}$ mice. Cardiovascular Research 2011;92(2):267-275.

18. Drummond GR, Cai H, Davis ME, Ramasamy S, Harrison DG. Transcriptional and Posttranscriptional Regulation of Endothelial Nitric Oxide Synthase Expression by Hydrogen Peroxide. Circulation Research 2000;86(3):347-354.

19. Yang Q, Xue H-M, Wong W-T, Tian X-Y, Huang Y, Tsui SKW, Ng PKS, Wohlfart P, Li H, Xia N, Tobias S, Underwood MJ, He G-W. AVE3085, an enhancer of endothelial nitric oxide synthase, restores endothelial function and reduces blood pressure in spontaneously hypertensive rats. British Journal of Pharmacology 2011;163(5):1078-1085.

20. Westermann D, Riad A, Richter U, Jäger S, Savvatis K, Schuchardt M, Bergmann N, Tölle M, Nagorsen D, Gotthardt M, Schultheiss H-P, Tschöpe C. Enhancement of the endothelial NO synthase attenuates experimental diastolic heart failure. Basic Research in Cardiology 2009;104(5):499-509.

21. Yang Q, Xue H-M, Underwood M, Yu C-M. Mechanistic Studies of AVE3085 Against Homocysteine in Endothelial Protection. Cardiovascular Drugs and Therapy 2013;27(6):511-520.

22. Xue H-M, Yu C-M, Underwood M, Huang J-H, Yang Q. AVE3085 Protects Coronary Endothelium from the Impairment of Asymmetric Dimethylarginine by Activation and Recoupling of eNOS. Cardiovasc Drugs Ther 2012;26(5):383-392.

23. Bendall JK, Alp NJ, Warrick N, Cai S, Adlam D, Rockett K, Yokoyama M, Kawashima S, Channon KM. Stoichiometric Relationships Between Endothelial Tetrahydrobiopterin, Endothelial NO Synthase (eNOS) Activity, and eNOS Coupling in Vivo: Insights From Transgenic Mice With Endothelial-Targeted GTP Cyclohydrolase 1 and eNOS Overexpression. Circ Res 2005;97(9):864-871.

24. Crabtree MJ, Tatham AL, Al-Wakeel Y, Warrick N, Hale AB, Cai S, Channon KM, Alp NJ. Quantitative Regulation of Intracellular Endothelial Nitric-oxide Synthase (eNOS) Coupling by Both Tetrahydrobiopterin-eNOS Stoichiometry and Biopterin Redox Status. Journal of Biological Chemistry 2009;284(2):1136-1144.

25. Hashimoto T, Sivakumaran V, Carnicer R, Zhu G, Hahn VS, Bedja D, Recalde A, Duglan D, Channon KM, Casadei B, Kass DA. Tetrahydrobiopterin Protects Against Hypertrophic Heart Disease Independent of Myocardial Nitric Oxide Synthase Coupling. Journal of the American Heart Association 2016;5(3).

26. Shimizu S, Ishibashi, M., Kumagai, S., Wajima, T., Hiroi, T., Kurihara, T., Ishii, M., Kiuchi, Y. Decreased cardiac mitochondrial tetrahydrobiopterin in a rat model of pressure overload. International Journal of Molecular Medicine 2013;31(3):589-596.

27. Du Y-H, Guan Y-Y, Alp NJ, Channon KM, Chen AF. Endothelium-Specific GTP Cyclohydrolase I Overexpression Attenuates Blood Pressure Progression in Salt-Sensitive Low-Renin Hypertension. Circulation 2008;117(8):1045-1054.

28. Riad A, Westermann D, Van Linthout S, Mohr Z, Uyulmaz S, Becher PM, Rütten H, Wohlfart P, Peters $\mathrm{H}$, Schultheiss H-P, Tschöpe C. Enhancement of endothelial nitric oxide synthase production reverses vascular dysfunction and inflammation in the hindlimbs of a rat model of diabetes. Diabetologia 2008;51(12):2325-2332. 



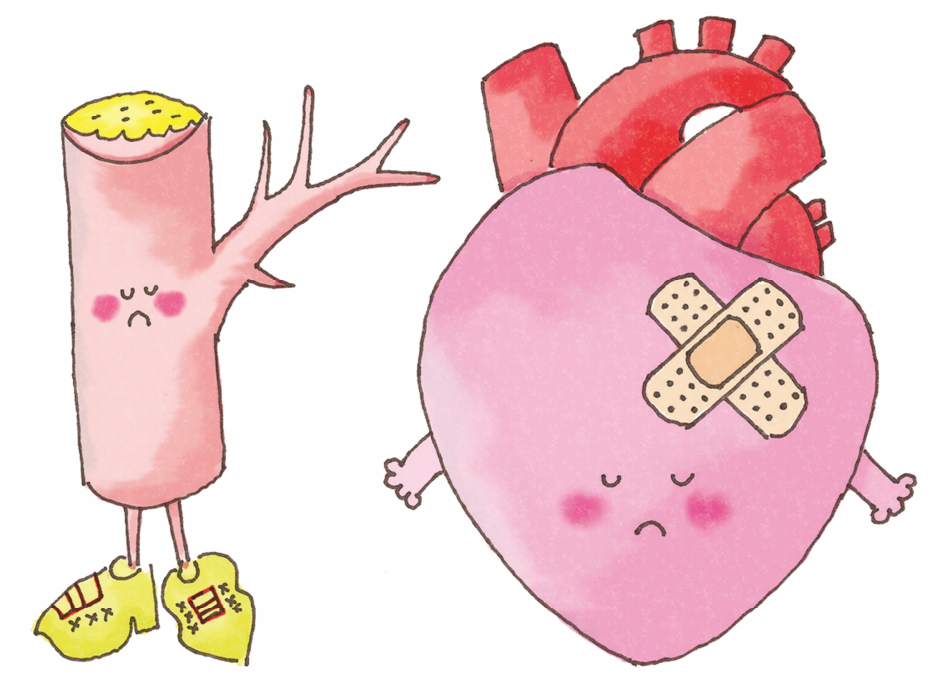


Chapter 6

\section{TNIP2: a novel regulator of inflammatory lymphangiogenesis in human atherosclerosis}

R. Kietadisorn , M. Manca , M. García-Caballero, T. Durré , T. Rademakers, F. Rühle, M. Stoll , A. Bveloso, K.J. Sikkink, M.J. Daemen, F. Dequiedt, J.C. Sluimer, A. Noel, E.A.L Biessen

(Submitted) 


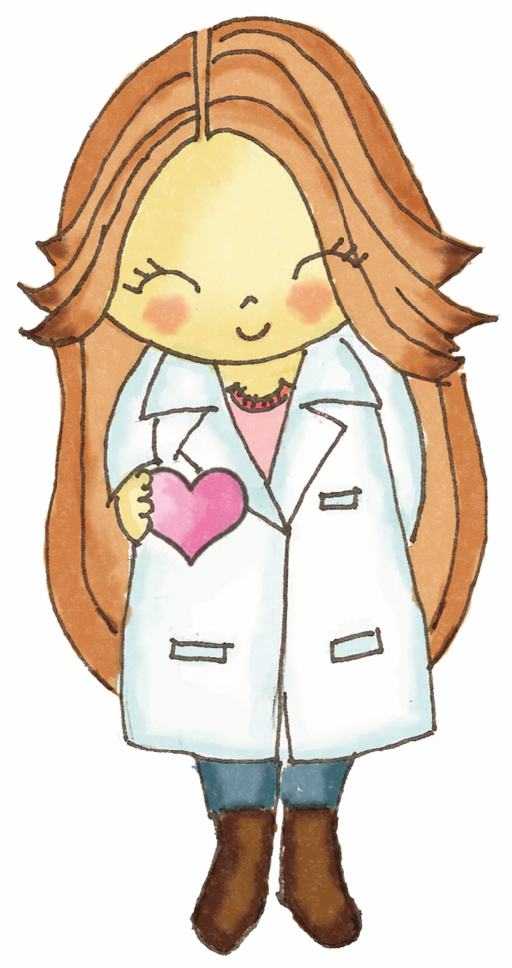


Chapter 7

General discussion 


\section{Main finding of the dissertation}

The overall aim of this dissertation was (I) to explore the therapeutic potential of modulating endothelial nitric oxide synthase (eNOS) using AVE3085, an eNOS transcription enhancer, which exerts a reversal eNOS uncoupling, in the setting of cardiac hypertrophy-induced by aortic constriction, (II) to identify specific candidate targets critical in the regulation of human lymphangiogenesis in atherosclerosis, via a systems medicine approach.

The key findings of the work presented in this dissertation are:

1. AVE3085 attenuated cardiac dysfunction and remodeling, through preserved eNOS homodimer instability, decreased myocardial reactive oxygen species (ROS) and reversed the eNOS uncoupling in a mouse model of left ventricular pressure overload (chapter 5)

2. Genomics- based methods identify potential novel targets involved in human plaque lymphangiogenesis (chapter 6)

3. TNFAIP3 Interacting Protein 2 (TNIP2) is a novel VEGF (vascular endothelial growth factor)-C independent key regulator of plaque lymphangiogenesis in humans, which potentially acts in an inflammation and lipid metabolism dependent manner. The mechanism may involve interferon gamma (IFNY) and peroxisome proliferator-activated receptor (PPAR)-related lipid and cholesterol metabolism signaling pathway (chapter 6).

\section{Correlation of EC function and heart function, focusing on eNOS-NO signaling}

The functional integrity of the endothelium is a fundamental element of cardiovascular health. Nitric oxide (NO) generated by eNOS is considered a critical player in maintaining this integrity. Many studies have established that endothelial dysfunction is not only an initiator, but could also be an important factor in the progression of cardiovascular disease. Hereafter, I will discuss the role of endothelial cells $(E C)$ in regulation of cardiovascular system.

The beneficial, regulatory activity of the vascular endothelium in the heart includes vasomotor, hemostatic, antioxidant, and pro- and anti-inflammatory activities ${ }^{1,2}$. EC regulate the release of endothelium-induced relaxing factors such $\mathrm{NO}$ and endothelium-derived hyperpolarization factor (EDHF), which further stimulates vascular smooth muscle cell relaxation and vasodilation. Likewise, NO in the heart affects the onset of ventricular relaxation, which allows for a precise optimization of cardiac pump function ${ }^{3}$. In addition, physiologic concentrations of vascular NO as generated by eNOS exerts antioxidant properties ${ }^{4-6}$, regulates mitochondrial function 7,8 and protects against mitochondrial oxidative stress ${ }^{9}$ and thus exerts 
cardioprotective effect ${ }^{10}$. Cardiomyocyte paracrine signaling can also regulate EC functions through VEGF-A and angiopoietin (Ang) $1^{3}$. In fact, paracrine cardiomyocyte -to- endothelium signaling and vice versa plays a critical role in the vascular adaptations that occur during cardiac hypertrophy. A failure of angiogenesis to match myocyte growth can lead to progressive cardiac dysfunction ${ }^{11}$.

Endothelial dysfunction is a hallmark of cardiovascular disease, and it is characterized by impaired endothelial-dependent vasodilatation, increased platelet activation, leukocyte adhesion, and smooth muscle proliferation; and all can be linked to inadequate $\mathrm{NO}$ generation ${ }^{12,13}$. Evidence indicates that endothelial dysfunction also results from eNOS dysfunction due to a reduced level of its essential cofactor, tetrahydrobiopterin $(\mathrm{BH} 4)$. When $\mathrm{BH} 4$ levels are depleted, the enzymatic reduction of molecular oxygen by eNOS is no longer coupled to L-arginine oxidation, which results in the generation of superoxide anion rather than NO, thus contributing to vascular oxidative stress and endothelial dysfunction ${ }^{14}$. Oxidative stress occurs when excess ROS are generated that cannot be adequately countered by intrinsic antioxidant systems. This plays an important role in the pathophysiology of heart failure ${ }^{15}$. Mechanistically, ROS contribute to the progression of heart failure through stimulating cardiac fibrosis ${ }^{16,17}$, inducing cardiomyocyte apoptosis ${ }^{18}$, modifying proteins central to excitation-contraction coupling ${ }^{19}$ and activating the hypertrophic signaling pathways ${ }^{15}$. In the heart, ROS are generated by several sources, including nicotinamide-adenine dinucleotide phosphate (NADPH) oxidase or xanthine oxidase $(\mathrm{XO})$, eNOS uncoupling, and mitochondria respiration ${ }^{15}$. Given the key role of $\mathrm{BH} 4$ in the production of vasoactive substances, such as NO generated by eNOS, it is not surprising that alteration in the bioavailability of $\mathrm{BH} 4$ alters cardiovascular function and homeostasis. In chapter $\mathbf{2}$, we highlighted that $\mathrm{BH} 4$ acts as a key regulator of eNOS in the setting of cardiovascular health and disease. Importantly, it has been suggested that $\mathrm{BH} 4$ deficiency is likely to represent the major cause for eNOS uncoupling ${ }^{12}$. In cardiovascular disease states, there is oxidative degradation of $\mathrm{BH} 4$ by ROS. Importantly, the interaction between $\mathrm{NO}$ and superoxide results in peroxynitrite generation, the potent oxidant, that enhances $\mathrm{BH} 4$ oxidation, leading to eNOS uncoupling. In addition, the exact location of ROS production in the heart remains unclear. eNOS is expressed in vascular endothelium and cardiomyocytes, with the latter representing approximately $20 \%$ of total cardiac eNOS ${ }^{20}$. This suggests that cardiac EC are the likely locus of the nitro-redox perturbation. Therefore, in chapter 3, we discussed how eNOS uncoupling is one of the major underlying causes of endothelial dysfunction. The bioavailability of NO produced by eNOS might be affected at multiple levels, including 1) eNOS mRNA or protein expression, 2) availability of its substrate L-arginine, which might compete with asymmetric dimethylarginine (ADMA) for eNOS binding sites, and 3) availability of its cofactor, $\mathrm{BH} 4$, which is determined by a balance of de novo synthesis and recycling, 
versus $\mathrm{BH} 4$ degradation in oxidative stress. Interestingly, $\mathrm{BH} 4$ can be regenerated by its oxidized form $\mathrm{BH} 2$ via dihydrofolate reductase (DHFR) in the salvage pathway, and can thus maintain eNOS coupling. Inadequate recycling of $\mathrm{BH} 2$ to $\mathrm{BH} 4$ by DHFR is at least in part, responsible for reduced $\mathrm{BH} 4$ levels and the accumulation of $\mathrm{BH} 2$, leading to eNOS uncoupling ${ }^{12,21,22}$. Furthermore, in chapter 4, we pointed out that modulation of eNOS function is crucial, and can be targeted at multiple levels, including 1) increased eNOS expression and/or activity, 2) augmenting its cofactor $\mathrm{BH} 4$ and 3) recoupling the uncoupled eNOS. The small molecule AVE3085 can enhance transcription of eNOS, and interference with eNOS-uncoupling has been suggested. It has been proposed that in pressure overload hypertrophic pathology, oxidative stress is initiated by NADPH oxidase (NOX), causing BH4 oxidation and subsequently resulting in eNOS uncoupling ${ }^{23}$ and that eNOS uncoupling is a prominent source of myocardial ROS ${ }^{24,25}$. Thus, in chapter 5, we tested if AVE3085 can prevent pressure overload-induced left ventricular (LV) hypertrophy. We demonstrated that AVE 3085 attenuated the pathological LV changes associated with pressure overload, in the absence of transcriptionally enhanced eNOS. Although AVE compounds have been shown to increase eNOS transcription and protein expression as discussed in chapter 4, we did not observe this beneficial effect. Our findings were similar to a study with porcine coronary arteries incubated with AVE3085, ADMA or AVE3085+ADMA for $1 \mathrm{~h}$ which also did not detect the alteration of eNOS protein expression ${ }^{26}$. The first possible explanation is a compensatory increase in eNOS levels in hypertension; as ROS production is increased, NO production is subsequently decreased ${ }^{27}$. Therefore, eNOS protein levels may be similar between groups. Alternatively, this compound may not reach the optimal intracellular compartments of cardiac tissue after 7 days. Nevertheless, in chapter 5, we are the first to provide evidence for a beneficial effect of AVE3085 treatment, by increasing functional eNOS stability; demonstrated by an increase eNOS dimer to monomer ratio and decreased myocardial ROS generation. AVE3085 attenuated downregulated NOX subunits p22phox and gp91phox ${ }^{28}$. This may at least, in part, be responsible for protecting $\mathrm{BH} 4$ from oxidation. Besides that, AVE3085 exerts pleiotropic effects including lowering blood pressure, improving endothelium-dependent relaxation ${ }^{29}$, thus these could contribute to improvement of cardiac function if mice following 1week of TAC.

In summary, endothelial dysfunction is characterized by impaired endothelial NO-dependent vasodilation and is associated with eNOS uncoupling, causing vasoconstriction, leukocyte or platelet activation, and a prothrombotic state. EC dysfunction has been implicated in the underlying pathology of many cardiovascular diseases ${ }^{30}$. Moreover, endothelial-cardiomyocyte interactions are essential in normal cardiomyocyte function, and in protection from injury. In line with our studies, this suggested that AVE3085 treatment promoted functional eNOS, 180 
reversed the eNOS uncoupling and protected $\mathrm{BH} 4$ from oxidation by ROS, subsequently ameliorating endothelial function and thus, may also contribute to improvement of cardiac function. As such, eNOS appears to be a homeostatic regulator of numerous essential cardiovascular functions.

\section{eNOS- NO signaling : protective effects against pressure overload-induced inflammation and fibrosis}

In response to injury, the heart initially begins compensatory hypertrophy, however eventually it progresses to maladaptive features, ultimately triggering transition to heart failure ${ }^{31}$. During the progression to heart failure, stressed cardiomyocytes increasingly exhibit contractile dysfunction and cell death ${ }^{32}$. This process is associated with inflammation and fibrosis ${ }^{33}$. Here we discuss main mechanisms underlying the protection of eNOS-NO signaling in pressure overload pathology.

$\mathrm{NO}$ is a soluble gas synthesized from L-arginine by NO synthase, with a wide range of biological properties that maintain vascular homeostasis and protect against vascular injury ${ }^{4,30}$. Under physiological conditions, eNOS is mostly expressed in EC ${ }^{34}$, and is a major source of NO production in vasculature ${ }^{35}$. NO dilates blood vessels through activation of soluble guanylyl cyclase (sGC)/ cyclic GMP signaling pathway (cGMP)/ protein kinase G (PKG), resulting in vascular smooth muscle cells (VSMC) relaxation ${ }^{36}$. NO exerts inhibitory effects on platelet activation and has antiinflammatory properties ${ }^{35}$, meanwhile it also protects against $\mathrm{EC}$ apoptosis through Snitrosylation ${ }^{37,38}$. It is known that inflammatory signaling and macrophage infiltration plays a role in in myocardial remodeling and cardiac dysfunction in pressure overloaded hearts ${ }^{39,40}$. Indeed, inflammation-mediated fibrosis is initiated by macrophage accumulation, associated with fibroblast proliferation and the induction of monocyte chemoattractant protein (MCP)-1 and intercellular adhesion molecule (ICAM)-1 expression in the myocardium. These events are most pronounced three days after TAC ${ }^{39,40}$. Subsequently, transforming growth factor (TGF)- $\beta$ expression, which plays a crucial role in the fibrotic process, reached a maximum at day $7^{40}$. After day 7 , concentric left ventricular (LV) hypertrophy developed, associated with reactive fibrosis and myocyte hypertrophy ${ }^{40}$. Taken together, concomitant inductions of MCP-1 and ICAM-1 may indicate their coordinated role in myocardial remodeling in pressure overload hearts, by enhancing macrophage recruitment. Those macrophages in turn produce TGF- $\beta$ and profibrotic cytokines, leading to accelerated myocardial fibrosis 40. In line with this view, our results in chapter $\mathbf{5}$ demonstrated that AVE3085 ameliorated myocardial fibrosis and myocyte width after TAC. However, the inflammatory process related to TAC was not determined in the present study. Nevertheless, several potential mechanisms could be involved in ameliorating effects 
of AVE3085 against TAC-induced inflammation and fibrosis. Indeed, NO decreases MCP-1 expression, and inhibits leukocyte adhesion to the vessel wall, either by interfering with the ability of the leukocyte adhesion molecule CD11/CD18 to form an adhesive bond with the endothelial cell surface, or by suppressing CD11/CD18 expression on leukocytes ${ }^{41}$. Previous studies have demonstrated that one week of TAC did not alter endogenous cardiac BH4 levels ${ }^{42}$ or affect eNOS activity ${ }^{25}$. This suggests that eNOS is functional and can still generate NO production in the presence of sufficient $\mathrm{BH} 4{ }^{12,14}$. Our results in chapter 5 showed that AVE3085 increased eNOS dimer to monomer ratio, as well as L-NAME inhibitable chemiluminescence, could not reduce basal cardiac superoxide generation. This indicates the enhanced capacity of NO generated by functional dimeric eNOS, as well as restored NO bioavailability. Thus, the perivascular macrophage accumulation observed shortly after TAC ${ }^{39,40}$ may be prevented by AVE3085 mediated eNOSgenerated NO production in our study. Besides this, ROS can activate proinflammatory mediator cascades, and is involved in the development of interstitial cardiac fibrosis ${ }^{43}$. AVE3085 inhibited ROS production, thus it might also reduce inflammatory cytokine production and fibrosis in TAC hearts. In addition, recent evidence shows $\mathrm{BH} 4$ involvement in inflammatory cell signaling ${ }^{44}$ and inhibition of macrophage infiltration and blocked inflammatory signaling by oral exogenous $\mathrm{BH} 4$ three days after TAC in mice ${ }^{45}$. We showed in chapter 5 that AVE3085 protected $\mathrm{BH} 4$ oxidation and tended to induce mRNA expression of the $\mathrm{BH} 4$-generating enzyme $\mathrm{GCH} 1$. Since cardiac BH4 levels were not altered one week after TAC ${ }^{42}$, the sufficient endogenous $\mathrm{BH} 4$ availability combined with the $\mathrm{BH} 4$ levels that were restored by AVE3085, may appear similar to the effect of exogenous $\mathrm{BH}_{4}{ }^{45}$. AVE3085 might have attenuated inflammatory signaling through restored (or even enhanced) $\mathrm{BH} 4$ levels and subsequently $\mathrm{BH} 4$ prevented TAC-induced inflammation and fibrosis. The exact role of AVE3085 in inflammation-associated pressure overload remains to be elucidated.

As discussed in chapter 4, AVE3085 exerts pleiotropic effects, including antifibrotic properties, through downregulation of TGF- $\beta$ and connective tissue growth factor (CTGF) in experimental diastolic heart failure ${ }^{28}$, and inhibition of Smad (mothers against decapentaplegic) 2/3 signaling in mice following 4 weeks of TAC ${ }^{46}$ : thus it protects against cardiac fibrosis. Moreover, AVE3085 attenuated adhesion molecules ICAM-1 and VCAM- 1 in experimental diabetes ${ }^{47}$. Together, these findings show that AVE3085 may directly inhibit inflammation-mediated fibrosis caused by TAC. In summary, based on our findings, possible mechanisms of AVE3085 mediated TAC-induced inflammatory response may result from (1) indirect effects, secondary to inhibition of macrophage infiltration and inflammatory signaling mediated by $\mathrm{NO}$ and/ or $\mathrm{BH} 4$, or (2) pleiotropic effects of AVE3085 on inflammation and fibrosis. 
When eNOS is healthy, it produces NO which acts as protector of cardiovascular health. When eNOS becomes dysfunctional, it shifts towards ROS generation and acts as pro-oxidant, rather than an antioxidant enzyme. Below, we discuss how dysregulation of eNOS can contribute to inflammation and progression of cardiovascular disease.

\section{Effect eNOS on inflammation}

Under physiological condition, eNOS produces a low basal amount of NO which exerts anti-inflammatory properties, and is responsible for cardiovascular homeostasis through regulating the interaction between the endothelium and inflammatory cells ${ }^{48}$.

A hallmark of inflammation is increased vascular permeability, during which inflammatory cells migrate and interact with $\mathrm{EC}{ }^{48}$. Upon activation, the endothelium releases inflammatory cytokines as well as adhesion molecules, facilitating the recruitment and attachment of circulating leukocytes to the vessel wall ${ }^{49}$. During inflammation, local agonists (e.g. shear stress and VEGF-A) that act on EC can influence eNOS activity through post-translational modifications ${ }^{48,50}$. It is known that phosphorylation of eNOS at serine (Ser)-1177 enhances eNOS activity ${ }^{51,52}$, and directly regulates NO and superoxide generation; the latter's activity depends on eNOS coupling status (i.e. when eNOS is uncoupled, phosphorylation of Ser-1177 increases eNOS-dependent superoxide generation ${ }^{53}$. NO reacts with superoxide and forms peroxynitrite, a potent proinflammatory and apoptotic agent ${ }^{54}$, indicating that phosphorylation of eNOS can modulate peroxynitrite generation. This suggests that under pathologic conditions where eNOS is often uncoupled ${ }^{55}$, activation of eNOS activity can exacerbate inflammatory processes.

VEGF-A is crucially involved in several chronic inflammatory disorders, in which it not only promotes pathologic angiogenesis but directly fosters inflammation ${ }^{56}$, 57. It has been suggested that eNOS may contribute to the inflammatory process indirectly through the stimulation of VEGF-A-induced permeability, as well as VEGF-Adependent-adhesion molecule expression. Indeed, VEGF-A upregulates the expression and activity of eNOS ${ }^{58,59}$, which in turn causes eNOS-derived NO to modulate both VEGF-A- induced angiogenesis and permeability ${ }^{60}$.

The proinflammatory effect of eNOS-derived NO occurs, at least in part, via a modulation of the activity of the transcription factor nuclear factor kappa beta (NFKB) ${ }^{61}$. NFKB has been shown to be a key regulator of proinflammatory genes, including cytokines, chemokines, and adhesion molecules ${ }^{62}$. It has also been demonstrated that laminar shear stress activates NFKB, which in turn increases eNOS transcription 
and expression, and thus enhances NO production. Subsequently, this NO inhibits $\mathrm{NFKB}$ activation in a negative feedback loop, resulting in the termination of eNOS transcription ${ }^{63,64}$. However, increased oxidative stress accelerates NO degradation through its reaction with superoxide, in turn peroxynitrite causes eNOS uncoupling through oxidation of $\mathrm{BH} 4{ }^{34}$. The consequences of eNOS uncoupling are both reduced synthesis and bioavailability of $\mathrm{NO}^{41}$, which can cause substantial activation of NFKB and leads to endothelial inflammation ${ }^{64}$.

Interestingly, as discussed in chapter 3, although many studies have shown that eNOS overexpression generates cardiovascular protective effects by increasing endothelium-derived $\mathrm{NO}{ }^{65,66}$, the expression of eNOS protein in endothelial dysfunction remains unchanged, or may, in some cases, even be increased ${ }^{67}$. In pressure overload pathology, lack of eNOS ameliorated ${ }^{24,68}$ TAC-induced cardiac remodeling and dysfunction ${ }^{68}$, whereas eNOS overexpression exacerbated this. The latter was associated with increased myocardial ROS production and enhanced eNOS uncoupling ${ }^{68}$. Because uncoupled eNOS not only generates NO, but also generates ROS, one should be aware that increased eNOS transcription, translation or activity does not guarantee improved endothelial function ${ }^{69}$. Hence, pharmacological approaches to preserve or restore eNOS functionality and prevent eNOS uncoupling are warranted. On the basis of the pathophysiology mentioned above, as discussed in chapter 2-4 there are several possible approaches to restore eNOS functionality (ie, recouple eNOS). This further highlighted that indeed, elevated eNOS expression without further increase in $\mathrm{BH} 4$ levels, results in eNOS uncoupling because of the enzyme cofactor imbalance ${ }^{70}$. In chapter $\mathbf{5}$, we demonstrated that treatment of AVE3085 1 week after TAC prevented $\mathrm{BH} 4$ oxidation rather than increased its synthesis. The long term effects of AVE3085 on BH4 levels in TAC mice, however, is not yet known.

In summary, eNOS-derived NO has an important role in preserving homeostasis in the interaction between the endothelium and inflammatory cells in basal physiological conditions. Post-translational modifications impact eNOS activity and can contribute to inflammatory process. Pharmacological approaches that increase eNOS protein levels are only beneficial when the produced eNOS is functional, and strategies to preserve or restore eNOS functionality and prevent eNOS uncoupling are thus warranted. 


\section{Opposite effects of angiogenesis in the heart versus atherosclerosis}

The role of angiogenesis in cardiovascular diseases depends on the pathophysiological context, and seems opposing in cardiac and vascular pathology. Vascular insufficiency occurs in cardiac hypertrophy ${ }^{71,72}$, myocardial infarction and coronary ischemia ${ }^{73}$. Patients with cardiomyopathy displayed decreased coronary capillary density in histological sections ${ }^{74}$. In contrast, excessive plaque angiogenesis is considered detrimental ${ }^{75}$, and neovessel formation is associated with disease progression and destabilization ${ }^{76}$.

In physiological cardiac hypertrophy, increased coronary angiogenesis is associated with preserved contractile function, whereas pathological cardiac hypertrophy (reduced contractility) is accompanied by impaired coronary angiogenesis ${ }^{77,78}$. In experimental pressure overload-induced cardiac hypertrophy, blocking VEGFA-dependent angiogenesis accelerated the transition from compensated to decompensated heart failure ${ }^{79}$, whereas activation of angiogenesis using adenovirusmediated expression of VEGF-A and Ang1 enhanced preserved contractile function ${ }^{80}$. Interestingly, pressure overload initially promoted cardiac angiogenesis through hypoxia-inducible factor-1 (HIF-1)-dependent angiogenic response. However, prolonged pressured overloaded resulted in reduced HIF-1 activity, was associated with impaired cardiac angiogenesis, despite persistent myocardial hypoxia in the hypertrophied hearts. This suggested that mismatch of angiogenesis in hypertrophied hearts exacerbated myocardial hypoxia and cardiac dysfunction. Taken together, angiogenesis is essential for adaptive cardiac growth, and that disruption of angiogenesis signaling impairs heart function and contributes to the progression from adaptive cardiac hypertrophy to heart failure ${ }^{77,79}$.

Plaque angiogenesis is the response to hypoxic conditions ${ }^{81}$. Plaque hypoxia predominantly occurs due to increasing oxygen demand in the inflammatory microenvironment, although plaque thickness also contributes to reduction of oxygen supply ${ }^{76}$. In addition, hypoxia-induced HIF-1-dependent proangiogenic gene expression has been implicated as an important mechanism responsible for plaque angiogenesis. Angiogenesis may be important for plaque pathogenesis during the initial stages of lesion growth, though it is also plausible that angiogenic stimuli may have a destabilizing role in the mature plaque ${ }^{73}$. However, neovessels, in particular those in the plaque shoulder region, appear to be immature and highly susceptible to leakage, and can cause intraplaque hemorrhage ${ }^{82}$. Ruptured plaques of patients that manifested atherosclerosis displayed increased microvessel density in ruptured plaques, as well as in the intraplaque hemorrhage, suggesting a contributory role for neovascularization in the process of plaque rupture ${ }^{83}$. Moreover, vasa vasorum (VV) density is correlated with disease severity ${ }^{76,84}$, as well as with inflammatory cell 
density in the plaque lesions ${ }^{85}$. Taken together, plaque angiogenesis is a physiological adaptation, but the associated proinflammatory and proatherogenic effects are deleterious for plaque vulnerability.

In summary, angiogenesis is beneficial in cardiac hypertrophy and ischemia by increasing blood perfusion in ischemic tissues and improving cardiac function. On the other hand, angiogenesis is detrimental in atherosclerosis by promoting disease progression and is considered as a risk factor for plaque rupture.

\section{Presence and functions of lymphatics in plaque}

Lymphangiogenesis and angiogenesis are tightly intertwined processes, which are orchestrated by similar regulatory cues ${ }^{86}$. Moreover, leakage of (newly formed) dysfunctional vessels will lead to interstitial pressure buildup, which in turn will trigger lymphangiogenic responses, in order to drain redundant fluids and restore interstitial pressure ${ }^{87}$. Therefore it is not unsurprising that besides angiogenesis, also lymphangiogenesis is instrumental in cardiovascular physiology and pathophysiology. Increased lymphatic density is associated with cardiovascular diseases, including progressive atherosclerosis, acute and chronic myocardial ischemia, myocarditis, endocarditis and cardiac hypertrophy ${ }^{88,}{ }^{89}$. In animal studies, lymphatics were observed in the adventitial and periadventitial regions of the arterial wall ${ }^{90-92}$. In human atherosclerotic internal carotid artery, iliac artery and aorta lesions, lymphatic vessels are detected in the adventitia. In fact, the adventitial lymphatic density was positively correlated with atherosclerosis severity, as assessed by intimal thickness ${ }^{93}$, ${ }^{94}$, suggesting a link between lymphatics and disease progression. Kholova et al. ${ }^{88}$ observed lymphatic vessels in fibro-calcified and fibrous atherosclerotic lesions. They reported profound lymphatic growth in adventitia, media and intima of atherosclerotic sections; the latter two were present only in progressive lesions. In plaque lesions, lymphatics were present in plaque shoulder and cholesterol crystal-rich area in plaques and associated with lymphatic remodeling, including collapsed and dilated lymphatic vessels. In agreement with this observation, in chapter $\mathbf{6}$, we observed podoplanin ${ }^{+}$lymphatic vessels were abundantly present in the adventitia and within atherosclerotic lesion such as in cholesterol crystal-rich area of ruptured segments. Importantly, we observed podoplanin ${ }^{+}$lymphatic vessels in the intima of advanced ruptured plaque lesions. This observation was consistent with previous studies observing lymphatic vessel development in the intima and was associated with areas rich in extracellular matrix as well as lipid core region ${ }^{88,95}$. Conversely, other studies observed no ${ }^{96}$ or rare lymphatic vessels and those lymphatic vessels mostly presented in the adventitia of human atherosclerotic vessels ${ }^{97}$. Together, lymphatic vessels have been readily identified in atherosclerotic and non-atherosclerotic arterial 
clinical samples in most, but not in all studies. This controversial result warrants further investigation.

\section{Lymphangiogenesis driving factors in plaque}

As mentioned, given the association between progressive atherosclerosis and lymphangiogenesis, it was postulated that lymphangiogenesis exacerbated atherosclerosis, and that intervention in lymphangiogenesis might be beneficial. In line with this view, Xu et al. ${ }^{98}$ hypothesized that in the atherosclerotic artery, adventitial lymphatics facilitate the delivery of inflammatory cells draining lymph nodes and lymphoid tissue, as well as their activation therein. The activated cells and derived cytokines will be transported via blood vessels to the plaque, causing intimal hyperplasia and vascular remodeling. Conversely, it has been suggested that the imbalance of angiogenesis and lymphangiogenesis in plaque may result in fluid buildup in atherosclerotic plaque and that a loss of lymphatics accelerates plaque progression ${ }^{97}$. In particular, recent evidence from mouse models support an essential contribution of lymphangiogenesis to the regression of atherosclerosis. Indeed, studies have revealed that lymphatics are critical for immune response and cholesterol metabolism in atherosclerosis. Moreover, hypercholesterolemic mice displayed lymphatic structural defects ${ }^{99}$. Lymphatic dysfunction may already occur before atherosclerosis onset ${ }^{100}$. In addition, pro-lymphangiogenic interventions reduced atherosclerosis, while anti-lymphangiogenic intervention enhanced plaque burden ${ }^{101}$, 102

\section{Role of lymphatics in atherosclerosis}

The lymphatics function I) as a route for migratory cells trafficking between plaque and secondary lymphoid organs ${ }^{103}$, and II) as conduit for drainage of interstitial macromolecules. The former function is evidenced by regulation of local $T$ cell content by adventitial lymphatics ${ }^{102}$. Indeed, an impaired capacity of monocytederived cells to emigrate out of the inflamed site through nearby lymphatic vessels is associated with atherosclerosis progression due to failure to resolve inflammation ${ }^{103}$, ${ }^{104}$. Moreover, surgical interruption of lymph drainage or blockade of VEGF-C/Ddependent lymphangiogenesis in collar-induced plaque in apo $\mathrm{E}^{-/}$mice resulted in exacerbated atherosclerotic plaque burden and increased intimal and adventitial $\mathrm{CD}^{+}$ T cell content ${ }^{102}$. Together, this suggests that lymphatic dysfunction may stimulate atherogenesis through enhanced inflammation, and hence contribute to atherosclerosis progression.

The second function of lymphatics is drainage of interstitial macromolecules back into the circulation. As lymph contains $30 \%$ more high-density lipoprotein (HDL) cholesterol than blood, this suggests a key role of lymphatic circulation in regulating 
reverse cholesterol transport (RCT) ${ }^{105}$. Surgical or genetic-induced lymphatic disruption in mice models emphasized the important role of lymphatic vessels in facilitating cholesterol removal from skin and transplanted aortic vessel ${ }^{101,}{ }^{106}$. Importantly, transplantation of pre-established atherosclerotic aortas, ex vivo incubated with stable isotope labeled cholesterol, to $\mathrm{apoE}^{-/}$recipient mice with impaired lymphangiogenesis (anti-VEGFR-3 treatment), caused cholesterol accumulation in the transplanted aortic plaque tissue ${ }^{101}$, and highlighted the essential role of lymphatics in removing cholesterol from aortic plaques. Furthermore, lymphatic insufficient transgenic mice displayed increased cholesterol and triglyceride levels in plasma, and exhibited accelerated plaque formation, and that atheroma formation was inversely associated with abundance of adventitial lymphatics in aorta ${ }^{107}$. This highlights the critical role of lymphatics in cholesterol metabolism, and indirectly supports the role of lymphatics in the removal of cholesterol from the atherosclerotic vessel. Moreover, Milasan et al. ${ }^{100}$ demonstrated in atherosclerotic low density lipoprotein receptor -deficient mice expressing the human apolipoprotein B100 transgene $\left(\mathrm{LDLR}^{-/} / \mathrm{hApoB} 10 \mathrm{O}^{+/+}\right)$that 3-month old mice displayed lymphatic dysfunction before atherosclerosis onset and that lymphatic dysfunction was associated with a defect of collecting lymphatic vessels in LDLR-dependent manner.

In chapter 6, we sought to identify novel players in pathologic lymphangiogenesis in human atherosclerosis. We employed a bioinformatics approach, weighted gene coexpression network analysis (WGCNA), to identify networks and candidate genes relevant to plaque lymphangiogenesis in humans. In this study, we correlated phenotypic traits i.e. D2-40+ lymphatic vessel density (LVD) in human atherosclerotic tissue, with transcription profiling derived from the same tissue samples. Using this approach we identified modules showing highest correlation to LVD. Subsequently, we could select potential candidate genes as well as transcription factor binding sites (TFBS), miRNAs, and potential pathways which may be involved in regulation of plaque lymphangiogenesis.

Taken together, lymphatic dysfunction and impaired lymphatic drainage accelerate plaque progression. Lymphatic vessels could be expected to have a protective effect against atherosclerosis by affecting both RCT and the local inflammatory milieu.

\section{Dual signaling cascades stimulate lymph- and angiogenesis}

The formation of lymphangiogenesis is a complex process, which has similarities with angiogenesis. Lymphangiogenesis and angiogenesis share regulatory mechanisms and often coexist in atherosclerotic lesions ${ }^{95}$. The adventitial lymphatic absorbing networks consist of large and sparsely distributed capillary structure, which form a wrapping plexus around large caliber arteries (periarterial lymphatics) ${ }^{90}$. This 188 
anatomical arrangement of the lymphatics within the arterial wall appeared to be consistent with arterial branches in the viscera, suggesting the role of lymphatics as an important drainage route for the arterial interstitium ${ }^{90}$.

Mechanistically, several factors that enhance lymphangiogenesis also promote angiogenesis ${ }^{86}$, including VEGF-C/D/VEGFR-3, VEGF-A/VEGFR-1/2 and Ang1/Ang2 signaling. The first signaling axis is well established to promote lymphangiogenesis ${ }^{108}$, however, mature VEGF-C and VEGF-D which are generated by proteolytic processing, can bind and activate VEGFR-2 ${ }^{109,110}$, and thus induce angiogenesis ${ }^{111}$. Interestingly, it has been demonstrated that VEGFR-2, but not VEGFR-3, is expressed in the vessel wall at every stage of atherosclerosis ${ }^{112}$. In addition, VEGFR-2 can bind to and reduce VEGF-C activity, and subsequently cause inhibition of lymphangiogenesis ${ }^{113}$. This may suggest that the interaction between VEGF-C/ VEGFR-2 may contribute to imbalance between lymphangiogenesis and angiogenesis during atherosclerosis progression.

The second dual signaling pathway involves VEGF-A, for which, signaling through VEGFR-2 is the major angiogenesis pathway ${ }^{76}$. However, VEGF-A also induces a lymphangiogenic response ${ }^{114}$, which is mediated mainly through VEGFR-2 115,116 . Interestingly, transduction of murine VEGF-A to the ear skin of mice induced abnormal lymphangiogenesis, characterized by enlarged lymphatic vessels, incompetent valves, and delayed lymph clearance, suggesting that overexpressed VEGF-A might result in development of abnormal lymphatics ${ }^{114}$. Thus, high expression of VEGF-A in atherosclerotic lesions ${ }^{117,118}$ may at least in part contribute to lymphatic dysfunction, leading to insufficient lymphatic drainage and subsequently exacerbate atherosclerosis formation.

The third overlapping signaling pathway involves Ang1 and Ang2. These two proteins have distinct functions in the blood vascular system, but redundant roles in lymphatic development ${ }^{119}$. In blood vessels, Ang1 and Ang2 can be pro-or antiangiogenic, owing to their respective agonist and antagonist signaling action through the Tie2 receptor ${ }^{120}$. In lymphatics, Ang2 is a prerequisite for lymphatic remodeling, stabilization, maturation and development ${ }^{121,122}$, specifically in regulating of lymphatic valve morphogenesis ${ }^{123}$. Ang2 deficient mice exhibited lymphatic defects, which could be rescued by Ang1 knock-in in the Ang2 genetic locus, suggesting a redundant role in lymphatic development, where either ligand can act as a Tie2 receptor agonist ${ }^{122}$. Ang2 has a stimulatory role in various processes associated with vulnerable plaques such as increased inflammation, plaque vascularity, and microvascular leakage ${ }^{124}$. Interestingly, Ang2 partially rescued the reduced lymphangiogenesis when VEGFC/VEGFR-3 signaling was blocked, suggesting a role of lymphangioenic factor ${ }^{123}$. The exact role of Ang2 in plaque lymphangiogenesis remains to be elucidated. 
In chapter 6, we identified novel lymphatic regulators in atherosclerosis. Our findings demonstrated that TNIP2 was associated with human plaque lymphatics, and was critical for lymphangiogenesis in vitro. TNIP2 expression was induced by inflammatory and lipid stimuli. TNIP2-silenced lymphatic endothelial cells (LEC) showed profound downregulation of LEC-specific genes and lymphangiogenic factors and impaired LEC proliferation, migration and differentiation. Further support for the involvement of TNIP2 in lymphangiogenic regulation was derived from the reciprocal effects of TNIP2 and the lymphangiogenic master regulator PROX1. We found inverse regulatory roles of TNIP2 and PROX1 in lymphangiogenesis in vitro, where TNIP2 knockdown appears to dampen PROX1 target gene expression, and thus LEC differentiation. It is also of note that other studies reported an interaction of TNIP2 with Tie2. This interaction depends on Tie2 autophosphorylation and is further enhanced by Ang1 stimulation ${ }^{125}$. This suggests that TNIP2 may also regulate lymphatic development through Ang1/Tie2 signaling.

Together, the formation of lymph- and angiogenic vessels is co-dependent, and mediated by shared signaling pathways such as VEGF-C/D/VEGFR-3, VEGF-A and Ang1/Ang2 signaling. TNIP2 may act as a novel regulator of lymphangiogenesis.

\section{Interventions in lymphangiogenesis to ameliorate disease?}

Emerging evidence has suggested that enhancement of lymphangiogenesis and lymphatic function in plaque may represent an effective therapeutic approach for inflammatory diseases ${ }^{126}$, including atherosclerosis ${ }^{95,100,101,107}$. To date, there are limited data on whether pro-lymphangiogenic targets could alter the risk for atherosclerosis ${ }^{127}$. Given that there is still much unknown regarding the role of lymphangiogenesis in atherosclerosis, the actual effects of therapeutic administration are unclear. While pro-lymphangiogenic therapy seems to be an attractive strategy for the treatment atherosclerosis, excess activation of lymphangiogenesis may result in increased exposure of lymph nodes to inflammatory mediators and promote the development of metastasis ${ }^{128}$. Therefore, the safety and efficacy of the lymphangiogenic therapy must be carefully evaluated within the context of each disorder and the desired therapeutic goals ${ }^{127}$.

In chapter 6, we have demonstrated that TNIP2, an inhibitor of NFKB, may positively regulate lymphangiogenesis in chronic inflammatory conditions in plaque. TNIP2 may be a potent target to approach in inhibiting atherosclerosis development, as it inhibits NFKB, a master regulator of inflammatory and atherogenenic genes ${ }^{129}$. We found that TNIP2 was upregulated in ruptured plaque segments in comparison to stable plaque segments. We further demonstrated that TNIP2 negatively regulated IFNy a key proinflammatory cytokine in atherogenesis ${ }^{130}$. Moreover, IFNy was seen to 190 
exert anti-lymphangiogenic properties in murine, porcine and human LEC ${ }^{131,132}$ which is compatible with our findings. TNIP2 also positively regulated PPARy activity, although there is little evidence for direct regulatory effect of PPARy on lymphangiogenesis. Interestingly, PROX1 interacts directly with PPARy and induces the downregulation of IFNy in T cells, suggesting PROX1 acts as a co-repressor for IFNy ${ }^{133}$. Moreover, PPARy can antagonize NFKB signaling-mediated proinflammatory pathways in macrophages ${ }^{134}$. Together, this may suggested the tight collaboration between TNIP2, PROX1 and PPARY in mediating proinflammatory pathways related to lymphangiogenesis in vitro. It has been demonstrated that activation of NFKB by inflammatory stimuli (i.e. IL-3 and LPS) elevated PROX1 and VEGFR-3 expression in cultured LEC, resulting in increased proliferation and migration; thus suggesting a role for inflammation-induced lymphangiogenesis ${ }^{135}$. Interestingly, we demonstrated in chapter 6 that treatment of LEC with LPS also upregulated TNIP2 mRNA expression. As mentioned above, we found that TNIP2 might induce PPAR-related lipid and cholesterol metabolism signaling. Together, this may indicate that TNIP2 cooperates with PPARy to play a negative feedback role in the regulation of NFKB-mediated inflammatory lymphangiogenesis in vitro.

In conclusion, we propose that TNIP2 could be a potent target in inhibiting atherosclerosis development; by inhibiting NFKB dependent inflammation and IFNY dependent lymphangiogenesis and enhancing PPAR- dependent lipid fluxes in vitro. Future delineation of these mechanisms might identify targets for therapeutic lymphangiogenesis in atherosclerosis.

The therapeutic potential of intervention in lymphangiogenesis for atherosclerosis is not well studied. One may also question that if increased lymphatic density is associated with plaque progression and is consistently found in advanced ruptured plaque, if lymphangiogenesis may thus even promote atherogenesis. However, evidence from in vivo studies have suggested that interrupted lymphatic drainage exacerbated atherosclerosis development, whereas inversely, promotion of lymphangiogenesis ameliorated atherosclerosis development ${ }^{100-103,106,107}$. Indeed, recent evidence demonstrated that VEGF-C 152s administration in this mouse model resulted in increased lymphatic vessel density in the adventitia of the aortic sinus and improved lymphatic cellular transport ${ }^{100}$. However, targeting VEGF-C remains somewhat controversial, as Ad-VEGF-C or AAV-VEGF-C treatment caused blood vascular changes, including enlargement, tortuosity and leakiness via interaction with VEGFR-2 ${ }^{136}$. Angiogenesis promotes plaque progression and lesion instability ${ }^{76}$ thereby raising concerns about VEGF-C capability to cause off-target proangiogenic effects. In addition, recent evidence has reported potential pro-lymphangiogenic agents, such as the FDA-approved 9-cis retinoic acid (9-cis RA; alitretinoin) ${ }^{137,138}$ or cholesterol-lowering compounds such as ezetimibe and proprotein convertase 
subtilisin/kexin type 9 (PCSK9) inhibitor, which may show pleiotropic roles in improvement of lymphatic functions, as it is documented in experimental atherosclerosis ${ }^{100,106}$. However, as we show in chapter 6 , TNIP2, being a specific regulator of pathologic lymphangiogenesis during atherosclerosis development and progression, would represent a much more suitable clinical target. Together, although lymphatics likely are important, the causal role and therapeutic options for plaque lymphangiogenesis remain underexplored.

\section{The suitability of animal models of atherosclerosis for studying plaque lymphangiogenesis.}

Zebrafish have gained interest for studying dyslipidemia, and genes related to atherosclerosis ${ }^{139}$. Several genes involved in lipid and lipoprotein metabolism including major classes of apolipoproteins, CETP, PPARs, LXLR and LDLR are conserved from zebrafish to human ${ }^{140-142}$. In addition, zebrafish develop only the early stages of atherosclerosis by interventions ${ }^{143-147}$. Zebrafish are however, suitable for studying inflammatory lymphangiogenesis ${ }^{148}$, investigating novel anti-lymphatic compounds ${ }^{149}$ and screening to identify candidate genes or novel pathways, leading to discoveries such as the novel mammalian lymphatic gene CCBE1 ${ }^{150}$. In chapter $\mathbf{6}$, we have demonstrated in zebrafish that tnip2 deficient morphants had an increased number of venous intersegmental vessels (vISVs), parachordal lymphangioblasts (PLs) and thoracic ducts (TD). In the secondary wave of zebrafish angiogenesis, half of the sprouts that directly bud from the posterior cardinal vein (PCV) reconnect with and convert primary arterial sprout-derived ISVs into vISVs. The other half do not connect, continue to migrate dorsally and constitute so-called parachordal lymphangioblasts (PLs), that align along the horizontal myoseptum, after which they migrate dorsally or ventrally (then referred to as LEC) at 3 days post-fertilization (dpf ) ${ }^{150,151}$. Since we found increased vISVs, we expected to see less PLs. Surprisingly, we also observed more PLs. This could only mean that more venous sprouts have emerged from the PCV, indicative of enhanced sprouting activity of tnip2 in venous endothelial cells (VEC). It is well documented that in zebrafish, vegf-c induced VEC proliferation in the $P C V{ }^{152,153}$. ccbe1 and vegf-c are required for the sprouting of venous precursors and PLs from the PCV during secondary angiogenesis ${ }^{150,154}$. Indeed, we found that TNIP2 silencing in LEC in vitro resulted in upregulated CCBE1 and VEGF-C, but dowregulated PROX1 and SOX18 mRNA expression. This may indicate that the upregulation of vegf-c and ccbe 1 expression may contribute to the increased vISVs, PLs and TD in tnip2 deficient morphants. In contrast, prox1, coup-TFIl and sox18 are not essential for lymphatic development in zebrafish ${ }^{155}$, this suggests another mode of lymphatic commitment ${ }^{156}$. This therefore also raises a note of caution regarding the interpretation of zebrafish studies. Alternatively, it is possible that TNIP2 effects are more prominent in adult lymphangiogenesis under pathological conditions. Together, 
this might also explain that tnip2 deficient morphants did not exhibit pronounce lymphangiogenesis defects. Nevertheless, our finding suggested that TNIP2 negatively regulates sprouting activity of endothelial cells in vivo, this seems to be specific for venous/lymphatic endothelial cells.

To date, most experimental lymphangiogenesis-associated atherosclerosis studies have utilized a combination of atherosclerotic mouse models with genetic and/or surgical interventions to induce lymphatic insufficiency. This raises the question whether the methods or results can be translated to human atherosclerosis. Wildtype mice are resistant to atherosclerosis because they exhibit high plasma HDL and low LDL and VLDL distribution, which is opposite to human lipoprotein profiles ${ }^{157-159}$. Nevertheless, mice models are suitable to study mechanisms, but one should be aware of differences hampering translation to human disease.

Unlike mice and rabbits, pigs develop spontaneous atherosclerosis upon feeding, and the development of plaques can be induced by intervention ${ }^{160}$. In addition, their plaque lesions closely mimick advanced human plaques ${ }^{161}$. A porcine disease model thus seems most suitable for the study of atherosclerosis related diagnostic and therapeutic interventions ${ }^{162}$; pig models of coronary atherosclerosis allow investigation of the impact of adventitial neovascularization by coronary imaging technologies ${ }^{162,163}$, and therefore may be applicable to adventitial lymphangiogenesis research. Therapeutic intervention targeting pro-lymphangiogenic factors have been investigated in lymphedema pigs ${ }^{164-166}$, which further suggested that similar strategies could be employed to investigate atherosclerosis ${ }^{127}$. As such, a new candidate or therapy focused on lymphangiogenesis should be tested in a pig model before venturing to human disease

\section{Conclusions and Perspectives}

In this thesis we addressed the role of eNOS and therapeutic possibilities in experimental pressure overload-induced cardiac hypertrophy in mice. eNOS-derived $\mathrm{NO}$ is crucial in maintaining cardiovascular homeostasis. In pressure overload-induced cardiac hypertrophy, eNOS uncoupling is a major source of myocardial ROS, which then contribute to dilatory remodeling and cardiac dysfunction ${ }^{167}$. Improvement of eNOS activity by stabilizing eNOS function and suppressing eNOS-derived ROS production is thus a promising therapeutic target for cardiovascular diseases. Compounds that increase eNOS expression and/or activity are only beneficial when accompanied by eNOS functionality ${ }^{35}$. Elevated eNOS expression without further increase in $\mathrm{BH} 4$ levels, generally results in eNOS uncoupling, because of the enzyme cofactor imbalance. We demonstrated that the eNOS enhancer AVE3085 also restored cardiac $\mathrm{BH} 4$ levels, reversing eNOS uncoupling in a mouse model of left ventricular pressure overload. Our study emphasizes the importance of eNOS as a 
regulator in nitroso-redox balance and as a therapeutic target in left ventricular hypertrophy induced by aortic stenosis, suggesting that eNOS enhancement may benefit heart failure patients. Despite the promising results in our in vivo experiments, the long-term therapeutic benefit of AVE3085 is not yet known. Further studies are required to better understand how modulation of nitroso-redox balance can be optimized and deployed to attenuate cardiac remodeling and dysfunction induced by aortic stenosis.

In the second part of my thesis, we have investigated another process in homeostatic fluid balance: lymphangiogenesis. Although recent studies have suggested the protective roles of atherosclerotic plaque lymphatics, the process of pathological lymphangiogenesis in the plaque is, however, not yet completely understood. Herein we provided a proof of concept that candidate genes correlating with plaque lymphangiogenesis, as identified by weighted coexpression analysis, do indeed control this process. Our study highlights TNIP2 as a novel gene regulator of plaque lymphangiogenesis, potentially through mechanisms related to inflammation and lipid metabolism. Further studies are required to dissect molecular mechanism of TNIP2-dependent lymphangiogenesis and to functionally validate our findings in other animal models.

In conclusion, we have provided evidence of molecular regulation of cardiovascular disease, focusing on eNOS and TNIP2. The next challenge is to integrate these findings and translate them to clinical utility for cardiovascular disease prevention and/or treatment. 


\section{References}

1. Shantsila E, Wrigley BJ, Blann AD, Gill PS, Lip GYH. A contemporary view on endothelial function in heart failure. European Journal of Heart Failure 2012;14(8):873-881.

2. Galley HF, Webster NR. Physiology of the endothelium. BJA: British Journal of Anaesthesia 2004;93(1):105-113.

3. Hsieh PCH, Davis ME, Lisowski LK, Lee RT. Endothelial-Cardiomyocyte Interactions in Cardiac Development and Repair. Annual review of physiology 2006;68:51-66.

4. Dimitris T, Anna-Maria K, Costas Tentolouris Nikolaos P, Christodoulos S. The Role of Nitric Oxide on Endothelial Function. Current Vascular Pharmacology 2012;10(1):4-18.

5. Wink DA, Miranda KM, Espey MG, Pluta RM, Hewett SJ, Colton C, Vitek M, Feelisch M, Grisham MB. Mechanisms of the Antioxidant Effects of Nitric Oxide. Antioxidants \& Redox Signaling 2001;3(2):203-213.

6. Gewaltig MT, Kojda G. Vasoprotection by nitric oxide: mechanisms and therapeutic potential. Cardiovascular Research 2002;55(2):250-260.

7. Shiva S. Mitochondria as metabolizers and targets of nitrite. Nitric oxide : biology and chemistry / official journal of the Nitric Oxide Society 2010;22(2):64.

8. Shiva S, Huang Z, Grubina R, Sun J, Ringwood LA, MacArthur PH, Xu X, Murphy E, DarleyUsmar VM, Gladwin MT. Deoxymyoglobin Is a Nitrite Reductase That Generates Nitric Oxide and Regulates Mitochondrial Respiration. Circulation Research 2007;100(5):654.

9. Borniquel S, Valle I, Cadenas S, Lamas S, Monsalve M. Nitric oxide regulates mitochondrial oxidative stress protection via the transcriptional coactivator PGC-1a. The FASEB Journal 2006;20(11):1889-1891.

10. Rassaf T, Flögel U, Drexhage C, Hendgen-Cotta U, Kelm M, Schrader J. Nitrite Reductase Function of Deoxymyoglobin. Circulation Research 2007;100(12):1749.

11. Tirziu D, Giordano FJ, Simons M. Cell Communications in the Heart. Circulation 2010;122(9):928937.

12. Bendall JK, Douglas G, McNeill E, Channon KM, Crabtree MJ. Tetrahydrobiopterin in Cardiovascular Health and Disease. Antioxidants \& Redox Signaling 2014;20(18):3040-3077.

13. Moens AL, Kietadisorn R, Lin JY, Kass D. Targeting endothelial and myocardial dysfunction with tetrahydrobiopterin. Journal of Molecular and Cellular Cardiology 2011;51(4):559-563.

14. Du Y-H, Guan Y-Y, Alp NJ, Channon KM, Chen AF. Endothelium-Specific GTP Cyclohydrolase I Overexpression Attenuates Blood Pressure Progression in Salt-Sensitive Low-Renin Hypertension. Circulation 2008;117(8):1045-1054.

15. Takimoto E, Kass DA. Role of Oxidative Stress in Cardiac Hypertrophy and Remodeling. Hypertension 2007;49(2):241-248.

16. Siwik DA, Pagano PJ, Colucci WS. Oxidative stress regulates collagen synthesis and matrix metalloproteinase activity in cardiac fibroblasts. American Journal of Physiology - Cell Physiology 2001;280(1):C53-C60.

17. Spinale FG. Bioactive Peptide Signaling Within the Myocardial Interstitium and the Matrix Metalloproteinases. Circulation Research 2002;91(12):1082-1084.

18. Cesselli D, Jakoniuk I, Barlucchi L, Beltrami AP, Hintze TH, Nadal-Ginard B, Kajstura J, Leri A, Anversa P. Oxidative Stress-Mediated Cardiac Cell Death Is a Major Determinant of Ventricular Dysfunction and Failure in Dog Dilated Cardiomyopathy. Circulation Research 2001;89(3):279286.

19. Zima AV, Blatter LA. Redox regulation of cardiac calcium channels and transporters. Cardiovascular Research 2006;71(2):310-321.

20. Gödecke A, Heinicke T, Kamkin A, Kiseleva I, Strasser RH, Decking UKM, Stumpe T, Isenberg G, Schrader J. Inotropic response to $\beta$-adrenergic receptor stimulation and anti-adrenergic effect of ACh in endothelial NO synthase-deficient mouse hearts. The Journal of Physiology 2001;532(1):195-204. 
21. Ionova IA, Vásquez-Vivar J, Whitsett J, Herrnreiter A, Medhora M, Cooley BC, Pieper GM. Deficient $\mathrm{BH}(4)$ production via de novo and salvage pathways regulates $\mathrm{NO}$ responses to cytokines in adult cardiac myocytes. American Journal of Physiology - Heart and Circulatory Physiology 2008;295(5):H2178-H2187.

22. Ren J, Duan J, Thomas DP, Yang X, Sreejayan N, Sowers JR, Leri A, Kajstura J, Gao F, Anversa P. IGF-I alleviates diabetes-induced RhoA activation, eNOS uncoupling, and myocardial dysfunction. American Journal of Physiology - Regulatory, Integrative and Comparative Physiology 2008;294(3):R793-R802.

23. Landmesser U, Dikalov S, Price SR, McCann L, Fukai T, Holland SM, Mitch WE, Harrison DG. Oxidation of tetrahydrobiopterin leads to uncoupling of endothelial cell nitric oxide synthase in hypertension. Journal of Clinical Investigation 2003;111(8):1201-1209.

24. Takimoto E, Champion HC, Li M, Ren S, Rodriguez ER, Tavazzi B, Lazzarino G, Paolocci N, Gabrielson KL, Wang Y, Kass DA. Oxidant stress from nitric oxide synthase-3 uncoupling stimulates cardiac pathologic remodeling from chronic pressure load. The Journal of Clinical Investigation 2005;115(5):1221-1231.

25. Moens AL, Takimoto E, Tocchetti CG, Chakir K, Bedja D, Cormaci G, Ketner EA, Majmudar M, Gabrielson K, Halushka MK, Mitchell JB, Biswal S, Channon KM, Wolin MS, Alp NJ, Paolocci N, Champion HC, Kass DA. Reversal of Cardiac Hypertrophy and Fibrosis From Pressure Overload by Tetrahydrobiopterin: Efficacy of Recoupling Nitric Oxide Synthase as a Therapeutic Strategy. Circulation 2008;117(20):2626-2636.

26. Xue H-M, Yu C-M, Underwood M, Huang J-H, Yang Q. AVE3085 Protects Coronary Endothelium from the Impairment of Asymmetric Dimethylarginine by Activation and Recoupling of eNOS. Cardiovasc Drugs Ther 2012;26(5):383-392.

27. Drummond GR, Cai H, Davis ME, Ramasamy S, Harrison DG. Transcriptional and Posttranscriptional Regulation of Endothelial Nitric Oxide Synthase Expression by Hydrogen Peroxide. Circulation Research 2000;86(3):347-354.

28. Westermann D, Riad A, Richter U, Jäger S, Savvatis K, Schuchardt M, Bergmann N, Tölle M, Nagorsen D, Gotthardt M, Schultheiss H-P, Tschöpe C. Enhancement of the endothelial NO synthase attenuates experimental diastolic heart failure. Basic Research in Cardiology 2009;104(5):499-509.

29. Yang Q, Xue H-M, Wong W-T, Tian X-Y, Huang Y, Tsui SKW, Ng PKS, Wohlfart P, Li H, Xia N, Tobias S, Underwood MJ, He G-W. AVE3085, an enhancer of endothelial nitric oxide synthase, restores endothelial function and reduces blood pressure in spontaneously hypertensive rats. British Journal of Pharmacology 2011;163(5):1078-1085.

30. Kietadisorn R, Juni RP, Moens AL. Tackling endothelial dysfunction by modulating NOSuncoupling: new insights in pathogenesis and therapeutic possibilities. American Journal of Physiology - Endocrinology And Metabolism 2011.

31. Pokharel S, Sharma UC, Pinto YM. Left ventricular hypertrophy: virtuous intentions, malign consequences. The International Journal of Biochemistry \& Cell Biology 2003;35(6):802-806.

32. Dorn GW. Apoptotic and non-apoptotic programmed cardiomyocyte death in ventricular remodelling. Cardiovascular Research 2009;81(3):465-473.

33. Frangogiannis NG. The immune system and cardiac repair. Pharmacological research : the official journal of the Italian Pharmacological Society 2008;58(2):88-111.

34. Förstermann U, Sessa WC. Nitric oxide synthases: regulation and function. European Heart Journal 2012;33(7):829-837.

35. Förstermann $\mathrm{U}, \mathrm{Li} \mathrm{H}$. Therapeutic effect of enhancing endothelial nitric oxide synthase (eNOS) expression and preventing eNOS uncoupling. British Journal of Pharmacology 2011;164(2):213223.

36. Denninger JW, Marletta MA. Guanylate cyclase and the -NO/cGMP signaling pathway. Biochimica et Biophysica Acta (BBA) - Bioenergetics 1999;1411(2):334-350. 
37. Sun J, Murphy E. Protein S-Nitrosylation and Cardioprotection. Circulation research 2010;106(2):285-296.

38. Lima B, Forrester MT, Hess DT, Stamler JS. S-Nitrosylation in Cardiovascular Signaling. Circulation research 2010;106(4):633-646.

39. Damilano F, Franco I, Perrino C, Schaefer K, Azzolino O, Carnevale D, Cifelli G, Carullo P, Ragona R, Ghigo A, Perino A, Lembo G, Hirsch E. Distinct Effects of Leukocyte and Cardiac Phosphoinositide 3-Kinase y Activity in Pressure Overload-Induced Cardiac Failure. Circulation 2011;123(4):391-399.

40. Kuwahara F, Kai H, Tokuda K, Takeya M, Takeshita A, Egashira K, Imaizumi T. Hypertensive Myocardial Fibrosis and Diastolic Dysfunction. Another Model of Inflammation? 2004;43(4):739745.

41. Förstermann U, Münzel T. Endothelial Nitric Oxide Synthase in Vascular Disease. Circulation 2006;113(13):1708.

42. Shimizu S, Ishibashi, M., Kumagai, S., Wajima, T., Hiroi, T., Kurihara, T., Ishii, M., Kiuchi, Y. Decreased cardiac mitochondrial tetrahydrobiopterin in a rat model of pressure overload. International Journal of Molecular Medicine 2013;31(3):589-596.

43. Seddon M, Looi YH, Shah AM. Oxidative stress and redox signalling in cardiac hypertrophy and heart failure. Heart 2007;93(8):903-907.

44. McNeill E, Crabtree MJ, Sahgal N, Patel J, Chuaiphichai S, Iqbal AJ, Hale AB, Greaves DR, Channon KM. Regulation of iNOS function and cellular redox state by macrophage Gch1 reveals specific requirements for tetrahydrobiopterin in NRF2 activation. Free Radical Biology \& Medicine 2015;79:206-216.

45. Hashimoto T, Sivakumaran V, Carnicer R, Zhu G, Hahn VS, Bedja D, Recalde A, Duglan D, Channon KM, Casadei B, Kass DA. Tetrahydrobiopterin Protects Against Hypertrophic Heart Disease Independent of Myocardial Nitric Oxide Synthase Coupling. Journal of the American Heart Association 2016;5(3).

46. Chen Y, Chen C, Feng C, Tang A, Ma Y, He X, Li Y, He J, Dong Y. AVE 3085, a novel endothelial nitric oxide synthase enhancer, attenuates cardiac remodeling in mice through the Smad signaling pathway. Archives of Biochemistry and Biophysics 2015;570:8-13.

47. Riad A, Westermann D, Van Linthout S, Mohr Z, Uyulmaz S, Becher PM, Rütten H, Wohlfart P, Peters $\mathrm{H}$, Schultheiss H-P, Tschöpe C. Enhancement of endothelial nitric oxide synthase production reverses vascular dysfunction and inflammation in the hindlimbs of a rat model of diabetes. Diabetologia 2008;51(12):2325-2332.

48. Cirino G, Fiorucci S, Sessa WC. Endothelial nitric oxide synthase: the Cinderella of inflammation? Trends in Pharmacological Sciences 2003;24(2):91-95.

49. Liao JK. Linking endothelial dysfunction with endothelial cell activation. The Journal of Clinical Investigation 2013;123(2):540-541.

50. Desjardins F, Gratton J-P. Post-translational regulation of eNOS activity in inflammation. In: Dauphinee S, Karsan A, eds. Endothelial Dysfunction and Inflammation. Basel: Springer Basel; 2010, p 65-80.

51. Dimmeler S, Fleming I, Fisslthaler B, Hermann C, Busse R, Zeiher AM. Activation of nitric oxide synthase in endothelial cells by Akt-dependent phosphorylation. Nature 1999;399(6736):601-605.

52. Fulton D, Gratton J-P, McCabe TJ, Fontana J, Fujio Y, Walsh K, Franke TF, Papapetropoulos A, Sessa WC. Regulation of endothelium-derived nitric oxide production by the protein kinase Akt. Nature 1999;399(6736):597-601.

53. Chen C-A, Druhan LJ, Varadharaj S, Chen Y-R, Zweier JL. Phosphorylation of Endothelial Nitricoxide Synthase Regulates Superoxide Generation from the Enzyme. The Journal of Biological Chemistry 2008;283(40):27038-27047.

54. Szabo C, Ischiropoulos H, Radi R. Peroxynitrite: biochemistry, pathophysiology and development of therapeutics. Nat Rev Drug Discov 2007;6(8):662-680. 
55. Li H, Witte K, August M, Brausch I, Gödtel-Armbrust U, Habermeier A, Closs El, Oelze M, Münzel T, Förstermann U. Reversal of Endothelial Nitric Oxide Synthase Uncoupling and Up-Regulation of Endothelial Nitric Oxide Synthase Expression Lowers Blood Pressure in Hypertensive Rats. Journal of the American College of Cardiology 2006;47(12):2536-2544.

56. Takahashi $\mathrm{H}$, Shibuya M. The vascular endothelial growth factor (VEGF)/VEGF receptor system and its role under physiological and pathological conditions. Clinical Science 2005;109(3):227.

57. Scaldaferri F, Vetrano S, Sans M, Arena V, Straface G, Stigliano E, Repici A, Sturm A, Malesci A, Panes J, Yla-Herttuala S, Fiocchi C, Danese S. VEGF-A Links Angiogenesis and Inflammation in Inflammatory Bowel Disease Pathogenesis. Gastroenterology 2009;136(2):585-595.e5.

58. Hood JD, Meininger CJ, Ziche M, Granger HJ. VEGF upregulates ecNOS message, protein, and NO production in human endothelial cells. American Journal of Physiology - Heart and Circulatory Physiology 1998;274(3):H1054.

59. Papapetropoulos A, García-Cardeña G, Madri JA, Sessa WC. Nitric oxide production contributes to the angiogenic properties of vascular endothelial growth factor in human endothelial cells. Journal of Clinical Investigation 1997;100(12):3131-3139.

60. Fukumura D, Gohongi T, Kadambi A, Izumi Y, Ang J, Yun C-O, Buerk DG, Huang PL, Jain RK. Predominant role of endothelial nitric oxide synthase in vascular endothelial growth factor-induced angiogenesis and vascular permeability. Proceedings of the National Academy of Sciences of the United States of America 2001;98(5):2604-2609.

61. Connelly L, Palacios-Callender M, Ameixa C, Moncada S, Hobbs AJ. Biphasic Regulation of NFKB Activity Underlies the Pro- and Anti-Inflammatory Actions of Nitric Oxide. The Journal of Immunology 2001;166(6):3873-3881.

62. Lawrence T. The Nuclear Factor NF-kB Pathway in Inflammation. Cold Spring Harbor Perspectives in Biology 2009;1(6):a001651.

63. Davis ME, Grumbach IM, Fukai T, Cutchins A, Harrison DG. Shear Stress Regulates Endothelial Nitric-oxide Synthase Promoter Activity through Nuclear Factor kB Binding. Journal of Biological Chemistry 2004;279(1):163-168.

64. Grumbach IM, Chen W, Mertens SA, Harrison DG. A negative feedback mechanism involving nitric oxide and nuclear factor kappa-B modulates endothelial nitric oxide synthase transcription. Journal of Molecular and Cellular Cardiology 2005;39(4):595-603.

65. Kawashima S, Yamashita T, Ozaki M, Ohashi Y, Azumi H, Inoue N, Hirata K-i, Hayashi Y, Itoh H, Yokoyama M. Endothelial NO Synthase Overexpression Inhibits Lesion Formation in Mouse Model of Vascular Remodeling. Arteriosclerosis, Thrombosis, and Vascular Biology 2001;21(2):201.

66. Ozaki M, Kawashima S, Yamashita T, Ohashi Y, Rikitake Y, Inoue N, Hirata K-I, Hayashi Y, Itoh $\mathrm{H}$, Yokoyama M. Reduced Hypoxic Pulmonary Vascular Remodeling by Nitric Oxide From the Endothelium. Hypertension 2001;37(2):322-327.

67. Channon K. Tetrahydrobiopterin: Regulator of Endothelial Nitric Oxide Synthase in Vascular Disease. Trends in Cardiovascular Medicine 2004;14(8):323-327.

68. van Deel ED, Octavia Y, de Boer M, Juni RP, Tempel D, van Haperen R, de Crom R, Moens AL, Merkus D, Duncker DJ. Normal and high eNOS levels are detrimental in both mild and severe cardiac pressure-overload. Journal of Molecular and Cellular Cardiology 2015;88(Supplement C): $145-154$.

69. Huang PL. eNOS, metabolic syndrome and cardiovascular disease. Trends in endocrinology and metabolism: TEM 2009;20(6):295-302.

70. Bendall JK, Alp NJ, Warrick N, Cai S, Adlam D, Rockett K, Yokoyama M, Kawashima S, Channon KM. Stoichiometric Relationships Between Endothelial Tetrahydrobiopterin, Endothelial NO Synthase (eNOS) Activity, and eNOS Coupling in Vivo: Insights From Transgenic Mice With Endothelial-Targeted GTP Cyclohydrolase 1 and eNOS Overexpression. Circ Res 2005;97(9):864-871 . 
71. Perrino C, Prasad SVN, Mao L, Noma T, Yan Z, Kim H-S, Smithies O, Rockman HA. Intermittent pressure overload triggers hypertrophy-independent cardiac dysfunction and vascular rarefaction. Journal of Clinical Investigation 2006;116(6):1547-1560.

72. Souders CA, Borg TK, Banerjee I, Baudino TA. Pressure Overload Induces Early Morphological Changes in the Heart. The American Journal of Pathology 2012;181(4):1226-1235.

73. Zachary I, Morgan RD. Therapeutic angiogenesis for cardiovascular disease: biological context, challenges, prospects. Heart 2010;97(3):181.

74. Karch R, Neumann F, Ullrich R, Neumüller J, Podesser BK, Neumann M, Schreiner W. The spatial pattern of coronary capillaries in patients with dilated, ischemic, or inflammatory cardiomyopathy. Cardiovascular Pathology 2005;14(3):135-144.

75. Carmeliet P. Angiogenesis in health and disease. Nat Med 2003;9(6):653-660.

76. Sluimer JC, Daemen MJ. Novel concepts in atherogenesis: angiogenesis and hypoxia in atherosclerosis. The Journal of Pathology 2009;218(1):7-29.

77. Shiojima I, Sato K, Izumiya Y, Schiekofer S, Ito M, Liao R, Colucci WS, Walsh K. Disruption of coordinated cardiac hypertrophy and angiogenesis contributes to the transition to heart failure. Journal of Clinical Investigation 2005;115(8):2108-2118.

78. Oka T, Akazawa H, Naito AT, Komuro I. Angiogenesis and Cardiac Hypertrophy. Circulation Research 2014;114(3):565.

79. Izumiya Y, Shiojima I, Sato K, Sawyer DB, Colucci WS, Walsh K. Vascular Endothelial Growth Factor Blockade Promotes the Transition From Compensatory Cardiac Hypertrophy to Failure in Response to Pressure Overload. Hypertension 2006;47(5):887-893.

80. Sano M, Minamino T, Toko H, Miyauchi H, Orimo M, Qin Y, Akazawa H, Tateno K, Kayama Y, Harada M, Shimizu I, Asahara T, Hamada H, Tomita S, Molkentin JD, Zou Y, Komuro I. p53induced inhibition of Hif-1 causes cardiac dysfunction during pressure overload. Nature 2007;446(7134):444-448.

81. de Vries MR, Quax PHA. Plaque angiogenesis and its relation to inflammation and atherosclerotic plaque destabilization. Current Opinion in Lipidology 2016;27(5):499-506.

82. Michel J-B, Martin-Ventura JL, Nicoletti A, Ho-Tin-Noé B. Pathology of human plaque vulnerability: Mechanisms and consequences of intraplaque haemorrhages. Atherosclerosis 2014;234(2):311-319.

83. Moreno PR, Purushothaman KR, Fuster V, Echeverri D, Truszczynska H, Sharma SK, Badimon JJ, O'Connor WN. Plaque Neovascularization Is Increased in Ruptured Atherosclerotic Lesions of Human Aorta. Circulation 2004;110(14):2032.

84. Ritman EL, Lerman A. The Dynamic Vasa Vasorum. Cardiovascular research 2007;75(4):649658.

85. Moulton KS, Vakili K, Zurakowski D, Soliman M, Butterfield C, Sylvin E, Lo K-M, Gillies S, Javaherian K, Folkman J. Inhibition of plaque neovascularization reduces macrophage accumulation and progression of advanced atherosclerosis. Proceedings of the National Academy of Sciences of the United States of America 2003;100(8):4736-4741.

86. Adams $\mathrm{RH}$, Alitalo K. Molecular regulation of angiogenesis and lymphangiogenesis. Nat Rev Mol Cell Biol 2007;8(6):464-478.

87. Vaahtomeri K, Karaman S, Mäkinen T, Alitalo K. Lymphangiogenesis guidance by paracrine and pericellular factors. Genes \& Development 2017;31(16):1615-1634.

88. Kholová I, Dragneva G, Čermáková P, Laidinen S, Kaskenpää N, Hazes T, Čermáková E, Šteiner I, Ylä-Herttuala S. Lymphatic vasculature is increased in heart valves, ischaemic and inflamed hearts and in cholesterol-rich and calcified atherosclerotic lesions. European Journal of Clinical Investigation 2011;41(5):487-497.

89. Niinimäki E, Mennander AA, Paavonen T, Kholová I. Lymphangiogenesis is increased in heart valve endocarditis. International Journal of Cardiology 2016;219:317-321.

90. Sacchi G, Weber E, L C. Histological framework of lymphatic vasa vasorum of major arteries: an experimental study. Lymphology 1990;23(3):135-139. 
91. Xu X, Lu H, Lin H, Li X, Ni M, Sun H, Li C, Jiang H, Li F, Zhang M, Zhao Y, Zhang Y. Aortic adventitial angiogenesis and lymphangiogenesis promote intimal inflammation and hyperplasia. Cardiovascular Pathology 2009;18(5):269-278.

92. Taher M, Nakao S, Zandi S, Melhorn MI, Hayes KC, Hafezi-Moghadam A. Phenotypic transformation of intimal and adventitial lymphatics in atherosclerosis: a regulatory role for soluble VEGF receptor 2. The FASEB Journal 2016;30(7):2490-2499.

93. Drozdz K, Janczak D, Dziegiel P, Podhorska M, Patrzałek D, Ziółkowski P, Andrzejak R, Szuba A. Adventitial lymphatics of internal carotid artery in healthy and atherosclerotic vessels. Folia Histochem Cytobiol 2008;46(4):433-436.

94. Drozdz K, Janczak D, Dziegiel P, Podhorska M, Piotrowska A, Patrzalek D, Andrzejak R, Szuba A. Adventitial lymphatics and atherosclerosis. Lymphology 2012;45(1):26-33.

95. Kutkut I, Meens MJ, McKee TA, Bochaton-Piallat M-L, Kwak BR. Lymphatic vessels: an emerging actor in atherosclerotic plaque development. European Journal of Clinical Investigation 2015;45(1):100-108.

96. Eliska O EM, Miller AJ. The absence of lymphatics in normal and atherosclerotic coronary arteries in man: a morphologic study. Lymphology 2006;39(2):76-83.

97. Nakano T, Nakashima $Y$, Yonemitsu $Y$, Sumiyoshi $S$, Chen $Y-X$, Akishima $Y$, Ishii T, lida M, Sueishi K. Angiogenesis and lymphangiogenesis and expression of lymphangiogenic factors in the atherosclerotic intima of human coronary arteries. Human Pathology 2005;36(4):330-340.

98. $\mathrm{Xu} \mathrm{X}$, Lin H, Lv H, Zhang M, Zhang Y. Adventitial lymphatic vessels- An important role in atherosclerosis. Medical Hypotheses 2007;69(6):1238-1241.

99. Lim HY, Rutkowski JM, Helft J, Reddy ST, Swartz MA, Randolph GJ, Angeli V. Hypercholesterolemic Mice Exhibit Lymphatic Vessel Dysfunction and Degeneration. The American Journal of Pathology 2009;175(3):1328-1337.

100. Milasan A, Dallaire F, Mayer G, Martel C. Effects of LDL Receptor Modulation on Lymphatic Function. Scientific Reports 2016;6:27862.

101. Martel C, Li W, Fulp B, Platt AM, Gautier EL, Westerterp M, Bittman R, Tall AR, Chen S-H, Thomas MJ, Kreisel D, Swartz MA, Sorci-Thomas MG, Randolph GJ. Lymphatic vasculature mediates macrophage reverse cholesterol transport in mice. The Journal of Clinical Investigation 2013;123(4):1571-1579.

102. Rademakers T, van der Vorst EPC, Daissormont ITMN, Otten JJT, Theodorou K, Theelen TL, Gijbels M, Anisimov A, Nurmi H, Lindeman JHN, Schober A, Heeneman S, Alitalo K, Biessen EAL. Adventitial lymphatic capillary expansion impacts on plaque $T$ cell accumulation in atherosclerosis. Scientific Reports 2017;7:45263.

103. Llodrá J, Angeli V, Liu J, Trogan E, Fisher EA, Randolph GJ. Emigration of monocyte-derived cells from atherosclerotic lesions characterizes regressive, but not progressive, plaques. Proceedings of the National Academy of Sciences of the United States of America 2004;101(32):11779-11784.

104. Randolph GJ. Emigration of monocyte-derived cells to lymph nodes during resolution of inflammation and its failure in atherosclerosis. Current opinion in lipidology 2008;19(5):462-468.

105. Nanjee MN, Cooke CJ, Wong JS, Hamilton RL, Olszewski WL, Miller NE. Composition and ultrastructure of size subclasses of normal human peripheral lymph lipoproteins: quantification of cholesterol uptake by HDL in tissue fluids. Journal of Lipid Research 2001;42(4):639-648.

106. Lim Hwee Y, Thiam Chung H, Yeo Kim P, Bisoendial R, Hii Chung S, McGrath Kristine CY, Tan Kar W, Heather A, Alexander JSteven J, Angeli V. Lymphatic Vessels Are Essential for the Removal of Cholesterol from Peripheral Tissues by SR-BI-Mediated Transport of HDL. Cell Metabolism 2013;17(5):671-684.

107. Vuorio T, Nurmi H, Moulton K, Pikkarainen J, Robciuc MR, öhman M, Heinonen SE, Samaranayake H, Heikura T, Alitalo K, Ylä-Herttuala S. Lymphatic vessel insufficiency in hypercholesterolemic mice alters lipoprotein levels and promotes atherogenesis. Arteriosclerosis, thrombosis, and vascular biology 2014;34(6):1162-1170. 
108. Veikkola T, Jussila L, Makinen T, Karpanen T, Jeltsch M, Petrova TV, Kubo H, Thurston G, McDonald DM, Achen MG, Stacker SA, Alitalo K. Signalling via vascular endothelial growth factor receptor-3 is sufficient for lymphangiogenesis in transgenic mice. The EMBO Journal 2001;20(6):1223-1231.

109. Joukov V, Sorsa T, Kumar V, Jeltsch M, Claesson-Welsh L, Cao Y, Saksela O, Kalkkinen N, Alitalo K. Proteolytic processing regulates receptor specificity and activity of VEGF-C. The EMBO Journal 1997;16(13):3898-3911.

110. Achen MG, Jeltsch M, Kukk E, Mäkinen T, Vitali A, Wilks AF, Alitalo K, Stacker SA. Vascular endothelial growth factor D (VEGF-D) is a ligand for the tyrosine kinases VEGF receptor 2 (Flk1) and VEGF receptor 3 (Flt4). Proceedings of the National Academy of Sciences of the United States of America 1998;95(2):548-553.

111. Cao Y, Linden P, Farnebo J, Cao R, Eriksson A, Kumar V, Qi J-H, Claesson-Welsh L, Alitalo K. Vascular endothelial growth factor $C$ induces angiogenesis in vivo. Proceedings of the National Academy of Sciences of the United States of America 1998;95(24):14389-14394.

112. Rutanen J, Leppänen P, Tuomisto TT, Rissanen TT, Hiltunen MO, Vajanto I, Niemi M, Häkkinen T, Karkola K, Stacker SA, Achen MG, Alitalo K, Ylä-Herttuala S. Vascular endothelial growth factor-D expression in human atherosclerotic lesions. Cardiovascular Research 2003;59(4):971979.

113. Nakao S, Zandi S, Hata Y, Kawahara S, Arita R, Schering A, Sun D, Melhorn MI, Ito Y, LaraCastillo N, Ishibashi T, Hafezi-Moghadam A. Blood vessel endothelial VEGFR-2 delays lymphangiogenesis: an endogenous trapping mechanism links lymph- and angiogenesis. Blood 2011;117(3):1081-1090.

114. Nagy JA, Vasile E, Feng D, Sundberg C, Brown LF, Detmar MJ, Lawitts JA, Benjamin L, Tan X, Manseau EJ, Dvorak AM, Dvorak HF. Vascular Permeability Factor/Vascular Endothelial Growth Factor Induces Lymphangiogenesis as well as Angiogenesis. The Journal of Experimental Medicine 2002;196(11):1497-1506.

115. Hirakawa S, Kodama S, Kunstfeld R, Kajiya K, Brown LF, Detmar M. VEGF-A induces tumor and sentinel lymph node lymphangiogenesis and promotes lymphatic metastasis. The Journal of Experimental Medicine 2005;201(7):1089-1099.

116. Wirzenius M, Tammela T, Uutela M, He Y, Odorisio T, Zambruno G, Nagy JA, Dvorak HF, YläHerttuala S, Shibuya M, Alitalo K. Distinct vascular endothelial growth factor signals for lymphatic vessel enlargement and sprouting. The Journal of Experimental Medicine 2007;204(6):1431.

117. Chen Y-X, Nakashima Y, Tanaka K, Shiraishi S, Nakagawa K, Sueishi K. Immunohistochemical Expression of Vascular Endothelial Growth Factor/Vascular Permeability Factor in Atherosclerotic Intimas of Human Coronary Arteries. Arteriosclerosis, Thrombosis, and Vascular Biology 1999;19(1):131.

118. Inoue M, Itoh H, Ueda M, Naruko T, Kojima A, Komatsu R, Doi K, Ogawa Y, Tamura N, Takaya K, Igaki T, Yamashita J, Chun T-H, Masatsugu K, Becker AE, Nakao K. Vascular Endothelial Growth Factor (VEGF) Expression in Human Coronary Atherosclerotic Lesions. Possible Pathophysiological Significance of VEGF in Progression of Atherosclerosis 1998;98(20):21082116.

119. Veikkola T, Alitalo K. Dual Role of Ang2 in Postnatal Angiogenesis and Lymphangiogenesis. Developmental Cell 2002;3(3):302-304.

120. Lobov IB, Brooks PC, Lang RA. Angiopoietin-2 displays VEGF-dependent modulation of capillary structure and endothelial cell survival in vivo. Proceedings of the National Academy of Sciences of the United States of America 2002;99(17):11205-11210.

121. Dellinger M, Hunter R, Bernas M, Gale N, Yancopoulos G, Erickson R, Witte M. Defective remodeling and maturation of the lymphatic vasculature in Angiopoietin-2 deficient mice. Developmental Biology 2008;319(2):309-320.

122. Gale NW, Thurston G, Hackett SF, Renard R, Wang Q, McClain J, Martin C, Witte C, Witte MH, Jackson D, Suri C, Campochiaro PA, Wiegand SJ, Yancopoulos GD. Angiopoietin-2 Is Required 
for Postnatal Angiogenesis and Lymphatic Patterning, and Only the Latter Role Is Rescued by Angiopoietin-1. Developmental Cell 2002;3(3):411-423.

123. Zheng W, Nurmi H, Appak S, Sabine A, Bovay E, Korhonen EA, Orsenigo F, Lohela M, D'Amico G, Holopainen T, Leow CC, Dejana E, Petrova TV, Augustin HG, Alitalo K. Angiopoietin 2 regulates the transformation and integrity of lymphatic endothelial cell junctions. Genes \& Development 2014;28(14):1592-1603.

124. Theelen TL, Lappalainen JP, Sluimer JC, Gurzeler E, Cleutjens JP, Gijbels MJ, Biessen EAL, Daemen MJAP, Alitalo K, Ylä-Herttuala S. Angiopoietin-2 blocking antibodies reduce early atherosclerotic plaque development in mice. Atherosclerosis 2015;241(2):297-304.

125. Verstrepen L, Carpentier I, Verhelst K, Beyaert R. ABINs: A20 binding inhibitors of NF-KB and apoptosis signaling. Biochemical Pharmacology 2009;78(2):105-114.

126. Dieterich LC, Seidel CD, Detmar M. Lymphatic vessels: new targets for the treatment of inflammatory diseases. Angiogenesis 2014;17(2):359-371.

127. Vuorio T, Tirronen A, Ylä-Herttuala S. Cardiac Lymphatics - A New Avenue for Therapeutics? Trends in Endocrinology \& Metabolism 2017;28(4):285-296.

128. Kim H, Kataru RP, Koh GY. Regulation and implications of inflammatory lymphangiogenesis. Trends in Immunology 2012;33(7):350-356.

129. Kivelä AM, Huusko J, Ylä-Herttuala S. Prospect and progress of gene therapy in treating atherosclerosis. Expert Opinion on Biological Therapy 2015;15(12):1699-1712.

130. McLaren JE, Ramji DP. Interferon gamma: A master regulator of atherosclerosis. Cytokine and Growth Factor Reviews 2009;20(2):125-135.

131. Chaitanya GV, Franks SE, Cromer W, Wells SR, Bienkowska M, Jennings MH, Ruddell A, Ando T, Wang Y, Gu Y, Sapp M, Mathis JM, Jordan PA, Minagar A, Alexander JS. Differential Cytokine Responses in Human and Mouse Lymphatic Endothelial Cells to Cytokines in Vitro. Lymphatic Research and Biology 2010;8(3):155-164.

132. Shao X, Liu C. Influence of IFN- $\alpha$ and IFN- $y$ on Lymphangiogenesis. Journal of Interferon \& Cytokine Research 2006;26(8):568-574.

133. Wang L, Zhu J, Shan S, Qin Y, Kong Y, Liu J, Wang Y, Xie Y. Repression of interferon-[gamma] expression in T cells by Prospero-related Homeobox protein. Cell Res 2008;18(9):911-920.

134. Chung SW, Kang BY, Kim SH, Pak YK, Cho D, Trinchieri G, Kim TS. Oxidized Low Density Lipoprotein Inhibits Interleukin-12 Production in Lipopolysaccharide-activated Mouse Macrophages via Direct Interactions between Peroxisome Proliferator-activated Receptor-y and Nuclear Factor-kB. Journal of Biological Chemistry 2000;275(42):32681-32687.

135. Flister MJ, Wilber A, Hall KL, Iwata C, Miyazono K, Nisato RE, Pepper MS, Zawieja DC, Ran S. Inflammation induces lymphangiogenesis through up-regulation of VEGFR-3 mediated by NF-KB and Prox1. Blood 2010;115(2):418-429.

136. Saaristo A, Veikkola T, enholm b, Hytönen M, Arola J, Pajusola K, Turunen P, Jeltsch M, Karkkainen Mj, Kerjaschki D, Bueler H, Ylä-herttuala S, Alitalo K. Adenoviral VEGF-C overexpression induces blood vessel enlargement, tortuosity, and leakiness but no sprouting angiogenesis in the skin or mucous membranes. The FASEB Journal 2002;16(9):1041-1049.

137. Bramos A, Perrault D, Yang S, Jung E, Hong YK, Wong AK. Prevention of Postsurgical Lymphedema by 9-cis Retinoic Acid. Annals of Surgery 2016;264(2):353-361.

138. Choi I, Lee S, Kyoung Chung H, Suk Lee Y, Eui Kim K, Choi D, Park EK, Yang D, Ecoiffier T, Monahan J, Chen W, Aguilar B, Lee HN, Yoo J, Koh CJ, Chen L, Wong AK, Hong Y-K. 9-Cis Retinoic Acid Promotes Lymphangiogenesis and Enhances Lymphatic Vessel Regeneration. Circulation 2012;125(7):872.

139. Schlegel A. Zebrafish Models for Dyslipidemia and Atherosclerosis Research. Frontiers in Endocrinology 2016;7:159.

140. Den Broeder MJ, Kopylova VA, Kamminga LM, Legler J. Zebrafish as a Model to Study the Role of Peroxisome Proliferating-Activated Receptors in Adipogenesis and Obesity. PPAR Research 2015;2015:11. 
141. Otis JP, Zeituni EM, Thierer JH, Anderson JL, Brown AC, Boehm ED, Cerchione DM, Ceasrine AM, Avraham-Davidi I, Tempelhof H, Yaniv K, Farber SA. Zebrafish as a model for apolipoprotein biology: comprehensive expression analysis and a role for ApoA-IV in regulating food intake. Disease Models \& Mechanisms 2015;8(3):295-309.

142. Hölttä-Vuori M, Salo Veijo TV, Nyberg L, Brackmann C, Enejder A, Panula P, Ikonen E. Zebrafish: gaining popularity in lipid research. Biochemical Journal 2010;429(2):235.

143. Stoletov K, Fang L, Choi S-H, Hartvigsen K, Hansen LF, Hall C, Pattison J, Juliano J, Miller ER, Almazan F, Crosier P, Witztum JL, Klemke RL, Miller YI. Vascular Lipid Accumulation, Lipoprotein Oxidation, and Macrophage Lipid Uptake in Hypercholesterolemic Zebrafish. Circulation Research 2009;104(8):952.

144. Fang L, Green SR, Baek JS, Lee S-H, Ellett F, Deer E, Lieschke GJ, Witztum JL, Tsimikas S, Miller YI. In vivo visualization and attenuation of oxidized lipid accumulation in hypercholesterolemic zebrafish. The Journal of Clinical Investigation 2011;121(12):4861-4869.

145. Yoon Y, Yoon J, Jang M-Y, Na Y, Ko Y, Choi J-H, Seok SH. High Cholesterol Diet Induces IL-1 $\beta$ Expression in Adult but Not Larval Zebrafish. PLOS ONE 2013;8(6):e66970.

146. O'Hare EA, Wang X, Montasser ME, Chang Y-PC, Mitchell BD, Zaghloul NA. Disruption of Idlr causes increased LDL-C and vascular lipid accumulation in a zebrafish model of hypercholesterolemia. Journal of Lipid Research 2014;55(11):2242-2253.

147. Liu C, Gates KP, Fang L, Amar MJ, Schneider DA, Geng H, Huang W, Kim J, Pattison J, Zhang J, Witztum JL, Remaley AT, Dong PD, Miller YI. Apoc2 loss-of-function zebrafish mutant as a genetic model of hyperlipidemia. Disease Models \& Mechanisms 2015;8(8):989-998.

148. Okuda KS, Misa JP, Oehlers SH, Hall CJ, Ellett F, Alasmari S, Lieschke GJ, Crosier KE, Crosier PS, Astin JW. A zebrafish model of inflammatory lymphangiogenesis. Biology Open 2015;4(10):1270-1280.

149. Astin JW, Jamieson SMF, Eng TCY, Flores MV, Misa JP, Chien A, Crosier KE, Crosier PS. An In Vivo Antilymphatic Screen in Zebrafish Identifies Novel Inhibitors of Mammalian Lymphangiogenesis and Lymphatic-Mediated Metastasis. Molecular Cancer Therapeutics 2014;13(10):2450.

150. Hogan BM, Bos FL, Bussmann J, Witte M, Chi NC, Duckers HJ, Schulte-Merker S. ccbe1 is required for embryonic lymphangiogenesis and venous sprouting. Nat Genet 2009;41(4):396-398.

151. Cermenati S, Moleri S, Neyt C, Bresciani E, Carra S, Grassini DR, Omini A, Goi M, Cotelli F, François M, Hogan BM, Beltrame M. Sox18 Genetically Interacts With VegfC to Regulate Lymphangiogenesis in Zebrafish. Arteriosclerosis, Thrombosis, and Vascular Biology 2013;33(6):1238-1247.

152. Helker CSM, Schuermann A, Karpanen T, Zeuschner D, Belting H-G, Affolter M, Schulte-Merker $\mathrm{S}$, Herzog W. The zebrafish common cardinal veins develop by a novel mechanism: lumen ensheathment. Development 2013;140(13):2776.

153. Le Guen L, Karpanen T, Schulte D, Harris NC, Koltowska K, Roukens G, Bower NI, van Impel A Stacker SA, Achen MG, Schulte-Merker S, Hogan BM. Ccbe1 regulates Vegfc-mediated induction of Vegfr3 signaling during embryonic lymphangiogenesis. Development 2014;141(6):1239-1249.

154. Villefranc JA, Nicoli S, Bentley K, Jeltsch M, Zarkada G, Moore JC, Gerhardt H, Alitalo K, Lawson ND. A truncation allele in vascular endothelial growth factor $\mathrm{c}$ reveals distinct modes of signaling during lymphatic and vascular development. Development (Cambridge, England) 2013;140(7):1497-1506.

155. van Impel A, Zhao Z, Hermkens DMA, Roukens MG, Fischer JC, Peterson-Maduro J, Duckers H, Ober EA, Ingham PW, Schulte-Merker S. Divergence of zebrafish and mouse lymphatic cell fate specification pathways. Development (Cambridge, England) 2014;141(6):1228-1238.

156. Chen H, Griffin C, Xia L, Srinivasan RS. Molecular and cellular mechanisms of lymphatic vascular maturation. Microvascular research 2014;0:16-22.

157. Yin W, Carballo-Jane E, McLaren DG, Mendoza VH, Gagen K, Geoghagen NS, McNamara LA, Gorski JN, Eiermann GJ, Petrov A, Wolff M, Tong X, Wilsie LC, Akiyama TE, Chen J, 
Thankappan A, Xue J, Ping X, Andrews G, Wickham LA, Gai CL, Trinh T, Kulick AA, Donnelly MJ, Voronin GO, Rosa R, Cumiskey A-M, Bekkari K, Mitnaul LJ, Puig O, Chen F, Raubertas R, Wong PH, Hansen BC, Koblan KS, Roddy TP, Hubbard BK, Strack AM. Plasma lipid profiling across species for the identification of optimal animal models of human dyslipidemia. Journal of Lipid Research 2012;53(1):51-65.

158. Tsutsumi K, Hagi A, Inoue Y. The Relationship between Plasma High Density Lipoprotein Cholesterol Levels and Cholesteryl Ester Transfer Protein Activity in Six Species of Healthy Experimental Animals. Biological and Pharmaceutical Bulletin 2001;24(5):579-581.

159. Zadelaar S, Kleemann R, Verschuren L, de Vries-Van der Weij J, van der Hoorn J, Princen HM, Kooistra T. Mouse Models for Atherosclerosis and Pharmaceutical Modifiers. Arteriosclerosis, Thrombosis, and Vascular Biology 2007;27(8):1706.

160. Santos A, Fernández-Friera L, Villalba M, López-Melgar B, España S, Mateo J, Mota RA, Jiménez-Borreguero J, Ruiz-Cabello J. Cardiovascular imaging: what have we learned from animal models? Frontiers in Pharmacology 2015;6:227.

161. Prescott MF, McBride CH, Hasler-Rapacz J, Von Linden J, Rapacz J. Development of complex atherosclerotic lesions in pigs with inherited hyper-LDL cholesterolemia bearing mutant alleles for apolipoprotein B. The American Journal of Pathology 1991;139(1):139-147.

162. van Ditzhuijzen NS, van den Heuvel M, Sorop O, van Duin RWB, Krabbendam-Peters I, van Haeren R, Ligthart JMR, Witberg KT, Duncker DJ, Regar E, van Beusekom HMM, van der Giessen WJ. Invasive coronary imaging in animal models of atherosclerosis. Netherlands Heart Journal 2011;19(10):442-446.

163. Alviar CL, Tellez A, Wallace-Bradley D, Lopez-Berestein G, Sanguino A, Schulz DG, Builes A, Ballantyne CM, Yang C-Y, Kaluza GL. Impact of adventitial neovascularisation on atherosclerotic plaque composition and vascular remodelling in a porcine model of coronary atherosclerosis. Eurolntervention: journal of EuroPCR in collaboration with the Working Group on Interventional Cardiology of the European Society of Cardiology 2010;5(8):981-988.

164. Visuri MT, Honkonen KM, Hartiala P, Tervala TV, Halonen PJ, Junkkari H, Knuutinen N, YläHerttuala S, Alitalo KK, Saarikko AM. VEGF-C and VEGF-C156S in the pro-lymphangiogenic growth factor therapy of lymphedema: a large animal study. Angiogenesis 2015;18(3):313-326.

165. Honkonen KM, Visuri MT, Tervala TV, Halonen PJ, Koivisto M, Lähteenvuo MT, Alitalo KK, YläHerttuala S, Saaristo AM. Lymph Node Transfer and Perinodal Lymphatic Growth Factor Treatment for Lymphedema. Annals of Surgery 2013;257(5):961-967.

166. Lähteenvuo M, Honkonen K, Tervala T, Tammela T, Suominen E, Lähteenvuo J, Kholová I, Alitalo K, Ylä-Herttuala S, Saaristo A. Growth Factor Therapy and Autologous Lymph Node Transfer in Lymphedema. Circulation 2011;123(6):613.

167. Hong G, Lee JC, Robinson JT, Raaz U, Xie L, Huang NF, Cooke JP, Dai H. Multifunctional in vivo vascular imaging using near-infrared II fluorescence. Nat Med 2012;18(12):1841-1846. 
Summary 


\section{Summary}

Cardiovascular disease (CVD) remains the most common cause of death in Europe and worldwide accounting for $31 \%$ of all deaths. Importantly, atherosclerosis is by far the most important cause of CVD, accounting for $80 \%$ atherosclerosis of CVD worldwide. Atherosclerosis is a lipid-driven chronic inflammatory disease, leading to the formation of plaques at vital segments of the arterial tree. Atherosclerotic plaques are deposits of cholesterol, lipids and cellular debris in the artery wall, resulting in narrowing of the larger arteries. Initial atherosclerotic lesions are characterized by subendothelial accumulation of macrophages and macrophage-derived foam cells. In progressive stages of disease development, medial smooth muscle cells will proliferate, migrate into the intima and produce collagen, forming a fibrous cap that covers the plaque (i.e. stable lesion). The vulnerable plaque is characterized by an extensive lipid core in the central atheroma, a high level of inflammation and a thin and inflamed fibrous cap covering the large necrotic core (thin-cap fibroatheromas; TFCA). In the final disease stage this vulnerable plaque will rupture leading to thrombus formation which can occlude the lumen causing distal ischemia and acute cardiovascular events (e.g. myocardial infarction (MI), stroke).

Endothelial cells play an important role in maintaining cardiovascular homeostasis. In this thesis we have focused on the molecular regulators thereof. The aim of this thesis is two-fold: 1) to study endothelial cells (EC) dysfunction mediated by impaired NO in heart failure, and 2) to define new molecular regulators of lymphatic EC (LEC) in atherosclerosis.

The first part of the thesis involves a study of endothelial dysfunction in the heart and vessels, which is often characterized by impaired NO bioavailability, leading to vasoconstriction, coagulation and inflammation. When chronic, this can lead to several pathological conditions, including MI, hypertension and atherosclerosis. In this dissertation it is hypothesized that modulation of endothelial nitric oxide synthase (eNOS) can protect against pressure overload-induced left ventricular hypertrophy.

In the first part of this thesis (chapter 2-5) are focused on the molecular mechanism of eNOS and its essential cofactor tetrahydrobiopterin (BH4), as well as potential therapeutic interventions to modulate eNOS in the pathogenesis of myocardial and endothelial dysfunction. As discussed in chapter 2, BH4 is a critical regulator of cardiovascular homeostasis, and substantial evidence implicates $\mathrm{BH} 4$ as a key regulator of eNOS in the setting of cardiovascular disease. Strategies to maintain $\mathrm{BH} 4$ bioavailability may be achieved by 1 ) enhancing the regeneration of $\mathrm{BH} 4$ from the inactive form $\mathrm{BH} 2,2$ ) chemically stabilizing $\mathrm{BH} 4$, and 3) reducing oxidative degradation. Indeed, eNOS-generated NO has a crucial role in the regulation of endothelial function. Chaper3 provides an extensive overview of the important role 206 
of eNOS-uncoupling in the pathogenesis of endothelial dysfunction. Evidence suggests that modulation of eNOS by stabilizing eNOS function, and suppressing eNOS-derived ROS is a promising therapeutic target for endothelial dysfunction. Subsequently, in chapter 4, two, novel pharmacologic small molecule compounds that transcriptionally enhance eNOS gene expression, AVE9488 and AVE3085, are discussed. These compounds are designed to increase eNOS transcription and enhance NO signaling and bioavailability. Interestingly, AVE have been shown to also increase $\mathrm{BH} 4$ bioavailability reversing eNOS uncoupling, and to augment eNOS activity. Although their precise mode of action remains to be clarified, AVE are likely to interact with eNOS uncoupling. Subsequently, in chapter 5, we test if AVE3085 can prevent pressure overload-induced left ventricular (LV) hypertrophy. We have demonstrated that AVE 3085 attenuates the pathological LV changes caused by pressure overload. Surprisingly, these effects are seen in the absence of transcriptional upregulation of eNOS. Importantly, we provide a novel beneficial function of AVE3085 treatment on eNOS stability, demonstrating by an increase in eNOS dimer to monomer ratio and by a decrease in myocardial ROS generation. This effect is likely the result of protection of BH4 against oxidation by ROS. Possible mechanisms for AVE3085 mediate modulation/dampening of transverse aortic constriction -induced inflammatory responses and fibrosis may result from (I) indirect effects secondary to inhibition of macrophage infiltration and inflammatory signaling mediated by $\mathrm{NO}$ and/ or $\mathrm{BH} 4$, or (2) pleiotropic effects of AVE3085 on antiinflammatory and anti-fibrotic effect.

The second part of this thesis is centered on the role of LEC in atherosclerosis. Angiogenesis, the sprouting of new blood vessels from the preexisting ones, is essential for physiological development. Pathological angiogenesis contributes to pathogenesis of cardiovascular diseases. Although plaque angiogenesis has been linked to proinflammatory and proatherosclerotic effects, lymphatic vessels have only recently been implicated in the pathogenesis of $\mathrm{MI}$ and atherosclerosis, where proper lymphatic drainage seemed to protect against disease. The lymphatic system is increasingly recognized as a critical process in atherosclerosis to transport cholesterol and immune cells to the lymph nodes and eventually to the circulation. However, the precise driving factors and consequences of lymphangiogenesis in the context of human atherosclerosis still remain to be elucidated. Plaque-resident factors specifically involved in pathologic lymphangiogenesis during atherosclerosis development and progression may well represent novel approaches for therapeutic modulation of plaque lymphangiogenesis. In this part, it is hypothesized that gene network analysis can provide powerful predictions of candidate genes and those genes represent potential novel targets for regulating lymphangiogenesisassociated atherosclerosis in human (approaches will be described below). 
In chapter 6 we attempt to identify novel players in pathologic lymphangiogenesis in atherosclerosis. We employ a bioinformatics approach, weighted gene coexpression network analysis (WGCNA), to identify networks and candidate genes relevant to plaque lymphangiogenesis in humans. In this study, we correlate phenotypic traits i.e. LVD, identified by $\mathrm{D} 2-40^{+}$in human atherosclerotic tissue with transcription profiles, derived from the same tissue. We are able to identify modules with high correlation to LVD, unveiling a novel role for the phosphatase TNIP2, as a VEGF- independent key regulator of plaque lymphangiogenesis in humans ex vivo, in LEC in vitro and in zebrafish in vivo. In addition, we also provide transcription factor binding sites, miRNAs, and potential pathways which may be involved in TNIP2-mediated plaque lymphangiogenesis. TNIP2-responsive genes are enriched in lymphatic signature genes and suggest the involvement of type I/II IFN signaling, and lipid/cholesterol homeostatic regulation in TNIP2 functional effects.

Finally, in chapter $\mathbf{7}$ we have discussed the most relevant findings of this thesis and provided the future perspectives. Altogether, this thesis affords novel insights into the molecular regulation of endothelial cells in CVD, with particular focus on eNOS and TNIP2. In conclusion, enhancement of functional eNOS can ameliorate endothelial and heart function in heart failure. In vessels, TNIP2 induction could represent an interesting target to stimulate plaque lymphangiogenesis, thereby promoting inflammation resolution in plaque. Considering the therapeutic potential of my findings we may conclude that (I) AVE3085 helps maintaining eNOS functionality and thus may improve eNOS/NO signaling dependent cardiovascular function, and (II) TNIP2 induction will increase lymphangiogenic responses in plaque, which could improve lymphatic drainage of constituents, cytokines and inflammatory cells from plaque, and thus may dampen atherosclerosis progression. Therefore, the next challenge is to translate these findings to clinical applications for cardiovascular diseases prevention and/or treatment. 


\section{Samenvatting}




\section{Samenvatting}

Hart- en vaatziekten (HVZ) zijn nog altijd de meest voorkomende doodsoorzaak en vertegenwoordigen $31 \%$ van alle sterfgevallen in wereldwijd. Belangrijk is dat atherosclerose verreweg de belangrijkste oorzaak is van HVZ, goed voor $80 \%$ van alle HVZ wereldwijd. Atherosclerose is een chronische ontstekingsziekte, geïnitieerd door verhoogde lipide bloedspiegels, die leidt tot de vorming van atherosclerotische plaques in de grote slagaders. Deze plaques bestaan uit afzettingen van cholesterol, lipiden en cellulaire resten in de vaatwand, wat resulteert in een vernauwing van de slagaders. Vroege atherosclerotische plaques worden gekenmerkt door subendotheliale accumulatie van macrofagen en macrofaag schuimcellen. In gevorderde stadia van de ziekte zullen mediale gladde spiercellen prolifereren, migreren naar de intima en collageen produceren, waarbij een vezelachtige kap wordt gevormd die de plaque bedekt (d.w.z. een stabiele plaque). De instabiele plaque wordt daarentegen gekenmerkt door een grote, lipidenrijke kern in, veel ontstekingscellen en een dunne fibreuze kap. Als de instabiele plaque scheurt, leidt dit tot thrombusvorming, afsluiting van het lumen, en vervolgens tot distale ischemie en acute cardiovasculaire aandoeningen, zoals een hartinfarct of beroerte.

Endotheelcellen spelen een belangrijke rol bij het handhaven van cardiovasculaire homeostase. In dit proefschrift hebben we ons gericht op de moleculaire regulatoren van het endotheel. Het doel van dit proefschrift is tweeledig: 1) onderzoek naar endotheelcel (EC) dysfunctie gemedieerd door verstoorde functie van stikstofoxide (NO) bij hartfalen, en 2) identificatie van nieuwe moleculaire regulatoren van lymfatische $\mathrm{EC}$ (LEC) in atherosclerose.

Het eerste deel van het proefschrift (hoofdstuk 2-5) bestudeert endotheel dysfunctie in hart en bloedvaten, wat vaak wordt gekenmerkt door een verminderde biologische beschikbaarheid van NO. Dit veroorzaakt vasoconstrictie, coagulatie en ontsteking, en leidt bij chronische dysfunctie tot verschillende pathologische aandoeningen, waaronder een hartinfarct, hypertensie en atherosclerose. In dit proefschrift wordt de hypothese geformuleerd dat hypertrofie van het linkerventrikel geïnduceerd door drukoverbelasting verminderd kan worden door modulatie van endotheel NO synthase (eNOS).

In hoofdstuk 2 wordt de rol van tetrahydrobiopterin (BH4) besproken, een belangrijke regulator van eNOS functie en vervolgens van cardiovasculaire homeostase en HVZ. De biologische beschikbaarheid van $\mathrm{BH} 4$ kan gehandhaafd worden door 1) het verbeteren van de regeneratie van $\mathrm{BH} 4$ uit de inactieve vorm $\mathrm{BH} 2$, 2) chemische stabilisatie van $\mathrm{BH} 4$ en 3) het verminderen van oxidatieve afbraak van $\mathrm{BH} 4$. Inderdaad heeft eNOS-afhankelijke productie van NO een cruciale rol in de regulatie van de endotheel functie. Hoofdstuk 3 geeft een uitgebreid overzicht van de 210 
belangrijke rol van eNOS-ontkoppeling in de pathogenese van endotheel dysfunctie. De stabilisatie van eNOS-functie en het onderdrukken van radikaal (ROS) produktie door eNOS zijn veelbelovende therapeutische methoden voor het verbeteren van endotheel dysfunctie. Vervolgens worden in hoofdstuk 4 twee nieuwe farmacologische stoffen besproken, AVE9488 en AVE3085. Deze stoffen zijn ontworpen om eNOS-transcriptie te verhogen, en NO-signalering en biologische beschikbaarheid te verbeteren. Interessant genoeg, verhogen AVE's ook de biologische beschikbaarheid van $\mathrm{BH} 4$, wat de ontkoppeling van eNOS omkeert, en zo de eNOS-activiteit versterkt. Hoewel het precieze mechanisme nog moet worden opgehelderd, heeft AVE waarschijnlijk een wisselwerking met de ontkoppeling van eNOS. Vervolgens bestuderen we in hoofdstuk 5 of AVE3085 linker ventrikel (LV) hypertrofie kan voorkomen. We hebben aangetoond dat AVE 3085 de pathologische veranderingen in het $L V$ die worden veroorzaakt door drukoverbelasting vermindert. Verrassenderwijs worden deze effecten waargenomen in de afwezigheid van verhoogde genexpressie van eNOS. Belangrijk is dat we een nieuw gunstige effect van de behandeling met AVE3085 op de stabiliteit van eNOS hebben ontdekt, wat blijkt uit de toegenomen verhouding van eNOS-dimeer tot monomeer, en verlaagde ROS-generatie. Dit effect is waarschijnlijk het gevolg van de bescherming van $\mathrm{BH} 4$ tegen oxidatie door ROS. DeAVE3085-afhankelijke vermindering LV ontstekingsreacties en fibrose kunnen het gevolg zijn van (I) indirecte effecten secundair aan de remming van macrofaag infiltratie en ontstekingssignalering gemedieerd door $\mathrm{NO}$ en / of BH4, of (2) pleiotrope effecten van AVE3085 op ontsteking-en fibrose remming.

Het tweede deel van dit proefschrift concentreert zich op de rol van LEC bij atherosclerose. Angiogenese, het ontspruiten van nieuwe, kleine bloedvaten uit reeds bestaande bloedvaten, is essentieel voor de fysiologische ontwikkeling. Pathologische angiogenese draagt daarentegen bij aan de ontwikkeling van HVZ. Hoewel plaque angiogenese is gekoppeld aan pro-inflammatoire en pro-atherosclerotische effecten, is het beschermende effect van drainage door lymfevaten in de ontwikkeling van HVS in proefdieren pas recent aangetoond. Het lymfestelsel wordt steeds meer herkend als een essentiële link in atherogenese, om cholesterol en immuun cellen via de lymfeklieren af te voeren naar het bloed. De precieze regulatoren en consequenties van lymfangiogenese in de context van humane atherosclerose moeten echter nog worden opgehelderd. Plaque factoren die specifiek betrokken zijn bij de vorming van pathologische lymfangiogenese tijdens de ontwikkeling en progressie van atherosclerose, zijn mogelijk interessante nieuwe aangrijpingspunten voor de interventie in plaque-lymfangiogenese. In dit deel wordt de hypothese getest dat netwerkanalyse een krachtige methode is kandidaat genen te identificeren die lymfangiogenese in humane atherosclerose reguleren. 
In hoofdstuk 6 gebruiken we een bio-informatica methode, gewogen gencoëxpressie-netwerkanalyse (WGCNA), om netwerken en kandidaat-genen te identificeren die relevant zijn voor plaque-lymfangiogenese bij mensen. In deze studie correleren we fenotypische kenmerken, d.w.z. dichtheid van D2-40+ lymfevaten (LVD) in humane atherosclerotische plaques met genexpressie patronen van dezelfde plaque. We hebben inderdaad gen modules geïdentificeerd die sterk correleerden met LVD. Er is een nieuwe functie vastgesteld voor de fosfatase TNIP2, die onafhankelijk van VEGF, plaque-lymfangiogenese reguleert bij de mens ex vivo, LEC in vitro en in de zebravis in vivo. Daarnaast leverde deze bio informatica methode ook transcriptiefactoren, micro RNA's en potentiële cellulaire processen op, die de regulatie van plaque lymfangiogenese door TNIP2 verklaren. TNIP2-afhankelijke genen zijn verrijkt in een genset, waarvan bekend is dat deze genen lymfangiogenese reguleren. Ook zijn TNIP2-afhankelijke genen betrokken bij type I/ II IFN-signalering en lipide/cholesterol metabolisme.

Ten slotte worden in hoofdstuk 7 de meest relevante bevindingen van dit proefschrift en de toekomstperspectieven besproken. Samenvattend, biedt dit proefschrift nieuwe inzichten in de moleculaire regulatie van endotheelcellen bij HVZ, in het bijzonder onder invloed van eNOS en TNIP2. We concluderen ten eerste dat verbetering van functioneel eNOS de functie van endotheelcellen en het hart bij hartfalen kunnen verbeteren. Ten tweeden, kan stimulatie van TNIP2 In slagaders een interessant aanpak vormen voor het stimuleren van plaque-lymfangiogenese, om de ontstekingsresolutie in plaques te verbeteren. Wat betreft de therapeutische mogelijkheden van mijn bevindingen kunnen we concluderen dat (I) AVE3085 helpt de eNOS-functionaliteit te behouden en daardoor de eNOS / NO-afhankelijke cardiovasculaire functie kan verbeteren, en (II) stimulatie van TNIP2 kan de lymfangiogenese reacties in plaque verhogen, wat de lymfedrainage van lipiden, cytokines en ontstekingscellen van plaque kan verbeteren, en zon de progressie van atherosclerose kan remmen. De volgende uitdaging is de om deze bevindingen te vertalen naar de patiënt voor preventie en / of behandeling van hart- en vaatziekten. 
Valorization 


\section{Valorization}

\section{Social and economic value of the current thesis}

Cardiovascular disease (CVD) is the most costly class of diseases, in comparison to other major diagnostic groups. Thus it accounts for an immense global health and economic burden ${ }^{1}$. A staggering 17 million people worlwide die annually from myocardial infarction and stroke (www.who.org). In the United States, CVD was responsible for an estimated health expenditure of around $\$ 316.1$ billion in 2012 and $2013^{1}$, and projections are even more alarming, with total costs expected to increase by $117 \%$ between 2012 and $2030{ }^{1}$. Atherosclerosis, specifically the rupture of an atherosclerotic plaque, is the main underlying cause of this tremendous cardiovascular mortality and morbidity ${ }^{2}$. Despite pharmacological advancements, no therapy is presently able to fully eradicate atherosclerosis or prevent plaque rupture ${ }^{3}$.

The studies contained within this thesis investigated novel therapeutic options in CVD, focusing on (I) heart failure as a consequence of pressure overload, and (II) atherosclerosis. Subsequently, we have demonstrated that (I) the small molecule AVE3085 helps to maintain eNOS function, and thus may improve eNOS/NO signaling-dependent cardiovascular function, and (II) TNIP2 induction is associated with lymphangiogenic responses in the atherosclerotic plaque, while TNIP2 knockdown prevented normal lymphangiogenic development in vitro and in zebrafish in vivo. This secondary finding implies that TNIP2 induction could improve lymphatic drainage of constituents, cytokines and inflammatory cells from human plaques, thus potentially dampening atherosclerosis progression. These findings are relevant both to healthcare providers and to individuals at risk for CVD. Furthermore, the knowledge acquired here will directly contribute to the expertise of the cardiovascular researchers involved, allowing them to continue to advance our understanding of the molecular mechanisms of CVD. While this thesis presents data from basic research, and is not applicable for direct translation into clinical practice, it nevertheless provides a novel starting point for future developments in cardiovascular research, and potential for the development of new therapies.

\section{Current and future treatment of heart failure}

Classification of heart failure (HF) is based on left ventricular ejection fraction $(E F)$. A reduced $E F$ in patients with clinical signs and symptoms of $\mathrm{HF}$ is referred to as, $\mathrm{HF}$ with reduced ejection fraction (HFrEF). However, more than $50 \%$ of all $\mathrm{HF}$ patients exhibit HF with preserved ejection fraction (HFpEF). These patients are predominantly elderly women, and have high rates of associated comorbidities, such as obesity and hypertension ${ }^{4,5}$. Unlike HFrEF, the diagnosis of HFpEF is difficult; being easily missed by echocardiography - especially in patients who often show 
normal EF, have multiple comorbidities and have no obvious physical signs of fluid overload $^{6,7}$.

HF cannot be cured, but it can be treated. The goal of treatment in patients with HF is to improve their clinical status, functional capacity and quality of life, preventing hospital admission and reducing mortality ${ }^{8,9}$. However, life prolongation dependents upon the inhibition of cardiac remodeling ${ }^{10}$. Anti-neuroendocrine treatment (i.e. angiotensin converting enzyme inhibitors, mineralocorticoid receptor antagonists, and beta-blockers) has been shown to reverse modeling, and is proven to be effective in treating patients with HFrEF. In contrast, modern heart failure pharmacotherapy has not been shown to improve outcome in $\mathrm{HFpEF}^{4,9,11}$. As such, there is a great unmet need for new therapeutic approaches for HFpEF. It has been well documented that oxidative stress, decreased NO bioavailability and dysfunctional eNOS (uncoupled eNOS) contribute to myocardial remodeling and dysfunction in $\mathrm{HFrEF}$ and HFpEF ${ }^{12,13}$. This indicates that maintaining or restoring eNOS functionality, subsequently increasing NO bioavailability, is a promising therapeutic intervention in HF.

\section{Perspectives on AVE3085}

In chapter 5, we have demonstrated that AVE 3085 attenuates the pathological left ventricular changes caused by pressure overload. AVE 3085 enhanced eNOS function by restoring its coupling ability, and subsequently reducing myocardial reactive oxygen species (ROS) generation. This effect most likely results from increased protection of $\mathrm{BH} 4$ from ROS-mediated oxidation. In addition, AVE3085 has been shown to ameliorate diastolic dysfunction and reverse cardiac remodeling in $\mathrm{DAHL}$; a salt sensitive rat model of $\mathrm{HFpEF}{ }^{14}$. These findings create new opportunities to use the eNOS/ NO pathway as a therapeutic target in the treatment of HF.

AVE3085 may have advantages over several other eNOS modulators. For instance, administration of $\mathrm{BH} 4$ has been shown to improve systolic and diastolic function in experimental $\mathrm{HF}{ }^{15,16}$. However, $\mathrm{BH} 4$ has a relatively narrow doseresponse window, which remains a point of concern for the translatability of $\mathrm{BH} 4$ supplementation for clinical disease ${ }^{17,18}$. Upon oral administration, $\mathrm{BH} 4$ is largely oxidized to $\mathrm{BH} 2$, which can then be re-reduced once inside the cell. This conversion may be limited by diseases with oxidative stress ${ }^{19}$. Moreover, higher doses of $\mathrm{BH} 4$ might tip the balance toward more $\mathrm{BH}$, which can then compete with $\mathrm{BH} 4$ to impair eNOS coupling, leading to a paradoxical reversal of benefit ${ }^{17,18}$. This suggests that alternative pharmacological approaches to prevent $\mathrm{BH} 4$ oxidation or increase $\mathrm{BH} 4$ biosynthesis may be a more rational therapeutic strategy to improve eNOS functionality ${ }^{20}$. This can potentially be accomplished by AVE3085 alone, or in combination with other eNOS modulators; restoring $\mathrm{BH} 4$ bioavailability to 
therapeutically perturb nitroso-redox balance in cardiovascular disease. For instance, folic acid and its metabolically active form 5-methyltetrahydrofolate (5-MTHF), increased binding affinity of $\mathrm{BH} 4$ to eNOS, and enhanced the regeneration of $\mathrm{BH} 4$ from its inactive form dihydrobiopterin (BH2) ${ }^{21,22}$. Moreover, Vitamin $\mathrm{C}$ or L-ascorbic acid have been shown to stabilize $\mathrm{BH} 4{ }^{23}$. Clearly, additional studies are needed to further clarify the potential role of AVE3085, with or without co-supplementation, for the treatment and/or prevention of cardiovascular disease. In future studies, I would determine the effect of AVE3085 in eNOS-deficient mice to confirm that AVE3085 is indeed eNOS-dependent. Furthermore, I would evaluate the effect of AVE3085 on reversal of pre-existing pressure overload-induced compensated cardiac dilation and decompensated dilation mice models, as this pathophysiology is more relevant to the patient clinical situation. In fact, AVE3085 has entered Phase I clinical trials for congestive heart failure in Europe (Sanofi Aventis business report 2007) and thus, has undergone pharmacokinetic and pharmacodynamic studies. The future study could therefore start at Phase II: according to the timeline of drug developments ${ }^{24}$, if AVE3085 is approved by FDA, it may be launched to the market in a minimum of 7-10 years.

\section{Current and future treatment of atherosclerosis}

Atherosclerosis is a chronic inflammatory disease associated with dyslipidemia ${ }^{25}$. In addition to healthy lifestyle changes, current atherosclerosis therapies focus on lowering blood cholesterol levels, improving blood pressure control and preventing thrombotic complications ${ }^{26}$. However, these strategies are not effective in all patients, and do not directly address the inflammatory mechanisms driving atheroprogression ${ }^{27,28}$. Results from the recent clinical trial "CANTOS" suggested that targeted anti-inflammatory therapy, i.e. canakinumab, a therapeutic monoclonal antibody targeting interleukin- $1 \beta$, leads to reduced cardiovascular risk and atherosclerosis, without lowering cholesterol level ${ }^{29}$. However, effect on cardiovascular mortality was not observed in this trial, and patients who received canakinumab were at greater risk of death from infection than those who received a placebo ${ }^{30}$. The tremendous costs associated with this new compound, along with minimal health benefits, indicate that new therapeutic interventions able to decrease metabolic disorder-associated inflammation are required. Emerging evidence has strongly suggested that lymphatics are critical for immune response and cholesterol metabolism in atherosclerosis, indicating an essential contribution of lymphangiogenesis to atherosclerosis regression. Below, I will discuss prolymphangiogenesis as a potential novel therapeutic approach for atherosclerosis. 
Therapeutic lymphangiogenesis - a new avenue for atherosclerosis treatment

The role of angiogenesis in atherosclerosis has been studied extensively; however, research on plaque lymphangiogenesis is relatively new. Lymphatics can be detected in human as well as mouse atherosclerotic plaque adventitia ${ }^{31-33}$, suggesting a contribution to atherosclerotic lesion progression. Enhancement of lymphatic function represents a potential therapeutic target in atherosclerosis, through the promotion of immune cell (e.g. macrophage) egression from the plaque, and prevention of cholesterol accumulation. In addition, prolymphangiogetic therapy may prevent local edema, caused by leakage from the plaque vasa vasorum ${ }^{32}$, or enhance the efficiency of proangiogenic therapy in CVD, by reducing revascularization and angiogenesis-related edema ${ }^{34}$. Advances in understanding the molecular underpinning of plaque lymphangiogenesis will offer insight into therapeutic options, potentially leading to the discovery of novel lymphangiogenic agents able to reverse atherosclerosis.

The identification of suitable target genes to influence the disease development is necessary for successful gene therapy ${ }^{28}$. In chapter 6 , we provided a new insight in bioinformatics; demonstrating the success of a weighted gene coexpression network analysis (WGCNA) in identifying and validating key regulators of plaque lymphangiogenesis. Unlike a more traditional approach that focuses on differentially expressed individual genes, our approach is unique: we have employed WGCNA to capture high-order gene-gene interrelation in association with phenotypic trait i.e. plaque lymphangiogenesis. WGCNA gives information about functional connections, providing a true systems medicine perspective ${ }^{35}$. To provide proof of concept that WGCNA can identify functionally relevant genes, in chapter $\mathbf{6}$, we have investigated the role of the candidate genes, and demonstrated that TNIP2 is indeed a novel regulator of inflammatory lymphangiogenesis. Together, we provide insights that WGCNA in can effectively integrate cardiovascular gene expression and trait data, to identify novel therapeutic targets or potential genetic biomarkers of the diseases.

\section{Perspectives on TNIP2 as a novel regulator of inflammatory lymphangiogenesis}

We show in chapter 6 that TNIP2 appears to be a specific regulator of pathologic lymphangiogenesis in atherosclerotic plaque instability. We postulate that TNIP2 may represent a much more suitable clinical target, possibly superior to other prolymphangiogenic agents. For instance, VEGF-C treatment has been reported to induce angiogenesis, increase inflammation and induce blood vascular leakage, leading to local edema which further impairs lymphatic function in experimental animal models ${ }^{36,37}$. These deleterious effects may promote plaque instability and rupture. In contrast, TNIP2 is not a growth factor per se, but interacts with A20, which exerts anti- 
atherogenic properties ${ }^{38,39}$. TNIP2 did not affect angiogenesis in our zebrafish studies and possibly would not promote the blood vascular "side effects". Nevertheless, the role of TNIP2 in angiogenesis remains to be elucidated. The beneficial effects of TNIP2 may extend beyond its prolymphangiogenic properties, as TNIP2 can interfere with the inflammatory process in atherogenesis at multiple levels, i.e. NFKB, the Ang1/Tie2 axis, PPARs and IFNy. It is well known that NFKB directly controls several proatherogenic genes and thus integrates multiple processes contributing to the formation of atherosclerotic plaques ${ }^{40}$. Indeed, TNIP2 exerts inhibitory effects on NFKB activation ${ }^{41}$. Moreover, it has been suggested that Ang 1/Tie2 exhibits antiatherogenic effects ${ }^{42}$. Interestingly, TNIP2 structurally and functionally interacts with Ang1/ Tie2 signaling, leading to the inhibition of NFKB -dependent inflammatory gene expression ${ }^{43-45}$. Importantly, it has been suggested that anti-inflammatory drugs with pro-lymphangiogenic activity are appealing treat inflammatory conditions. This is because the activation of lymphatic function reduces the severity of tissue inflammation and thus, contributes to accelerated inflammation resolution ${ }^{46,47}$. In chapter 6, we have highlighted such a regulatory role for TNIP2 in the PROX1 axis, enhancing PPAR-related lipid and cholesterol metabolism signaling and inhibiting that of IFNY; indicating that TNIP2 exerts, not only lymphangiogenic, but also antiinflammatory effects in lymphatic endothelial cells. Together, these findings suggest that TNIP2 may be an interesting target for the development of novel therapeutic strategies to treat inflammatory diseases, particularly in atherosclerosis. Further steps will have to be taken to confirm the findings in relevant animal models of atherosclerosis. For instance, target validation studies can be tested by overexpression or deletion of TNIP2 in atherogenic ApoE-deficient mice, or in mice with perivascular carotid collar placement-induced atherosclerosis. Subsequently, a small molecular weight chemical compound (SMOL) should be designed and tested in vitro and in vivo. In addition, the protection of intellectual property is required for the potential compounds, in order to eliminate the competition and to gain the freedom to operate ${ }^{48}$. Furthermore, large animal efficacy and toxicity studies are required; for which I prefer PCSK9-overexpressing mini pigs ${ }^{49,50}$, as their phenotype more closely resembles human plaques. Importantly, porcine models allow investigation of the impact of adventitial neovascularization by coronary imaging technologies ${ }^{51,52}$. Thus, this may suitable to investigate adventitial lymphangiogenesis, and therefore will be easier to translate the results to the human situation. Subsequently, the suitable drug will eventually be utilized in multiple phases of human clinical trials and human randomized control studies. The particular target patients include those afflicted with atherosclerosis, $\mathrm{Ml}$ and potentially lymphedema. In total, the de novo drug development requires 10-20 years before market launch ${ }^{24}$. GlaxoSmithKline may here be involved in developing the compounds; the company has an ongoing investigation of the TNIP2/ TPL-2/ NFKB1 p105 complex for anti-inflammatory pharmaceuticals ${ }^{53}$. 
In conclusion, although our findings cannot directly be translated into clinical application, we have provided a very promising concept which has therapeutic potential in future treatment and prevention of CVD. Further studies in combination with experimental verification are strongly encouraged to clarify their detailed role, and subsequently meet their clinical reality. 


\section{References}

1. Writing Group M, Benjamin EJ, Blaha MJ, Chiuve SE, Cushman M, Das SR, Deo R, de Ferranti SD, Floyd J, Fornage M, Gillespie C, Isasi CR, Jiménez MC, Jordan LC, Judd SE, Lackland D, Lichtman JH, Lisabeth L, Liu S, Longenecker CT, Mackey RH, Matsushita K, Mozaffarian D, Mussolino ME, Nasir K, Neumar RW, Palaniappan L, Pandey DK, Thiagarajan RR, Reeves MJ, Ritchey M, Rodriguez CJ, Roth GA, Rosamond WD, Sasson C, Towfighi A, Tsao CW, Turner MB, Virani SS, Voeks JH, Willey JZ, Wilkins JT, Wu JHY, Alger HM, Wong SS, Muntner P. Heart Disease and Stroke Statistics-2017 Update: A Report From the American Heart Association. Circulation 2017;135(10):e146-e603.

2. Virmani R, Kolodgie FD, Burke AP, Finn AV, Gold HK, Tulenko TN, Wrenn SP, Narula J. Atherosclerotic Plaque Progression and Vulnerability to Rupture Angiogenesis as a Source of Intraplaque Hemorrhage. Arterioscler Thromb Vasc Biol 2005;25(10):2054-61.

3. Sever PS, Dahlof B, Poulter NR, Wedel H, Beevers G, Caulfield M, Collins R, Kjeldsen SE, Kristinsson A, McInnes GT, Mehlsen J, Nieminen M, O'Brien E, Ostergren J. Prevention of coronary and stroke events with atorvastatin in hypertensive patients who have average or lowerthan-average cholesterol concentrations, in the Anglo-Scandinavian Cardiac Outcomes Trial-Lipid Lowering Arm (ASCOT-LLA): a multicentre randomised controlled trial. Lancet 2003;361(9364):1149-58.

4. van Heerebeek L, Paulus WJ. Understanding heart failure with preserved ejection fraction: where are we today? Netherlands Heart Journal 2016;24(4):227-236.

5. Iwano H, Little WC. Heart failure: What does ejection fraction have to do with it? Journal of Cardiology 2013;62(1):1-3.

6. Huis in 't Veld AE, de Man FS, van Rossum AC, Handoko ML. How to diagnose heart failure with preserved ejection fraction: the value of invasive stress testing. Netherlands Heart Journal 2016;24(4):244-251.

7. Ferrari R, Böhm M, Cleland JGF, Paulus WJS, Pieske B, Rapezzi C, Tavazzi L. Heart failure with preserved ejection fraction: uncertainties and dilemmas. European Journal of Heart Failure 2015;17(7):665-671.

8. Ramzy I. Standards and new drugs in the treatment of heart failure. E-Journal of Cardiology Practice 2017;14(39).

9. Ponikowski P, Voors AA, Anker SD, Bueno H, Cleland JGF, al. e. 2016 ESC Guidelines for the diagnosis and treatment of acute and chronic heart failure. European Journal of Heart Failure 2016;18(8):891-975.

10. Cohn JN. Continue what we are doing to treat HF, but do it better. Nature Reviews Cardiology 2013;11:69.

11. Berliner D, Bauersachs J. Current Drug Therapy in Chronic Heart Failure: the New Guidelines of the European Society of Cardiology (ESC). Korean Circulation Journal 2017;47(5):543-554.

12. Paulus WJ, Tschöpe C. A Novel Paradigm for Heart Failure With Preserved Ejection Fraction: Comorbidities Drive Myocardial Dysfunction and Remodeling Through Coronary Microvascular Endothelial Inflammation. Journal of the American College of Cardiology 2013;62(4):263-271.

13. Münzel T, Gori T, Keaney JJF, Maack C, Daiber A. Pathophysiological role of oxidative stress in systolic and diastolic heart failure and its therapeutic implications. European Heart Journal 2015;36(38):2555-2564.

14. Westermann D, Riad A, Richter U, Jäger S, Savvatis K, Schuchardt M, Bergmann N, Tölle M, Nagorsen D, Gotthardt M, Schultheiss H-P, Tschöpe C. Enhancement of the endothelial NO synthase attenuates experimental diastolic heart failure. Basic Research in Cardiology 2009;104(5):499-509.

15. Moens AL, Takimoto E, Tocchetti CG, Chakir K, Bedja D, Cormaci G, Ketner EA, Majmudar M, Gabrielson K, Halushka MK, Mitchell JB, Biswal S, Channon KM, Wolin MS, Alp NJ, Paolocci N, Champion HC, Kass DA. Reversal of Cardiac Hypertrophy and Fibrosis From Pressure Overload 
by Tetrahydrobiopterin: Efficacy of Recoupling Nitric Oxide Synthase as a Therapeutic Strategy. Circulation 2008;117(20):2626-2636.

16. Silberman GA, Fan T-HM, Liu H, Jiao Z, Xiao HD, Lovelock JD, Boulden BM, Widder J, Fredd S, Bernstein KE, Wolska BM, Dikalov S, Harrison DG, Dudley SC. Uncoupled Cardiac Nitric Oxide Synthase Mediates Diastolic Dysfunction. Circulation 2010;121(4):519-528.

17. Moens AL, Ketner EA, Takimoto E, Schmidt TS, O'Neill CA, Wolin MS, Alp NJ, Channon KM, Kass DA. Bi-modal Dose-dependent Cardiac Response to Tetrahydrobiopterin in Pressureoverload Induced Hypertrophy and Heart Failure. Journal of Molecular and Cellular Cardiology 2011;51(4):564-569.

18. Bendall JK, Douglas G, McNeill E, Channon KM, Crabtree MJ. Tetrahydrobiopterin in Cardiovascular Health and Disease. Antioxidants \& Redox Signaling 2014;20(18):3040-3077.

19. Cunnington C, Van Assche T, Shirodaria C, Kylintireas I, Lindsay AC, Lee JM, Antoniades C, Margaritis M, Lee R, Cerrato R, Crabtree MJ, Francis JM, Sayeed R, Ratnatunga C, Pillai R, Choudhury RP, Neubauer S, Channon KM. Systemic and Vascular Oxidation Limits the Efficacy of Oral Tetrahydrobiopterin Treatment in Patients With Coronary Artery Disease. Circulation 2012;125(11):1356-1366.

20. Antoniades C, Channon KM, Stefanadis C. Letter by Antoniades et al Regarding Article, "Uncoupled Cardiac Nitric Oxide Synthase Mediates Diastolic Dysfunction". Circulation 2010;122(21):e558.

21. Moens AL, Champion HC, Claeys MJ, Tavazzi B, Kaminski PM, Wolin MS, Borgonjon DJ, Van Nassauw L, Haile A, Zviman M, Bedja D, Wuyts FL, Elsaesser RS, Cos P, Gabrielson KL, Lazzarino G, Paolocci N, Timmermans J-P, Vrints CJ, Kass DA. High-Dose Folic Acid Pretreatment Blunts Cardiac Dysfunction During Ischemia Coupled to Maintenance of HighEnergy Phosphates and Reduces Postreperfusion Injury. Circulation 2008;117(14):1810-1819.

22. Octavia Y, Kararigas G, de Boer M, Chrifi I, Kietadisorn R, Swinnen M, Duimel H, Verheyen FK, Brandt MM, Fliegner D, Cheng C, Janssens S, Duncker DJ, Moens AL. Folic acid reduces doxorubicin-induced cardiomyopathy by modulating endothelial nitric oxide synthase. Journal of Cellular and Molecular Medicine 2017;21(12):3277-3287.

23. Heller R, Unbehaun A, Schellenberg B, Mayer B, Werner-Felmayer G, Werner ER. I-Ascorbic Acid Potentiates Endothelial Nitric Oxide Synthesis via a Chemical Stabilization of Tetrahydrobiopterin. Journal of Biological Chemistry 2001;276(1):40-47.

24. Sukhai MA, Spagnuolo PA, Weir S, Kasper J, Patton L, Schimmer AD. New sources of drugs for hematologic malignancies. Blood 2011;117(25):6747-6755.

25. Hansson GK. Inflammation, Atherosclerosis, and Coronary Artery Disease. New England Journal of Medicine 2005;352(16):1685-1695.

26. Catapano AL, Graham I, De Backer G, Wiklund O, Chapman MJ, Drexel H, Hoes AW, Jennings CS, Landmesser U, Pedersen TR, Reiner Ž, Riccardi G, Taskinen M-R, Tokgozoglu L, Verschuren WMM, Vlachopoulos C, Wood DA, Zamorano JL. 2016 ESC/EAS Guidelines for the Management of Dyslipidaemias. Atherosclerosis 2016;253:281-344.

27. Weber $\mathrm{C}$, Noels $\mathrm{H}$. Atherosclerosis: current pathogenesis and therapeutic options. Nature Medicine 2011;17:1410.

28. Laakkonen JP, Ylä-Herttuala S. Recent Advancements in Cardiovascular Gene Therapy and Vascular Biology. Human Gene Therapy 2015;26(8):518-524.

29. Ridker PM, Everett BM, Thuren T, MacFadyen JG, Chang WH, Ballantyne C, Fonseca F, Nicolau J, Koenig W, Anker SD, Kastelein JJP, Cornel JH, Pais P, Pella D, Genest J, Cifkova R, Lorenzatti A, Forster T, Kobalava Z, Vida-Simiti L, Flather M, Shimokawa H, Ogawa H, Dellborg M, Rossi PRF, Troquay RPT, Libby P, Glynn RJ. Antiinflammatory Therapy with Canakinumab for Atherosclerotic Disease. New England Journal of Medicine 2017;377(12):1119-1131.

30. Harrington RA. Targeting Inflammation in Coronary Artery Disease. New England Journal of Medicine 2017;377(12):1197-1198. 
31. Martel C, Li W, Fulp B, Platt AM, Gautier EL, Westerterp M, Bittman R, Tall AR, Chen S-H, Thomas MJ, Kreisel D, Swartz MA, Sorci-Thomas MG, Randolph GJ. Lymphatic vasculature mediates macrophage reverse cholesterol transport in mice. The Journal of Clinical Investigation 2013;123(4):1571-1579.

32. Rademakers T, van der Vorst EPC, Daissormont ITMN, Otten JJT, Theodorou K, Theelen TL, Gijbels M, Anisimov A, Nurmi H, Lindeman JHN, Schober A, Heeneman S, Alitalo K, Biessen EAL. Adventitial lymphatic capillary expansion impacts on plaque $\mathrm{T}$ cell accumulation in atherosclerosis. Scientific Reports 2017;7:45263.

33. Vuorio T, Nurmi H, Moulton K, Pikkarainen J, Robciuc MR, öhman M, Heinonen SE, Samaranayake H, Heikura T, Alitalo K, Ylä-Herttuala S. Lymphatic vessel insufficiency in hypercholesterolemic mice alters lipoprotein levels and promotes atherogenesis. Arteriosclerosis, thrombosis, and vascular biology 2014;34(6):1162-1170.

34. Henri O, Pouehe C, Houssari M, Galas L, Nicol L, Edwards-Lévy F, Henry J-P, Dumesnil A, Boukhalfa I, Banquet S, Schapman D, Thuillez C, Richard V, Mulder P, Brakenhielm E. Selective Stimulation of Cardiac Lymphangiogenesis Reduces Myocardial Edema and Fibrosis Leading to Improved Cardiac Function Following Myocardial Infarction. Circulation 2016;133(15):1484.

35. Langfelder P, Mischel PS, Horvath S. When Is Hub Gene Selection Better than Standard MetaAnalysis? PLOS ONE 2013;8(4):e61505.

36. Gousopoulos E, Proulx ST, Bachmann SB, Dieterich LC, Scholl J, Karaman S, Bianchi R, Detmar M. An Important Role of VEGF-C in Promoting Lymphedema Development. Journal of Investigative Dermatology 2017;137(9):1995-2004.

37. Cao R, Eriksson A, Kubo H, Alitalo K, Cao Y, Thyberg J. Comparative Evaluation of FGF-2-, VEGF-A-, and VEGF-C-Induced Angiogenesis, Lymphangiogenesis, Vascular Fenestrations, and Permeability. Circulation Research 2004;94(5):664.

38. Verstrepen L, Carpentier I, Verhelst K, Beyaert R. ABINs: A20 binding inhibitors of NF-KB and apoptosis signaling. Biochemical Pharmacology 2009;78(2):105-114.

39. Moll HP, Lee A, Minussi DC, da Silva CG, Csizmadia E, Bhasin M, Ferran C. A20 Regulates Atherogenic Interferon (IFN)- $\gamma$ Signaling in Vascular Cells by Modulating Basal IFN $\beta$ Levels. Journal of Biological Chemistry 2014;289(45):30912-30924.

40. Baker RG, Hayden MS, Ghosh S. NF-kB, inflammation and metabolic disease. Cell metabolism 2011;13(1):11-22.

41. Van Huffel S, Delaei F, Heyninck K, De Valck D, Beyaert R. Identification of a Novel A20-binding Inhibitor of Nuclear Factor-kB Activation Termed ABIN-2. Journal of Biological Chemistry 2001;276(32):30216-30223.

42. Camaré $C$, Pucelle M, Nègre-Salvayre A, Salvayre R. Angiogenesis in the atherosclerotic plaque. Redox Biology 2017;12:18-34.

43. Hughes DP, Marron MB, Brindle NPJ. The Antiinflammatory Endothelial Tyrosine Kinase Tie2 Interacts With a Novel Nuclear Factor-KB Inhibitor ABIN-2. Circulation Research 2003;92(6):630636.

44. Gu H, Cui M, Bai Y, Chen F, Ma K, Zhou C, Guo L. Angiopoietin-1/Tie2 signaling pathway inhibits lipopolysaccharide-induced activation of RAW264.7 macrophage cells. Biochemical and Biophysical Research Communications 2010;392(2):178-182.

45. Jeon BH, Khanday F, Deshpande S, Haile A, Ozaki M, Irani K. Tie-ing the Antiinflammatory Effect of Angiopoietin-1 to Inhibition of NF-KB. Circulation Research 2003;92(6):586-588.

46. Dieterich LC, Seidel CD, Detmar M. Lymphatic vessels: new targets for the treatment of inflammatory diseases. Angiogenesis 2014;17(2):359-371.

47. Huggenberger R, Ullmann S, Proulx ST, Pytowski B, Alitalo K, Detmar M. Stimulation of lymphangiogenesis via VEGFR-3 inhibits chronic skin inflammation. The Journal of Experimental Medicine 2010;207(10):2255-2269.

48. Gashaw I, Ellinghaus P, Sommer A, Asadullah K. What makes a good drug target? Drug Discovery Today 2011;16(23):1037-1043. 
49. Pedrigi RM, Poulsen CB, Mehta VV, Ramsing Holm N, Pareek N, Post AL, Kilic ID, Banya WA, Dall'Ara G, Mattesini A, Bjorklund MM, Andersen NP, Grondal AK, Petretto E, Foin N, Davies JE, Di Mario C, Fog Bentzon J, Erik Botker H, Falk E, Krams R, de Silva R. Inducing Persistent Flow Disturbances Accelerates Atherogenesis and Promotes Thin Cap Fibroatheroma Development in D374Y-PCSK9 Hypercholesterolemic Minipigs. Circulation 2015;132(11):1003-12.

50. Al-Mashhadi RH, Sørensen CB, Kragh PM, Christoffersen C, Mortensen MB, Tolbod LP, Thim T, Du Y, Li J, Liu Y, Moldt B, Schmidt M, Vajta G, Larsen T, Purup S, Bolund L, Nielsen LB, Callesen H, Falk E, Mikkelsen JG, Bentzon JF. Familial Hypercholesterolemia and Atherosclerosis in Cloned Minipigs Created by DNA Transposition of a Human PCSK9 Gain-ofFunction Mutant. Science Translational Medicine 2013;5(166):166ra1-166ra1.

51. Alviar CL, Tellez A, Wallace-Bradley D, Lopez-Berestein G, Sanguino A, Schulz DG, Builes A, Ballantyne CM, Yang C-Y, Kaluza GL. Impact of adventitial neovascularisation on atherosclerotic plaque composition and vascular remodelling in a porcine model of coronary atherosclerosis. Eurolntervention: journal of EuroPCR in collaboration with the Working Group on Interventional Cardiology of the European Society of Cardiology 2010;5(8):981-988.

52. van Ditzhuijzen NS, van den Heuvel M, Sorop O, van Duin RWB, Krabbendam-Peters I, van Haeren R, Ligthart JMR, Witberg KT, Duncker DJ, Regar E, van Beusekom HMM, van der Giessen WJ. Invasive coronary imaging in animal models of atherosclerosis. Netherlands Heart Journal 2011;19(10):442-446.

53. Kümper S, Gantke T, Chen C-S, Soneji Y, Pattison MJ, Chakravarty P, Kjær S, Thomas D, Haslam C, Leavens BJ, House D, Powell DJ, Ley SC. Assaying kinase activity of the TPL-2/NFKB1 p105/ABIN-2 complex using an optimal peptide substrate. Biochemical Journal 2017. 



\section{List of abbreviations}




\section{List of abbreviations}

\begin{tabular}{|c|c|}
\hline 5-MTHF & 5-methyltetrahydrofolate \\
\hline ACE & angiotensin-converting enzyme \\
\hline ACS & acute coronary syndromes \\
\hline ACVRL1 & activin A receptor like type 1 \\
\hline ADMA & asymmetric dimethylarginine \\
\hline Ang & angiopoetin \\
\hline ANP & A-type natriuretic peptide \\
\hline apoE & apolipoprotein E \\
\hline AT2 & angiotensin II \\
\hline b.i.d. & bis in die/ two times a day \\
\hline BEC & blood endothelial cells \\
\hline $\mathrm{BH} 2$ & dihydrobiopterin \\
\hline $\mathrm{BH} 4$ & tetrahydrobiopterin \\
\hline BMC & bone marrow-derived mononuclear cells \\
\hline BMI & body mass index \\
\hline BNP & B-type natriuretic peptide \\
\hline cav-1 & caveolin-1 \\
\hline $\mathrm{CHD}$ & coronary heart disease \\
\hline $\mathrm{CHF}$ & congestive heart failure \\
\hline COUP-TFII & chicken ovalbumin upstream promoter-transcription factor II \\
\hline CRP & C-reactive protein \\
\hline CVD & cardiovascular disease \\
\hline DAB & 3,3'-Diaminobenzidine \\
\hline DHF & diastolic heart failure \\
\hline DHFR & dihydrofolate reductase \\
\hline DHPR & dihydropteridine reductase \\
\hline DLL4 & delta-like 4 \\
\hline DM & diabetes mellitus \\
\hline dpf & days post-fertilization \\
\hline EC & endothelial cells \\
\hline EDHF & endothelium-derived hyperpolarization factor \\
\hline EDR & endothelium-dependent relaxation \\
\hline EF & ejection fraction \\
\hline eNOS & endothelial nitric oxide synthase \\
\hline EPC & endothelial progenitor cells \\
\hline FA & folic acid \\
\hline $\mathrm{Fe}^{++}$ & ferrous ion \\
\hline FGF & fibroblast growth factor \\
\hline
\end{tabular}




$\begin{array}{ll}\text { Foxc2 } & \text { forkhead box C2 } \\ \text { FS } & \text { fraction shortening } \\ \text { GO } & \text { gene ontology } \\ \text { GTPCH } & \text { GTP cyclohydrolase } \\ \text { HDL } & \text { high-density lipoprotein } \\ \text { HE } & \text { hematoxylin and eosin } \\ \text { HF } & \text { heart failure } \\ \text { HFmrEF } & \text { heart failure with mid-range ejection fraction } \\ \text { HFpEF } & \text { heart failure with preserved ejection fraction } \\ \text { HFrEF } & \text { heart failure with reduced ejection fraction } \\ \text { HIF } & \text { hypoxia-inducible factor } \\ \text { hpf } & \text { hours post-fertilization } \\ \text { HUVEC } & \text { human umbilical vein endothelial cells } \\ \text { I/R } & \text { ischemia/reperfusion } \\ \text { ICAM-1 } & \text { intracellular adhesion molecule-1 } \\ \text { ICMP } & \text { ischemic cardiomyopathy } \\ \text { IFNG/Y } & \text { interferon gamma } \\ \text { IHD } & \text { ischemic heart disease } \\ \text { IL1B/ } \beta & \text { interleukin 1 beta } \\ \text { IPH } & \text { intraplaque haemorrhage } \\ \text { ISVs } & \text { intersegmental vessels } \\ \text { LEC } & \text { lymphatic endothelial cells } \\ \text { LPS } & \text { lipopolysaccharide } \\ \text { LV } & \text { left ventricular } \\ \text { LVD } & \text { lymphatic vessel density } \\ \text { LVEDD } & \text { left ventricular end-diastolic diameter } \\ \text { LVESD } & \text { left ventricular end-systolic diameter } \\ \text { LYVE-1 } & \text { lymphatic vessel hyaluronan receptor 1 } \\ \text { MDA } & \text { malondialdehyde } \\ \text { MHC } & \text { myosin heavy chain } \\ \text { MI } & \text { myocardial infarction } \\ \text { miR } & \text { microRNA } \\ \text { mtNOS } & \text { mitochondrial Nos } \\ \text { MVD } & \text { microvessel density } \\ \text { NFKB } & \text { nuclear factor kappa beta } \\ \text { NO } & \text { nitric oxide } \\ \text { Notch1 } & \text { notch homolog 1, translocation associated (Drosophila) } \\ \text { NOX } & \text { NADPH oxidases } \\ \text { NRP2 } & \text { neuropilin-2 } \\ \text { ORA } & \text { over-representation analysis } \\ \text { OxLDL } & \text { oxidized-low density lipoprotein } \\ & \end{array}$




$\begin{array}{ll}\text { p.o. } & \text { per os/ orally } \\ \text { PAD } & \text { peripheral arterial disease } \\ \text { PDPN } & \text { podoplanin } \\ \text { PKG } & \text { protein kinase G } \\ \text { PLB } & \text { phospholamban } \\ \text { PLS } & \text { parachordal vessels } \\ \text { PPARG/Y } & \text { peroxisome proliferator-activated receptor gamma } \\ \text { PPIN } & \text { protein-protein interaction network } \\ \text { PROX1 } & \text { prospero homeobox 1 } \\ \text { PSR } & \text { picro-sirius red } \\ \text { PSS } & \text { plaque structural stress } \\ \text { RCT } & \text { reverse cholesterol transport } \\ \text { RIN } & \text { RNA Integrity Number } \\ \text { ROS } & \text { reactive oxygen species } \\ \text { SDF-1 } & \text { stromal cell-derived factor 1 } \\ \text { siRNA } & \text { small interfering RNA } \\ \text { SMC } & \text { smooth muscle cells } \\ \text { SOX18 } & \text { sex determining region Y box 18 } \\ \text { STAT1 } & \text { signal transducer and activator of transcription 1 } \\ \text { STP } & \text { staurosporine } \\ \text { STZ } & \text { streptozotocin } \\ \text { TAC } & \text { transverse aortic constriction } \\ \text { TD } & \text { thoracic duct } \\ \text { TFBS } & \text { transcription factor binding site } \\ \text { TFCA } & \text { thin-cap fibroatheromas } \\ \text { TGF- } \beta & \text { transforming growth factor beta } \\ \text { TLR4 } & \text { toll-like receptor 4 } \\ \text { TNFA/ } \alpha & \text { tumor necrosis factor alpha } \\ \text { TNIP2 } & \text { TNFAIP3 Interacting Protein 2 } \\ \text { VASP } & \text { vasodilator-stimulated phosphoprotein } \\ \text { VCAM-1 } & \text { vascular cell adhesion molecule-1 } \\ \text { VEC } & \text { venous endothelial cells } \\ \text { VEGF } & \text { vascular endothelial growth factor } \\ \text { VEGFR } & \text { vascular endothelial growth factor receptor } \\ \text { VSMC } & \text { vascular smooth muscle cells } \\ \text { VV } & \text { vasa vasorum } \\ \text { WGCNA } & \text { weighted gene co-expression network analysis } \\ \text { WSS } & \text { wall (or endothelial) shear stress } \\ \text { WT } & \text { wild-type } \\ \text { XO } & \text { xanthine oxidase } \\ & \end{array}$





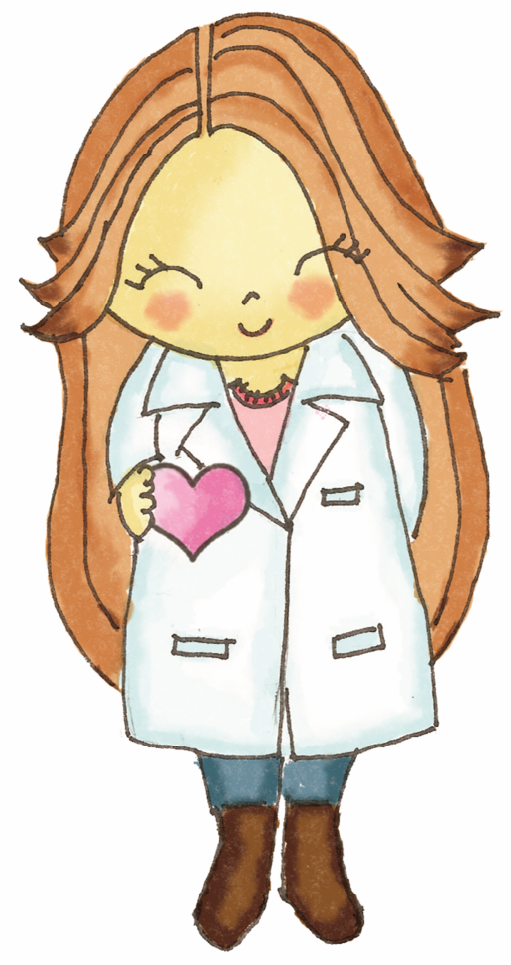


Acknowledgements/ Dankwoord 


\section{Dankwoord}

The completion of this $\mathrm{PhD}$ thesis would not have been possible without the support of many people during my time in Maastricht. In your own special way, you made this work possible, and these years memorable. I am grateful to spend the last words of this thesis to thank you all.

First of all, my utmost gratitude goes to my supervisor Prof. Biessen. Dear Erik, thank you very much for providing me with the opportunity to pursue my $\mathrm{PhD}$ in the experimental vascular pathology group. I am luckier than children left unattended around draaimolentje and sold to the circus. As an unattended PhD student, I was adopted by you. I still remember our first meeting and you explained me about my new project and drew a cartoon of "gene co-expression network" (it looked like the orbits of the planets - I still keep that paper). It has now become a chapter...the great manuscript! I thank you for your expertise, guidance, faith and endless support.

It is difficult to overstate my gratitude to my co-promoter, Dr. Sluimer who is more than just a co-promoter of my thesis. Funnily, she was the one who made the song "I will survive" pop into my head when I first met, especially this part of the lyrics "At first I was afraid, I was petrified". Dear Judith, you are the best! Thank you very much for helping speed up the PhD studies, especially during the thesis-writing period. You are so helpful, kind, generous and in fact you are funny. Your insights for research are always precise and your vision is sharp like laser. You have provided me with ongoing encouragement and endless support. At the end, you make me hum a particular part of the aforementioned song "I grew strong, and I learned how to get along". I thank you for everything.

I would like to thank my thesis committee members Prof. Arts, Prof. Crijns, Prof. Duncker, Dr. van de Akker and Dr. de Vries for all of their guidance through this process; your discussion, ideas, and feedback have been very valuable.

Many thanks and appreciation goes to my co-authors/collaborators who substantially contributed to this thesis and the publications. Thank you very much for your very useful and critical comments in the manuscript. Merci beaucoup Prof. Noel for welcoming me and giving me an opportunity to work in your lab. I would like to thank you for the supervision and support you provided during my time in LBTD and beyond. I would like to thank Prof. Stoll and Dr. Rühle for the microarray experiments, Prof. Dequiedt and Alexandra Bveloso for the zebrafish studies, Dr. Wohlfart for AVE3085 study. Thank you Prof. Daemen and Dr. Sikkink for your cooperation.

Yanti, I do not know what to say if I did not have you during my time in Maastricht. We indeed shared many moments together (good, fun and roller coaster- 
alike feeling). I really missed all the time we spent together in the office sharing Asian food, juicy news and more. I wish you luck and become a doctor in Australia soon.

An Moens, thank you very much for giving me a first opportunity to do $\mathrm{PhD}$ in Maastricht. You are smart and nice person. You were my boss, and are also my friend. It was fun to share moments with your family. It was also very nice to be your family vet.

Special thanks go to my Paranimfen Lieve and Margaux. You started as colleagues, and then you became my friends and guardian angels (or Charlie's angels). Hup Team Jeanneke Hup. Dear Lieve, you are one of a kind. I love your friendly and lively personality. Your laugh always brightens up the room and lab. I was lucky to have you as my office mate. But now I am luckier to have you as my paranimf. It was fun every time when I talked to you. Thank you very much.

Ma Chouquette Margaux thank you for all the joyful time and laughs, which kept me entertained whenever I came across you. I really appreciate your encouragement while I was feeling down. Thanks a lot for letting me stay at your apartment during my last visit. It was fun to stay with you (except for the part that Mowgli jumped on my tummy, while I was sleeping). You can be very fierce with "no unicorn caca attitude" which I think it is totally awesome. Good luck with your PhD my Lil' Meggie.

A big thanks to all colleagues in the "experimental vascular pathology group" for letting me have this unforgettable experience working in the lab. I would like to thank Marion for your advices regarding the LVD and interpretation of plaque lesions. You were very sweet and it was very nice to be your officemate (also, you even gave me your favorite sweet i.e. "salty drop"). Dear Marjo, you are a very kind person and always help me when I have a problem. Dear Sylvia, thank you very much for your support. Dear Jack, thank you very much for teaching me the imaging techniques.

I would like to say thanks for all technical support I received. My PhD life would be very difficult without all of your help and advice. Mat, thank you very much for teaching me laboratory skills and all of the stories you shared. You provided a socalled "lab survival skills for dummies" that made a dummy to be a smarter dummy. You have changed my attitude from "I have a problem" to "I have a challenge". You were always there when I had "a challenge" in my experiments. Thank you Erwin for your jokes, which keep me smiling. You saved my life as you helped me keep my monster (in Dutch d'oh!). Clairy, thank you very much for helping me with the human vessels paraffin blocks. Anique, thank you for teaching me IHC. Nicole (cardio), thank you a lot for teaching me microsurgery and being a good friend and colleague. Thank 
you very much Audrey and Danielle for your assistance in administrative tasks throughout my PhD study and during submission of the thesis.

Thanks (ex-) AIO's crews for providing a stimulating and fun environment in which to learn and grow. I must say that my stay in the dept. of Pathology would not probably be half as enjoyable without you guys. Daily work was surprisingly "gezellig"! This atmosphere was mainly due to a group of "gezellige" people working near each other (probably, very very very near hahaha). I met some of you walking around the 3rd floor (UM side) and also in the papendal courses. It was unbelievable that later we shared the same office and became friends. Danke für alles, Elke. You were actually my first mentor who babysitted me once I joined the group. I cannot spell thank you without YOU! You always willing to help and give the best suggestions in every manner, from lab work to my drama. I always appreciate your trustful friendship and inspiring conversations. Thomas, thank you for always being helpful and offering me advice and laughter. You were always helpful whenever I had doubts. Emiel, the reason that I donated my high cholesterol blood for your studies was actually because I wanted chocolate. I strongly recommend for current AIO's that blood donors should be well fed with chocolate at least 1 week before the donation in future studies. Bart, you are as nice as Belgian chocolate and thank you for being my friend. Timo and Marco thanks a lot for the lymphatic data and all your advices. Kosta, thanks for a good laugh and for sharing me a trick how to access papers. Anke, you are such a sweet princess. Thank you for your smile and friendship. Jasper thanks a lot for lending me your badge last visit (sorry that I did not top up the card for your lunch hehe). Kim, Thanks a lot for taking care of me when my Lil' Meggie was away. Jan, danke for offering the student card, and Han, xiè xie for the heatmap. Thank you very much Olivia for helping me check and edit my chapters. You are so sweet. Dear Pieter and Cristina, although we met each other for a short time, you both were very nice to talk with. Finally, I wish the entire current AIO's crews good luck with your PhD. Just work hard, play harder and get more borrel-ing (the more papers you have been published, the more borrels you get).

Thanks to members of the experimental cancer pathology for being the ultimate lab-neighbors, providing a great work environment, and for their help. Dear Edith and Peter, thank you very much for good advice and help me when I have a problem with some experiments. Especially, Edith you helped me many times when I went to the lab very early in the morning and I could not access the entrance as my card was expired. Dear Nathalie, you are a sweet and very friendly. It was nice to have a chat with you in the corridor. Dear Jaleesa, thank you very much for helping me with the evil complicated Ventana machine. Kathleen you are very nice and always encourage me for the daily life. I will ask you to teach me how to wear high heels and run one day. 
A very special thanks to people in the Laboratory of Tumor and Development Biology, GIGA, University of Liège for technical support and friendships. Melissa, a big Muchas Gracias for sharing a great deal of knowledge and tips and tricks to make the experiments work. Without you, the good results in LEC project would not be possible. Not only are you a talented postdoc, you are also very beautiful. You are so inspiring. Tania thank you for your assistance and advices on cell culture and other experiments. You helped me a lot especially when the Belgium train strikes. Dear Maureen, thank you for sharing some reagents and media with me. Erika, thank you a lot with teaching me the Cyquant assay and ELISA reader. Emilie, thanks for excellent tissue sectioning and staining. You showed me that a pressure cooker not only cooks boeuf bourguignon, but can also do antigen retrieval. Nathalie, thanks for the PCR. You tried very hard to explain me in French and that was very sweet of you.

Everything in my life would not have been possible without my family, especially Mom and Dad, you have dedicated all to my education. May, my little sister who is more mature than me. Thank you for encouraging me to pursue my education abroad. I am happy that I can say that all efforts resulted in PhD thesis. You all were the ones who always believed in me and it made me keep going. I am very grateful for all you have done and mean for me. มาร์ชขอขอบคุณอาปา แม่ เมย์ และอาๆ ที่คอยสนับสนุน และช่วยเหลือในทุกๆเรื่อง ทำให้มาร์ชมีอนาคตที่ดี และในที่สุดมาร์ชก็ได้จบปริญญาเอก. Robert, having you by my side has made all the difference. I do not know how I could have done it without you. Thank you. 

Curriculum Vitae 


\section{CURRICULUM VITAE}

\section{RINRADA KIETADISOR N}

$\begin{array}{ll}\text { Date of birth } & \text { March } 14,1973 \\ \text { Place of birth } & \text { Nakhon Sawan, Thailand } \\ \text { Nationality } & \text { Thai }\end{array}$

\section{EDUCATION}

May 2010 - May 2016

Sep 2008 - Feb 2010

May 1992- Mar 1998
PhD. Student, Research group:

Experimental Vascular Pathology, CARIM School for Cardiovascular Diseases, Maastricht, The Netherlands

MSc. (Veterinary science), Faculty of Veterinary Medicine, Utrecht University, Utrecht, The Netherlands

D.V.M. (Doctor of Veterinary Medicine), Faculty of Veterinary Science, Chulalongkorn University, Bangkok, Thailand

\section{PUBLICATIONS}

1. Octavia Y, Kararigas G, de Boer M, Chrifi I, Kietadisorn R, Swinnen M, Duimel H, Verheyen FK, Brandt MM, Fliegner D, Cheng C, Janssens S, Duncker DJ, Moens AL.

Folic acid reduces doxorubicin-induced cardiomyopathy by modulating endothelial nitric oxide synthase. J Cell Mol Med. 2017 Dec;21(12):3277-3287.

2. Kietadisorn R, Juni RP, Moens AL.

Tackling endothelial dysfunction by modulating NOS uncoupling: new insights into its pathogenesis and therapeutic possibilities.Am $\mathrm{J}$ Physiol Endocrinol Metab. 2012 Mar 1;302(5):E481-95. 
3. Moens AL, Kietadisorn R, Lin JY, Kass D

Targeting endothelial and myocardial dysfunction with tetrahydrobiopterin.J Mol Cell Cardiol. 2011 Oct;51(4):559-63.

4. Kietadisorn R, Kietselaer BL, Schmidt HH, Moens AL.

Role of tetrahydrobiopterin (BH4) in hyperhomocysteinemia-induced endothelial dysfuction: new indication for this orphan-drug?Am J Physiol Endocrinol Metab. 2011 Jun;300(6):E1176

5. Kietadisorn R, Schmidt HH, Moens AL.

Folic Acid as a cardiovascular drug: dose matters. Am J Cardiol. 2010 Dec 1;106(11):1673-4.

\section{MEETING ABSTRACTS}

1. Kietasidorn R, Rademakers T, Manca M, van der Vorst EPC, Alitalo K, Sluimer JC, Noel A, Biessen EAL. Plaque lymphangiogenesis: to drain or not to drain. Cardiology (2016) 134(S1) 1-460

2. Kietadisorn R, Octavia Y, Juni RP, Moens AL. Highlights of Basic Science Research: Enhancing eNOS transcription prevents pressure-overload induced ventricular hypertrophy. European Journal of Heart Failure Supplements (2012) 11 ( S1), S59.

3. Octavia $Y$, Kietadisorn R, Crijns HJ, Janssens S, Moens AL. Modulating endothelial nitric oxide synthase by folic acid reduces acute doxorubicin-induced cardiotoxicity and mortality. European Journal of Heart Failure Supplements (2012) 11 ( S1 ), S243.

4. Octavia $Y$, Swinnen M, Verheyen FK, Lenders M, Duimel H, Gillijns $H$, Kietadisorn R, Janssens S, Moens AL. The Endothelial Nitric Oxide Synthase Modulator Folic Acid Reduces Acute Doxorubicin-Induced Cardiac Damage and Mortality. Circulation (2012) 126, A17461. 